Portland State University

PDXScholar

Summer 8-15-2013

\title{
Exploring Tissue Engineering: Vitamin D3 Influences on the Proliferation and Differentiation of an Engineered Osteoblast Precursor Cell Line During Early Bone Tissue Development
}

Shelley S. Mason

Portland State University

Follow this and additional works at: https://pdxscholar.library.pdx.edu/open_access_etds

Part of the Developmental Biology Commons, and the Musculoskeletal System Commons Let us know how access to this document benefits you.

Recommended Citation

Mason, Shelley S., "Exploring Tissue Engineering: Vitamin D3 Influences on the Proliferation and Differentiation of an Engineered Osteoblast Precursor Cell Line During Early Bone Tissue Development" (2013). Dissertations and Theses. Paper 1000.

https://doi.org/10.15760/etd.1000

This Dissertation is brought to you for free and open access. It has been accepted for inclusion in Dissertations and Theses by an authorized administrator of PDXScholar. Please contact us if we can make this document more accessible: pdxscholar@pdx.edu. 
Exploring Tissue Engineering: Vitamin $\mathrm{D}_{3}$ Influences on the Proliferation and Differentiation of an Engineered Osteoblast Precursor Cell Line During Early Bone

Tissue Development

by

Shelley S. Mason

A dissertation submitted in partial fulfillment of the requirements for the degree of

Doctor of Philosophy

in

Biology

Dissertation Committee:

Randy D. Zelick, Chair

Sean S. Kohles

Shelley R. Winn

Michael S. Bartlett

Susan E. Masta

David H. Peyton

Portland State University

2013 
(C) 2013 Shelley S. Mason 


\section{ABSTRACT}

Most of the load-bearing demand placed on the human body is transduced by skeletal tissue, and the capacity of the skeleton to articulate in various opposing directions is essential for body movement and locomotion. Consequently, cartilage and bone defects due to trauma, disease, and developmental abnormalities result in disabling pain and immobility for millions of people worldwide. A novel way of promoting cartilage and bone regeneration is through the incorporation of either primary cells or multipotent progenitor cells in a three-dimensional (3D) biomaterial scaffold, and/or the addition of exogenous growth and differentiation factors. The first part of this study reports a protocol for using freshly isolated mature chondrocytes seeded in a 3D hydrogel biomaterial scaffold, developed to explore mechanotransduction of engineered cartilage constructs cultured in a designed bioreactor. The bioreactor was designed to allow the application of physiological mechanical forces (compression and fluid flow), as well as a non-invasive/non-destructive method for analyzing regenerating tissue in real time through ultrasound transducers and a computerized monitoring system. In the second part of this study, an engineered immortalized osteoprecursor cell line, designated OPC1 (osteoblastic precursor cell line 1), was used as a culture model system for exploring the effects of exogenous growth and differentiation factors, mainly vitamin D, on early bone development. OPC1 was previously designed to provide a consistent reproducible culture system for direct comparisons of engineered bone constructs, evaluating bone development and cell/biomaterial interactions, and for investigating putative bone 
differentiating factors. One of the objectives of this research effort was to explore tissue development and regeneration by culturing OPC1 in the presence of vitamin D metabolites vita $\mathrm{D}_{3}$ and $1,25 \mathrm{OH}_{2} \mathrm{D}_{3}$, while assaying the concomitant biological response. Results indicate that $\mathrm{OPC} 1$ is capable of metabolizing the parental metabolite vitaD $\mathrm{D}_{3}$, and thus $25 \mathrm{OHD}_{3}$, to the active vitamin $\mathrm{D}$ form $1,25 \mathrm{OH}_{2} \mathrm{D}_{3}$. The metabolism of vita resulted in an anti-proliferative and pro-differentiative influence on OPC-1. These results support the hypothesis that extra-endocrine synthesis of $1,25 \mathrm{OH}_{2} \mathrm{D}_{3}$ functions in a tissue specific manner to regulate growth and differentiation, in addition to the classic calcimic actions of the vitamin D endocrine pathway. Understanding the influence of vitamin D on bone development will have significant implications on healthy aging, including the susceptibility to skeletal disorders involved in development and aging, such as osteoarthritis (OA) and osteoporosis. 


\section{DEDICATION}

I dedicate this dissertation to my loving and supportive family. A special dedication goes out to my partner Erik Long who is the love of my life, my best friend, and my rock, and to my son Thomas Long whom makes every day worth living. To my parents Cheryl Ann Rumage (Bonnie Parker) and Thomas Michael Mason, and my step mom Shannon Mason, who have helped me become the person I am today. I would also like to dedicate this to my late grandparents Thomas Francis and Marian Mason, and Marjorie Rumage; and to my grandpa George Curtis Rumage. Last but not least, I dedicate this to my amazing and wonderful sisters Halley, Stephanie, and Hannah Mason. 


\section{ACKNOWLEDGEMENTS}

I would like to thank my wonderful advisors, Dr. Randy D. Zelick and Dr. Sean S. Kohles, who helped guide and support me through this process. A special thanks to Dr. Shelley Winn, an external committee member from Oregon Health Science University (OHSU), for his continued support and generous help with essential supplies, laboratory work space, and time. Thank you Dr. Michael Bartlett, Dr. Susan Masta, and Dr. Peyton for agreeing and taking the time to serve on my committee.

I would like to acknowledge lab members from the Regenerative Bioengineering Laboratory, Hank Chui, Fay Gibson, and Johnathan Righetti; interns Jessica Blank and Ulysses Duckler from the Saturday Academy, and Iesha Washington from Central State University (CSU). Thank you members of the Carry Harding lab, Department of Molecular and Medical Genetics, OHSU, for all your assistance and continued support. A special thank you to my friend and colleague Autumn Fletcher for her countless hours of assistance with laboratory protocols, troubleshooting, and most of all emotional support, and Katie Cobb whom is philanthropizing in an African Hospital.

Support was provided by the National Institutions of Health as a Research Infrastructure for Minority Institution (RIMI) Exploratory Program (Grant No. P20MD003350) establishing the CSU center for Allaying Health Disparities through Research and Education (CADRE), the Collins Medical Trust, and a PSU Faculty Enhancement Grant. Caleb Janicich, Hank Chiu, Thadeous Bamford, and Fay Gibson of PSU as well as Dr. Timothy P. Quinn and Doug V. Gallagher of the National Institutes of 
Science and Technology, Boulder, $\mathrm{CO}$ contributed valuable design and fabrication efforts. 


\section{TABLE OF CONTENTS}

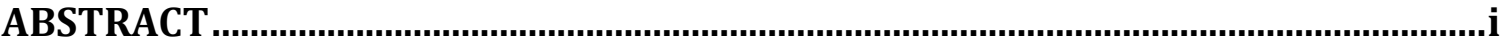

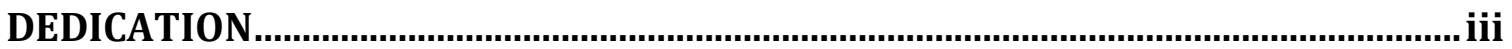

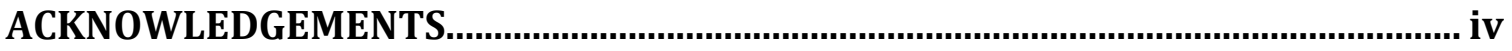

LIST OF TABLES............................................................................................................. ix

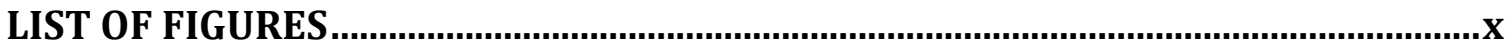

LIST OF ABBREVIATIONS................................................................................................

Chapter I. INTRODUCTION ....................................................................................... 1

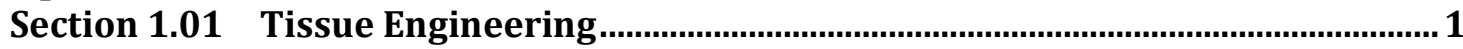

Section 1.02 Three-Dimensional Culture System ….................................................. 4

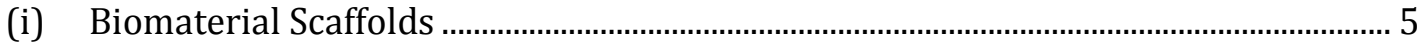

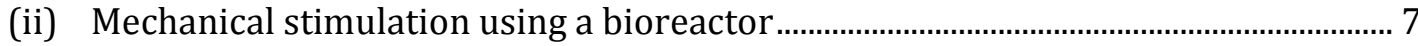

(iii) Nondestructive techniques to assess 3D tissue constructs .....................................10

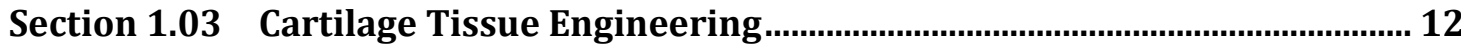

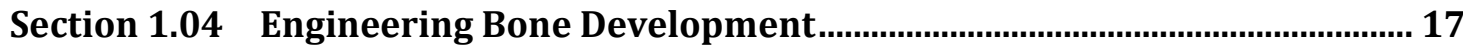

(i) Engineered Osteoprecursor Cell Culture System ............................................................19

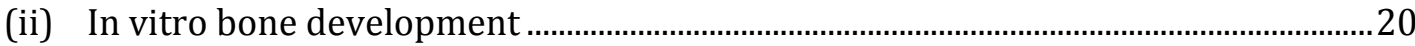

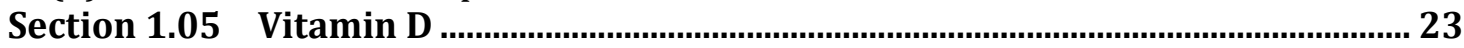

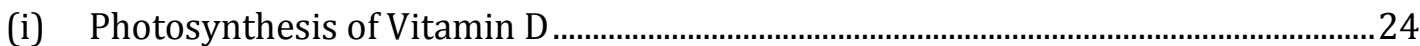

(ii) Vitamin D Metabolism and Regulation ...........................................................................26

(iii) Signal Transduction and Gene Expression.................................................................28

(iv) Nongenomic[not sure what you mean by nongenomic - but this is not how the

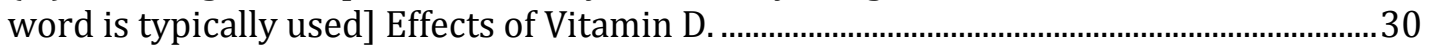

(v) Free Hormones and Local Vitamin D Storage Pools....................................................... 31

(vi) The Autocrine/Paracrine Vitamin D Paradigm...........................................................36

(vii) Vitamin D and In Vitro Bone Development ............................................................... 37

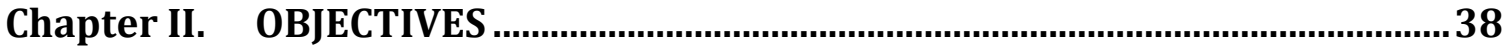

Section 2.01 3D Cell Culture for Cartilage Tissue Engineering ..................................... 38

Section 2.02 OPC1 Bone Development and Vitamin D Metabolism .......................... 42

Chapter III. Three-Dimensional Culture of Cells and Matrix Biomolecules for

Engineered Tissue Development and Biokinetics Model Validation..................44

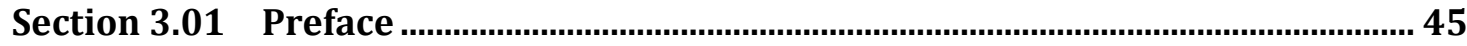

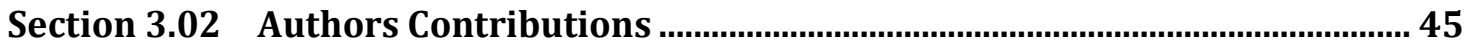

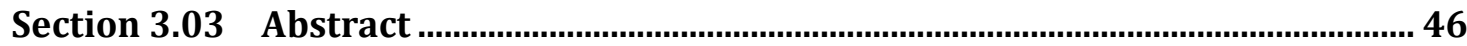

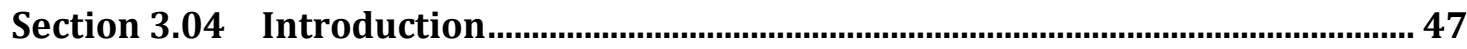

(i) Biomaterial Scaffolds and Three-Dimensional Culture .................................................50

(ii) Mechanical Stimulation and Biological Response........................................................52

Section 3.05 Engineering and Experimental Design Methods: ...................................... 54

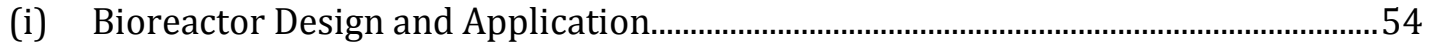

(ii) Cartilage Dissection and Disaggregation .......................................................................59 


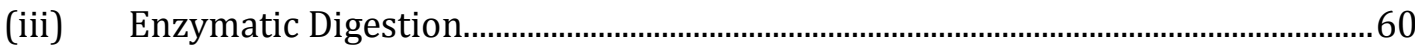

(iv) Cell-Seeding and Biomaterial Polymerization............................................................61

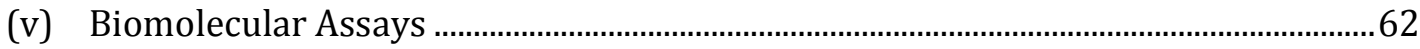

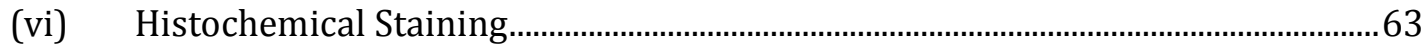

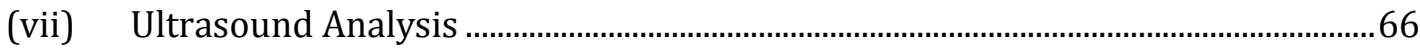

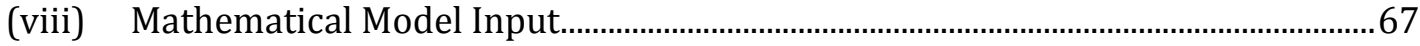

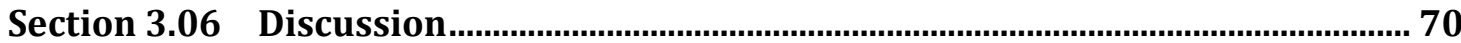

Chapter IV. Ultrasonic Wave Propagation Assessment of Native Cartilage Explants and Hydrogel Scaffolds for Tissue Engineering .................................78

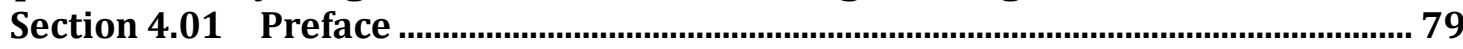

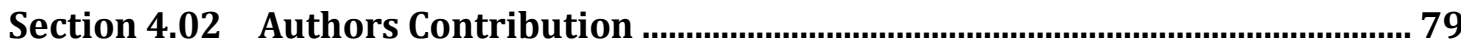

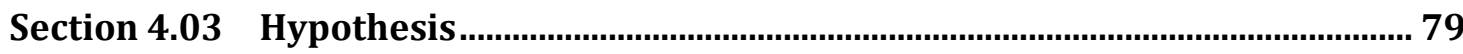

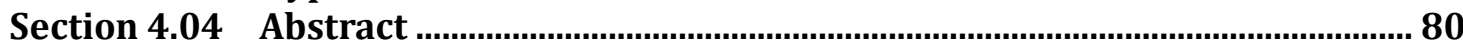

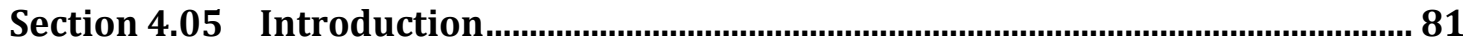

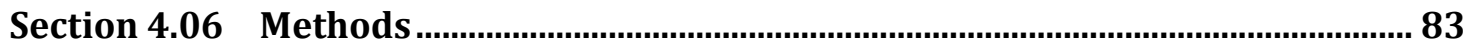

(i) Articular Cartilage Harvest and Ultrasonic Testing .......................................................83

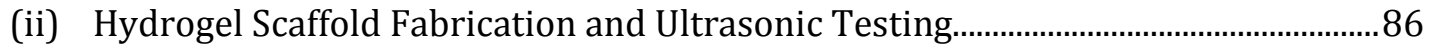

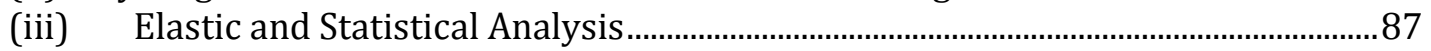

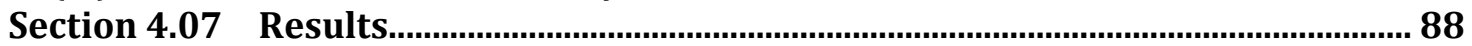

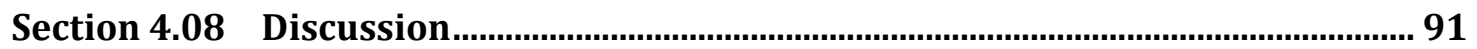

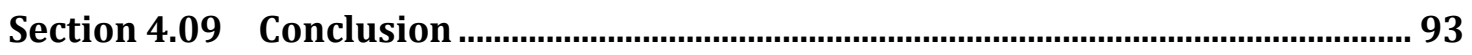

Chapter V. Extrahepatic 25-Hydroxylation of Vitamin $D_{3}$ in an Engineered Osteoblast Precursor Cell Line Exploring the Influence on Cellular

Proliferation and Matrix Maturation During Bone Development ......................98

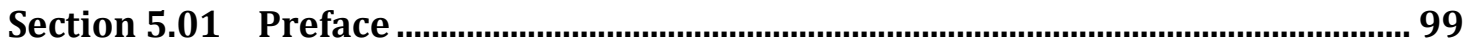

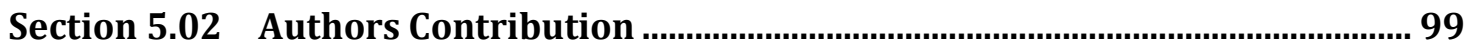

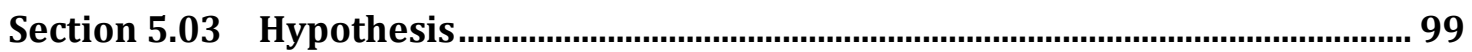

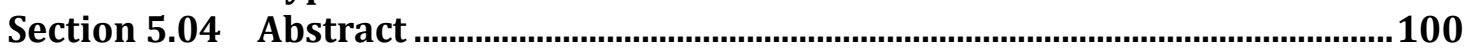

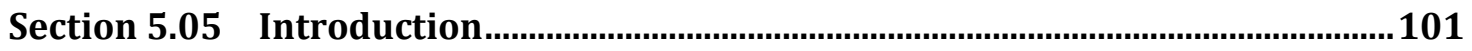

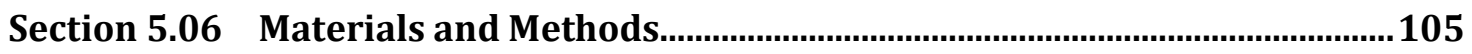

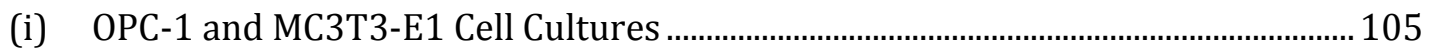

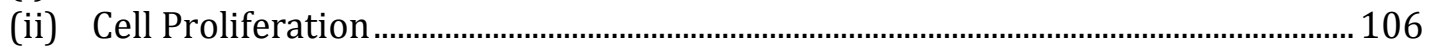

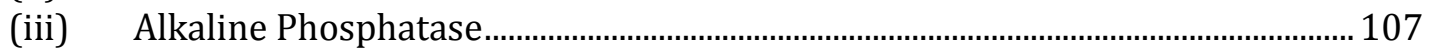

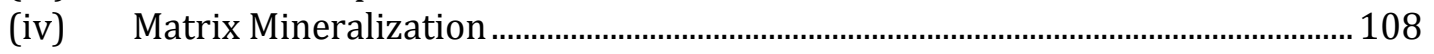

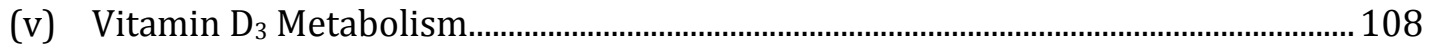

(vi) Statistical Analysis and Mathematical Modeling .......................................................109

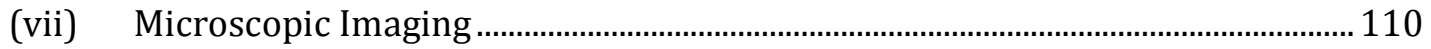

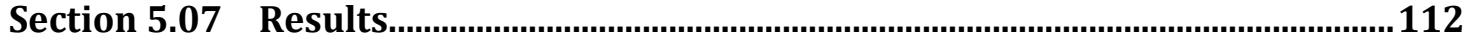

(i) ALP Activity and Early Matrix Mineralization ...........................................................112

(ii) Influence of Vitamin $\mathrm{D}_{3}$ and $1,25 \mathrm{OH}_{2} \mathrm{D}_{3}$ on Osteoprecursors.....................................116

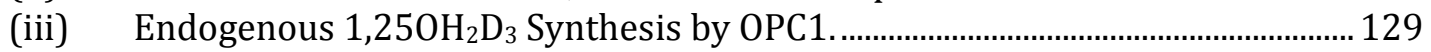

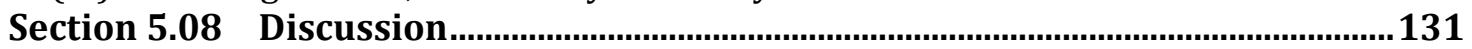

Chapter VI. investigation the regulation of mRNA expression involved in extra-endocrine vitamin D metabolism during opc1 bone maturation and mineralization.. 


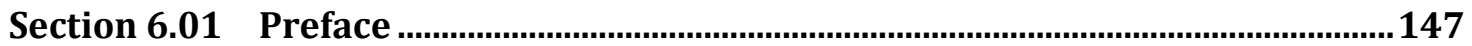

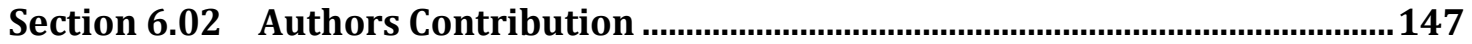

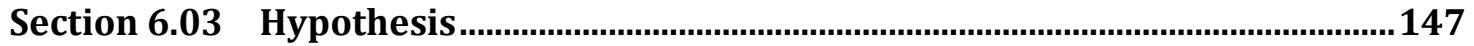

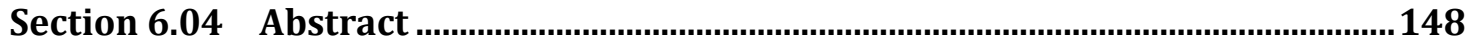

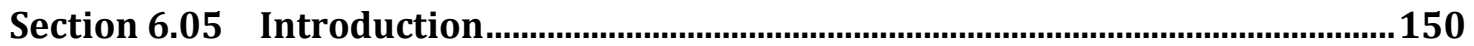

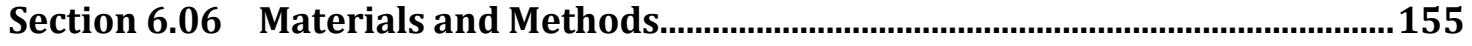

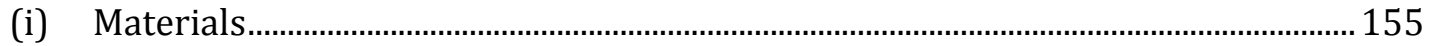

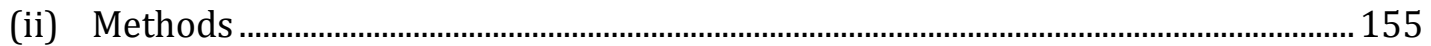

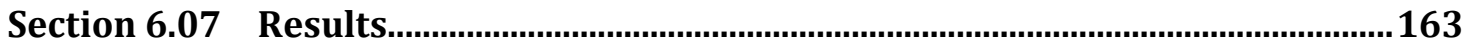

(i) Influence of vitamin D metabolites and osteogenic factors on OPC1 bone matrix

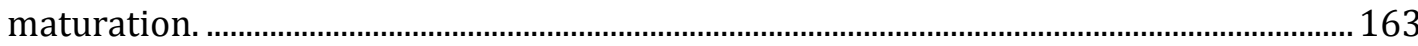

(ii) Influence of vitamin D metabolites and osteogenic factors on OPC1 bone matrix

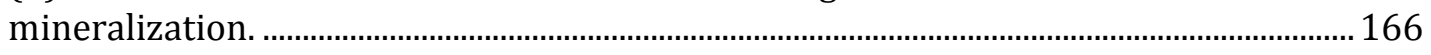

(iii) Expression of Vitamin D Associated mRNA in OPC1.............................................170

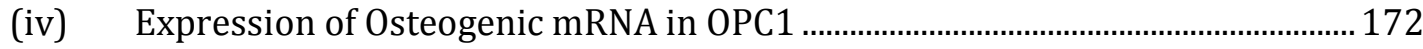

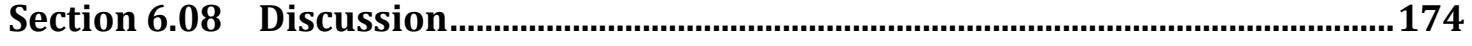

Works Cited .................................................................................................................. 184

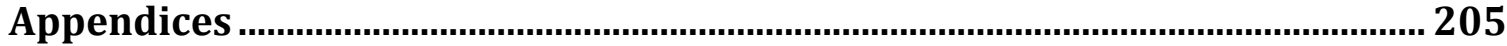

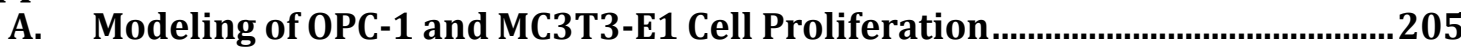

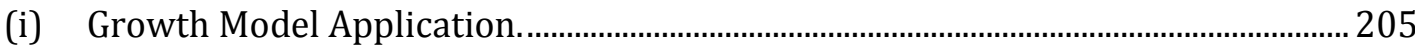

B. Supplemental Material and Methods: Cartilage Engineering (Chapters 3 and 4) 209

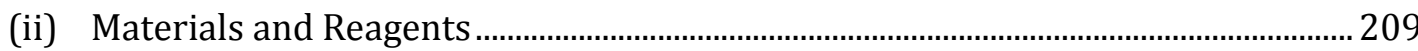

(iii) Methods ................................................................................................................. 210

C. Supplemental Materials and Methods: Bone Development and $\mathrm{VitaD}_{3}$

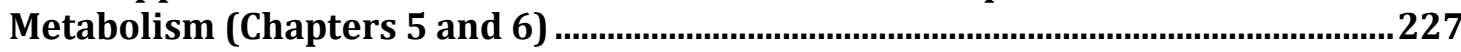

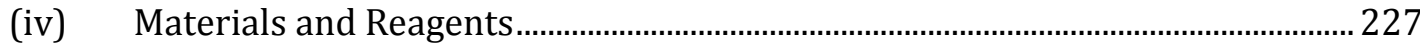

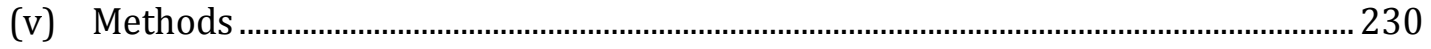




\section{LIST OF TABLES}

Table 3-1. Focal biomarkers and the assay products applied to evaluate the state of extracellular matrix biokinetics. The biomarkers and the listed typical secretion standards will be measured as boundary conditions characterizing the experimental progress of the engineered tissue development. These data will also provide input for model initiation and validation during statistical comparison. *Enzyme-linked immuno-sorbent assay (ELISA), Rhuemera and Immunodiagnostics System (Astarte Biologics, LLC, Redmond, WA). ** ELISA (Antibodies-online, Atlanta, GA). ***Sircol (Biocolor Life Science Assays, Carrickfergus, UK. [p.65].

Table 6-1. Vitamin D biomarkers associated with vitamin D metabolism. [p.159].

Table 6-2. Osteoblast biomarkers associated with bone development. [p.160].

Table 6-3. Oligonucleotide sequences utilized in quantitative real-time RT-PCR. [p.158].

Table A-1: Proliferation modeling metrics summary. [p.206].

Table A-2. ALP standards.[p.236].

Table A-3. Alizarin Red Standard Curve. [p.239]. 


\section{LIST OF FIGURES}

Figure 1-1. The novel multiphysics bioreactor with five culture wells. The highresolution, copper-colored load-cells measure the dynamic loads transferred via the loadrods through the square load-platens into the culture-well designs (upper right) and onto the cell-biomaterial constructs (pink cube, lower right) [Mason et al., 2011; Kohles et al., 2011]. [p.10].

Figure 1-2. MSC bone developmental pathway. An important aspect of bone biology is to address the regulatory events related to commitment of pluripotent progenitor cells into the developmental pathway that restricts options for specialization to either the osteoblast and chondrocyte pathways [Lian \& Stein, 1992]. [p.19].

Figure 1-3. Temporal expression of cell growth and osteoblast phenotype during the in vitro formation of bone tissue. This figure is based on studies conducted by Lian \& Stein, 1995. [p.22].

Figure 1-4. Schematic of photosynthesis, metabolism, and regulation of vitamin D metabolites. Vitamin D precursors and metabolites are in black, and metabolic enzymes are in blue. [p.25].

Figure 1-5. The active metabolite of vitaD $\mathrm{D}_{3}, 1,25 \mathrm{OH}_{2} \mathrm{D}_{3}$, regulates calcium-phosphorous homeostasis and bone health through its classic hormonal actions in concert with its nuclear transcriptional factor, VDR, on target genes containing the VDRE (Brannon 2012). [p.30].

Figure 1-6. The 'free hormone' and 'local vitamin D storage' hypotheses change the traditional endocrine views of vitamin D metabolism, and explain paracrine and autocrine mechanisms of vitamin D metabolism, involved in the regulation of proliferation and differentiation that have been observed in vitro in response to supraphysiological doses of $1,25 \mathrm{OH}_{2} \mathrm{D}_{3}$ and $25 \mathrm{OHD}_{3}$. [p.32].

Figure 1-7. Traditional vitamin D endocrine mode of action (A) and revised vitamin D mode of action (B) based on the 'free hormone hypothesis' and the theory of 'local vitamin D storage pools' [Brannon, 2012; and Berg, 1999]. [p.34].

Figure 3-1. Three-dimensional reconstruction via micro-computed tomography of a through-thickness section of human articular cartilage [after Jadin and Sah, 2006]. The total transverse slice dimension is $1,500 \mathrm{~mm}$ representing the articular surface (top), three histologic zonal layers, and the bony osteochondral transition (bottom). [p.48]. 
Figure 3-2. A solid model of the assembled chemomechanical bioreactor for threedimensional culture [after Quinn, et al., 2009]. The image includes the upper electromechanical actuator applying high-resolution load-deformation control to the 'hat' which distributes the mechanical stimulus to the five load arms and, as such, to the five culture-wells below. The wells can be rotated into the view of single ultrasonic or digital imaging sensors. [p.54].

Figure 3-3. The now-fabricated, novel chemomechanical bioreactor with five culture wells (on the left) and a load-train applying load-displacement for measuring exact loads (on the right). The high-resolution, copper-colored load-cells measure the dynamic loads transferred via the load-rods through the square load-platens into the culture-wells and onto the eventual cell-biomaterial constructs. [p.56].

Figure 3-4. Open-view (model) of a bioreactor test chamber for engineered tissue chemomechanical stimulation indicating the cell-biomaterial construct $\left(125 \mathrm{~mm}^{3}\right.$ pink cube) (on the left) and three current well designs for static and dynamic threedimensional culture (on the right). The middle culture-well, which provides perfused flow and dynamic culture will be described in a future article [Kohles, et al., 2011]. [p.56].

Figure 3-5. Expected cell-matrix preparations [after Rice et al., 2009]. During matrix synthesis, cells will be distributed throughout the collagen (on the left, to be stained with Masson's Trichome) and aggrecan (on the right, to be stained with safranin-O/fast) constituents as are typical for this cell-scaffold arrangement. The solid dark circles each represent a single cell at $\sim 20 \mathrm{~mm}$ in diameter. [p.65].

Figure 3-6. Representative biokinetic modeling results (applying equation 6) from expected biomolecular accumulation data as gathered from the chemomechanical bioreactor (as boundary conditions and validation). Here the model is initially allowed to run as the ECM concentration (\%, GAG and collagen) peaks in the response to local resources and then drops to a steady state level. A chemomechanical stimulus is then applied at $5 \times 105$ relative time units, driving the accumulation upward in an anabolic response. [p.69].

Figure 4-1. Schematics of explant anatomic orientation and propagating ultrasonic waveforms. [p.84].

Figure 4-2: Images of harvested bovine cartilage tissue (a) and fabricated agarose hydrogel scaffold cubes (b). [p.85].

Figure 4-3. Mean (+/- SD) longitudinal (a) and transverse (b) propagation wave velocities as gathered from through-thickness (anterior-posterior) and within-plane (superior-inferior plus medial-lateral) orientations of harvested cartilage explants. [p.89]. 
Figure 4-4. Comparison of mean (+/- SD) ultrasonic propagation velocities of $n=35$ agarose biomaterial samples as driven by longitudinal wave impulses at varying frequencies. [p.90].

Figure 4-5. Fluid-dominated stiffness's of the agarose biomaterial scaffolds and cartilage explants as measured using the $100 \mathrm{kHz}$ longitudinal and transverse wave transducers. [p.90].

Figure 5-1. Alkaline phosphatase activity (ALP) of osteoblast precursor OPC1 and MC3T3-E1 after 10 days in culture after being treated with or without vitamin $\mathrm{D}_{3}$ (BMControl). After 10 days there was not a significant effect $(p=0.2166)$ on ALP activity between treatment with either $1 \mu \mathrm{M}$ or $10 \mu \mathrm{M}$ vitamin $\mathrm{D}_{3}$, however there was an overall statically significant increase $(p=0.0026)$ in ALP activity between vitamin $\mathrm{D}_{3}$ treated cultures and controls. [p.113].

Figure 5-2. Osteoblast precursor cell lines OPC1 (A-C) and MC3T3-E1 (D-F) stained with ARS after 10 days in culture. OPC1 without treatment of vitamin $\mathrm{D}_{3}$ (ethanol control) (A) did not absorb a statistically significant amount of ARS per cell population (see Figure 5-3), than with treatment of either $1 \mu \mathrm{M}$ vitamin $\mathrm{D}_{3}(\mathrm{~B})$ or $10-\mu \mathrm{M}$ vitamin $\mathrm{D}_{3}$ (C). Similar results were seen with MC3T3-E1 without vitamin $\mathrm{D}_{3}$ (ethanol control) (D), $1 \mu \mathrm{M}$ vitamin $\mathrm{D}_{3}(\mathrm{E})$, and $10-\mu \mathrm{M}$ vitamin $\mathrm{D}_{3}(\mathrm{~F})$. [p.114].

Figure 5-3. Semi-quantification of matrix mineralization was conducted by taking the optical density (resolution, $450 \mathrm{~nm}$ ) of the ARS extracted from each treatment group (shown in Figure 5-2). Vitamin $\mathrm{D}_{3}$ at both $1 \mu \mathrm{M}$ and $10 \mu \mathrm{M}$ did not have a statistically significant effect on the ECM mineralization of OPC1 $(p=0.2881)$ or MC3T3-E1 $(p=$ $0.1101)$ after 10 days, compared to the control group. [p.115].

Figure 5-4. Absolute proliferation of OPC1 cells maintained in six types of tissue culture medium over three two-week periods $(n=24)$. At day 5, the OPC1 cell counts in the wells containing vitamin $\mathrm{D}$ metabolites \pm osteogenic factors $(\mathrm{BM}+)$ were statistically lower then than the negative control (BM-). OPC1 treated with $\mathrm{BM}+$ and $1,25 \mathrm{OH}_{2} \mathrm{D}_{3}$ experienced the largest statistically $(\mathrm{p}<0.001)$ anti-proliferative effect. The effect of vitamin $\mathrm{D}_{3}$ was similar to $1,25 \mathrm{OH}_{2} \mathrm{D}_{3}$ in both groups of medium. [p.117].

Figure 5-5. Percent proliferation of OPC1 cells maintained in six types of tissue culture medium over three two-week periods $(n=24)$. By 7 to 10 days, the OPC 1 cell counts in the wells containing vitamin D metabolites \pm osteogenic factors $(\mathrm{BM}+)$ were statistically lower then than the negative control (BM-). By day 10, OPC1 treated with BM+ and active $1,25 \mathrm{OH}_{2} \mathrm{D}_{3}$ remained around $50 \%$ of the $\mathrm{BM}$ - cellular confluency. In both BMand $\mathrm{BM}+$ groups, vitamin $\mathrm{D}_{3}$ treated cells proliferated in a manner very similar to those treated with $1,25 \mathrm{OH}_{2} \mathrm{D}_{3}$. [p.118]. 
Figure 5-6. Absolute proliferation of MC3T3-E1 cells maintained in six types of tissue culture medium in duplicates over three two-week periods, and assayed in duplicates ( $\mathrm{n}=$ 12). Two types of medium was used, one with osteogenic factors (BM+), and one without (BM-). At day 5, the MC3T3-E1 cell counts in the wells containing vitamin D metabolites \pm osteogenic factor were statistically lower then than the negative control (BM-). MC3T3-E1 cells treated with $\mathrm{BM}+$ and vitamin $\mathrm{D}_{3}$ were indistinguishable from $1,25 \mathrm{OH}_{2} \mathrm{D}_{3}$, in that both experienced the largest statistically $(p<0.001)$ anti-proliferative effect. [p.119].

Figure 5-7. Percent proliferation of MC3T3-E1 cells maintained in six types of tissue culture medium. At day 10, the OPC1 cell counts in the wells containing vitamin D metabolites \pm osteogenic factors $(\mathrm{BM}+)$ were very statistically lower $(* * *)$ then than the negative control (BM-) and remained at around 50\% of the BM-cellular confluency. By day 10, MC3T3-E1 cells treated with $\mathrm{BM}+$ and vitamin $\mathrm{D}_{3}$ were indistinguishable from $1,25 \mathrm{OH}_{2} \mathrm{D}_{3}$, as in the absolute proliferation; both experienced the most significant ( $p<$ 0.001) anti-proliferative effect. [p.120].

Figure 5-8. ALP activity of OPC1 and MC3T3-E1 cells maintained in six types of tissue culture medium aggregated over three two-week periods $(n=12)$. After two-weeks, the OPC1 ALP activity of $1,25 \mathrm{OH}_{2} \mathrm{D}_{3}$ and osteogenic factors (BM+) treated cells were statistically greater when compared to the negative control (BM-). ALP activity of OPC1 treated with vitamin $\mathrm{D}_{3}$ and $\mathrm{BM}+$ was significantly higher than $\mathrm{BM}-$, but not higher than the $\mathrm{BM}+$ control containing ethanol vehicle. All cellular groups containing $\mathrm{BM}+$ had a significantly higher ALP activity compared to the control within the MC3T3-E1 cell line. MC3T3-E1 response to vitamin $\mathrm{D}_{3}$ was indistinguishable from the response to $1,25 \mathrm{OH}_{2} \mathrm{D}_{3}$. [p.122].

Figure 5-9. ALP activity of OPC1 cells maintained in six types of tissue culture medium described over three two-week periods $(n=12)$. After two-weeks, the OPC1 ALP activity of $1,25 \mathrm{OH}_{2} \mathrm{D}_{3}$ and osteogenic factors $(\mathrm{BM}+)$ treated cells were statistically greater than the negative control (BM-). ALP activity of OPC1 treated with vitamin $\mathrm{D}_{3}$ and $\mathrm{BM}+$ was significantly higher than BM-, but not higher than the BM+ control containing ethanol vehicle. [p. 123].

Figure 5-10. ALP activity of MC3T3-E1 cells maintained in six types of tissue culture medium and characterized over three two-week periods $(n=12)$. After two-weeks, the MC3T3-E1 ALP activity of $1,25 \mathrm{OH}_{2} \mathrm{D}_{3}$ and osteogenic factors $(\mathrm{BM}+)$ treated cells were again statistically greater than the negative control (BM-). All groups containing BM+ had a statistically greater ALP activity compared to the control in the MC3T3-E1 cell line. The MC3T3-E1 response to vitamin $\mathrm{D}_{3}$ treatment was indistinguishable from the response to $1,25 \mathrm{OH}_{2} \mathrm{D}_{3}$ treatment. [p.124]. 
Figure 5-11. Osteoblast precursor cell lines OPC1 stained with ARS after two weeks in experimental conditions. Images of OPC1 cells without either osteogenic factors (BM-) or vitamin $\mathrm{D}$ (ethanol control) (A), BM- with $1 \mu \mathrm{M}$ vitamin $\mathrm{D}_{3}(\mathrm{~B})$, and BM- with $10 \mu \mathrm{M}$ vitamin $\mathrm{D}_{3}(\mathrm{C})$, consistently did not absorb a statistically perceptible amount of ARS compared to groups containing osteogenic factors $(\mathrm{BM}+)(\mathrm{D}-\mathrm{F})$. However, cells cultured with $\mathrm{BM}+$ and $1 \mu \mathrm{M}$ vitamin $\mathrm{D}_{3}(\mathrm{E})$, and $\mathrm{BM}+$ with $10 \mu \mathrm{M}$ vitamin $\mathrm{D}_{3}(\mathrm{~F})$ had a statistically significant $(p<0.05)$ amount of calcium associated with ECM mineralization compared to the BM+ control (D). [p.126].

Figure 5-12. Osteoblast precursor cell line MC3T3-E1 stained with ARS after two weeks within the experimental treatment groups. MC3T3-E1 cells without either osteogenic factors (BM-) or vitamin $\mathrm{D}$ (ethanol control) (A), BM- with $1 \mu \mathrm{M}$ vitamin $\mathrm{D}_{3}(\mathrm{~B})$, and BM- with $10 \mathrm{nM} 1,25 \mathrm{OH}_{2} \mathrm{D}_{3}(\mathrm{C})$, consistently did not absorb a significant amount of ARS compared to groups containing osteogenic factors $(\mathrm{BM}+)(\mathrm{D}-\mathrm{F})$. Cells cultured with vitamin $\mathrm{D}_{3}$ and $\mathrm{BM}+(\mathrm{E})$ were statistically significant compared to the negative control (A), but were not comparable with the parallel control (D). However, cells cultured with $\mathrm{BM}+$ and $10 \mathrm{nM} 1,25 \mathrm{OH}_{2} \mathrm{D}_{3}(\mathrm{~F})$ had a statistically significant $(p=0.0055)$ amount of calcium associated with ECM mineralization compared to the BM+ control (D). [p.127].

Figure 5-13. Semi-quantification of matrix mineralization of cultured experimental groups qualitatively shown in Figures 5-11 and 5-12). OPC1 treated with vitamin $\mathrm{D}_{3}$ or $1,25 \mathrm{OH}_{2} \mathrm{D}_{3}$ in $\mathrm{BM}+$ had a statistically significant $(p<0.05)$ amount of calcium deposition in comparison to both BM- and BM+ controls. MC3T3-E1 cells cultured with $1,25 \mathrm{OH}_{2} \mathrm{D}_{3}$ in $\mathrm{BM}+$ had a statistically significant $(p=0.0055)$ amount of calcium deposition in comparison with both BM- and BM+ controls. [p.128].

Figure 5-14. Endogenous production of $1,25 \mathrm{OH}_{2} \mathrm{D}_{3}$ by $\mathrm{OPC} 1$ in response to incubation with vitamin $\mathrm{D}_{3}$. A $1,25 \mathrm{OH}_{2} \mathrm{D}_{3} / \mathrm{VDR}$ ELISA was performed to analyze the metabolism of precursor vitamin $\mathrm{D}_{3}$ to the hormonally active form. The dose of vitamin $\mathrm{D}_{3}$ was controlled and administered at logarithmic concentration levels. A log base-10 model was applied to the resulting response data. [p.130].

Figure 6-1. Temporal alkaline phosphatase activity of OPC1 treated with (A) ethanol vehicle control in standard bone medium (BM-), BM- containing $10 \mu \mathrm{M}$ vitamin $\mathrm{D}_{3}$, and BM- with $1,25 \mathrm{OH}_{2} \mathrm{D}_{3}$; (B) ethanol control in osteogenic medium $(\mathrm{BM}+)$ containing ascorbic acid, $\beta$-glycerophosphate, and dexamethasone, $\mathrm{BM}+$ containing $10 \mu \mathrm{M}$ vitamin $\mathrm{D}_{3}$, and $\mathrm{BM}+$ with $1,25 \mathrm{OH}_{2} \mathrm{D}_{3} ;(\mathrm{C})$ ethanol control in $\mathrm{BM}+$ containing rhBMP $(\mathrm{BMP}+)$, $\mathrm{BMP}+$ containing $10 \mu \mathrm{M}$ vitamin $\mathrm{D}_{3}$, and $\mathrm{BM}$ - with $1,25 \mathrm{OH}_{2} \mathrm{D}_{3}$. Cellular isolates were collected on day 7, 14, and 21 during the differentiation time course. Treatment with both vitamin D metabolites significantly $(\mathrm{P}<0.01)$ influenced OPC1 ALP activity in all medium groups. [p.164-165]. 
Figure 6-2. Calcium deposition stained with alizarin red stain (ARS) (A) of OPC1 cultured in $\mathrm{BM}$ - and vitamin $\mathrm{D}$ metabolites vitaD $\mathrm{D}_{3}$ and $1,25 \mathrm{OH}_{2} \mathrm{D}_{3}$. After microscopic analysis, ARS was extracted from each culture well, and read on a microplate reader (B). By week three of culture time, there was a significant $(\mathrm{P}<0.001)$ amount of calcium deposition detected by ARS in cells treated with either vitaD $\mathrm{D}_{3}$ or $1,25 \mathrm{OH}_{2} \mathrm{D}_{3}$ compared to that of the ethanol control. [p. 167].

Figure 6-3. Calcium deposition stained with ARS (A) of OPC1 cultured in BM+ and vitaD $\mathrm{D}_{3}$ or $1,25 \mathrm{OH}_{2} \mathrm{D}_{3}$. After microscopic analysis, ARS was extracted from each culture well, and read on a microplate reader (B). By week three of culture time, there was a significant $(\mathrm{P}<0.001)$ amount of calcium deposition detected by ARS in cells treated with either vitaD $\mathrm{D}_{3}$ or $1,25 \mathrm{OH}_{2} \mathrm{D}_{3}$ compared to that of the ethanol control. There was a significant $(\mathrm{P}<0.001)$ amount of calcium deposition compared to all $\mathrm{BM}$ - groups (see Figure 6-2). [p.168].

Figure 6-4. Calcium deposition stained with ARS (A) of OPC1 cultured in BM+ containing rhBMP-2 (BMP+) and vitaD ${ }_{3}$ or $1,25 \mathrm{OH}_{2} \mathrm{D}_{3}$. After microscopic analysis, ARS was extracted from each culture well, and read on a microplate reader $(\mathrm{B})$. In the second week of culture time, the $\mathrm{BMP}+\mathrm{EtOH}$ control had a significant amount of calcium deposition in comparison with the treatment groups. By week three of culture, there was a significant $(\mathrm{P}<0.01)$ amount of calcium deposition detected by ARS in cells treated with either vitaD $\mathrm{D}_{3}$ or $1,25 \mathrm{OH}_{2} \mathrm{D}_{3}$ compared to that of the ethanol control. There was a significant $(\mathrm{P}<0.001)$ amount of calcium deposition compared to all $\mathrm{BM}$ - groups (see Figure 6-2). [p. 169].

Figure 6-5. Induced mRNA expression of (A) CYP27A1, (B) CYP27B1, (C) CYP24A1, and (D) VDR in OPC1 by vitaD3 and 1,25OH2D3 in standard bone medium (BM-) and medium containing osteogenic factors (BM+ and BMP+). Total RNA was isolated and examined by quantitative RT-PCR. Data was normalized to GAPDH. [p. 171].

Figure 6-6. Induced mRNA expression of (A) proColI, (B) OC, and (C) OP mRNA in OPC1 cultures containing vitaD 3 or $1,25 \mathrm{OH}_{2} \mathrm{D}_{3}$ and/or osteogenic factor $(\mathrm{BM}+$ or $\mathrm{BMP}+$ ). Total RNA was isolated and examined by quantitative RT-PCR. Data was normalized to GAPDH. [p. 173].

Figure A-1. OPC-1 Aggregate Data, cell population over time. [p.207].

Figure A-2. OPC-1 Isolated Test Group Data, cell population over time. [p. 207].

Figure A-3. MC3T3-E1 Aggregate Data, cell population over time. [p. 208].

Figure A-4. MC3T3-E1 Isolated Test Group Data, cell population over time. [p. 208]. 
Figure A-5. Dissection of cartilage from the bovine metacarpophalangeal joint. (A) The skin is removed, exposing the outer joint capsule. (B) An incision through the anterior surface of the join capsule is made which spares the cartilage within. (C) After the joint has been opened and exposed, a scalpel is used to excise articular cartilage by shaving along the curved surface of the exposed joint. (D) The same joint with some of the cartilage removed, revealing the underlying bone [Liebman and Goldberg, 2001]. [p. 213]. 


\section{LIST OF ABBREVIATIONS}

\begin{tabular}{|c|c|}
\hline $1,25 \mathrm{OH}_{2} \mathrm{D}_{3}$ & $1 \alpha, 25$-dihydroxy vitamin $\mathrm{D}_{3}$, calcitriol \\
\hline $24 \mathrm{R}, 25 \mathrm{OH}_{2} \mathrm{D}_{3}$ & 24R,25-dihydroxy vitamin $\mathrm{D}_{3}$ \\
\hline $25 \mathrm{OHD}_{3}$ & 25-hydroxyvitamin $\mathrm{D}_{3}$, calcidiol \\
\hline 2D & Two-dimensional \\
\hline 3D & Three-dimensional \\
\hline 7-DHC & provitamin $\mathrm{D}_{3} \mathrm{D} 7$-dehydrocholesterol \\
\hline $\mathrm{AB} / \mathrm{AM}$ & Antibiotic/antimycotic \\
\hline ACT & Autologous chondrocyte transplantation \\
\hline ALP & Alkaline phosphatase \\
\hline ARS & Alizarin red stain \\
\hline BGLAP & Bone gamma carboxyglutamate protein, osteocalcin \\
\hline BM- & Standard bone medium \\
\hline $\mathrm{BM}+$ & Standard bone medium containing common osteogenic factors \\
\hline BMP & Bone morphogenetic protein, see rhBMP-2 \\
\hline BMSC & Bone marrow stromal cell \\
\hline BSPI & Bone Sialoprotein I \\
\hline ColI & Collagen Type I \\
\hline ColII & Collagen Type II \\
\hline ColX & Collagen Type X \\
\hline CYP & Cytochrome P450 oxidase \\
\hline CYP24A1 & vitamin D 24-hydroxylase \\
\hline CYP27A1 & sterol 27-hydroxylase, vitamin $\mathrm{D}_{3} 25$-hydroxylase \\
\hline CYP27B1 & 25 hydroxyvitamin $\mathrm{D}_{3}-1 \alpha$ hydroxylase \\
\hline DBD & DNA binding domain \\
\hline DBP & Vitamin $\mathrm{D}$ binding protein \\
\hline DMEM/F-12 & Dulbecco's modified essential medium and Hamm's F-12 \\
\hline DPBS & Dulbecco's phosphate buffer solution \\
\hline ECM & Extracellular matrix \\
\hline ELISA & Enzyme linked immuno sorbent assay \\
\hline $\mathrm{EtOH}$ & Ethanol \\
\hline FBS & Fetal bovine serum \\
\hline GAG & Glycosaminoglycan \\
\hline $\mathrm{HF}$ & High frequency \\
\hline LBD & Ligand binding domain \\
\hline L-Glut & L-Glutamine \\
\hline MC3T3-E1 & Clonal murine calvarial precursor cell line \\
\hline$\alpha \mathrm{MEM}$ & Modified essential medium \\
\hline MLR & Multivariate logistical regression \\
\hline
\end{tabular}

xvii 


$\begin{array}{ll}\text { MSC } & \text { Mesenchymal stem cell } \\ \text { } N P P & \text { Para-nitrophenyl phosphate } \\ \text { OC } & \text { Osteocalcin } \\ \text { OP } & \text { Osteopontin, see SPP1 } \\ \text { OPC1 } & \text { Osteoblastic precursor cell line 1 } \\ \text { OR } & \text { Odds ratio } \\ \text { PDIA3 } & \text { Protein disulfide isomerase family A, member 3, vitamin D } \\ \text { PEG } & \text { membrane binding protein } \\ \text { PEGDM } & \text { Poly(ethylene glycol) } \\ \text { PEO } & \text { Polyethylene glycol dimethylacrylate } \\ \text { PG } & \text { Polyethylene oxide } \\ \text { PGA } & \text { Proteoglycans } \\ \text { PKC } & \text { Polyglycolic acid } \\ \text { proColI } & \text { Protein kinase C } \\ \text { rhBM-2 } & \text { Procollagen } \\ \text { RNAPII } & \text { Recombinant human bone morphogenetic protein-2 } \\ \text { RT } & \text { RNA polymerase II } \\ \text { SPP1 } & \text { Room temperature } \\ \text { ProColI } & \text { Secreted phosphoprotein I, Osteopontin } \\ \text { TE } & \text { Pro-collagen I } \\ \text { TF } & \text { Tissue engineering } \\ \text { UVB } & \text { Transcription Factor } \\ \text { VDR } & \text { Ultraviolet light } \\ \text { VDRE } & \text { Vitamin D receptor } \\ \text { VitaD } 3 & \text { Vitamin D response element } \\ & \text { Vitamin D }, \text { cholecalciferol }\end{array}$




\section{Chapter I. INTRODUCTION}

\section{Section 1.01 Tissue Engineering}

Cartilage and bone defects are one of the most common causes of long-term disability world-wide, an economic burden with an annual cost that exceeds 28 billion dollars in orthopedic repair each year in the United States alone, and the number continues to increase with an aging population suffering from bone and cartilage defects caused by deterioration, disease, and trauma [Chao et al., 2007; Mason et al., 2011]. Tissue engineering (TE) and regenerative medicine are multidisciplinary fields that integrate the principles of engineering (material sciences and biomedical engineering) and life sciences (biochemistry, genetics, cellular and molecular biology) to develop biological cellular/tissue/organ replacements that can repair, restore, maintain or improve tissue function [Brockbank, 2000], and provides a promising solution for cellular and tissue replacement therapies as well as an alternative for animal models used in clinical research.

TE has two applications: therapeutic and diagnostic. Therapeutic applications involve growing tissue either in vivo or ex vivo for subsequent transplantation, while diagnostic applications involve growing tissue in vitro and using the tissue to study biological mechanisms such as drug metabolism, uptake, and toxicity. The foundation for most TE strategies, whether therapeutic or diagnostic, encompasses living cells combined with a biomaterial scaffolds capable of mimicking the tissue-specific ECM, 
signaling factors that promote growth and differentiation, and/or specialized culture devices or bioreactor that can facilitate growth and differentiation by creating physical conditions that closely resembles the native environment [Tortelli \& Cancedda, 2009; Mason et al., 2011; Chao et al., 2007]. In addition, for diagnostic application of studying metabolism of tissue growth and development, mathematical and computational modeling can be used to characterize biological phenomena.

In the case of skeletal tissue, the key to long-term success of cell-based tissue engineered constructs, depends largely on its ability to function mechanically and to appropriately respond to biological and biomechanical signals [Freed et al., 2006; Haj et al., 2005]. In native tissue, the forces created by the environment provides important mechanical cues in directing cellular process, including adhesion, spreading, migration, cytoskeletal organization, growth, differentiation, apoptosis, and tissue morphogenesis [Cheung et al., 2009]. Mechanotransduction, the process of cells transducing mechanical signals into chemical signals, is known to play an essential role in bone tissue remodeling and repair; for example, dynamic mechanical loading at physiological magnitudes has been shown to initiate bone deposition and remodeling in animal models and in organ cultures, while the lack of mechanical load results in tissue atrophy and bone loss [Haj et al., 2005].

There are several factors that need to be taken into consideration for TE experimental design, such as cell source and acquisition, and appropriate signaling molecules. For example, TE for bone regeneration generally utilizes a combination of biomaterial scaffolding with either an osteoblast or precursor cell source and growth 
factors such as bone morphogenetic proteins (BMPs) [Winn et al., 1999], while many studies have indicated that a primary cell culture from mature functional articular cartilage, is a logical cell choice for cartilage TE [Hardingham, Tew, \& Murdoch, 2002]. Each cell source has its benefit and challenge. One of the major challenges of using mesenchymal stem cells (MSCs)/progenitor cells for in vitro and in vivo studies is the isolation sufficiency and expansion for possible clinical applications [Huang et al., 2012]. MSCs and progenitor cells from bone marrow can differentiate into bone, cartilage, fat, and fibrous connective tissue when guided by appropriate growth factors, however isolates are typically heterogenous and limited by variability in their phenotypes, including proliferation capacity, differentiation, expression of cell surface markers and ability to secrete cytokines [Pevsner-Fischer, Levin, \& Zipori, 2011]. Tissue-specific differentiated cells isolated from mature tissue are also limited by the ability to isolate a sufficient number of cells and maintain phenotypic stability. Primary cell cultures can become senescent or dedifferentiate during the culture period [Fodor, 2003], which causes them to loose phenotypic structure and function. In addition, repeated isolations of primary human osteoblasts and chondrocytes have been reported to result in cellular preparations that have variable differentiation potential and proliferative capacity during expansion [Otero et al., 2012; Winn et al., 1999]. The incorporation of growth and differentiation factors can facilitate proliferation and differentiation, however cannot entirely control for phenotypic variability. Therefore, an established cell line with a reproducible stable phenotype is most desirable for the diagnostic application of tissue engineering. In the following studies, a primary cell culture protocol was established and 
used for cartilage tissue constructs, while an engineered osteoblast precursor cell line (OPC1) was used for early bone tissue development.

\section{Section 1.02 Three-Dimensional Culture System}

While there have been rapid advancements in TE, to date, the properties and structure of native cartilage and bone tissue have not been entirely mimicked by engineered tissues. Limitations of current tissue replacement therapies, such as autologous transplantation (the patient receives their own cells/tissue), include difficulty in obtaining a required amount of cells for a TE construct, dedifferentiation during cellular expansion, degeneration at the donor site, and long-term success rate. Reconstruction of skeletal tissue can be accomplished by using an appropriate cell source, biomaterial scaffold, and growth factors; however recreating the unique structure of ECM and mechanical properties of load-bearing tissue is a major challenge in TE.

In healthy connective tissue, structural protein fibers such as collagen and elastin fibers, which make up the ECM, entangle to form a nonwoven mesh that provides tensile strength and elasticity [Zuwei, et al., 2005]. Cells embedded within the tissue are responsible for the synthesis and maintenance of the tissue-specific ECM, thus they are the true "tissue engineers." It is the unique make-up of the ECM that allows mechanical movement of the body. In order to successfully engineer load bearing connective tissue, the distinctive structure and function that gives the tissue the capability of bearing mechanical loads during daily activities has to be mimicked. It has been demonstrated that cells often exhibit unnatural behavior when they are excised from their native 3D 
environment and confined to a two-dimensional (2D) monolayer. A 2D monolayer environment allows cells to attach to the bottom of culture vessels and gradually spread, which causes them to lose their spherical morphology and acquire an elongated fibroblast-like phenotype. Morphological alterations acquired in 2D culture are accompanied by critical biochemical changes, which change the functionality of the cell.

\section{(i) Biomaterial Scaffolds}

In order to enhance cell and tissue growth, and maintain phenotype in vitro, many studies have indicated the usefulness in employing a biomaterial scaffold as a vehicle for growing tissue constructs [Tellisi \& Nureddin, 2007]. Biomaterial scaffolds can be used to recreate the native $3 \mathrm{D}$ environment and mimic the physical structure, biological function, and biochemical nature of ECM [Villanueva, Weigal, \& Bryant, 2009]. In order for a biomaterial to function as an ECM-like scaffold, a number of considerations and criteria have to be met, depending on the TE application, such as biocompatibility, biodegradability, and mechanical property.

Native ECM is a physical substrate that doesn't just provide physical support for cells and tissue, but also contains specific ligands for cell adhesion and migration, as well as signaling factors that regulates and facilitates cellular proliferation, differentiation, and function [Zuwei, et al., 2005]. Cartilage and bone regenerative therapeutics under clinical development, have utilized 
biomaterials as scaffolds to provide an anchor for attachment and differentiation of endogenous migratory precursor cells [Winn, et al., 1999]. Cells must adhere, migrate, proliferate, function, and secrete ECM macromolecules within the provided space of the scaffold. Therefore, the scaffold has to be porous and biocompatible, and for therapeutic TE constructs, it has to be non-immunogenic and biocompatible with the body.

The overall purpose of the scaffold is to serve as a temporary support for growing cells and new tissue formation, therefore it must be biodegradable in a such a way that the scaffold degrades at a complimentary rate to the cellular proliferation and ECM development, ultimately resulting in a TE construct that consists entirely of newly formed tissue. During healthy balanced tissue development and regulation, growth factors stimulate the anabolic synthesis of ECM macromolecules, a process that is complimented by the catabolic degradation of ECM during tissue remodeling and repair [Saha \& Kohles, 2010; Saha \& Kohles, 2011]. In order for this process to take place in vitro, the biomaterial scaffold needs to degrade at a rate that compliments the synthesis of neotissue, be responsive to the local biological environment, and provide the appropriate physical cues [Bahney, et al., 2011].

In addition to facilitating permeation, attachment, proliferation, differenitation, and ECM turnover, the architecture of the scaffold has to mimic the mechanical strength of native tissue. One of the greatest challenges of engineering load-bearing tissue like cartilage and bone is producing a scaffold 
with adequate mechanical properties [O'Brien, 2011]. A scaffold needs to have sufficient mechanical integrity to function from the time cells are seeded within it to the completion of tissue remodeling. Therefore, the scaffold needs to maintain its mechanical property as it degrades and is replaced with tissue-specific ECM.

\section{(ii) Mechanical stimulation using a bioreactor}

Conventional tissue culture methods are limited in their ability to replicate the physiological anabolic and catabolic environment of the body. Normal cells and tissue are continuously exposed to various forms of physiological stresses and stimuli. Cells extracted from a 3D environment and expanded in a 2D monolayer tend to dedifferentiate as they adhere and spread along the surface of the culture vessel. Dedifferentiated cells that have been expanded in a $2 \mathrm{D}$ monolayer have the capacity to redifferentiate if they are transferred into a 3D environment that supports their native morphology; however, their original phenotype may not be fully re-acquired if the in vitro environment does not mimic the physical native environment [Barbero \& Martina, 2007]. When 3D cellular constructs are grown in static culture, cells on the outer surface of the constructs are typically viable and proliferate, while cells within the construct may be less active or necrotic [Cartnmell, et al., 2003].

3D culture techniques that encompass biomaterials allow spherical cells to remain round, yielding cells that continue to express tissue specific genes, but are limited relative to proliferation capacity and lack the ECM molecules found in 
native tissue [Choi, et al., 2007]. Mechanical stimulation (fluid, solid, thermal, etc.) of 3D constructs consisting of cells, biomaterials, and growth factors have shown promising results in the production of viable load-bearing tissues such as cartilage and bone [Kohles, Wilson, \& Bonassar, 2007]. The transduction of mechanical signals to chemical signals from cell-cell and cell-ECM interactions determines the formation of healthy tissue morphology. Thus, preserving these interactions is essential in recreating the native tissue.

A bioreactor is a tissue-culture device that provides a controllable, physically active environment that can be used to study and potentially improve engineered tissue structure and properties [Freed, et al., 2006]. For the cultivation of engineered tissues, bioreactors can improve construct shape and size, cell and ECM density and molecular composition, and can permit the studies of (i) mass transport of oxygen and signaling factors, (ii) hydrodynamic conditions, and (iii) mechanotransduction [Freed, et al., 2006], as well (iv) the study of drug metabolism, intake and toxicity. Utilizing a bioreactor can help recreate the native physiological mechanical environment and facilitate tissue development.

A novel bioreactor has been fabricated by Portland State University's Regenerative Bioengineering Laboratory, capable of providing mechanical stimulation (compressive loading and fluid perfusion), real-time mechanical characterization, optical inspection, and non-destructive ultrasonic assessment of ECM-biomaterial content (Figure 1-1). The device combines a linear actuator (Electro Force, Bose, Eden Prairie, MN) connected to five load transducers 
$(1,000 \mathrm{~g},+/-0.15$ to $0.25 \%$, Model $31 \mathrm{Mid}$, Sensotec/Honeywell, Golden Valley, MN) connected to solid platens that contact specimens from above and apply compressive solid mechanical loads. The actuator can be controlled via displacement $(+/-2.5 \mathrm{~mm})$ or force $(20 \mathrm{~N})$ to apply a variety of waveforms (Win Test, Bose) for dynamic stimulation of five concurrent cube-shaped test samples. Access for a digital video microscope and ultrasound transducers facilitates the minimally invasive assessment of cultured tissue constructs. The entire bioreactor can fit inside an incubator (Galaxy R Series Incubator, New Brunswick, Edison, $\mathrm{NJ}$ ) with sensor control of the internal environment chemistry, carbon dioxide $\left(\mathrm{CO}_{2}\right)$, oxygen $\left(\mathrm{O}_{2}\right)$, and nitrogen $\left(\mathrm{N}_{2}\right)$. The bioreactor is capable of controlled monitoring of biological, chemical, and mechanical components associated with engineered tissue constructs, which includes cells, biomaterials, growth stimulants/inhibitors, and the developing neotissue in order to address the complexities of developing native tissue. 

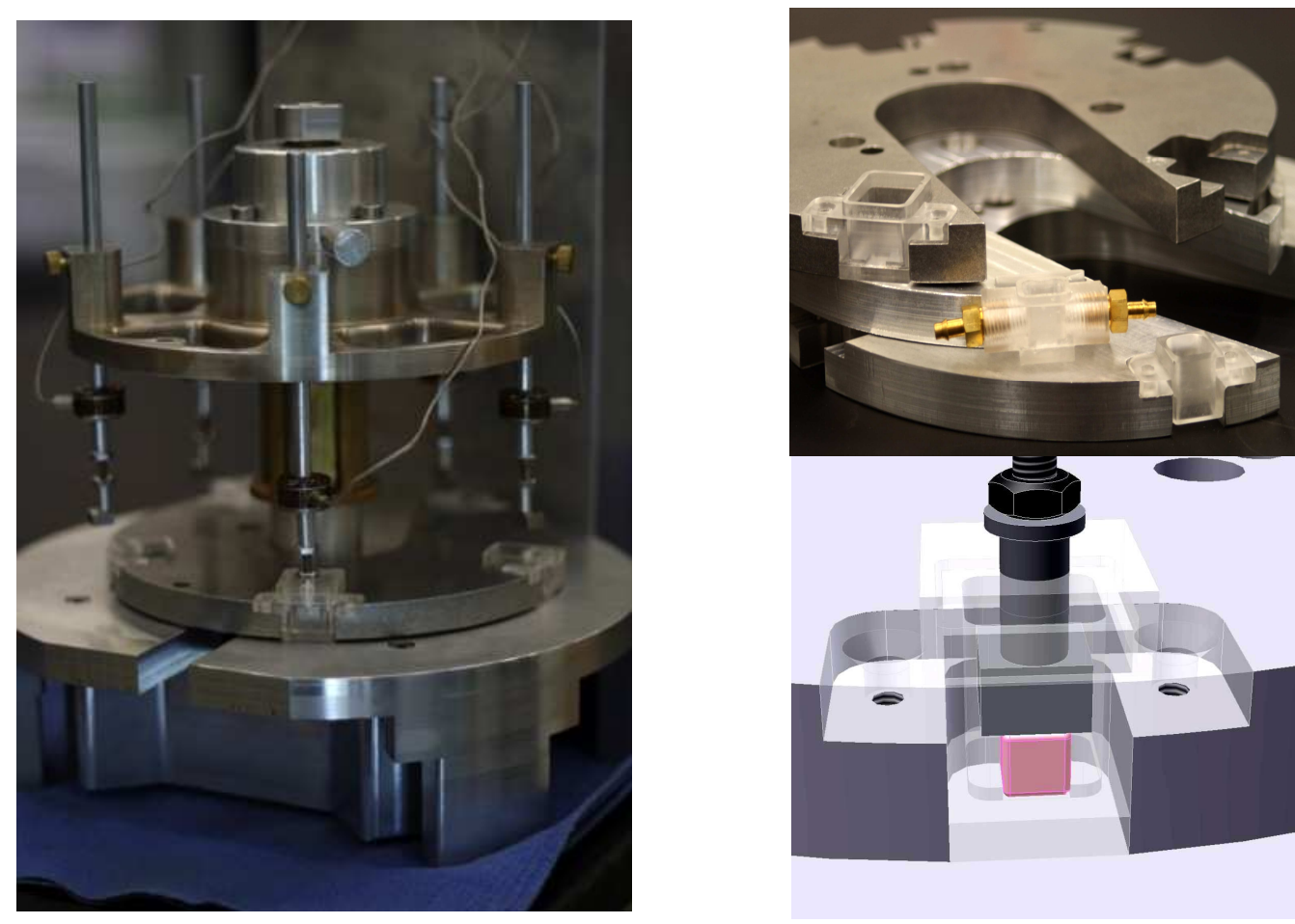

Figure 1-1: The fabricated, novel multiphysics bioreactor with five culture wells. The highresolution, copper-colored load-cells measure the dynamic loads transferred via the load-rods through the square load-platens into the culture-well designs (upper right) and onto the cellbiomaterial constructs (pink cube, lower right) [Mason et al., 2011; Kohles et al., 2011].

\section{(iii) Nondestructive techniques to assess 3D tissue constructs}

Most mechanical and biochemical assessment of engineered tissue constructs require destructive endpoint-testing and/or compromise the sterility of the bioreactor environment used during construct formation [Walker, et al., 2011]. Ultrasonic imaging is a standard clinical diagnostic tool that is based on propagating high-frequency (HF) sound waves and offers a technology for tissue characterization and stimulation in a noninvasive and nondestructive manner. The response to mechanical stimulation induced in passive tissues by external sources 
such as low to high frequency vibration or compression can be used to analyze tissue elasticity as a metric for tissue health [Hein \& O'Brien, 1993]. Recently, it has been shown that ultrasonic assessment can predict the process of native cartilage regeneration and engineered cartilage histology [Hattori, et al., 2005].

The bioreactor described in the previous section has the capability of providing ultrasonic assessment of $3 \mathrm{D}$ engineered tissue constructs. As a ultrasonic wave passes through a specimen, the speed of attenuation provides a metric associated with the density of accumulated matrix molecules, while the speed of sound is associated with Young's Modulus or elasticity (stress-strain) [Kohles, Bowers, Vailas, \& Vanderbery, 1997]. When a sound wave travels through a medium, its amplitude decreases with distance. In homogenous materials, the amplitude of sound waves are only reduced by the spreading of the wave, however, in natural heterogenous materials, objects within the medium (such as cells in tissue) weakens the amplitude which results from scattering (the reflection of the sound waves in other directions) and absorption (the conversion of sound energy to other energy forms) of the sound wave. Ultrasonic attenuation, the decay rate of the wave as it propagates through the material, can be used to explain physical or chemical phenomenon that decreases ultrasonic intensity, while the speed of sound, which is related to elastic property and material density, can be used to describe the mechanical property. Therefore, ultrasound provides a nondestructive means to assess the mechanical properties of growing engineered tissue in real time 


\section{Section 1.03 Cartilage Tissue Engineering}

Cartilage disease and injury affects more than $15 \%$ (approximately 40 million people) of the US population and with more than 250,000 knee and hip replacements performed each year, exceeds an annual cost of $\$ 60$ billion per year [Chung \& Burdick, 2008; Steward, Liu, \& Wagner, 2011]. With an aging population suffering from defects or deterioration of articular cartilage by $\mathrm{OA}$ and trauma, the number continues to increase. Articular cartilage provides a unique challenge for tissue engineering in that its structure appears simple and it only contains one cell type, the chondrocyte, however the ECM is highly organized and complex [Hardingham, et al., 2002]. Articular cartilage is not innervated and avasculature so normal mechanisms involving the recruitment of cells from blood or bone marrow to a wound site, can not occur, limiting the capacity of selfrepair [Vinatier, et al., 2009; Hardingham, et al., 2002]. In cases of cartilage damage caused by trauma, severe injuries are frequently followed by degeneration [Appleman, et al., 2009]. Because chondrocytes do not sustain a healing response on their own, tissue engineering has the potential to provide functional cartilage tissue to help the millions of people who suffer from degenerated, diseased, or damaged articular cartilage.

There have been rapid advancements in cell-based therapies, which include the in vitro engineering of functional tissue substitutes for subsequent in vitro transplantation [Chung \& Burdick, 2008]. To date, however, the properties and structure of native cartilage tissue have not been entirely mimicked by engineered tissue. Limitations of the 
current solutions such as autologous chondrocyte transplantation (ACT) include difficulty in obtaining a required amount of cells for a construct and cellular dedifferentiation during expansion, as well as degeneration at the donor site. Although recorded success rates of ACT are between 60-90\% depending on the localization of the injury [Yilmaz, et al., 2010], long-term success rates are considerably lower.

Articular cartilage is a highly specialized tissue that reduces joint friction at the extremities of long bones, and helps absorb mechanical load. Articular cartilage consists of chondrocytes and ECM that is composed of a network of collagens, particular type II collagen (ColII), which gives the tissue its shape and strength, and proteoglycans, which give resistance to mechanical stress and compression [Vinatier, et al, 2009; Hardingham, et al., 2002]. Although only about $10 \%$ by volume, the immobilized chondrocytes embedded within the ECM are responsible for the synthesis, organization, and maintenance of ECM macromolecules [Pazanno, et al., 2000; Lanza, Langer, \& Vacanti, 2007; Hardingham, Tew, \& Murdoch, 2002]. The continuous remodeling of cartilage ECM in response to exogenous mechanical stimuli occurs through biokinetic anabolic and catabolic reactions of ECM macromolecules [Saha \& Kohles, 2011; Saha \& Kohles, 2010a; Saha \& Kohles, 2010b], which allow the tissue to respond to the physiological environment and protect the underlying bone.

The structural integrity of cartilage is derived from the fibrous network formed by the cartilage-specific collagen type II (ColII), which is immersed in a gelatin formed by proteoglycans rich in sulfated glycosaminoglycans (GAG). Because it is abundant in sulfate and carboxyl groups, GAG is negatively charged which draws water into the 
tissue with such high affinity that it makes up $\sim 70 \%$ of the total weight creating a large osmotic swelling pressure [Wilson, et al., 2002; Hardingham, et al., 2002]. This hydration permits the diffusion of water-soluble molecules throughout the tissue. GAG is too large and immoble to redistribute itself, therefore swells and expands the ECM, placing the collagen network under tension. Equilibrium in the tissue is reached when the tension from the collagen network balances the swelling pressure. It is this unique molecular combination that allows low friction movement of joint surfaces. In return, joint loading from body movement induces fluid flow within the tissue, which maintains ion movement, and nutrient/waste exchange, therefore reducing the need for vascularization. Recreating this dynamic is a major challenge in TE.

Because chondrocytes from mature articular cartilage are capable of producing ColII and GAG ECM macromolecules, it has been suggested that isolates from adult articular cartilage is a logical cell choice for cartilage TE [Hardingham, et al., 2002]. Although chondrocytes have been widely used in cartilage repair, they have been shown to be unstable when cultured in a standard 2D monolayer. In the body, cells exist, proliferate, and differentiate, within a 3D environment, but when chondrocytes are cultured in a 2D environment, they tend to lose their overall hyaline structure and functional elasticity, thus their overall differentiated phenotype. In vitro expansion of static monolayer cultures are associated with cellular dedifferentiation and reduced or total loss of the ability to produce ECM and redifferentiate [Barbero \& Martina, 2007; Barlic \& Kregar-Velikonja, 2008; Ando, et al., 2009]. Many authors have described a fibrocartilaginous quality observed in chondrocytes prepared in monolayer [Ando, et al., 
2009]. A 2D environment allows chondrocytes to attach and gradually spread, which causes them to lose their spherical morphology and acquire an elongated fibroblast-like phenotype. Morphological alterations acquired in monolayer are accompanied by critical biochemical changes. Loss of the hyaline morphology is associated with the expression or total loss of aggrecan and ColII synthesis, and an increase in the expression of fibrocartillage associated ECM molecules collagen type I (ColI) and versican [Barbero \& Martina, 2007; Barlic \& Kregar-Velikonja, 2008].

Chondrocytes that have dedifferentiated have the capacity to redifferentiate if they are transferred to a 3D environment that supports their native spherical morphology; however, their original phenotype may not fully be re-acquired [Barbero \& Martina, 2007]. Because cartilage-specific ECM macromolecules bind to water with such high affinity, hydrated biomaterials (hydrogels) can be used to recreate the native 3D environment and mimic the physical structure, biological function, and biochemical nature of cartilage ECM. Natural or synthetic polymers such as proteoglycan aggrecans and collagen have been found to provide 3D support, induce chondrocyte proliferation and improve their synthetic function [Tellisi \& Nureddin, 2007]. Recent studies have indicated that bioabsorbable polymers such as polyglycolic acid (PGA), enhances proteoglycan synthesis, while collagen scaffolds stimulate collagen synthesis [Atala \& Lanza, 2002]. It has been shown that 3D cultures, such as those grown in with alginate or agarose allows chondrocytes to remain round and supports cartilage-specific gene expression [Hardingham, Tew, \& Murdoch, 2002], but may be limited relative to proliferation capacity and lack the zonal distribution of cells and ECM molecules found 
in native tissue [Choi, et al., 2007]. Part of the challenge of engineering cartilage is providing the essential cells and signals that will establish cartilage ECM and recapitulate the molecular organization that forms the basis for the essential mechanical properties of the tissue [Hardingham, et al., 2002].

Although cartilage is made up of only one cell type, it is characterized by zonal differences in architecture and distribution of ECM components. There are four histologically distinct zones (superficial tangential or resting zone, proliferative of middle zone, hypertrophic or deep zone, and the calcified zone) characterized by orientation and density of ECM molecules, morphology, and biochemistry [Kohles et al. 2012; Atala \& Lanza, 2002]. Because of the depth-dependent structural arrangement of chondrocytes and ECM macromolecules, articular cartilage is a heterogenous and mechanically anisotropic material. Assessing the mechanical properties of cartilage constructs in realtime via ultrasound while tissue is developing may elucidate the physical interactions and localized biomechanics (stresse, strain, and elastic property) between cell-cell and cell ECM that occurs within and between zones.

Healthy chondrocytes undergo hydrostatic, compressive, tensile, and shear forces within a physiological environment, which act to maintain the phenotype and promote production of new cartilage tissue [Ramage, et al., 2009]. Abnormal mechanical forces, such as those sustained in traumatic skeletal injuries, can alter chondrocyte behavior, regulating in degradation of cartilage from increased catabolic activity and apoptosis. In order to engineer a cartilage construct ex vivo an environment that supports chondrocyte development into functional cartilage needs to be recreated, including the appropriate 
scaffold bioactivity and mechanical stimulation [Appleman, et al., 2009]. Since normal cartilage is continuously exposed to various forms of physiological stresses, diffusionbased nutrient supply is believed to be a vital mechanism for the maintenance of cartilage homeostasis, along with the concurrent physiological stimulations [Park, et al., 2007]. Utilizing a multi-scale bioreactor as previously described, can recreate native biomechanical and biochemical stimuli, facilitate cartilage development investigations, and validate ongoing biokinetic modeling.

\section{Section 1.04 Engineering Bone Development}

Imbalances between osteoblastic bone formation and osteoclastic bone resorption can result in a net bone loss and osteoporosis [Hens, et al., 2005]. While many therapies aim to inhibit bone resorption, in order to cure skeletal diseases associated with bone loss, new bone formation is essential. Bone formation in the embryo or during adult bone repair or remodeling involves the progeny of MSCs (osteoprecursors) [Bruder, et al., 1994]. MSCs are multipotent cells that continuously replicate while a portion become committed to the mesenchymal cell lineage such as bone, cartilage, tendon, ligament and muscle (see Figure 1-2). Bone regeneration is based on the hypothesis that healthy progenitor cells, either recruited or delivered to a bone defect, can regenerate damaged or degenerated tissue [Shea, et al., 2000]. Culturing osteogenic cells in an enviornment that supports bone formation is a possible solution for the treatment of extensive bone defects and osteoprosis. A source of human cells that can be produced in large numbers and can predictably differentiate into bone is critical for the therapeutic application of engineering 
human bone replacements [Marolt, et al., 2010], and for the diagnostic application of studying bone formation in vitro.

The differentiation of MSCs and progenitor cells within each specialized celular lineage is a complex multistep pathway involving discrete cellular transitions that depend on the presence of specific signaling factors, nutrients, and environmental cues. An important aspect of bone biology is to experimentally address the regulatory events related to the commitment of progenitor cells into the developmental pathway and elucidating the regulatory factors that influence bone formation, remodeling, and regeneration [Lian \& Stein, 1995]. While human-derived immortalized and conditionally immortalized osteogenic cell lines that have been used as model systems to develop bone constructs, a human derived cell-line that exhibits a consistent differentiation pattern and is stable over generations is essential for modeling bone development, and for studying biomaterial-cellular interactions necessary for optimizing bone regenerative therapies. 


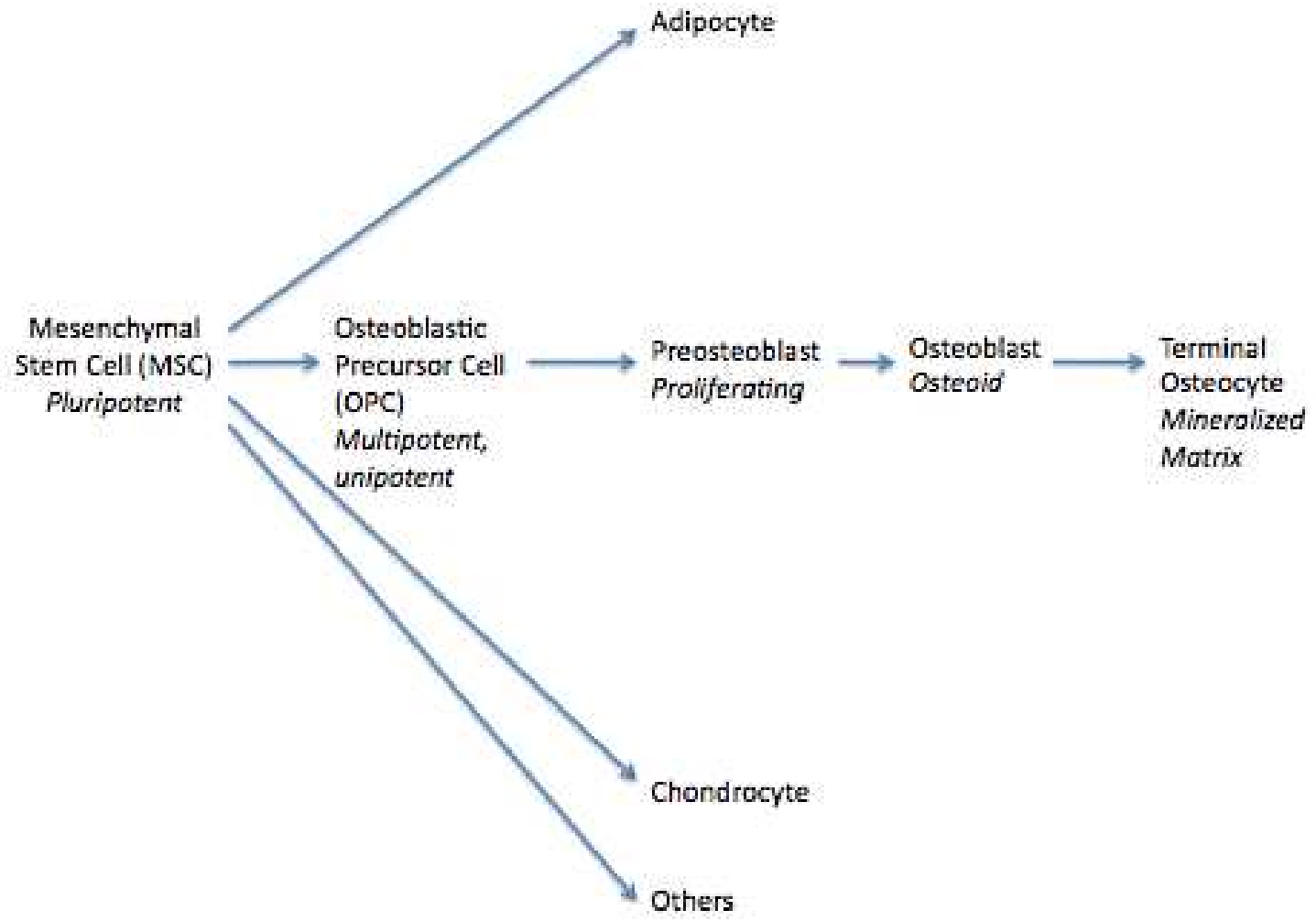

Figure 1-2. MSC bone developmental pathway. An important aspect of bone biology is to address the regulatory events related to commitment of pluripotent progenitor cells into the developmental pathway that restricts options for specialization to either the osteoblast and chondrocyte pathways [ Lian \& Stein, 1992].

\section{(i) Engineered Osteoprecursor Cell Culture System}

Advancements in the design of biomedical engineering technologies, especially those supporting regenerative medicine through cell and tissue engineering, include the use of precursor cell lines, which can consistently be manipulated to develop neotissue. An osteoblastic precursor cell line (OPC1), derived from human fetal bone tissue from the periosteum and femur, was originally 
established to provide a consistent and reproducible culture system for evaluating bone development and cell/biomaterial interactions, and for screening putative differentiating factors in a culture system that would be applicable to a clinical situation [Winn, et al., 1999]. In addition, OPC1 can be used to study the growth and differentiation of osteoprogenitors and offers the possibility of examining events associated with stem cell differentiation to osteoblasts. Because OPC1 is a stable osteoblast precursor that has displayed consistent reproducible cultures, and may be useful for elucidating bone differentiation patterns during bone development and evaluating putative differentiating factors, it is an ideal culture system to study the effects of vitamin D on bone development.

\section{(ii) In vitro bone development}

Several osteoblast culture systems have demonstrated that cells undergo a temporal developmental sequence that starts with a proliferation phase and results in fully mature osteocyte-like cells embedded in mineralized ECM [Pockwinse et al., 1995; Owen et al., 1991]. There are three stages of in vitro bone development that have been characterized by morphology and gene expression: (1) a proliferation and ECM biosynthesis stage, (2) an ECM development and maturation stage noted by an increase in ALP activity, and (3) a final stage of ECM mineralization in which hydroxyapetite is organized and deposited (see Figure 1-3) [Pockwinse et al., 1995; Owen et al., 1991; Lian \& Stein, 1995]. 
In the first stage, following initial cell-seeding, the cells actively proliferate for the first 10 to 12 days of culture and several genes associated with ECM formation, including procollagen type I (proColl) and osteopontin (OP), are actively expressed then gradually decline as proliferation rate decreases and ECM maturation begins (see Figure 1-3). Immediately following the decrease in proliferation, ALP activity is greatly increased. This post-proliferative period occurs between days 12 and 18, and it is during this time that the ECM matures and becomes competent for mineralization [Pockwinse et al., 1995; Lian \& Stein, 1995]. ALP expression is used as a marker for osteoblast phenotype, however its function still remains unclear. It has been postulated to increase concentration of inorganic phosphate, a concept known as the "booster hypothesis" [Golub \& Boesze-Battaglia, 2007]. During the third stage of bone development, ALP expression decreases and other genes associated with bone mineralization are expressed at maximal level [Owen et al., 1991; Lian \& Stein, 1995; Golub \& Boesze-Battaglia, 2007], which include OP and osteocalcin (OC) and are known to interact with the mineralized ECM in vivo [Lian \& Stein, 1995]. OP is expressed in both the proliferation and mineralization periods, and downregulated post-proliferatively during matrix maturation; however, during proliferation, OP expression reaches only about $25 \%$ of its maximal level which peaks between days 16 and 20 during mineralization. In contrast, OC, the calcium binding protein that binds to hydroxyapatite, is expressed only post-proliferatively 
with the onset of nodule formation, and is expressed maximally with ECM mineralization in vivo and in vitro [Lian \& Stein, 1995].

Temporal Expression of proliferation and Osteoblast Phenotype and Function During Early Development

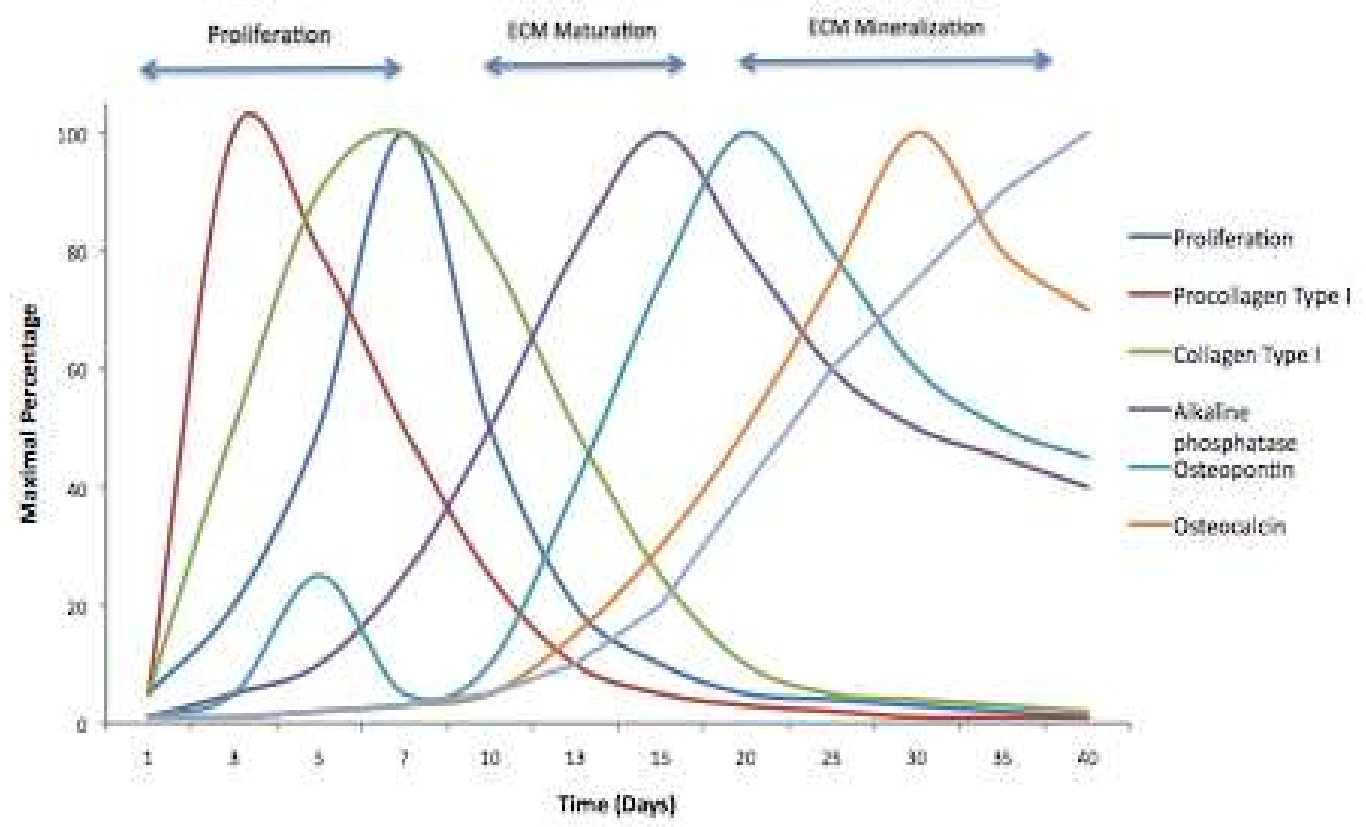

Figure 1-3. Temporal expression of cell growth and osteoblast phenotype during in vitro formation of bone tissue. This figure is based on studies conducted by Lian \& Stein, 1995. 


\section{Section 1.05 Vitamin D}

Vitamin D, also known as calciferol, refers to a collective group of fat-soluble pluripotent, seco-steroid metabolites that together carry out the known vitamin D-related functions. The classic understanding of vitamin D stems from the essential role it plays in the regulation and maintenance of calcium and phosphorous homeostasis and bone metabolism. Elucidating the steps required for the metabolism of vitamin D precursors, vitaD 3 (cholecalciferol) and $25 \mathrm{OHD}_{3}$ (calcidiol), to the active hormone $1,25 \mathrm{OH}_{2} \mathrm{D}_{3}$ (calcitriol) led to the discovery of regulatory cytochrome P-450 (CYP) hydroxylases involved in the activation and inactivation of vitamin $\mathrm{D}$, and the nuclear vitamin $\mathrm{D}$ receptor (VDR) and its interactions with transcriptional machinery inside vitamin D target cells [Jones, et al., 1998]. $1,25 \mathrm{OH}_{2} \mathrm{D}_{3}$ directly influences osteoblasts, by binding to VDR, which consequently elicits nuclear and extra-nuclear cellular responses related to the production and maintenance of the skeleton [Biswas \& Zanello, 2009].

Once it was demonstrated that VDR and vitamin D regulatory CYPs were present in multiple tissues and cells not involved in the classic endocrine actions of vitamin $\mathrm{D}$, it was acknowledged that its functions extended far beyond mineral homeostasis and bone metabolism. It is now recognized that vitamin D is associated with the regulation of many cellular process including proliferation, differentiation, and apoptosis in multiple tissues in an autocrine/paracrine manner [Brannon, 2012; Hobaus et al., 2013; Jones et al., 1998]. However, because there are few detailed reports of the extrarenal synthesis of $1,25 \mathrm{OH}_{2} \mathrm{D}_{3}$, and limited reporting on the extrahepatic metabolism of vita $\mathrm{D}_{3}$, extraendocrine vitamin D metabolism is not widely recognized. 


\section{(i) Photosynthesis of Vitamin D}

Vitamin D is one of the oldest prohormes that has been produced by almost all life forms for over 750 million years [Hollick, 2003]. The production of vitaD $\mathrm{D}_{3}$ begins with the photosynthesis of the subcutaneous pro-vitamin D 7dehydrocholesterol (7-DHC) in the basal and suprabasal layers of the skin when it is exposed to ultraviolet (UVB) light (See Figure 1-4) [Hollick et al., 2008; Jones et al., 1998; Lehman, 2008]. Once 7-DHC is photochemically transformed to previtamin $\mathrm{D}_{3}$ (previta $\mathrm{D}_{3}$ ), then it undergoes thermal-isomerization to vitaD $\mathrm{D}_{3}$ [Kumar, 1990; Lehman, 2008; MacLaughlin et al., 1982]. During prolonged exposure to the sun, both $\operatorname{previtaD}_{3}$ and $\operatorname{vitaD}_{3}$, undergo reversible photoisomerization reactions to biologically inert sterols, including lumisterol and tachysterol [Lehman, 2008]. Consequently, this prohibits vitamin D toxicity from prolonged sun exposure because it limits vita $\mathrm{D}_{3}$ formation. Previta $\mathrm{D}_{3}$ is also subject to reversal leading to the regeneration of 7-DHC [Lehman, 2008]. There are several intrinsic and extrinsic factors that influence the conversion of 7-DHC to previta $\mathrm{D}_{3}$, including pigmentation, age, percent of body-fat, latitude, season, time of day, and the usage of sunscreen [Lehman, 2008]. 


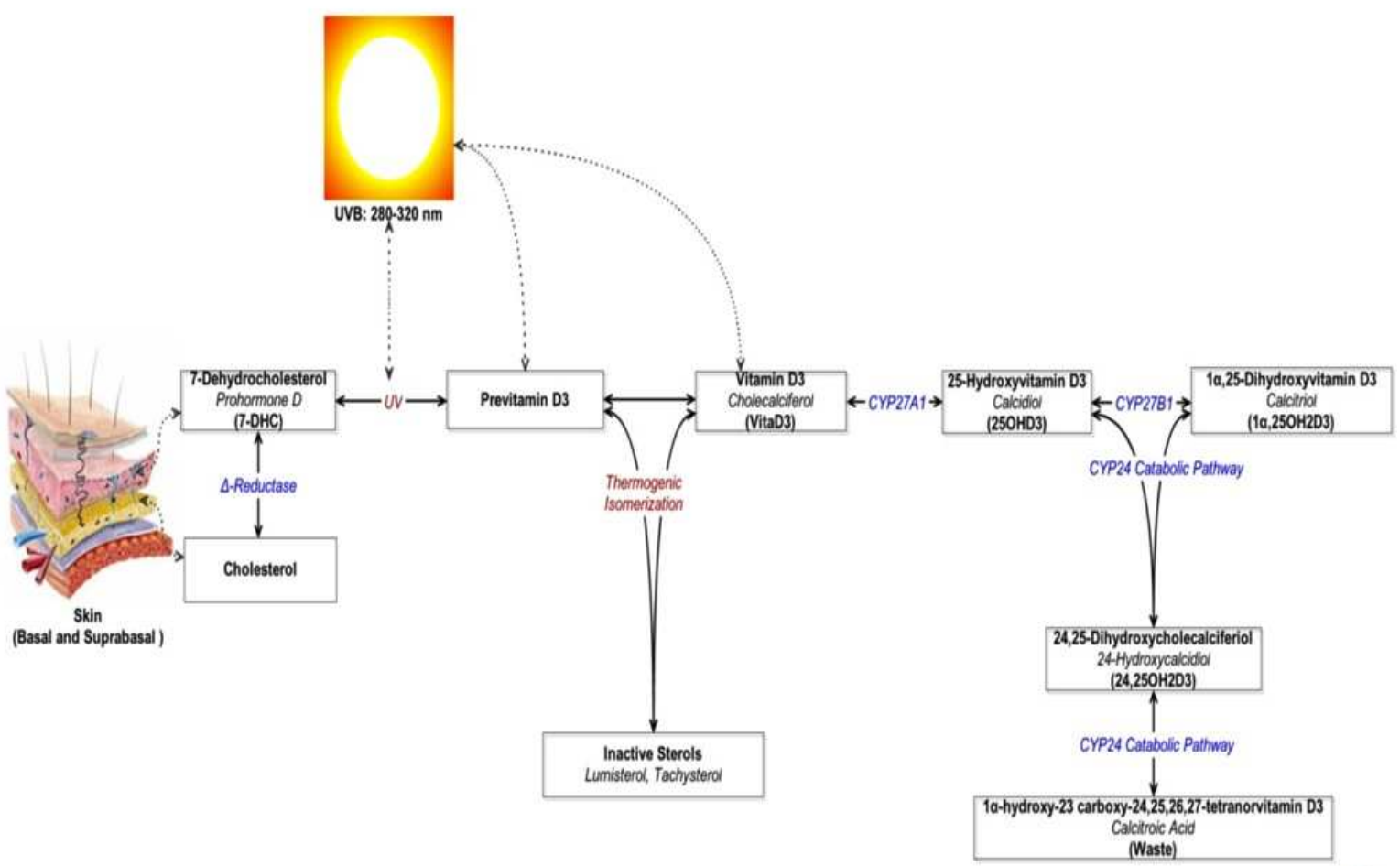

Figure 1-4. Schematic of photosynthesis, metabolism, and regulation of vitamin D metabolites. Vitamin D precursors and metabolites are in black, and metabolic enzymes are in blue. 


\section{(ii) Vitamin D Metabolism and Regulation}

After vitaD $\mathrm{D}_{3}$ is endogenously made from cholesterol via themerisomerization of previta $\mathrm{D}_{3}$, it passively diffuses into the blood and slowly transfers to the vitamin D binding protein (DBP), a highly polymorphic glycoprotein that is a member of a gene family including albumin and $\alpha$-fetoprotein [Berg, 1999; Kumar, 1990; Ahmed and Shoker, 2010]. Alternatively vitamin D can be acquired by diet in either the vitaD $\mathrm{D}_{3}$ (derived from animals) or vitaD 2 (derived from plants) form. VitaD 3 , the metabolic precursor to $25 \mathrm{OHD}_{3}$, itself is biologically inert, or inactive, in that it does not directly increase the active transport of calcium or mediate any of the other vitamin D-related activities in physiological concentrations unless it its metabolized to a more polar compound (Kumar, 1990).

There are many metabolites or isomers of vitamin D. The active metabolite, $1,25 \mathrm{OH}_{2} \mathrm{D}_{3}$, and the immediate metabolic precursor to the active metabolite, $25 \mathrm{OHD}_{3}$, are among the most studied. In the classic endocrine metabolic pathway of vitamin $\mathrm{D}$, both endogenous and dietary vita $\mathrm{D}_{3}$, are transloacted by $\mathrm{DBP}$ to the liver and kidney, sequentially for bioactivation. Generally, the first stop for circulation vitaD $\mathrm{D}_{3}$ is the liver, where it is hydroxylated to the major circulating form, $25 \mathrm{OHD}_{3}$, by CYP-related 25-hydroxylases CYP2R1 (microsomal) or by CYP27A1 (mitochondrial) [Ahmed \& Shoker 2010; Norman, 1998; Jones et al. 1998]. Circulating $25 \mathrm{OHD}_{3}$ from the liver is transported via DBP to the kidney, where it is metabolized by the biologically active form $1,25 \mathrm{OH}_{2} \mathrm{D}_{3}$ by 25 hydroxyvitaminD $\mathrm{D}_{3}-1 \alpha$-hydroxylase (CYP27B1) in the kidneys [Ahmed \& Shoker 
2010; Norman, 1998; Jones et al. 1998]. CYP27B1 is a mixed function oxidase comprised of a ferredoxin and an iron sulfur protein, and is regulated by several factors that work in concert to maintain normal concentrations of plasma calcium and phosphorous [Kumar 1990]. During states of calcium or phosphorus demand, $1,25 \mathrm{OH}_{2} \mathrm{D}_{3}$ is readily converted from the circulating $25 \mathrm{OHD}_{3}$ metabolite; conversely, during states of calcium and phosphate homeostatic balance, $25 \mathrm{OHD}_{3}$ is metabolized to the inactive $24 \mathrm{R}, 25 \mathrm{OH}_{2} \mathrm{D}_{3}$ metabolite [Kumar, 1990], which is excreted from the endocrine system.

While early data suggested that the liver is the only significant site of 25hydroxylation in vivo, there have been occasional reports of extrahepatic 25hydroxylation of vitamin $\mathrm{D}_{3}$ [Jones et al., 1998; Hollick, 2010]. Recently extrarenal metabolism of $25 \mathrm{OHD}_{3}$ to $1,25 \mathrm{OH}_{2} \mathrm{D}_{3}$ has been demonstrated [Zhou et al., 2012; Hobaus et al., 2013]. In vitro, many non-renal cells, including MSCs, bone, cartilage, keratinocytes, placenta, prostrate, macrophages, lymphocytes, dendritic cells, and several cancer cell lines can convert $25 \mathrm{OHD}_{3}$ to $1,25 \mathrm{OH}_{2} \mathrm{D}_{3}$ [Zhou et al., 2012]. Several of these cell types have been shown to express both CYP27A1 and CYP27B1, which may explain the occasional reports of extrahepatic 25-hydroxylation of vitaD 3 [Lehman, 2008; Hollick, 2010; Jones et al.,1998]. Besides the local renal activity of $1,25 \mathrm{OH}_{2} \mathrm{D}_{3}$, the hormonally active vitamin D metabolite is translocated by DBP to other target tissues that express VDR to operate in a genomic or nongenomic manner [Lehman, 2008]. 
The action of vitamin D is limited by the catabolic enzyme 24-hydroxylase (CYP24A1), which results in a compound that is more soluble and has a substantially lower affinity for VDR [Trump, et al., 2010; Ahmed \& Shoker, 2010; Ambrecht, et al.,1998]. CYP24A1 has been shown to hydroxylate both $25 \mathrm{OHD}_{3}$ and $1,25 \mathrm{OH}_{2} \mathrm{D}_{3}$ to form $24,25 \mathrm{OH}_{2} \mathrm{D}_{3}$ and $1,24,25 \mathrm{OH}_{3} \mathrm{D}_{3}$, respectively [Flanagan, et al., 2006]. The main function of CYP24A1 is to regulate the circulating concentration of vitamin $\mathrm{D}$ metabolites. $1,25 \mathrm{OH}_{2} \mathrm{D}_{3}$ induces and mediates CYP24A1 via an autocatalytic loop through vitamin D response elements (VDRE) located in the promoter region of the CYP24 gene [Chen et al., 2011]. Generally, basal expression of CYP24 is extremely low but the gene is highly induced by $1,25 \mathrm{OH}_{2} \mathrm{D}_{3}$ [Geng, et al., 2011; Atkins, et al., 2007]. Thus, the synthesis and degradation of $1,25 \mathrm{OH}_{2} \mathrm{D}_{3}$ is highly regulated, and the concentration is controlled at the cellular level.

\section{(iii) Signal Transduction and Gene Expression.}

The molecular effects of vitamin $\mathrm{D}$ are mediated through the intra-nuclear receptor VDR, which acts as a ligand-activated transcription factor for target genes when bound to $1,25 \mathrm{OH}_{2} \mathrm{D}_{3}$ [Seiffert et al., 2004]. VDR is a member of the superfamily of nuclear hormone receptors, and like other members of the nuclear receptor family, is composed of distinct structural domains within the protein that include a ligand binding domain (LBD) and DNA binding domain (DBD) [Ahmed \& Shoker, 2010]. LBD is responsible for hormone binding, strong 
receptor dimerization and interaction with co-repressors and co-activators, which are all essential for the regulation of VDR transcriptional activities.

VDR has a high affinity for $1,25 \mathrm{OH}_{2} \mathrm{D}_{3}$, and following $1,25 \mathrm{OH}_{2} \mathrm{D}_{3}$ binding forms a heterodimer with the retinoid $X$ receptor, which allows it to bind to the response/receptor element (VDRE) in the promoter regions of target genes [Flanagan et al., 2006; Brannon, 2012; Geng et al., 2011]. VDR heterodimers and associated factors binding to the VDRE of vitamin D responsive genes increases the rate of transcription of vitamin D associated genes by RNA polymerase II (RNAPII) [Adorini et al., 2007]. Responsive genes include those associated with calcium homeostasis, immune response and maintenance of immune cells, cellular growth, differentiation, cell cycle arrest, apoptosis, and the enzymes required for vitamin D metabolism (Figure 1-5) [Chen et al., 2011; Flanagan et al., 2006; Boyan et al., 2009; Geng et al., 2011]. VDR is nearly ubiquitously expressed, and almost all cells are genetically regulated by $1,25 \mathrm{OH}_{2} \mathrm{D}_{3}$ [Bouillon, et al., 2008]. In summary, VDR has been reported to regulate a large range of genes (200-3065) and has been estimated to modulate 5-10\% of the human genome [Morris \& Anderson, 2010; Flanagan et al., 2006; Hollick, 2010; Norman, 1998; Naeem, 2010]. 


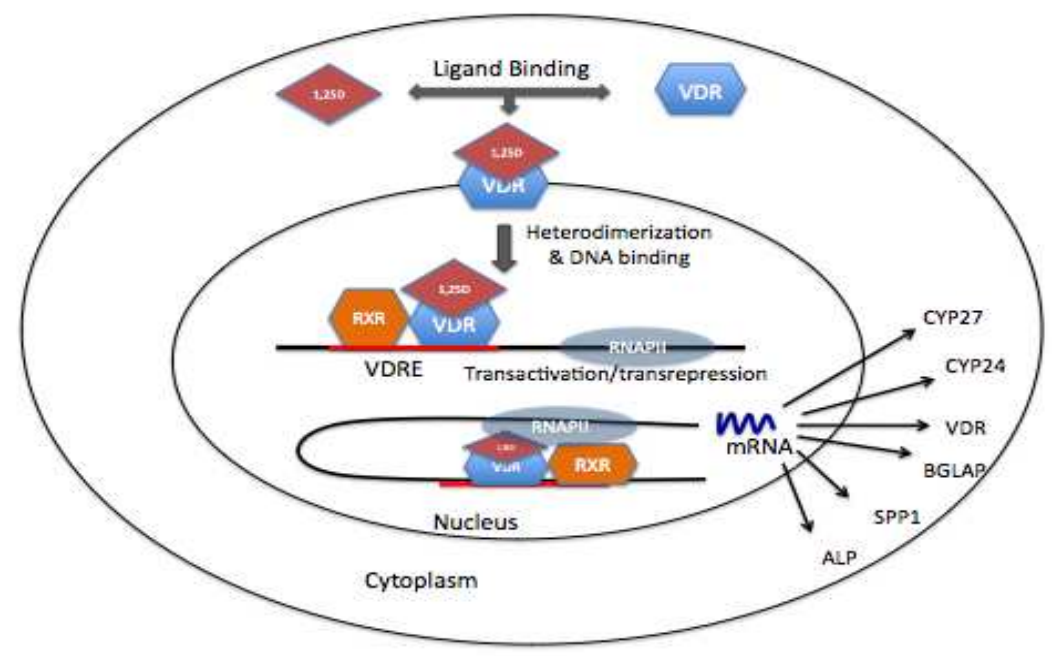

Figure 1-5. The active metabolite of vitaD3, $1,25 \mathrm{OH}_{2} \mathrm{D}_{3}$, regulates calcium-phosphorous homeostasis and bone health through its classic hormonal actions in concert with its nuclear transcriptional factor, VDR, on target genes containing the VDRE [Brannon, 2012].

(iv) Nongenomic [not sure what you mean by nongenomic - but this is not how the word is typically used] Effects of Vitamin D.

It has previously been shown that the nongenotropic actions of $1,25 \mathrm{OH}_{2} \mathrm{D}_{3}$ at the level of the plasma membrane leads to the activation of ion channels and the induction of regulated exocytosis in osteoblasts. These activities are predicted to be related to the bone anabolic functions of the vitamin D [Biswas \& Zanello, 2009]. In osteoblasts, $1,25 \mathrm{OH}_{2} \mathrm{D}_{3}$ increases intracellular calcium concentration by opening calcium-permeating channels present in the plasma membrane and depleting internal $\mathrm{Ca}^{2+}$ stores [Biswas \& Zanello, 2009]. $1,25 \mathrm{OH}_{2} \mathrm{D}_{3}$ initiates rapid membrane-associated signaling pathways via the $1,25 \mathrm{OH}_{2} \mathrm{D}_{3}$ membrane binding protein PDIA3 (protein disulfide isomerase, family A, member 3) [Boyan 
et al., 2012]. The mechanisms involved in membrane-associated $1,25 \mathrm{OH}_{2} \mathrm{D}_{3}$ signal transduction include activation of voltage gated $\mathrm{Ca}^{2+}$ ion channels and $\mathrm{Ca}^{2+}$ influx, as well as activation of several kinase cascades including protein kinase $\mathrm{C}$ (PKC) [Boyan et al., 2012]. 1,25OH $\mathrm{OH}_{2} \mathrm{D}_{3}$ activates $\mathrm{PKC}$ signaling in both osteoblasts and chondrocytes via VDR and PDIA3 [Boyan et al., 2012; OlivaresNavarrete et al., 2012].

\section{(v) Free Hormones and Local Vitamin D Storage Pools}

The serum concentration of hormones depends on the concentration of their respective transport proteins, and only the concentration of free hormone is considered to be physiologically important [Boulion, et al.,1981], this concept is known as the "free hormone hypothesis". Vitamin D metabolites are transported and circulated throughout the body by DBP, which is generally found in high concentrations in plasma. $25 \mathrm{OHD}_{3}$ is the main ligand for $\mathrm{DBP}$, and therefore the major "circulating" form. While it was originally thought that there is no correlation between the serum concentration of $25 \mathrm{OHD}_{3}$ and $\mathrm{DBP}$, an indication that the level of free $25 \mathrm{OHD}_{3}$ is not feedback regulated [Boulion et al., 1981], it was recently demonstrated that the amount of DBP inversely influenced the available free $25 \mathrm{OHD}_{3}$ in cultured human monocytes [Brannon 2012]. There has also been a significant positive correlation between the increase of $1,25 \mathrm{OH}_{2} \mathrm{D}_{3}$ and DBP, which indicates that it is feedback regulated. 
The binding affinity of vitamin D metabolites to DBP plays a large role in regulating vitamin $\mathrm{D}$ concentration. $25 \mathrm{OHD}_{3}$ has a very high binding affinity $(\mathrm{Km})$ to DBP, and with the high concentrations of DBP seen in plasma (0.3$0.5 \mathrm{mg} / \mathrm{ml} ; 5-6 \mu \mathrm{mol} / \mathrm{L}$ ) virtually all $25 \mathrm{OHD}_{3}$ molecules in the circulatory system are bound to DBP, and only $\sim 0.03 \%$ are found in the free form [Ahmed \& Shoker, 2010; Lehman, 2008]. Although $1,25 \mathrm{OH}_{2} \mathrm{D}_{3}$ has lower affinity for DBP, $0.4 \%$, approximately $6 \times 10^{-13} \mathrm{M}$, of $1,25 \mathrm{OH}_{2} \mathrm{D}_{3}$ circulating in free form, a concentration that is approximately ten times lower than $25 \mathrm{OHD}_{3}$ [Lehman, 2008; Berg, 1999]. In a study conducted on the serum levels of DBP in pregnant and normal woman, it was found that there was a 10 -fold difference in free concentrations of $1,25 \mathrm{OH}_{2} \mathrm{D}_{3}$ over $25 \mathrm{OHD}_{3}$, while there was a 320 -fold molar excess of total $25 \mathrm{OHD}_{3}$ over $1,25 \mathrm{OH}_{2} \mathrm{D}_{3}$ [Boulion et al. 1981].

Many studies have shown that antiproliferative effects of $1,25 \mathrm{OH}_{2} \mathrm{D}_{3}$ requires unbound concentrations higher than $10^{-8} \mathrm{M}$, which is equivalent to a highly unphysiological concentration of approximately $2.5 \times 10^{-6} \mathrm{M}$ circulating in blood [Lehman, 2008], although it is believed that local vitamin D storage pools throughout the body that may account for this [Brannon , 2012]. According to the 'free hormone' hypothesis, the sterols bound to DPB are a reservoir that can be made available to vitamin $\mathrm{D}$ receptors or enzymes that modify the sterols by dissociation from the DBP [Berg, 1999]. The 'free hormone' and 'local vitamin D storage' hypotheses change the traditional endocrine views of vitamin $\mathrm{D}$ metabolism, and explain paracrine and autocrine mechanisms of vitamin D 
metabolism, involved in the regulation of proliferation and differentiation that have been observed in vitro in response to supraphysiological doses of $1,25 \mathrm{OH}_{2} \mathrm{D}_{3}$ and $25 \mathrm{OHD}_{3}$ (Figure 1-6 and 1-7).

DBP may also slow the release of $25 \mathrm{OHD}_{3}$ and regulate the level of free sterol available, as free $25 \mathrm{OHD}_{3}$ can diffuse across cell membranes, which appears to be nearly a ubiquitous mechanism of vitamin D uptake [Brannon , 2012], preventing the rapid metabolism and excretion of vitamin D. 


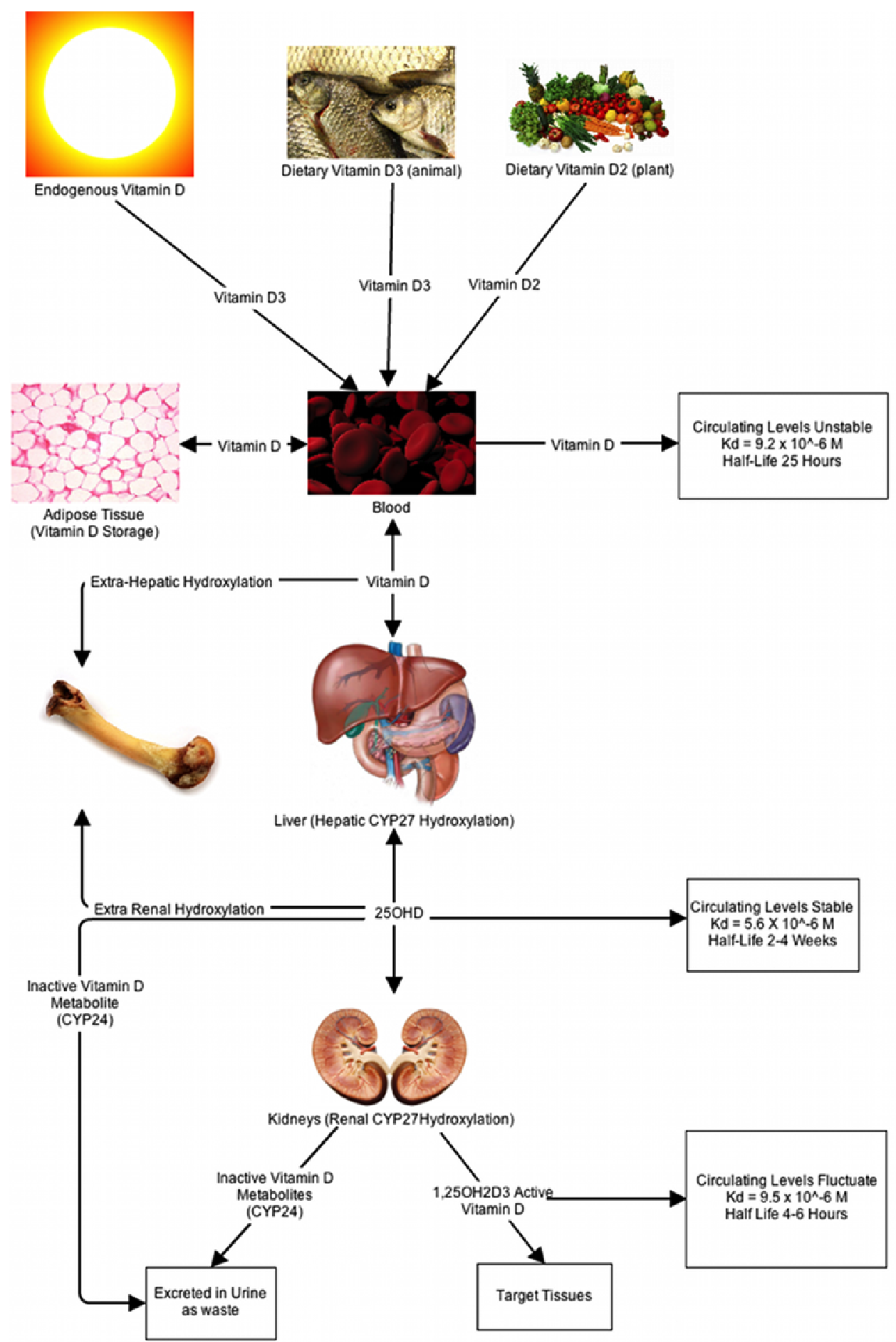

Figure 1-6. The 'free hormone' and 'local vitamin D storage' hypotheses change the traditional endocrine views of vitamin D metabolism, and explain paracrine and autocrine mechanisms of vitamin D metabolism, involved in the regulation of proliferation and differentiation that have been observed in vitro in response to supraphysiological doses of 


\section{A) Classic Endocrine Vitamin D Metabolism and Action}

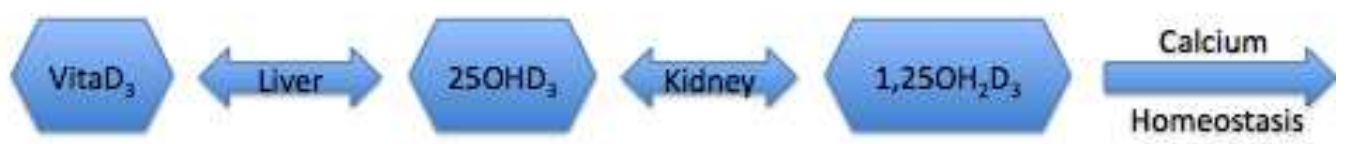

B) Endocrine \& Paracrine/Autocrine Vitamin D Metabolism and Action

Calcium
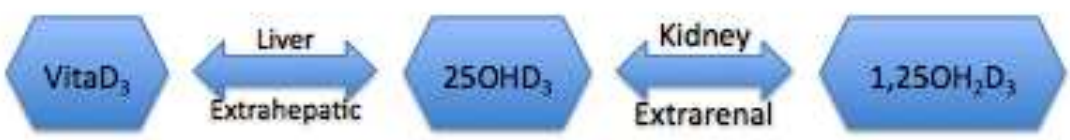

Homeostasis

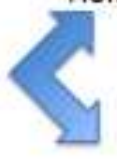

Cell Signaling

Figure 1-7. Traditional vitamin D endocrine mode of action (A) and revised vitamin D mode of action (B) based on the 'free hormone hypothesis' and the theory of 'local vitamin D storage pool' [Brannon, 2012; and Berg, 1999]. 


\section{(vi) The Autocrine/Paracrine Vitamin D Paradigm}

In the early 1900's vitamin D was the fourth identified essential vitamin, thus named vitamin "D" by convention. It wasn't until 50 years later that it was realized that vitamin $\mathrm{D}$ is metabolized and acts as a steroid hormone in an endocrine manner, a paradigm that has dominated the classic thought of vitamin D function until the end of the $20^{\text {th }}$ century [Morris \& Anderson, 2010]. Recently, it has been demonstrated that number of organ systems are influenced by vitamin $\mathrm{D}$ in an autocrine manner, that is $1,25 \mathrm{OH}_{2} \mathrm{D}_{3}$ is being synthesized within those cells, and/or within adjacent cells (paracrine action) (see Figure 1-6 and 1-7). It has been hypothesized that local production of $1,25 \mathrm{OH}_{2} \mathrm{D}_{3}$ in extrarenal tissues regulates cell growth, differentiation, and apoptosis, however there are few detailed reports and is still not widely recognized [Atkins, et al., 2007].

There has been reports of extra-endocrine CYP27 hydroxylase expression in the parathyroid gland, lymph nodes, macrophages, prostate cells, skin, colon, adrenal medulla, dendritic cells, endothelial cells, brain, hypothalamus, and placenta [van Driel, et al., 2006]. Interestingly enough, the expression of the enzymes required to metabolize and activate vitamin D were reported in human bone cultures 25 years ago, but bone is still not identified as a vitamin D synthesizing tissue. 


\section{(vii) Vitamin D and In Vitro Bone Development}

$1,25 \mathrm{OH}_{2} \mathrm{D}_{3}$ influences many aspects of bone cell biology, and has been implicated in the regulation of both osteoblastic and osteoclastic activity affecting both resorptive and synthetic phases of bone remodeling [Atkins, et al., 2007]. Bone remodeling is a dynamic process coordinated by osteoblasts (boneforming) and osteoclasts (bone-resorbing), in which resorption is followed by bone formation. An imbalance in this process can lead to bone density loss and osteoporosis. A typical feature of vitamin D deficiency is impairment of bone formation and mineralization. Paradoxically, $1,25 \mathrm{OH}_{2} \mathrm{D}_{3}$ has been demonstrated to indirectly simulate bone formation and mineralization by stimulating intestinal calcium absorption, and induce bone resorption by inducing calcium mobilization from bone [Suda, et al., 2012].

Interestingly enough, the benefits of using vitamin $\mathrm{D}$ for bone development in vitro, is separate from the in vivo calcimic actions. $1,25 \mathrm{OH}_{2} \mathrm{D}_{3}$ has been demonstrated to regulate osteoblast and chondrocyte gene transcription, proliferation, differentiation, and mineralization of ECM [Boyan

et al., 2009; Atkins et al., 2007]. In addition, $1,25 \mathrm{OH}_{2} \mathrm{D}_{3}$ has been shown to stimulate the osteoblastogenesis of MSCs, which suggests that vitamin D metabolism may play an autocrine/paracrine role in osteoblast differentiation of MSCs [Zhou et al., 2012]. 


\section{Chapter II. OBJECTIVES}

\section{Section 2.01 3D Cell Culture for Cartilage Tissue Engineering}

Previous studies focusing on engineering cartilage have indicated that a primary chondrocyte cell culture isolated and harvested from mature functional articular cartilage is a logical cell choice for cartilage constructs [Hardingham, et al., 2002]. Due to the avascular and hypoxic nature of cartilage, chondrocytes can be isolated from both postoperative and post-mortem cartilage tissue, as well as from refrigerated stored tissue [Tew, et al., 2008]. The first objective for the present research was to develop a protocol for harvesting articular cartilage tissue and isolating chondrocytes from the metacarpophalangeal joints of freshly slaughtered bovine. These procedures are described in detail in Chapter 3.

Successful engineered cartilage constructs require a combination of several components, including the appropriate cell type and a temporary artificial and/or molecular scaffold to provide structure for regenerating tissue [Steward, et al., 2011]. In vivo, chondrocytes exist, proliferate, and differentiate, within a $3 \mathrm{D}$ enviornment. When they are excised from their native enviornment, and placed in a $2 \mathrm{D}$ monolayer for expansion, the naturally round chondrocytes, attach and spread, causing them to lose their spherical morphology and acquire an elongated fibroblast-like phenotype. These morphological alterations are accompanied by critical biochemical changes associated with the loss of mechanical function. Because cartilage-specific GAG binds to water with 
such high affinity, natural hydrated biomaterials can be used to recreate the 3D enviornment.

Using agarose as a biomaterial scaffold has been shown to allow chondrocytes to remain round, promote chondrogenic induction, induce cartilage phenotype and support cartilage-specific gene expression [Hardingham, et al., 2002; Steward, et al., 2011]. While agarose has an advantage in its inherent biocompatiility, the mechanical properties of agarose can be a set back, as they have a compressive modulus that is about $15 \%$ of native cartilage tissue [Steward, Liu, \& Wagner, 2011]. Photocrosslinkable hydrogels such as poly(ethylene glycol) (PEG) can be modified for photopolymerization, which enables spatial and temporal control of the gelation process, and has been shown to support MSC survival, differentiation, and accumulation of chondrogenic ECM. In the current study, 3D culture protocols using low-melting point agarose and PEG are described in Chapter 3 and Chapter 4 for maintaining cellular and biomolecular constituents within defined parameters.

Mechanical and chemical signals are instrumental in the development, remodeling, and pathogenesis of load-bearing tissues through cellular mechanotransduction. In vivo, chondrocytes experience hydrostatic, compresive, tensile, and shear forces within a physiologic 3D environment which maintains the phenotype and production of regenerating cartilage tissue. Abnormal mechanical forces have been shown to alter chondrocyte behavior, resulting in pathological matrix synthesis, increased catabolic activity (degradation), and ultimately cell death. Convential culture methods are limited in their ability to replicate the natural balance of anabolic and catabolic 
reactions necessary for tissue remodeling and regeneration. A variety of designs have been applied to regenerative medicine through tissue engineering applications including rotating vessels [Pollack, et al., 2000], pressure combined with fluid perfusion [Cartnmell, et al., 2003], and direct perfusion [Pazanno, et al., 2000]. As an extension of these technologies, a bioreactor has been designed which provides compressive mechanical stimulation (solid and fluid), real-time mechanical characterization, optical inspection, and integrated ultrasonic assessment of ECM, that can fit on a shelf of a standard incubator (Figure 1-1). Preliminary validation of the bioreactor's form and function, expected bioassays of the resulting matrix components, and application to biokietic models are described in Chapter 3.

Non-destructive techniques characterising the mechanical properties of cells, tissues, and biomaterials provide baseline metrics for tissue engineering design. Ultrasonic wave propagation and attentuation has previously demonstrated the dynamics of ECM synthesis in chondrocyte-seeded hydrogel constructs in a non-invasive and nondestructive manner [Kohles, et al., 2012]. In Chapter 4, an ultrasonic method to analyse two of the construct elements used to engineer articular cartilage in real-time, native cartilage explants and an agarose biomaterial is described.

The overall objective of this project was to characterize biomechanical influence on the anabolic and catabolic behavior of chondrocytes cultured in a $3 \mathrm{D}$ enviornment, and to characterize the developing ECM response to mechanical stimuli. In addition, protocols which established the environment most effective in developing healthy adaptive cellular 
responses such as cellular proliferation, cytoskeleton remodeling, induction of differentiation, and ECM regulation. 


\section{Section 2.02 OPC1 Bone Development and Vitamin D Metabolism}

A novel way of promoting cartilage and bone regeneration as a tissue development model is through the use of MSCs or multipotent progenitor cell lines. MSCs can expand rapidly in culture, but the rate of expansion and the yield of multipotential progenitors are inversely related to the plating density and incubation time of each passage [Sekiya, et al., 2002], which could lead to a heterogenous population of precursors of different potential over time. $\mathrm{OPC} 1$ is a multipotent progenitor cell line derived from human fetal bone tissue that provides a stable and reproducible culture system and represents a homogenous osteogenic cell line with the capacity to generate programmed differentiation [Winn, et al., 1999]. The specific objective of this project was to characterize the influence of vitamin D and other commonly used osteogenic factors on the programmed differentiation of OPC1 during early bone development.

Because OPC1 is a homogenous, stable, and reproducible culture system, it provides a means to screen for putative growth and differentiation factors for bone development. While recent studies have shown extra-renal metabolism of $25 \mathrm{OHD}_{3}$ [Zhou, et al., 2012], the immediate precursor to the active vitamin D hormone $1,25 \mathrm{OH}_{2} \mathrm{D}_{3}$, there has been occasional reports of extrahepatic 25 -hydroxylation of the parental precursor vitamin $\mathrm{D}_{3}$ [Jones, et al., 1998]. In the present study, the capacity for osteoblast precursors to convert parental vitamin $\mathrm{D}_{3}$ to $1,25 \mathrm{OH}_{2} \mathrm{D}_{3}$ in a dose-dependent manner was examined and described in Chapter 5. The objective of this study was to 
investigate the potential of parental vitaD 3 to induce $1,25 \mathrm{OH}_{2} \mathrm{D}_{3}$ bone-associated biological responses during early stages of bone development.

One major goal of bone-tissue engineering is the ability to predictably enforce the osteoinductive program of stem and progenitor cells [De Kok, et al., 2006]. In addition to extrahepatic vitamin D metabolism, the influence of vitamin D metabolites in combination of commonly used osteogenic factors ascorbic acid, $\beta$-glycerophosphate, bone morphogenetic protein-2 (BMP-2), and the synthetic steroid, dexamethasone, on OPC1 ECM maturation and mineralization during bone development was explored. The objective of the study described in Chapter 6 was to investigate the influence of vitamin D metabolites vitaD 3 and $1,25 \mathrm{OH}_{2} \mathrm{D}_{3}$ with or without osteogenic factors on the temporal development stage sequences of early bone development in order to find the optimal chemical environment for ECM maturation and mineralization.

The overall goal of the studies described in Chapter 5 and Chapter 6 were to establish a reproducible culture system for the in vitro osteogenic differentitation of human osteoblast precursor cells, and to characterize the capacity of osteoblast precursors to convert vitaD $\mathrm{D}_{3}$ to $1,25 \mathrm{OH}_{2} \mathrm{D}_{3}$ and the potential of vitaD $\mathrm{D}_{3}$ to induce $1,25 \mathrm{OH}_{2} \mathrm{D}_{3}$ associated biological activities. In addition, to investigate the effects of vitamin D metabolites as ostegenic factors on the temporal development sequence of bone development which include proliferation, maturation, and mineralization. These studies will provide a 2D culture foundation for future 3D engineered tissue studies using the OPC1 cell line. 


\title{
Chapter III. THREE-DIMENSIONAL CULTURE OF CELLS AND MATRIX BIOMOLECULES FOR ENGINEERED TISSUE DEVELOPMENT AND \\ BIOKINETICS MODEL VALIDATION
}

\author{
Shelley S. Mason ${ }^{1}$ \\ Sean S. Kohles ${ }^{1, *}$ \\ Randy D. Zelick ${ }^{1}$ \\ Shelley R. Winn ${ }^{2}$ \\ Asit K. Saha ${ }^{3}$ \\ ${ }^{1}$ Regenerative Bioengineering Laboratory, \\ Department of Mechanical \& Materials Engineering and \\ Department of Biology, \\ Portland State University, Portland, OR 97201; \\ ${ }^{2}$ Department of Molecular \& Medical Genetics, \\ Oregon Health \& Science University, \\ Portland, OR 97239; \\ ${ }^{3}$ Center for Allaying Health Disparities through Research and Education (CADRE), \\ Department of Mathematics \& Computer Science, \\ Central State University, \\ Wilberforce, Ohio 45384
}




\section{Section 3.01 Preface}

The chapter is comprised of material from a manuscript submitted to the Journal of Nanotechnology in Engineering and Medicine as a Design Innovation Paper (NANO-111022) and published in March 2011. This paper encompasses protocols for 3D cartilage TE culture systems and mathematical modeling that characterizes the organization, mechanical properties, and physiologic response at multiple scales, from molecular to cellular, and to tissue and organ levels.

\section{Section 3.02 Authors Contributions}

The work presented here was carried out in collaboration between all authors. SSM, SSK, SRW, and RDZ defined the research theme. SSM designed the biological methods and experiments, while SSK and AKS designed the mathematical modeling and statistical analysis. SSM and SSK wrote the paper. All authors have contributed to, seen and approved the manuscript. 


\section{Section 3.03 Abstract}

There has been considerable progress in cellular and molecular engineering due to recent advances in multiscale TE technology. Such technologies allow controlled manipulation of physiochemical interactions among cells in tissue culture. In particular, a novel chemomechanical bioreactor has recently been designed for the study of bone and cartilage tissue development, with particular focus on extracellular matrix formation. The bioreactor is equally significant as a tool for validation of mathematical models that explore biokinetic regulatory thresholds [Saha and Kohles, 2010, J Nanotechnol Eng Med. 1(3):031005; Saha and Kohles, 2010, J Nanotechnol Eng Med. 1(4):041001]. In the current study, three-dimensional culture protocols are described for maintaining the cellular and biomolecular constituents within defined parameters. Preliminary validation of the bioreactor's form and function, expected bioassays of the resulting matrix components, and application to biokinetic models are described. This approach provides a framework for future detailed explorations combining multiscale experimental and mathematical analyses, at nanoscale sensitivity, to describe cell and biomolecule dynamics in different environmental regimes. 


\section{Section 3.04 Introduction}

Cartilage and bone defects are a leading cause of disability, an economic burden that exceeds 28 billion dollars in orthopedic repair in the United States alone [Chao et al., 2007]. More than 250,000 knee and hip replacements are performed each year [Chung, 2008], and the number continues to increase with an aging population suffering from defects or deterioration of articular cartilage caused by osteoarthritis and trauma. Because cartilage is avascular, and has a limited capability for self-repair, it has been the focus of many bioengineering investigations in nanomedicine. TE is an evolving field that has the potential to provide functional cartilage tissue to help the millions of people who suffer from degenerated, diseased, or damaged articular cartilage. There have been rapid advancements in cell-based therapies, which includes the in vitro engineering of functional tissue substitutes for subsequent in vitro transplantation [Chung, 2008]. To date, however, the properties and structure of native cartilage tissue have not been entirely mimicked by engineered tissue (Figure 3-1). Limitations of the current solutions such as autologous chondrocyte transplantation (ACT) include difficulty in obtaining a required amount of cells for a construct and cellular dedifferentiation during expansion, as well as degeneration at the donor site. Although recorded success rates of ACT are between $60-90 \%$ depending on the localization of the injury [Yilmaz et al., 2010], longterm success rates are considerably lower. 


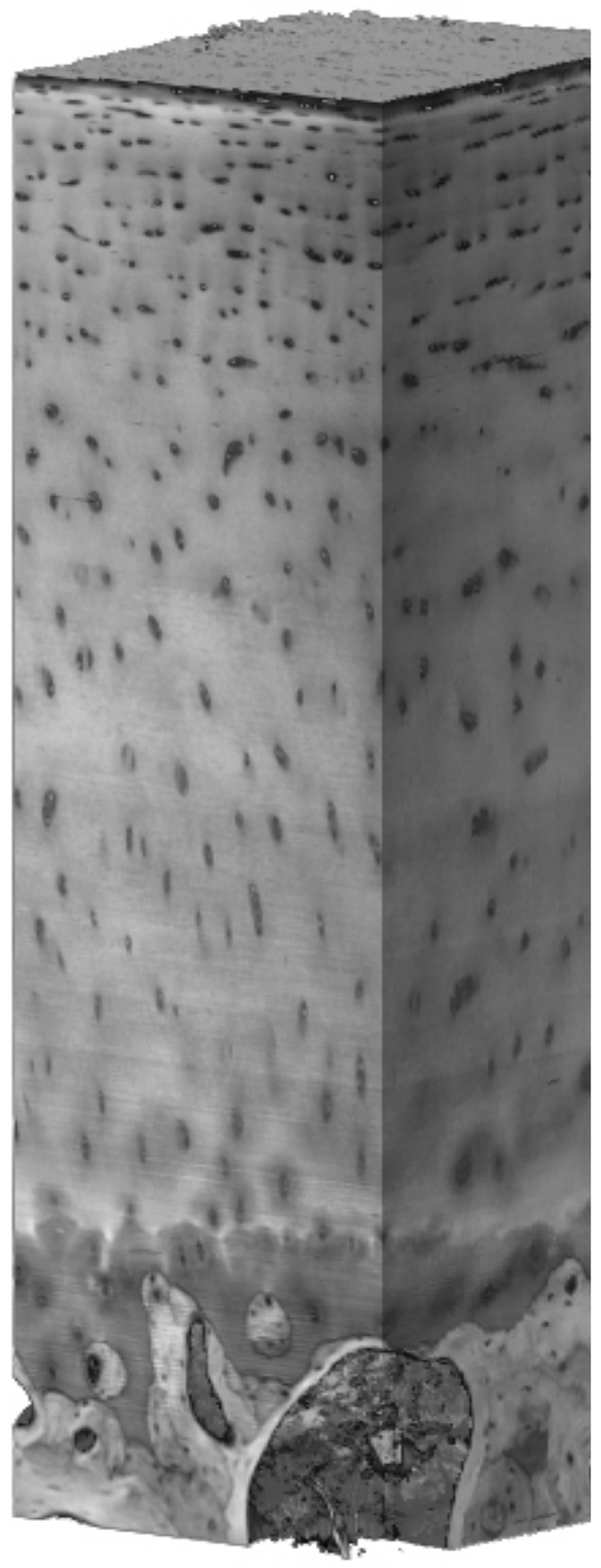

Figure 3-1: Three-dimensional reconstruction via micro-computed tomography of a throughthickness section of human articular cartilage [after Jadin and Sah, 2006]. The total transverse slice dimension is $1,500 \mathrm{~mm}$ representing the articular surface (top), three histologic zonal layers, and the bony osteochondral transition (bottom).

TE is the process of creating functional 3D tissues using cells combined with scaffolds, signaling factors, and devices that facilitate growth, organization and differentiation. The development of mathematical models based on the interaction 
between cells and biomaterials can help understand the basic mechanisms of cartilage physiology [Tortelli \& Cancedda, 2009]. In order to create an environment for tissue development, the mathematical models need to characterize the organization, mechanical properties, and physiologic response at multiple scales, from cellular to molecular to tissue levels. Harnessing nanobiotechnology, this approach can help design new drug development and delivery systems, regenerative medicine, and tissue remodeling procedures [Saha and Kohles, 2010a; 2010b; 2011].

In healthy connective tissue, structural protein fibers such as collagen and elastin fibers have diameters ranging from several tens to several hundreds of nanometers. The nanoscale protein fibers entangle with each other to form a nonwoven mesh that provides tensile strength and elasticity for the connective tissue [Zuewei et al., 2005]. Articular cartilage is composed of immobilized chondrocytes which secret the cartilage specific biomolecules that make up the tissue's ECM [Pazano et al. 2000; Lanza et al. 2007]. Physiological regulation, synthesis and maintenance of ECM are maintained by the chondrocytes (although only 10\% of the volume) through biokinetic reactions [Saha and Kohles, 2010a; 2010b; 2011]. The structural integrity of cartilage is derived from the fibrous network formed by the cartilage-specific protein, collagen type II (ColII), which is immersed in a gelatin formed by proteoglycans rich in sulfated glycosaminoglycans (GAG), and water, which binds with such high affinity that it makes up $70 \%$ of the total weight [Wilson et al., 2002]. It is this unique ECM that allows low friction movement of joint surfaces. In return, joint loading from body movement induces fluid velocities in the tissue that maintain waste and nutrient flow, as well as ion movement. Recreating the 
unique mechanical properties that give cartilage tissue the capability of bearing compressive loads during daily activities is a major challenge in TE.

\section{(i) Biomaterial Scaffolds and Three-Dimensional Culture}

Recent work has shown that cells often exhibit unnatural behavior when they are excised from their native $3 \mathrm{D}$ environment and confined to a $2 \mathrm{D}$ monolayer. The acute disparities in cellular function between 2D and 3D cultures warrant further biological examination [Tibbitt and Anseth, 2009]. When articular chondrocytes are cultured in a static 2D monolayer, they lose their overall hyaline structure and functional elasticity. In vitro expansion of such cultures is associated with cellular dedifferentiation and reduced or total loss of their ability to redifferentiate [Barbero and Martin, 2007; Barlic and Kregar-Velikonja, 2008]. A 2D environment allows chondrocytes to attach and gradually spread, which causes them to lose their spherical morphology and acquire an elongated fibroblast-like phenotype. In our current work, we observed morphological changes that occur within the first few days of cells cultured in a static monolayer, as the freshly isolated cells begin to adhere and spread along the culture vessel.

Morphological alterations acquired in monolayer are accompanied by critical biochemical changes. Loss of the hyaline morphology is associated with the expression or total loss of aggrecan and ColII synthesis, and an increase in the expression of fibrocartillage associated ECM molecules collagen type I (ColI) and 
versican [Barbero and Martin 2007; Barlic and Kregar-Velikonja 2008]. Hydrated biomaterials may recreate the native $3 \mathrm{D}$ environment and mimic the physical structure, biological function, and biochemical nature of ECM. Native ECM provides physical support for cells, as well as a substrate with specific ligands for cell adhesion and migration, and regulates cellular proliferation and function by providing growth factors [Zuewei et al., 2005]. During healthy balanced tissue regulation, growth factors stimulate the anabolic synthesis of essential ECM macromolecules, a process that is complemented by the catabolic degradation of ECM by proteinases during tissue remodeling and repair [Saha and Kohles, 2010a; 2010b; 2011]. In order for this process to take place in vitro the biomaterial scaffold needs to degrade at a rate that compliments the synthesis of neotissue and be responsive to the local biological environment [Bahney et al., 2011].

For the experimental design described herein, hydrated polymers (hydrogel) offer a biomaterial scaffold with customizable and biomimetic properties. This material is manipulated by photopolymerization for quick formation of the liquid mixture into gel when exposed to ultraviolet B (UVB) rays. Photopolymerization has been examined as a method to create scaffolds with specific nanoscale topography to promote control of cell migration and function [Elisseeff et al., 2000]. 


\section{(ii) Mechanical Stimulation and Biological Response}

Dedifferentiated chondrocytes have the capacity to redifferentiate if they are transferred into a 3D environment that supports a spherical morphology; however, their original phenotype may not be fully re-acquired [Barbero and Martin, 2007]. When 3D cellular constructs are grown in static culture, cells on the outer surface of the constructs are typically viable and proliferate, while cells within the construct may be less active or necrotic [Cartmell et al., 2003]. 3D culture techniques that encompass biomaterials and so allow chondrocytes to remain round yield cells that continue to express cartilage specific genes, but are limited relative to proliferation capacity and lack the zonal distribution of cells and ECM molecules found in native tissue [Choi et al., 2007]. Mechanical stimulation (fluid, solid, thermal, etc.) of 3D constructs consisting of cells, biomaterials, and growth stimulant inhibitors have shown promising results in the production of viable load-bearing tissues such as cartilage and bone [Kohles et al., 2007]. The transmission of biochemical and biomechanical signals from the cell-cell and cellECM interactions determines the formation of healthy tissue morphology. Thus, preserving these interactions is essential in recreating the native tissue.

In one cartilage engineering approach, it has been suggested that isolating cells from distinct histological zones and seeding the cells layer-wise within a scaffold may help to preserve the native zonal distribution that contributes to the function of absorbing compressive and tensile forces. Utilizing a multiscale bioreactor as described in this design innovation paper, that can recreate native 
biomechanical and biochemical stimuli, will facilitate tissue development investigations and validate ongoing biokinetic modeling. 


\section{Section 3.05 Engineering and Experimental Design Methods:}

\section{(i) Bioreactor Design and Application}

A chemomechanical bioreactor was recently designed [Quinn et al. 2009; Chiu et al., 2010] with the primary objectives of providing mechanical stimulus (solid and fluid), mechanical characterization, optical inspection, and ultrasonic assessment of engineered tissue development (Figure 3-2). In humans, articular cartilage is a thin layer of 0.5 to $5 \mathrm{~mm}$ thick hydrated soft tissue [Mahmoudifar \& Doran, 2005]; as such the 3D culture environment was designed to support constructs 5-mm in height to mimic native cartilage geometry.

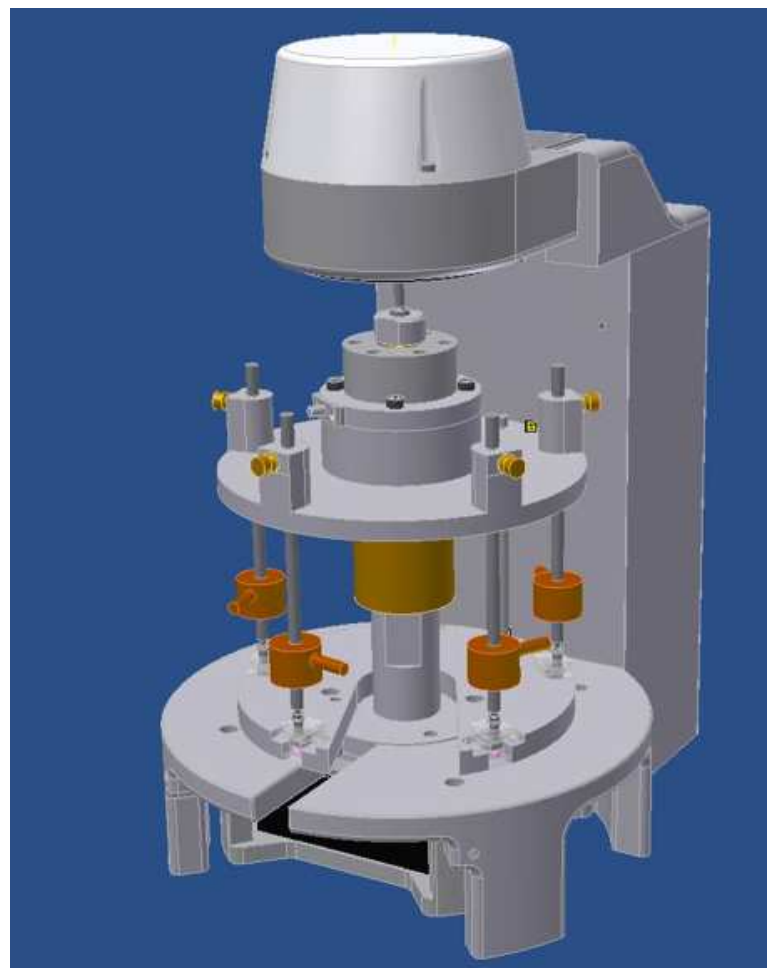

Figure 3-2: A solid model of the assembled chemomechanical bioreactor for three-dimensional culture [after Quinn et al., 2009]. The image includes the upper electromechanical actuator applying high-resolution load-deformation control to the 'hat' which distributes the mechanical stimulus to the five load arms and, as such, to the five culture-wells below. The wells can be rotated into the view of single ultrasonic or digital imaging sensors. 
A prototype bioreactor has now been fabricated for stimulating and monitoring cell, ECM, and scaffold development of 3D engineered cartilage constructs (Figure 3-3). The device combines a linear actuator (ElectroForce, Bose, Eden Prairie, MN) connected to an array of five load transducers $(1,000 \mathrm{~g},+/-0.15$ to 0.25\%, Model $31 \mathrm{Mid}$, Sensotec/Honeywell, Golden Valley, MN). The actuator can be controlled via displacement $(+/-2.5 \mathrm{~mm})$ or force $(20 \mathrm{~N})$ to apply a variety of waveforms (WinTest, Bose) for dynamic stimulation of five concurrent cubeshaped test samples (Figure 3-4). Access for a digital video microscope and ultrasound transducers facilitate minimally invasive construct assessment. The entire bioreactor is sized to fit inside an incubator (Galaxy R Series Incubator, New Brunswick, Edison, NJ) with sensor control of the internal environment chemistry, carbon dioxide $(\mathrm{CO} 2)$, oxygen $(\mathrm{O} 2)$, and nitrogen $(\mathrm{N} 2)$. 


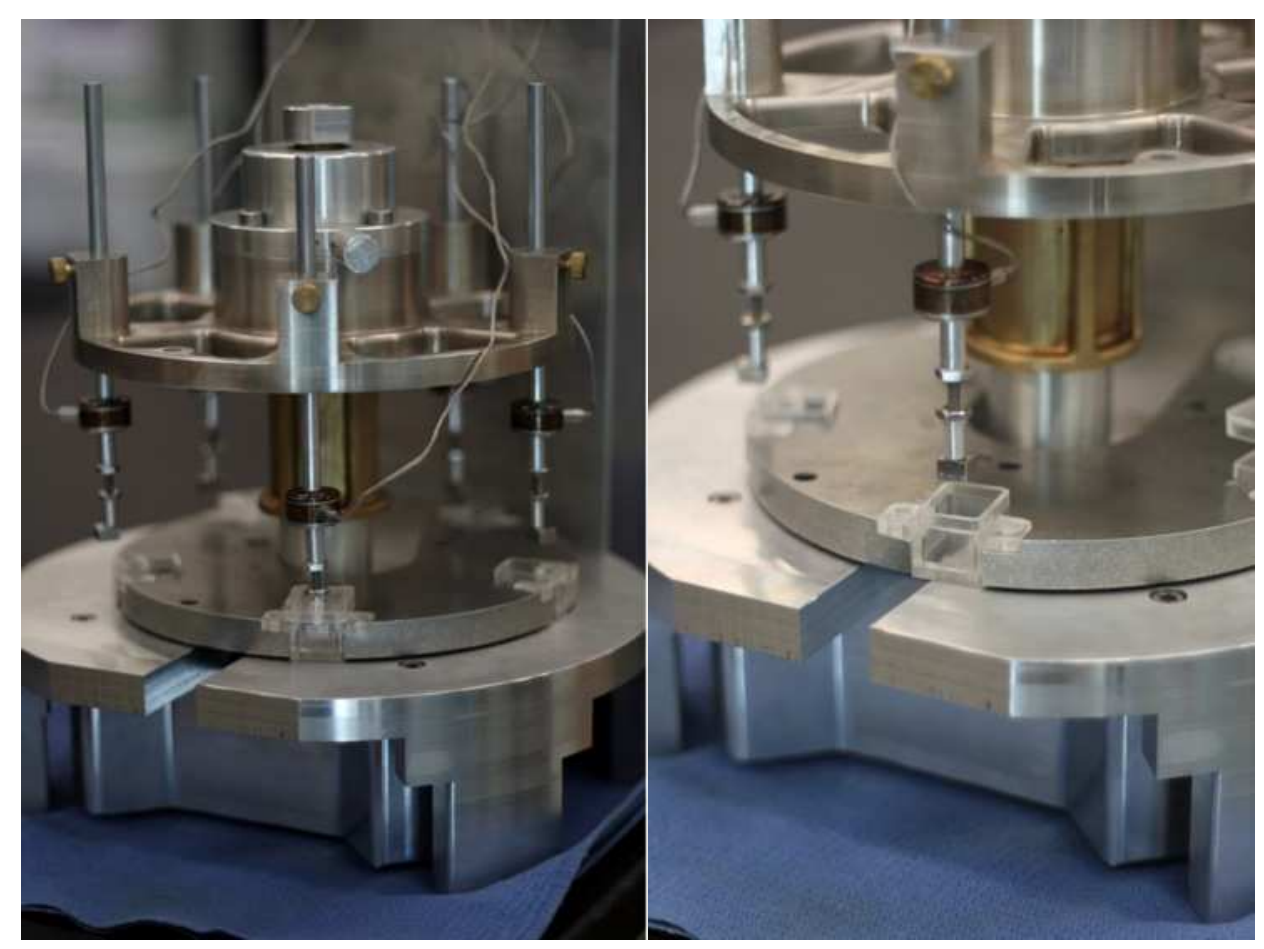

Figure 3-3: The now-fabricated, novel chemomechanical bioreactor with five culture wells (on the left) and a load-train applying load-displacement for measuring exact loads (on the right). The high-resolution, copper-colored load-cells measure the dynamic loads transferred via the load-rods through the square load-platens into the culture-wells and onto the eventual cell-biomaterial constructs.

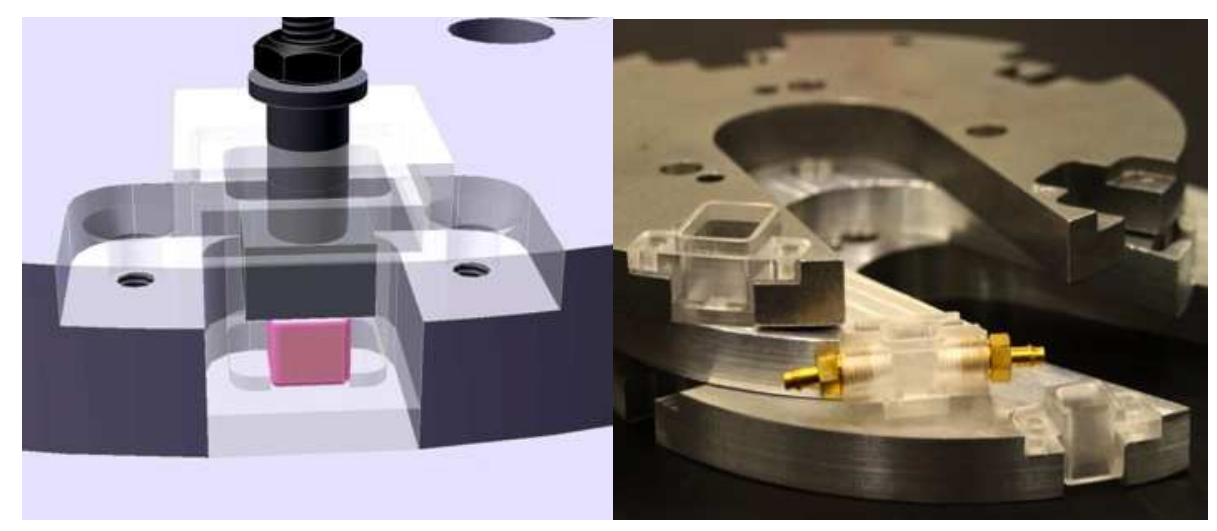

Figure 3-4: Open-view (model) of a bioreactor test chamber for engineered tissue chemomechanical stimulation indicating the a) cell-biomaterial construct $(125 \mathrm{~mm} 3$ pink cube) and b) three current well designs for static and dynamic three-dimensional culture. The middle culture-well, which provides perfused flow and dynamic culture will be described in a future article [Kohles et al., 2011]. 
Elastic moduli of 3D hydrogel-cell constructs are typically measured in compression after 2,4 , and 6 weeks of in vitro culture time. Samples are initially unloaded, then subjected to compressive strain at a rate of $0.5 \mathrm{~mm} / \mathrm{min}$ [Rice et al., 2009]. The compression modulus will be determined by analyzing the linear regions of the stress versus strain curve on samples at low deformation $(<15 \%)$. Initial mechanical stimulation will relate dynamic constituent masses with elastic properties applying a basic rule of mixtures. More complex spherical-composite models will eventually be applied [Kohles et al., 2007]. The modeled (and measured) scaffold and cell-ECM masses $\left(\mathrm{m}_{\mathrm{i}}\right)$ can be converted to constituent volumes $\left(\mathrm{V}_{\mathrm{i}}\right)$ using density values $\left(\mathrm{r}_{\mathrm{i}}\right)$ :

Cell-ECM: $\quad V_{\mathrm{CE}}=\frac{\mathrm{m}_{\mathrm{CE}}}{\rho_{\mathrm{CE}}} \quad$ (totaled for multiple ECM constituents)

Scaffold: $\quad \forall_{\mathrm{s}}=\frac{\mathrm{m}_{\mathrm{s}}}{\rho_{\mathrm{s}}}$

The total porosity $(\mathrm{P})$ of the construct can be calculated from constituent volumes estimated from the biomarkers and the current gross volume of the construct composite $\left(\mathrm{V}_{\mathrm{o}}\right)$ using the relationship:

$$
\mathrm{P}=\frac{\forall_{\mathrm{o}}-\left(\forall_{\mathrm{s}}+\forall_{\mathrm{CE}}\right)}{\forall_{\mathrm{o}}}=1-\frac{\left(\forall_{\mathrm{s}}+\forall_{\mathrm{CE}}\right)}{\forall_{\mathrm{o}}}
$$


For constructs with distinct porosities, the elastic modulus of the cell-ECMscaffold composite structure ( $\mathrm{E}_{\text {structure }}$ ) may be characterized by the phenomenological relationship [Martin et al., 1998]:

$\mathrm{E}_{\text {structure }}=\mathrm{E}_{\text {solid }}(1-\mathrm{P}) \mathrm{k}$

Where $\mathrm{k}$ is a curve-fit parameter and $\mathrm{E}_{\mathrm{solid}}$ can be defined by the cell-ECM $\left(\mathrm{E}_{\mathrm{CE}}\right)$ and polymeric scaffold $\left(\mathrm{E}_{\mathrm{s}}\right)$ moduli using the two-phase, Voigt model [Hashin and Shtrikman, 1963]:

$\mathrm{E}_{\mathrm{solid}}=\mathrm{v}_{\mathrm{CE}} \mathrm{E}_{\mathrm{CE}}+\mathrm{v}_{\mathrm{s}} \mathrm{E}_{\mathrm{s}}$

Here, the solid volume of the engineered construct is defined by the volume fractions of the cell-ECM $\left(\mathrm{v}_{\mathrm{CE}}\right)$ and polymeric scaffold $\left(\mathrm{v}_{\mathrm{s}}\right)$, respectively:

Cell-ECM: $\quad \mathrm{v}_{\mathrm{CE}}=\frac{\forall_{\mathrm{CE}}}{\mathrm{V}_{\mathrm{s}}+\mathrm{V}_{\mathrm{CE}}}$

Scaffold: $\quad \mathrm{v}_{\mathrm{s}}=\frac{\forall_{\mathrm{s}}}{\forall_{\mathrm{s}}+\forall_{\mathrm{CE}}}$ where $\mathrm{v}_{\mathrm{CE}}+\mathrm{v}_{\mathrm{s}}=1$

This preliminary micromechanical arrangement assumes that the scaffold and neo-ECM experience equivalent deformation in response to an applied load 
[Jones, 1999]. These metrics will provide a quantitative means of comparing the developing engineered tissues with native tissues as an approach for assessing the designed 3D culture environment.

\section{(ii) Cartilage Dissection and Disaggregation}

In the initial preparations of cell-scaffold constructs which will be developed into cell-ECM-scaffold constructs using the bioreactor, fresh tissue is excised from the chondylar surface cartilage of 6 month to 2 year old bovine metacarpophalangeal joints contributed by a local abattoir within 1 to 8 hours of death (Mark's Meat, Canby, OR). To decrease the chances of contamination, the joints are dissected in cold, sterile dissection solution containing a high concentration (5\%) of antibiotic/antimycotic (AB/AM) solution (100x) stabilized (Sigma) in Dulbecco's phosphate buffered saline (DPBS; Sigma Aldrich Co., St. Louis, MO) to give a final concentration of $250 \mu \mathrm{g} / \mathrm{mL}$ or $0.625 \mu \mathrm{g} / \mathrm{mL}$ amphotericin B. The soft muscle and connective tissue is removed utilizing a sterile scalpel (sizes 11 and 23), and cartilage is carved from the bone utilizing a sterile scalpel (size 15) from the bone and separated from any remaining soft tissue. The excised tissue is rinsed several times with cold DPBS and 2.5\% $\mathrm{AB} / \mathrm{AM}$ solution through a 70- $\mu \mathrm{m}$ mesh filter (Cell Mirco Sieves TM, BioDesign Inc. of New York), weighed, and measured for ultrasonic propagation as described in Section vii. The resulting tissue fragments are mechanically disaggregated and finely minced with surgical scissors and opposing scalpels into 
$\sim 1 \mathrm{~mm} 3$ pieces. The cells released from supporting matrix during disaggregation are centrifuged and resuspended in $5 \mathrm{ml}$ of media containing Dulbecco's modified eagle medium mixture and Ham's F12 nutrient mixture (DMEM/F12 (1:1); Sigma-Aldrich) supplemented with $10 \%$ fetal bovine serum (FBS, HyClone), $5 \%$ L-Glutamine (L-Glut Lonza-BioWhitaker), $1 \% \mathrm{AB} / \mathrm{AM}$, and stored at $4^{\circ} \mathrm{C}$ until digestion is complete. To allow timely detection of microbial contamination, it has been suggested to incubate the fragments for 24 to $48 \mathrm{hrs}$ before digestion [Harris, Graham, \& Rickwood, 2006].

\section{(iii) Enzymatic Digestion.}

The explanted tissue fragments are consecutively digested with $0.25 \%$ trypsin (BioWhittaker, Lonza, Basel, Switzerland) and 0.5\% collagenase (Liberase Blendzyme III, Roche Diagnostics, Madison, WI) to release the chondrocytes from the ECM with a high cell count of $\sim 5 \times 10^{6} / \mathrm{ml}$ per calf hoof. Warm trypsinization is carried out at $37^{\circ} \mathrm{C}$ on a hot-plate/magnetic stirrer for 1 hour in Hank's buffered salt solution (HBSS; Lonza) supplemented with 1\% AB/AM solution. Culture media containing fetal bovine serum (FBS; Thermo Scientific HyClone, Logan, UT) is added to inhibit trypsin activity and the cell suspension obtained is filtered through a $70-\mu \mathrm{m}$ sterile nylon filter to remove any tissue debris. Cells are collected by centrifugation at $1,500 \mathrm{rpm}$ for $10 \mathrm{~min}$ and rinsed several times with culture media, which consisted of Dulbecco's modified Eagle's medium and Ham's F-12 nutrient mixture (DMEM/F12: Sigma), and resuspended 
in $5 \mathrm{ml}$ chondrocyte culture media containing DMEM/F12 supplemented with $10 \% \mathrm{FBS}, 5 \%$ L-Glutamine (Lonza), and 1\% AB-AM and stored at $4{ }^{\circ} \mathrm{C}$ until further digestion with collagenase is complete. The undigested tissue debris collected after trypsination, which appeared more gelatinous then solid, is digested overnight in $0.5 \%$ collagenase at $37^{\circ} \mathrm{C}$ for 16 to $24 \mathrm{~h}$. Sterile disposable $15 \mathrm{ml}$ transfer pipets (VWR Int., Radnor, PA) are used to aspirate the fragments several times in order to release loosened cells from the gelatinous tissue debris. Digestion is continued in the samples that appeared to have tissue fragments still intact or a low cell count, at a higher concentration $(0.75 \%)$ for an additional hour. Isolated viable chondrocytes from each collection set (i.e., cells from disaggregation, trypsin and collagenase digestion) were counted using a hemocytometer and trypan-blue exclusion dye (0.4\% in DPBS). The sample collections having a cellular health viability of $>75 \%$ as indicated by a lack of trypan dye incorporation are resuspended in chondrocyte media at a concentration of $\sim 5 \times 10^{6 /} \mathrm{ml}$.

\section{(iv) Cell-Seeding and Biomaterial Polymerization}

The hydrogel scaffold mixture, consisting of poly(ethylene oxide) (PEO), poly(ethylene glycol) dimethacrylate (PEGDM), and the photoinitiator, 1hydroxycyclohexyl phenyl ketone (Sigma Aldrich), is dissolved in sterile saline,

penicillin G, and streptomycin to form a $20 \%$ (w/v) solution [Gibson and Kohles, 2010]. The hydrogel constituents are combined in a 3:2 ratio (PEO:PEGDM). The 
UV photoinitiator creates a final concentration of $0.05 \%$ [Elisseeff et al., 2000]. Individual $125-\mu l$ aliquots of chondrocyte suspension $\left(5 \times 10^{6}\right.$ cells $/ \mathrm{ml}$ in growth media as applied previously [Wilson et al., 2002]) are added and polymerized layer-wise in cubic molds of $125-\mathrm{mm}^{3}$ under $365-\mathrm{nm}$ UV light for $3 \mathrm{~min}$, a wavelength not harmful to the living cells [Fedorovich et al., 2009]. The resulting hydrogels (five per batch) are removed from the $125 \mathrm{~mm}^{3}$ cubic molds using a sterile spatula, weighed, and measured for ultrasonic propagation (as input for equations 1 to 5) before being placed into each of the five culture wells fabricated for the bioreactor (Figures 3-3 and 3-4).

\section{(v) Biomolecular Assays}

Constituents representing the greatest total volume fraction and primary influence on cartilage biology and biomechanics will be monitored during cartilage development and biokinetic interactions. These are the chondrocytes, proteoglycan, and collagen content. Cell density can be measured through fluorometric assay as an indicator of proliferation or death overtime [Rice et al., 2009]. The primary components of ECM are easily measured by colorimetric assay after construct digestion, and constituent distribution is assessed through histological staining of the neotissue sections. Specific proteoglycans and collagen isoforms, namely aggrecan and collagen type II, can be quantified through immunoassays or visualized by antibody staining [Rice et al., 2009]. Total GAG content is quantified utilizing dimethyl-methylene blue assay; total 
collagen content is quantified by a hydroxyproline assay. DNA content can be measured by Hoeschst-33258 and related to cell number by dividing DNA content by 7.7 pg per chondrocyte [Rice et al., 2009]. While these techniques provide useful information about the tissue grown in vitro, they require digestion and destroy the samples at specific end points. Ongoing design efforts are directed toward development of a bioreactor in which the quality of the neo-ECM and scaffold may be measured in real-time, utilizing digital imaging and ultrasonic sensors.

\section{(vi) Histochemical Staining}

At typical selected time points of 2, 4, and 6 weeks, constructs are removed from the chemomechanical culture environment, fixed in $10 \%$ formalin for 8 to $24 \mathrm{~h}$, dehydrated, paraffin-embedded, and partially sectioned (10- $\mu \mathrm{m}$ thick) using a microtome. Sections are then stained with fast green and safranin-O (GAGs stains red-orange), and Masson's trichrome method (collagen stains blue) (Figure 3-5). Colorimetric assays will determine planar and volumetric densities of the assayed constituents as harvested time points. Remaining section geometries will be weighed and measured for ultrasonic propagation (as input for equations 1 to 5). The biomolecular assays characterize the state of the ECM as assessment of the tissue development as well as input for validation of the biokinetic models (Table 3-1). The primary assays will characterize antibodies associated with immunohistochemistry and histochemical staining to include: 
Type II Collagen as the predominant collagen in healthy articular cartilage. Type II collagen forms a three-dimensional fibrillar network essential for the tensile stiffness and strength of cartilage [Oesser and Seifert 2003].

Aggrecan as the third major component of articular cartilage, constituting the majority of the proteoglycan-hyaluronic acid polymers. These large macromolecules are embedded within the fibrous network of collagen type II, providing the compressibility and elasticity of cartilage. During tissue turnover aggrecan and its fragments originating from the core protein part of aggrecan are released into the supernatant of cartilage explant cultures. The total aggrecan can be identified via an enzyme-immunoassay for the quantitative determination of aggrecan and its fragments containing the G1 and/or G2 domains that are released into the supernatant from articular cartilage explants [Oesser and Seifert 2003].

Type I Collagen as an indicator of dedifferentiation of articular chondrocytes during expansion of cells grown in a monolayer and as an indicator for fibrocartilage. An assay kit is designed to quantify the amount of ColI from bovine cell and/or tissue cultures (Chondrex, Inc.). Type X Collagen $(\operatorname{Col} \mathrm{X})$ as an indicator of hypertrophic cartilage. 


\begin{tabular}{|l|l|l|}
\hline Biomarkers & Assay Product & Cell Secretion Rate (in vitro values) \\
\hline Type II Collagen & $\begin{array}{l}\text { Rhuemera }{ }^{\circledR} \text { Native Type II Collagen } \\
\text { Capture* }\end{array}$ & $\begin{array}{l}\sim 1.5 \text { to 3.0 } \mu \text { g per 106 chondrocytes } \\
\text { (basal media) [Oesser and Seifet, 2003] }\end{array}$ \\
\hline $\begin{array}{l}\text { Glycosaminoglycan } \\
\text { (GAG) }\end{array}$ & $\begin{array}{l}\text { Rhuemera }{ }^{\circledR} \text { Assay Kit for } \\
\text { Proteoglycan* }\end{array}$ & $\begin{array}{l}\sim 55 \text { to } 105 \mathrm{mg} \text { per } 106 \text { chondrocytes } \\
\text { (basal media) }\end{array}$ \\
\hline Type I Collagen & Rhuemera ${ }^{\circledR}$ Type I Collagen Kit* & $\sim 10$ to 15 ng per 106 fibroblasts \\
\hline Type X Collagen & Kit for Collagen Type X** & $? \mu$ g per 106 chondrocytes \\
\hline
\end{tabular}

Table 3-1: Focal biomarkers and the assay products applied to evaluate the state of extracellular matrix biokinetics. The biomarkers and the listed typical secretion standards will be measured as boundary conditions characterizing the experimental progress of the engineered tissue development. These data will also provide input for model initiation and validation during statistical comparison. *Enzyme-linked immuno-sorbent assay (ELISA), Rhuemera and Immunodiagnostics System (Astarte Biologics, LLC, Redmond, WA). ** ELISA (Antibodies-online, Atlanta, GA). ***Sircol (Biocolor Life Science Assays, Carrickfergus, UK.
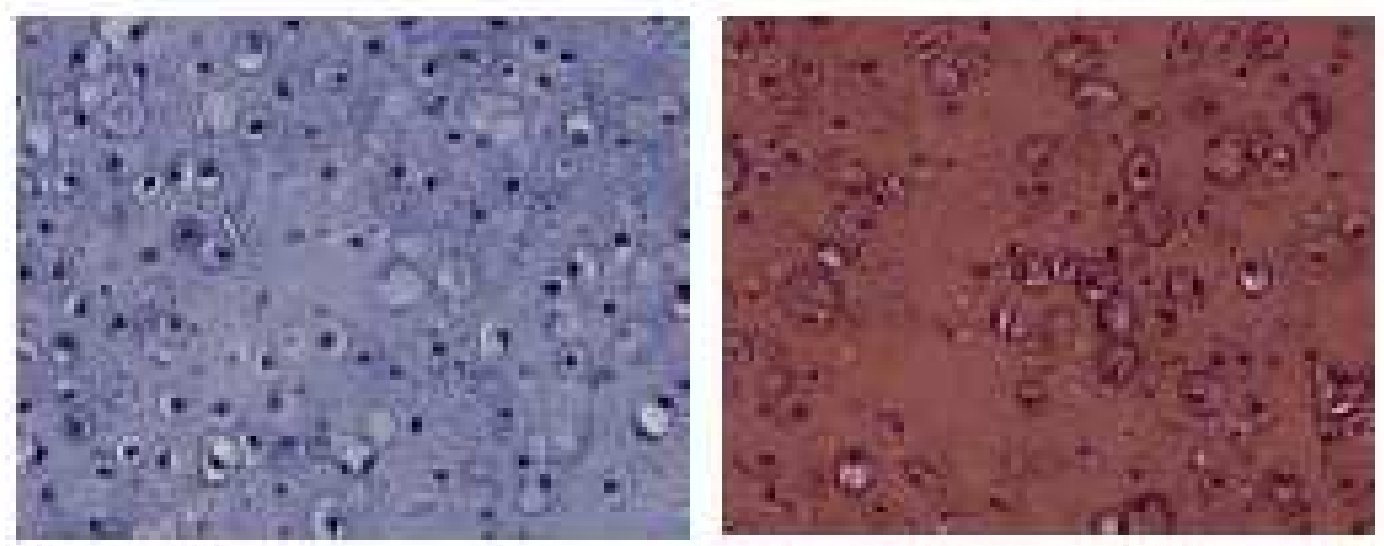

Figure 3-5: Expected cell-matrix preparations [after Rice et al., 2009]. During matrix synthesis, cells will be distributed throughout the collagen (on the left, stained with Masson's Trichome) and aggrecan (on the right, stained with safranin-O/fast) constituents as are typical for this cell-scaffold arrangement. The solid dark circles each represent a single cell at $\sim 20 \mathrm{~mm}$ in diameter. 


\section{(vii) Ultrasound Analysis}

Ultrasound transmission velocities are measured in vitro with the objective of defining acute and post facto elasticity metrics for characterizing developing engineered cartilage constituents. Ultrasound analysis is non-destructive techniques that can assess macroscopic construct properties and constituent quality. Ultrasonic longitudinal $\left(\mathrm{v}_{\mathrm{ii}}\right)$ and transverse $\left(\mathrm{v}_{\mathrm{ij}}\right)$ wave propagation velocities are measured in three orthogonal orientations (planar and thickness directions) for 6 measurements per sample. The test set-up includes a pulserreceiver (Model 5058PR, Panametrics, Olympic Corp., Waltham, MA), a multichannel oscilloscope (Model TDS460A, Tektronix, Beaverton, OR), and an array of sending-receiving transducers: $5 \mathrm{MHz}$ (Model V156), $10 \mathrm{MHz}$ (Model V112), $50 \mathrm{kHz}$ (Model X1021), and $100 \mathrm{kHz}$ (Models X1020 and V1548) transducers (Panametrics) facilitating a total of at most 1,050 measurements. Aggregate cell-ECM-scaffold densities (r) of the samples are determined and system time delays are accounted for during each transducer arrangement. Bulk

$\left(\mathrm{K}=\mathrm{r}_{\mathrm{f}} \mathrm{V}_{\mathrm{ii}}{ }^{2}\right)$ and aggregate $\left(\mathrm{Ha}=\mathrm{r}_{\mathrm{s}} \mathrm{v}_{\mathrm{ii}}{ }^{2}\right)$ moduli can be measured from separated fluid (f) and solid (s) ultrasound propagations, respectively [Shull, 2002], and used as input for equations 3 and 4 . The measurement of intrinsic ultrasonic properties may indicate the structure and composition of the tissue under 
investigation, as well as its mechanical and physical properties [Rice et al. 2005]. Initial cartilage pieces are excised as described earlier under aseptic conditions, sliced into $800-1000 \mu \mathrm{m}$ sections with a microtome. Preliminary native cartilage testing confirmed density $(\mathrm{r}=1,330 \mathrm{~kg} / \mathrm{m} 3)$ and propagation velocities similar to that reported in the literature (1,500 to 1,720 m/s) [Agemura et al., 1990].

\section{(viii) Mathematical Model Input}

Previous mathematical frameworks characterized nanoscale biokinetic mechanisms as stimulated within the micromechanical environment of a single cell [Saha and Kohles, 2010a; 2010b; 2011]. The model results described the influence of mechanical stress on the anabolic and catabolic pathways including the interactions with cytokines (C) and growth factors (G), fundamental regulatory processes that lead to matrix homeostasis. The engineering and experimental designs presented here monitor the catabolic (negative influence) and anabolic (positive influence) effects of chemomechanical stimuli (T), C, and $\mathrm{G}$ on a multi-cellular level using the mathematical framework exploring these differential interactions through time (dt):

$$
\begin{aligned}
& \frac{\mathrm{d}}{\mathrm{dt}}\left[\begin{array}{l}
\mathrm{C} \\
\mathrm{G}
\end{array}\right]=\left[f_{\mathrm{i}}\left(\mathrm{C}, \mathrm{G}, \alpha_{\mathrm{i}}, \beta_{\mathrm{i}}, \Omega_{\mathrm{i}}\right)\right]+\left[\xi_{\mathrm{i}}(\mathrm{T})\right] \\
& \frac{\mathrm{d}}{\mathrm{dt}}(\text { collagen }+\mathrm{GAG})=f(\mathrm{C}, \mathrm{G}, \text { collagen }+\mathrm{GAG}, \lambda, \delta)
\end{aligned}
$$


This computational framework defines the secretion rates of $\mathrm{C}$ and $\mathrm{G}$ as functions (f) of the their current levels and associated rate constants derived from the tissue engineering literature $\left(\mathrm{a}_{\mathrm{i}}, \mathrm{b}_{\mathrm{i}}\right.$, and $\left.\mathrm{W}_{\mathrm{i}}\right)$ and the bioreactor controls $\left(\xi_{\mathrm{i}}\right)$, for $\mathrm{i}=\mathrm{C}$ or G, as previously described [Saha and Kohles, 2010a; 2010b; 2011]. The dynamic state of the $\mathrm{C}$ and $\mathrm{G}$ is then applied as a positive or negative influence on the accumulation rate of ECM, defined as the total amount of collagen plus GAG. Boundary conditions for these levels will be determined from the protocols described in Sections $v$ and $v i$ (Table 3-1). The dynamic state of the ECM is defined as a function of the matrix molecules themselves and rate constants ( 1 and d) modified to optimize description of the model with the collected data. This is an iterative modeling process which will allow us to initiate an assumed biokinetic state and 'back calculate' the levels of $\mathrm{C}$ and $\mathrm{G}$ from the measured ECM abundance through multiple iterations. Combinations of positive and negative feedback/influences can be explored by varying the chemomechanical bioreactor control system. Iterative analyses of the biokinetic models (equation 6) are run through $5 \times 10^{3}$ to $10 \times 10^{5}$ normalized time steps using commercial software (MathCAD 14.0, Parametric Technology Corp., Needham, MA) at each sample harvest/collection period (Figure 3-6). Recreating the tissue in vitro by utilizing the bioreactor's capability provides an approach to validate biokinetic models as a descriptor of dynamic inter- and intra-cellular interactions, necessary to promote tissue synthesis, regulation and maintenance of the resulting ECM. 
Statistical validation and assessment of influencing variables will be conducted with multiple analyses of co-variance (MANCOVA) techniques (JMP v9, SAS Concepts, Inc., Cary, NC).

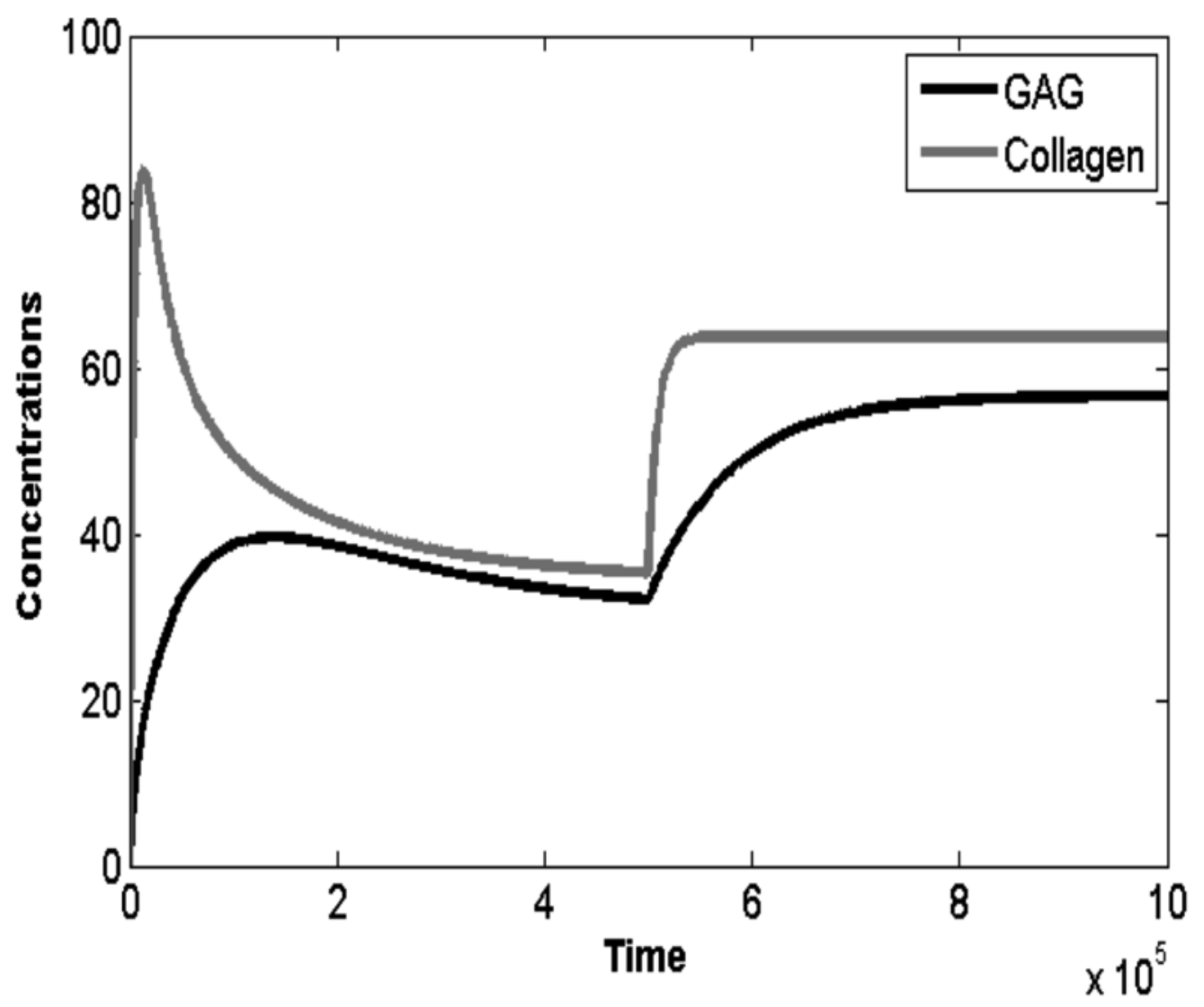

Figure 3-6: Representative biokinetic modeling results (applying equation 6) from expected biomolecular accumulation data as gathered from the chemomechanical bioreactor (as boundary conditions and validation). Here the model is initially allowed to run as the ECM concentration (\%, GAG and collagen) peaks in the response to local resources and then drops to a steady state level. A chemomechanical stimulus is then applied at 5 x105 relative time units, driving the accumulation upward in an anabolic response. 


\section{Section 3.06 Discussion}

The successful large-scale production of engineered tissues requires an adequate source of healthy expandable cells, the optimization of biomaterial scaffolds, and the application of bioreactors, which mimic the in vivo environment of the body and are amenable to scale-up [Griffith and Naughton 2002]. The in vitro environment provided by the chemomechanical bioreactor described here provides an experimental platform to explore cell-cell and cell-matrix molecular communication associated with ECM synthesis and degradation as a nanomedicine application. The importance of static or dynamic chemical and/or mechanical stimulation as characterized in biokinetic models for cartilage has indicated mechanisms which increase proteoglycan and collagen expression, thus suggesting an active role in maintaining healthy chondrocytic phenotype [Tortelli and Cancedda, 2009].

The engineering and experimental design innovation described here recreates the in vivo environment of load bearing articular cartilage on micro- to milli-scales (cells and scaffold architecture) by measuring/modeling nano-scale biomolecular interactions. As an approach to exploring highly resolved, intra-sample heterogeneity, distinct zonal distributions of ECM macromolecules and chondrocyte morphology in articular cartilage may be controlled through layer-wise construct fabrication. Articular cartilage is stratified in a depth-dependent manner with distinct layers (superficial, middle, and deep). Each distinct zone is well characterized by cellular shape, ECM ultra-structure, and material properties (Figure 3-1). The superficial region has a dense network of collagen fibers primarily aligned parallel to the joint surface, whereas collagen fiber 
orientation is more random in the middle and perpendicular in the deepest zone [Vanderploeg et al., 2008]. Being avascular in nature, it is not a surprise that articular cartilage has reduced oxygen tension, and each zone has varying oxygen levels that decrease from superficial $(\sim 6 \%$ O2) to deep ( $\sim 1 \%$ O2) zones [Fermor et al., 2007]. Oxygen tension can alter matrix synthesis, as well as the material properties of articular cartilage in vitro, which can be a testable explanation for the zonal distribution along the depth of the tissue. The bioreactor described here has the potential to test the influence of many such parameters including oxygen tension and offers a novel arrangement in comparison to current bioreactor designs [Cartmell et al., 2003; Lujan et al., 2011].

Ongoing efforts are exploring the chemomechanical environments in support of dynamic cell and tissue culture. These efforts include optimizing the scaffold's material and structural properties (local stiffness, porosity, etc.) in a manner that supports cell, nutrient, waste, and other biomolecular transport concomitant with controllable mechanical properties. Future capabilities will monitor and evaluate the developing neotissue in a nondestructive manner, accommodating real-time measurement. Utilizing a bioreactor that encompasses the ability to culture tissue as well as monitor matrix growth and maintenance may have a much broader scope then facilitating tissue development; it has the potential of replacing animal models in drug response studies, cellular and molecular engineering, and regenerative medicine. It may be possible to better understand the roles of specific mammalian genes involved with essential metabolic pathways without manipulating an animal model. 


\section{ACKNOWLEDGMENTS}

Support was provided by the National Institutes of Health as a Research Infrastructure for Minority Institutions (RIMI) Exploratory Program grant (No. P20MD003350) establishing the CSU Center for Allaying Health Disparities through Research and Education (CADRE), the Collins Medical Trust, and a PSU Faculty Enhancement Grant. Valuable design and fabrication efforts were contributed by Caleb Janicich, Hank Y. Chiu, Thadeous C. Bamford, and Fay Gibson of PSU as well as Dr. Timothy P. Quinn and Doug V. Gallagher of the National Institutes of Science \& Technology, Boulder, CO.

\section{REFERENCES}

Agemura DH, O'Brien WD, Olerud JE, Chun LE, Eyre DE. Ultrasonic propagation properties of articular cartilage at $100 \mathrm{MHz}$. J Acoust Soc Am. 1990;87(4):1786-1791.

Bahney CS, Hsu CW, Yoo JU, West JL, Johnstone B. A bioresponsive hydrogel tuned to chondrogenesis of human mesenchymal stem cells. FASEB J. 2011, 25(5):14861496.

Barbero A, Martina I. Human articular chondrocyte culture. In: Tissue Engineering, 2nd Ed. Edited by H. Hauser and M. Fussenegger. Methods in Molecular Medicine, Humana Press Inc., Totowa, NJ. 2007:237-247.

Barlic A, Kregar-Velikonja. Re-differentiation of human articular chondrocytes is not enhanced by a rotary bioreactor system. Folia Biologica. 2008;54:177-170. 
Cartmell SH, Porter BD, Garcia AJ, Guldberg RE. Effects of medium perfusion rate on cell-seeded three-dimensional bone constructs in vitro. Tissue Eng. 2003; 9(6):1197-1203.

Chao PG, Grayson W, Vunjak-Novakovic G. Engineering cartilage and bone using human mesenchymal stem cells. J Orthop Sci. 2007;12:398-404.

Chiu HY, Saha AK, Kohles SS. A Mechanical Bioreactor for Cell and Tissue Engineering, Sigma Xi Scientific Honor Society, Columbia-Willamette Chapter Student Research Symposium, Portland, OR, 2010.

Choi JB, Youn I, Cao L, Leddy HA, Gilchrist CL, Setton LA, Guilak F. Zonal changes in the three-dimensional morphology of the chondron under compression: The relationship among cellular, pericellular, and extracellular deformation in articular cartilage. J Biomech. 2007;40:2596-2603.

\section{Elisseeff J, McIntosh W, Anseth K, Riley S, Ragan P, Langer R.} Photoencapsulation of chondrocytes in poly(ethylene oxide)-based semi-interpenetrating networks. J Biomed Mater Res. 2000;51:164-171.

Fedorovich NE, Oudshoorn MH, van Geemen D, Hennink WE, Alblas J, Dhert WJ. The effect of photopolymerization on stem cells embedded in hydrogels. Biomaterials. 2009;30(3):344-53.

Fermor B, Christensen SE, Young I, Cernanec JM, Davies CM, Weinberg JB. Oxygen, nitric oxide and articular cartilage. Eur Cells Mater. 2007;13:56-65. 
Gibson F, Kohles SS. Hydrogel Biomaterials Engineering for Regenerative Cartilage Strategies, Sigma Xi Scientific Honor Society, Columbia-Willamette Chapter Student Research Symposium, Portland, OR, 2010.

Griffith LG, and Naughton G. Tissue Engineering-current challenges and expanding opportunities. Science. 2002;295:1009-16.

Harris JR, Graham J, Rickwood D. Cell Biology Protocols. New Jersey: John Wiley \& Sons Ltd.; 2006.

Hashin Z, Shtrikman S. A variation approach to the theory of the elastic behavior of multiphase materials. J Mech Phys Solids. 1963;11:127-140.

Jadin KD, Sah RL. Human articular cartilage. Cartilage Tissue Engineering Lab, University of California, San Diego, CA, 2006.

Jones RM. Mechanics of Composite Materials. 2nd edition, Taylor \& Francis, Philadelphia, 1999.

Kohles SS, Respini-Irwin D, Inoue H, Barnett J, Adib S, Chiu HY, Saha AK. A Mechanical Bioreactor Enhanced with Fluid Perfusion for Cell and Tissue Engineering, J Medical Devices. in preparation, 2011.

Kohles SS, Wilson CG, Bonassar LJ. A mechanical composite spheres analysis of engineered cartilage dynamics. J Biomech Eng. 2007:129(4):473-80.

Lanza R, Langer R, Vacanti J. Principles of Tissue Engineering. 3rd Ed. Elsevier Academic Press. San Diego Ca. 2007. 
Lujan TJ, Wirtz KM, Bahney CS, Madey SM, Johnstone B, Bottlang M. A novel bioreactor for the dynamic stimulation and mechanical evaluation of multiple tissueengineered constructs. Tissue Eng Part C Methods. 2011;17(3):367-74.

Mahmoudifar N, Doran PM. Tissue engineering of human cartilage in bioreactors using single and composite cell-seeded scaffolds. Biotech Bioeng. 2005;91(3):1-18.

Martin RB, Burr DB, Sharkey NA. Skeletal Tissue Mechanics, Springer-Verlag, NY, 1998.

Nagpal S, Na S, Rathnachalam R. Noncalcemic actions of vitamin D receptor ligands. Endocrine Rev. 2005;26(5):662-687.

Oesser S, Seifert J. Stimulation of type II collagen biosynthesis and secretion in bovine chondrocytes cultured with degraded collagen. Cell Tissue Res. 2003;311(3):393399.

Pazzano D, Mercier KA, Moran JM, Fong SS, DiBiaso DD, Rulf JX, Kohles SS, Bonassar LJ. Comparison of chondrogenesis in static and perfused bioreactor culture. Biotech Prog. 2000; 16:893-896.

Quinn TP, Flannery CM, Lauria D, Gallagher DV, Anseth KS. An instrumented bioreactor for cartilage tissue engineering, Ann Mtg Soc Biomat, San Antonio, TX, 2009.

Rice MA, Waters KR, Anseth KS. Ultrasound monitoring of cartilaginous matrix evolution in degradable PEG hydrogels. Acta Biomaterials. 2009;152-161.

Saha AK, Kohles SS. A distinct catabolic to anabolic threshold due to single-cell nanomechanical stimulation in a cartilage biokinetics model. J Nanotechnol Eng Med. 2010a;1(3):031005. 
Saha AK, Kohles SS. Periodic nanomechanical stimulation in a biokinetics model identifying anabolic and catabolic pathways associated with cartilage matrix homeostasis. J Nanotechnol Eng Med. 2010b;1(4):041001.

Saha AK, Kohles SS. A Cell-Matrix Model of Anabolic and Catabolic Dynamics During Cartilage Biomolecule Regulation. Int J Comp Healthcare. 2011;1(3).

Shull PJ. (ed). Nondestructive Evaluation: Theory, techniques, and applications. Marcel Dekker Inc., 2002.

Schipani E. Meeting Report from the 28th Ann Mtg Am Soc Bone Min Res. September. 2006.

Tibbitt MW, Anseth KS. Hydrogels as Extracellular Matrix Mimics for 3D Cell Culture. Biotech Bioeng. 2009;103: 655-663.

Tortelli F, Cancedda R. Three-dimensional cultures of osteogenic and chondrogenic cells: a tissue engineering approach to mimic bone and cartilage in vitro. Eur Cells Mater. 2009;17:1-4.

Vanderploeg EJ, Wilson CG, Levenston ME. Articular chondrocytes derived from distinct tissue zones differentially respond to in vitro oscillatory tensile loading. Osteoarth Cart. 2008;16(10):1228-36.

Vilanueva I, Weigal CA, Bryant SJ. Cell-matrix interactions and dynamic mechanical loading influence chondrocyte gene expression and bioactivity in PEG-RGD hydrogels. Acta Biomater. 2009;5(8):2832-2846.

Wilson CG, Bonassar LJ, Kohles SS. Modeling the dynamic composition of engineered cartilage. Arch Biochem Biophys. 2002;408(2):246-54. 
Yilmaz BC, Yilmaz G, Yilmaz NS, Balli E, Tasdelen B. Optimal transport time and conditions for cartilage tissue samples and expanded chondrocyte suspensions. Orthopedics 2010;33(1):25.

Zuwei MA, Kotaki M, Inani R, Ramakrishna A. Potential of nanofiber matrix as tissue-engineering scaffolds. Tissue Eng. 2005;11(1-2):101-109. 
Chapter IV. ULTRASONIC WAVE PROPAGATION ASSESSMENT OF NATIVE CARTILAGE EXPLANTS AND HYDROGEL SCAFFOLDS FOR TISSUE ENGINEERING

\author{
Sean S. Kohles ${ }^{1, \dagger}$ \\ Shelley S. Mason ${ }^{1}$ \\ Anya P. Adams ${ }^{1}$ \\ Robert J. Berg ${ }^{1}$ \\ Jessica Blank ${ }^{1}$ \\ Fay Gibson ${ }^{1}$ \\ Johnathan Righetti ${ }^{1}$ \\ Iesha S. Washington ${ }^{2}$ \\ Asit K. Saha ${ }^{2}$ \\ ${ }^{1}$ Regenerative Bioengineering Laboratory, \\ Departments of Mechanical \& Materials Engineering and Biology, \\ Portland State University, \\ Portland, Oregon, USA, 97201; \\ ${ }^{2}$ Center for Allaying Health Disparities through Research and Education (CADRE), \\ Department of Mathematics \& Computer Science, \\ Central State University, \\ Wilberforce, Ohio, USA, 45384
}




\section{Section 4.01 Preface}

The following chapter encompasses material from a manuscript submitted to the International Journal of Biomedical Engineering and Technology as a Research Paper (IJBET) in February 2012, and published in April 2012. The application of ultrasound analysis presented here will be used to distinguish between the fluid and solid properties of engineered cartilage constructs, including the cell and matrix biokinetics as a nondestructive means to evaluate growing tissue, as well as a validation of previous mathematical models described in Chapter 3.

\section{Section 4.02 Authors Contribution}

The work presented here was carried out in collaboration between all authors. SSM and SSK defined the research theme. SSM designed the biological methods and experiments, while SSK designed the engineering methods and mathematical modeling. SSM, APA, RJB, JB, FG, JR, and ISW carried out the laboratory experiments. SSM and SSK analyzed the data, interpreted the results and wrote the paper. AKS co-designed the mathematical modeling. All authors have contributed to, seen and approved the manuscript.

\section{Section 4.03 Hypothesis}

Using ultrasound as an application of acoustoelastic analysis, agarose, as a natural biomaterial scaffold, will have similar elastic and shear properties as cartilage explants. 


\section{Section 4.04 Abstract}

Nondestructive techniques characterizing the mechanical properties of cells, tissues, and biomaterials provide baseline metrics for tissue engineering design. Ultrasonic wave propagation and attenuation has previously demonstrated the dynamics of extracellular matrix synthesis in chondrocyte-seeded hydrogel constructs. In this paper, we describe an ultrasonic method to analyze two of the construct elements used to engineer articular cartilage in real-time, native cartilage explants and an agarose biomaterial. Results indicated a similarity in wave propagation velocity ranges for both longitudinal $(1,500$ to $1,745 \mathrm{~m} / \mathrm{s})$ and transverse $(350$ to $950 \mathrm{~m} / \mathrm{s})$ waveforms. Future work will apply an acoustoelastic analysis to distinguish between the fluid and solid properties including the cell and matrix biokinetics as a validation of previous mathematical models. 


\section{Section 4.05 Introduction}

Cartilage tissue engineering (TE) is a promising solution for cellular and tissue replacement therapies as well as an alternative for animal models used in clinical research; however, many of the current TE approaches have not been fully validated. Most mechanical and biochemical assessment of TE constructs require destructive endpoint-testing and/or compromise the sterility of the bioreactor environment used during construct formation [Walker et al., 2011]. Ultrasonic imaging is a standard clinical diagnostic tool that is based on propagating sound waves and offers a technology for tissue characterization and stimulation in a noninvasive and nondestructive manner. The response to mechanical stimulation induced in passive tissues by external sources such as low to high frequency vibration or compression can be used to analyze tissue elasticity as a metric for tissue health [Hein et al., 1993]. Recently, it has been shown that ultrasonic assessment can predict the process of native cartilage regeneration and engineered cartilage histology [Hattori et al., 2005].

Native articular cartilage is divided into four distinct histological zones (superficial tangential or resting zone; the proliferative or middle zone; the hypertrophic or deep zone; and the calcified zone) based on the preferential orientation of matrix molecules, cellular morphology, and biochemistry. Ultrastructural studies of adult cartilage have shown that the preferential orientation of collagen fibrils varies from the articular surface to the intermediate and deep zones [Agemura et al., 1990]. The depthdependent structural arrangement of chondrocytes and extracellular matrix (ECM) macromolecules, such as proteoglycans (PG) and fibrillar collagens, mainly collagen type 
II (ColII), results in a structurally heterogeneous and mechanically anisotropic material. For example, at any given depth from the articular surface, PG concentration may change as a function of the distance from the chondrocytes [Jurvelin et al., 1997]. The zonal distribution of ECM molecules gives rise to the tissue's unique poroelastic properties and ability to act as a load-bearing cushion in which mechanical forces transmitted through the joint to the underlying subchondral bone can be properly distributed [Waldman et al., 2004].

The localized biomechanics (stresses, strains, and elastic properties) of articular cartilage ECM is thought to be actively modulated by chondrocyte-matrix interaction driving biosynthesis regulation [Korhonen et al., 2008; Saha and Kohles, 2012]. Characterizing the mechanical properties of cartilage constituents including cells and ECM as a means to define constitutive relationships between stress and strain may elucidate their physical interactions and contribute to the understanding of cartilage development, adaptation, and degeneration [Kohles et al., 2007]. In addition, the distinct histologic zones within articular cartilage have exhibited distinct material properties at both the cell and tissue level [Ginat et al., 2006; Shieh and Athanasiou, 2006]. Selection of cells and replication of matrix organization based on zonal mimicry may provide strong design specifications when constructing regenerative or tissue replacement therapies. In this work, ultrasonic wave transmission was investigated as one of many baseline bioengineering design metrics with the objective of characterizing and comparing key engineered cartilage constituents. 


\section{Section 4.06 Methods}

\section{(i) Articular Cartilage Harvest and Ultrasonic Testing}

Full-thickness articular cartilage was harvested from a two-year-old steer (Mark's Meat, Canby, OR) within 4 hours of slaughter. The cartilage was extracted from the metacarpophalangeal joint using a scalpel (Figure 4-2). Fullthickness cartilage parallelepipeds (typically $\mathrm{x}=4 \mathrm{~mm}, \mathrm{y}=4 \mathrm{~mm}$, and $\mathrm{z}$ or $\mathrm{t}=$ $1.5 \mathrm{~mm})$ were created from the tissue samples. Ultrasonic longitudinal $\left(\mathrm{v}_{\mathrm{ii}}\right)$ and transverse $\left(v_{i j}\right)$ wave propagation velocities were measured in three orthogonal orientations (planar and thickness directions indicated by i, j subscripts) for 6 measurements per sample (Figure 4-1). The experimental test set-up included a pulser-receiver (Model 5058PR, Panametrics, Billerica, MA, USA), a multichannel oscilloscope (Model TDS460A, Tektronix, Beaverton, OR, USA), and an array of sending-receiving transducers: $5 \mathrm{MHz}$ (Model V156), $10 \mathrm{MHz}$ (Model V112), 50 kHz (Model X1021), and 100 kHz (Models X1020 and V1548) transducers (Panametrics) facilitating a total of 1,050 measurements. Aggregate tissue density $(\rho t)$ of the samples was determined and system time delays were accounted for during each transducer arrangement. 


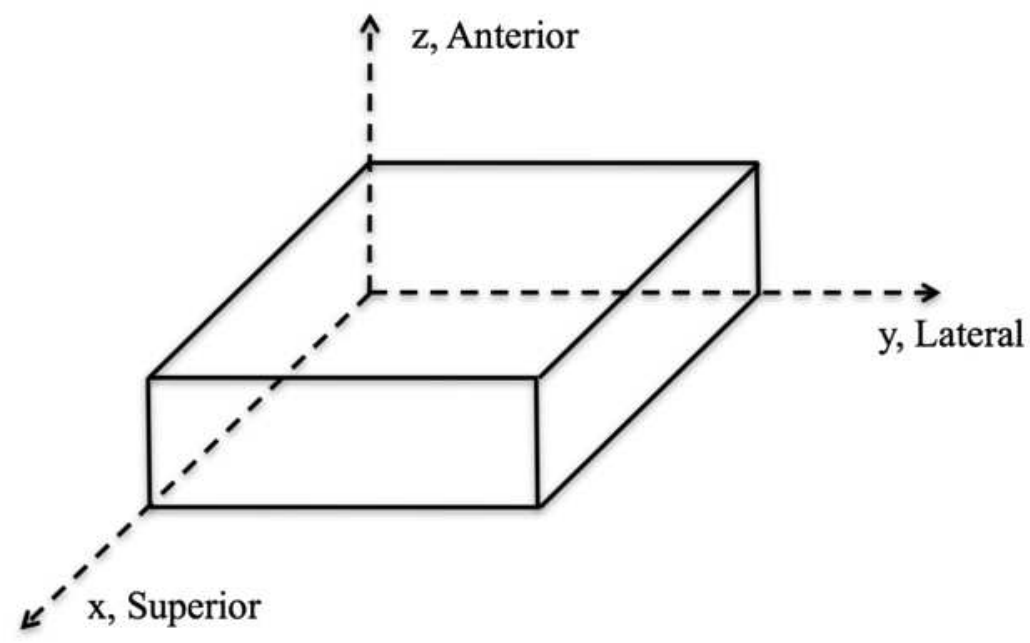

Longitudinal Wave

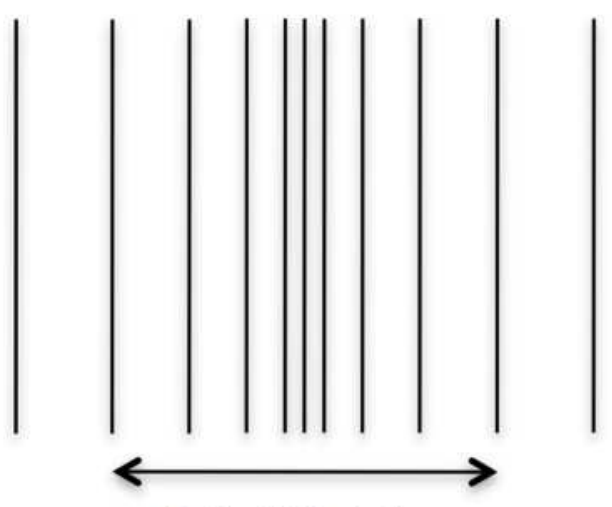

Pulse Orientation

Transverse Wave

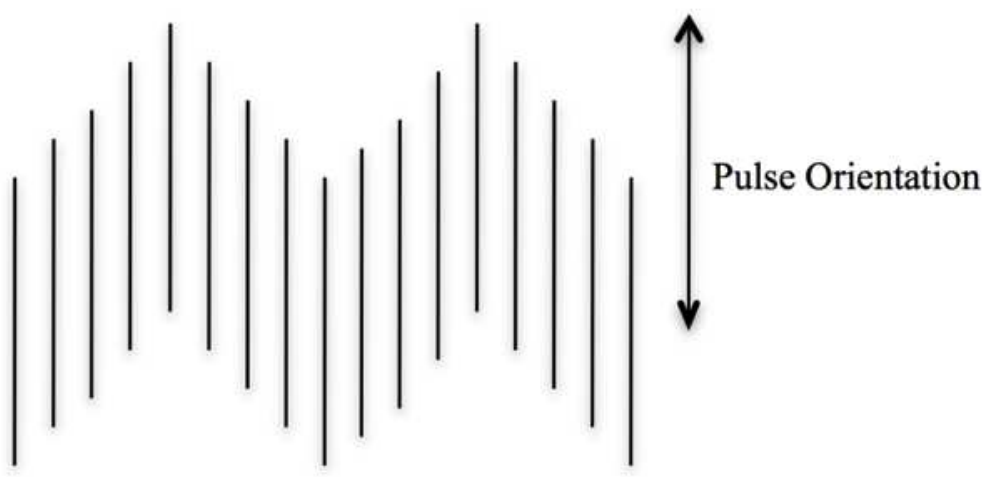

Figure 4-1: Schematics of explant anatomic orientation and propagating ultrasonic waveforms. 
a)

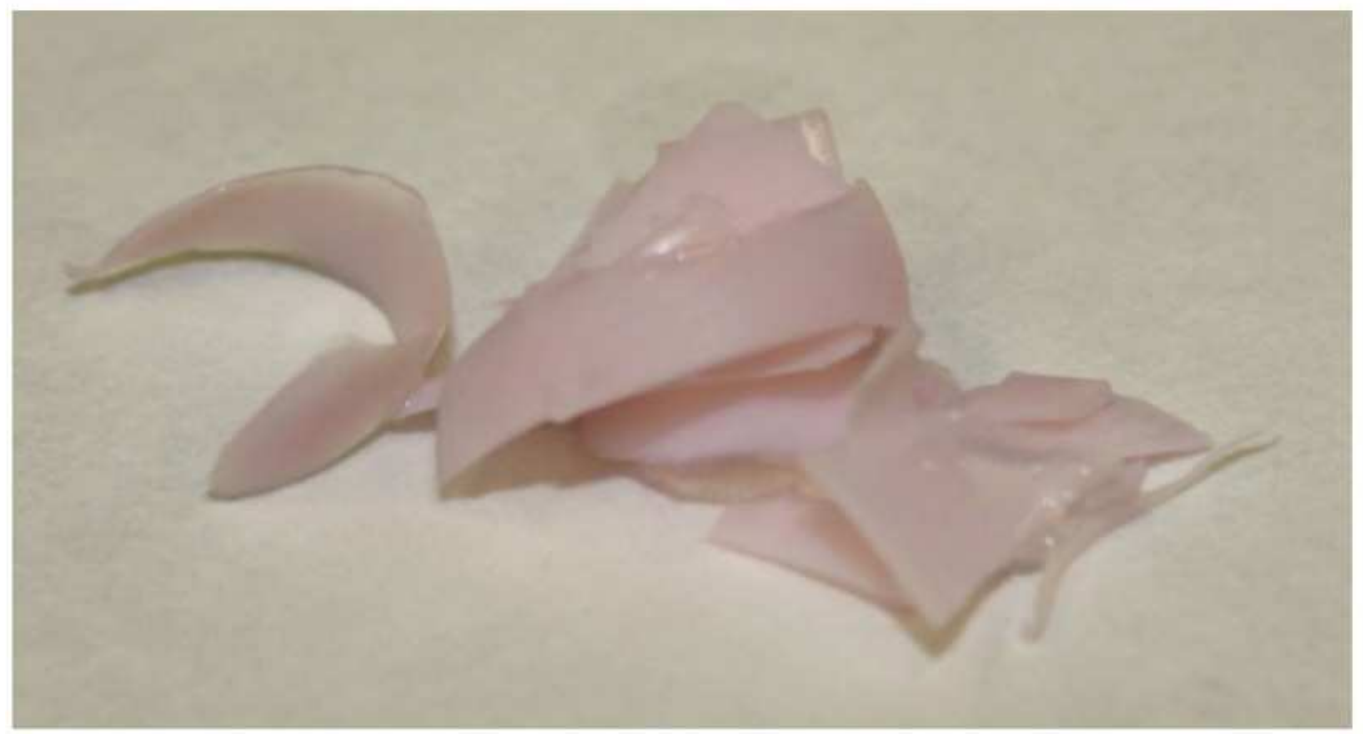

b)

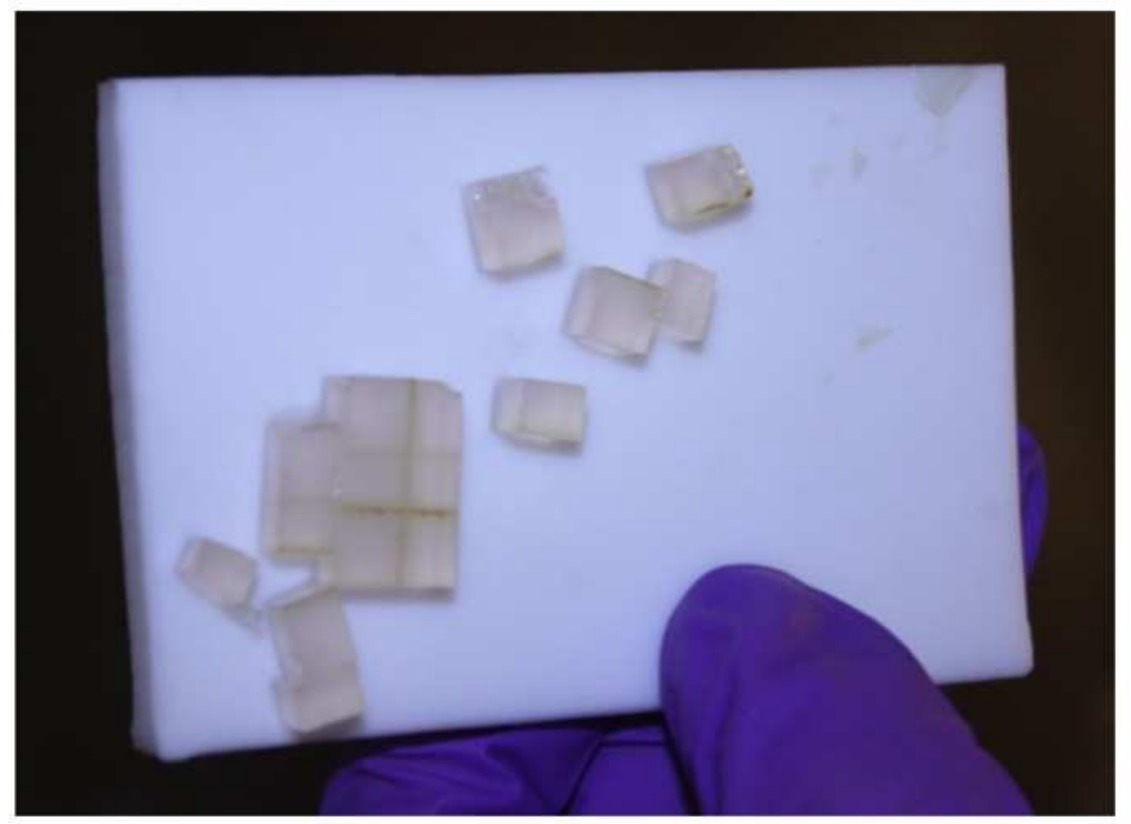

Figure 4-2: Images of harvested bovine cartilage tissue (a) and fabricated agarose hydrogel scaffold cubes (b). 


\section{(ii) Hydrogel Scaffold Fabrication and Ultrasonic Testing}

An agarose hydrogel formulation has been widely accepted as a host-biomaterial for cartilage TE culture [Nicodemus \& Bryant, 2008], providing an appropriate technology for the bioengineering of modern scaffolds [Mata, 2011; Morsi et al., 2011]. Here, a $2 \%$ agarose solution was made by slowly adding low-melting agarose (Type VII, Sigma-Aldrich, St. Louis, MO, USA) to a beaker containing Dulbecco's phosphate buffered solution (DPBS, Sigma-Aldrich) while being stirred on a hot plate. The concentration change due to excessive heating was taken into consideration in order to maintain a $2 \%$ concentration by weighing the beaker and solution prior to heating. The solution was brought to a boil for 10 minutes stirring continuously until the agarose was completely dissolved. Hot sterile water was added to return the contents to the original weight and mixed continuously. The mixture was allowed to cool to $45^{\circ} \mathrm{C}$ and casted in a $5 \mathrm{~mm} \mathrm{x}$ $5 \mathrm{~mm} \times 5 \mathrm{~mm}$ mold, immediately being placed in a refrigerator at $4^{\circ} \mathrm{C}$ for 10 minutes.

For an equal-weighted statistical comparison with the cartilage explants, 35 agarose samples were prepared (Figure 4-2). Due to the homogeneity of the 125-mm3 agarose cubes, ultrasonic longitudinal $\left(\mathrm{v}_{\mathrm{ii}}\right)$ and transverse $\left(\mathrm{v}_{\mathrm{ij}}\right)$ wave propagation velocities were only measured in the z-direction. Three measurements per sample from each of the five sending-receiving transducers, described above, were used facilitating a total of 525 measurements per sample. 
Aggregate biomaterial density ( $\rho b)$ of all of the samples was determined and system time delays were accounted for during each transducer arrangement.

\section{(iii) Elastic and Statistical Analysis}

The measured propagation velocities were examined as a distinguishing elastic feature between the cartilage/hydrogel structure (when wavelength, $\lambda>t$, typically at $\mathrm{kHz}$ ) or the constituent matrix/polymer material (when $\lambda<\mathrm{t}$, typically at $\mathrm{MHz}$ ). Transverse isotropy was tested and confirmed in the cartilage samples, while full-isotropy was affirmed in the agarose samples. Generalized stiffness or moduli (as a Young's and Shear Moduli variants) were calculated $\left(\rho v_{\mathrm{ii}}{ }^{2}\right.$ and $\left.\rho v_{\mathrm{ij} 2}\right)$ for both the cartilage explants and agarose samples. An analysis of variance was applied for all comparisons (JMP v5.0.1, SAS Institute, Inc., Cary, NC, USA). Means (+/- standard deviation, SD) are shown for graphical comparisons. 


\section{Section 4.07 Results}

In this work, ultrasonic measurements analyzed an agarose hydrogel formulation as a scaffold substrate for cartilage TE in comparison with native cartilage samples. The analyzed cartilage samples confirmed an aggregate density (here $\rho t=1,330 \mathrm{~kg} / \mathrm{m} 3$ ) and both longitudinal and transverse propagation velocities similar to that reported in the literature $\left(\mathrm{v}_{\mathrm{ii}}=1,500\right.$ to $\left.1,720 \mathrm{~m} / \mathrm{s}\right)$ [Agemura et al., 1990] (Figure 4-3). The statistical influence of propagation orientation on longitudinal $(\mathrm{p}=0.8763)$ and transverse $(\mathrm{p}=$ 0.0006) wave velocities in the native cartilage samples was statistically inconsistent. However, the wavelength of propagating waves relative to the propagating distance as indicated by $\mathrm{MHz}(\lambda<\mathrm{t})$ versus $\mathrm{kHz}(\lambda>\mathrm{t})$ frequencies was statistically significant for both longitudinal $(\mathrm{p}=0.0001)$ and transverse $(\mathrm{p}=0.0001)$ waves within the cartilage samples.

In comparison, the fabricated agarose cubes had a mean density of $\rho b=1,110$ $\mathrm{kg} / \mathrm{m} 3$. A longitudinal propagation velocity range of 1,595 to $1,745 \mathrm{~m} / \mathrm{s}$ was also determined for the biomaterial indicating a statistical similarity $(\mathrm{p}>0.05)$ with native cartilage (Figure 4-4). Overall, the basic calculation addressing the ultrasonic elastic and shear moduli for both the cartilage and hydrogel samples was dominated by similar density, propagation velocity measurements, and water content (nearly 80\%) [D'Arrigo $\&$ Paparelli, 1988]. These influences produced statistically similar $(p>0.05)$ hydrated stiffness values having large magnitudes dominated by the incompressible nature of 
water when assessed with both longitudinal and transverse wave propagation modes (Figure 4-5).

a)

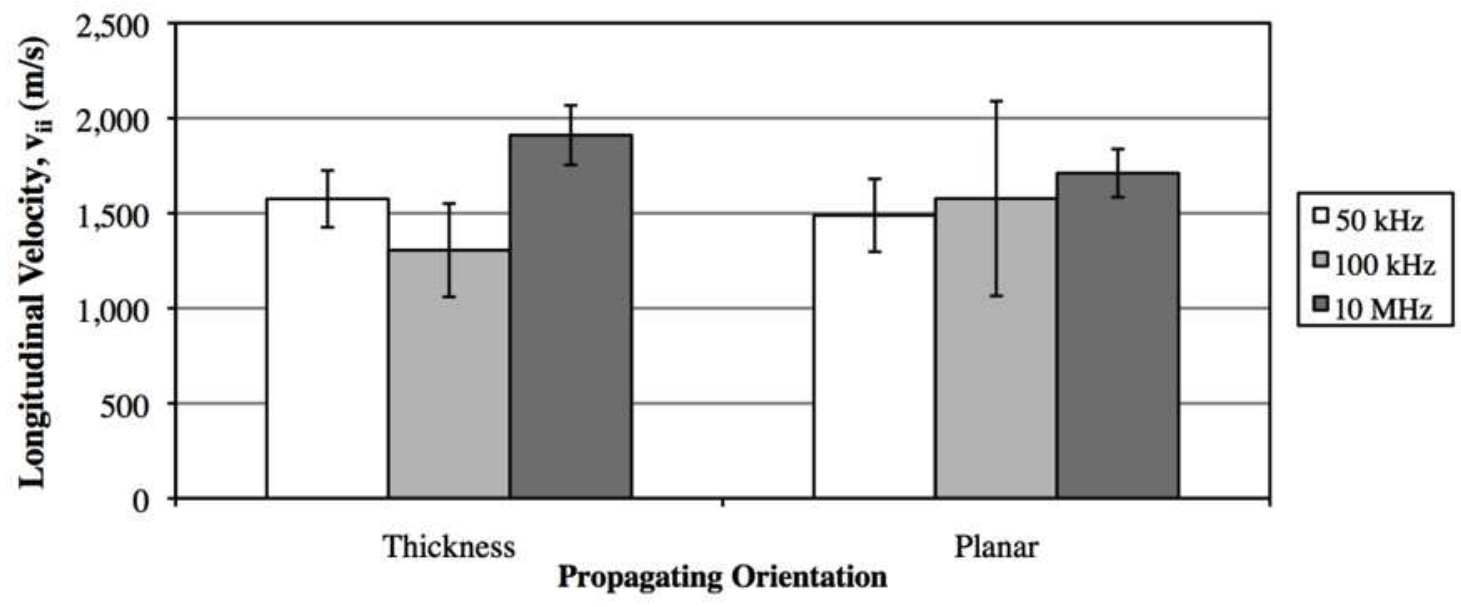

b)

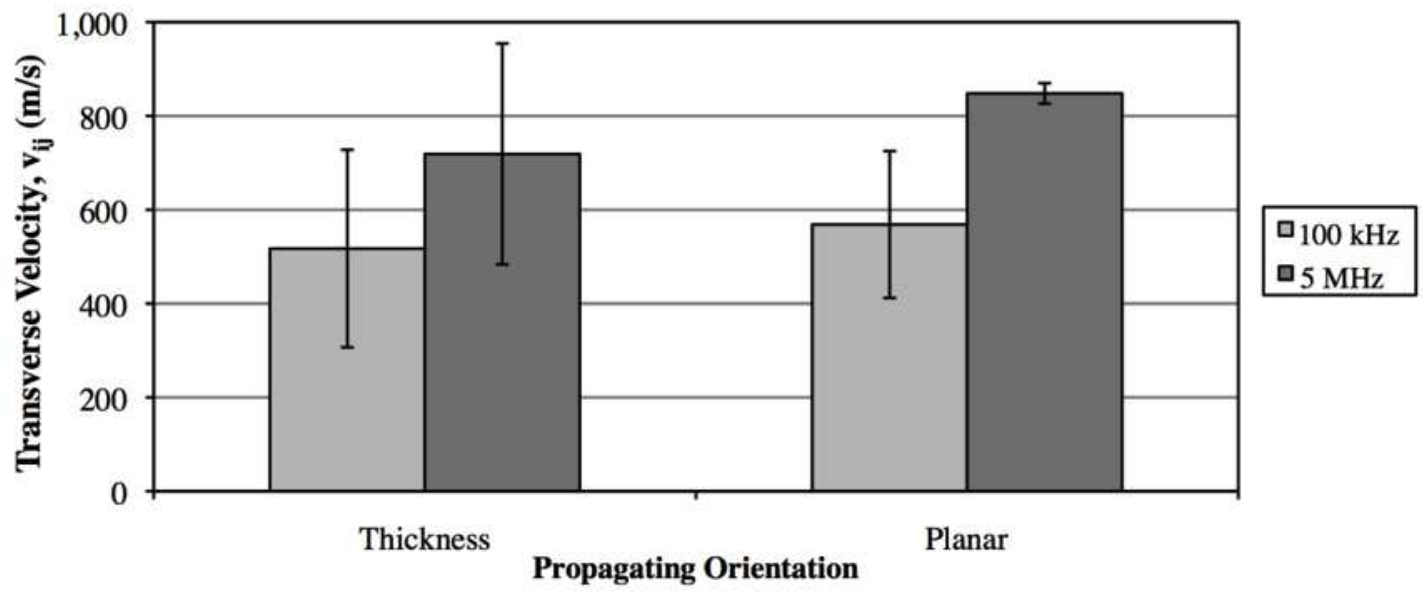

Figure 4-3: Mean (+/- SD) longitudinal (a) and transverse (b) propagation wave velocities as gathered from through-thickness (anterior-posterior) and within-plane (superior-inferior plus medial-lateral) orientations of harvested cartilage explants. 


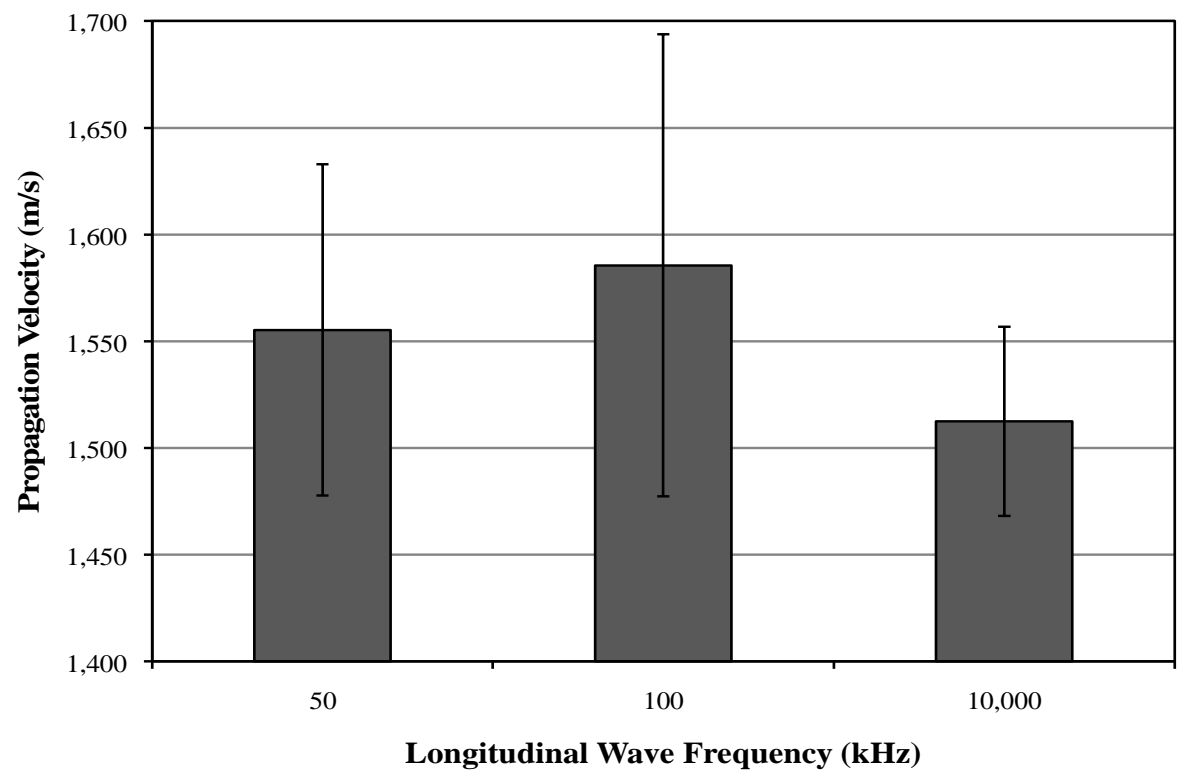

Figure 4-4. Comparison of mean (+/- SD) ultrasonic propagation velocities of $\mathrm{n}=$ 35 agarose biomaterial samples as driven by longitudinal wave impulses at varying frequencies.

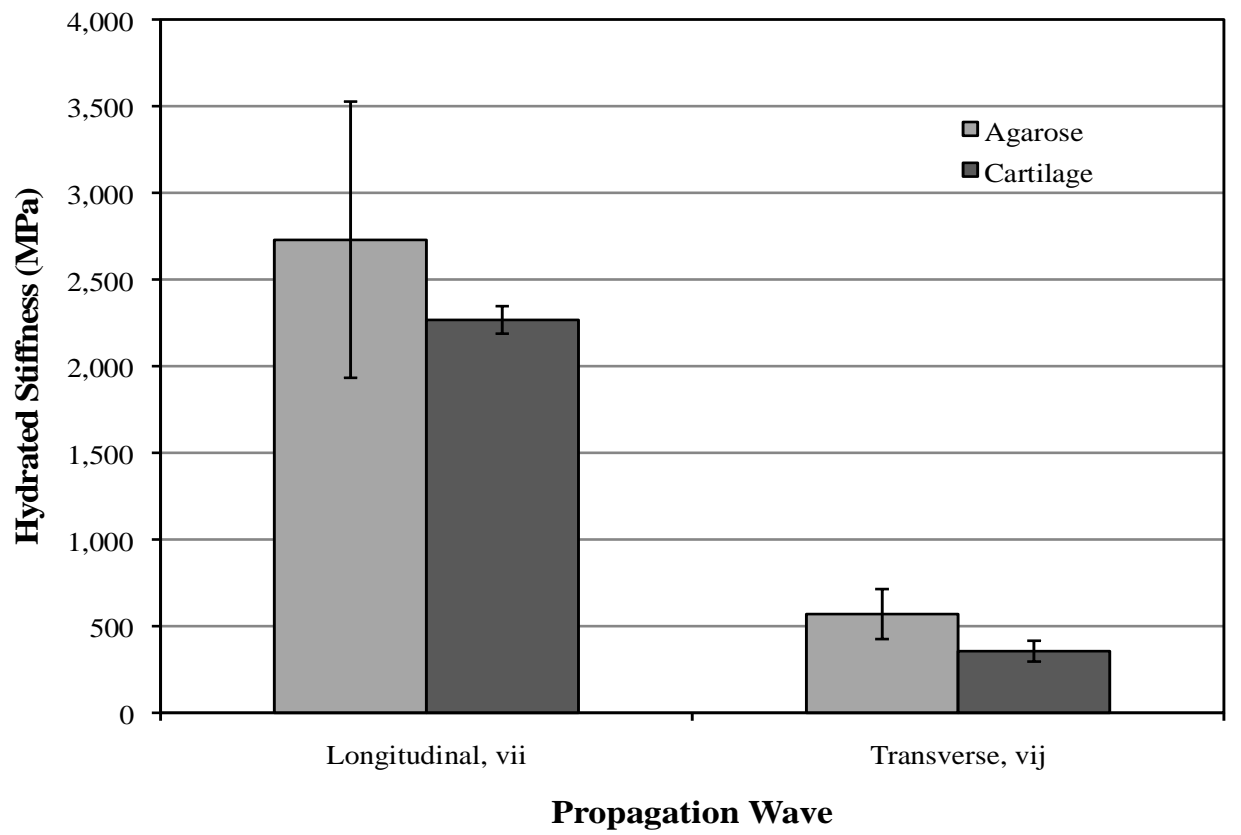

Figure 4-5. Fluid-dominated stiffnesses of the agarose biomaterial scaffolds and cartilage explants as measured using the $100 \mathrm{kHz}$ longitudinal and transverse wave transducers. 


\section{Section 4.08 Discussion}

The application of ultrasonic wave propagation was explored as a means to compare an agarose biomaterial as a scaffold for cartilage TE design. Here, the results provided baseline measurements for analyzing future neotissue growth in a nondestructive manner. It was found that $2 \%$ agarose constructs had an ultrasonic propagation velocity similar to that of native cartilage, and that this approach may be used to assess the integrity of agarose constructs seeded with chondrocytes while ECM macromolecules are being synthesized without destroying the engineered tissue. Due to the aqueous nature of both the articular cartilage explants and the agarose hydrogels, the reported propagation values are highly dominated by the mechanical wave transfer through the water constituent.

As a limitation in this approach, the ultrasonic propagation velocities themselves may not provide critical information in assessing native or TE cartilage. However, the signal resolution may be tuned in a manner sufficient to identify cellular or molecular influences on wave propagation during chondrocyte and ECM biokinetics. The difference in ultrasonic signals when comparing isolated agarose with cell-seeded agarose, may be used to assess the elastic properties of chondrocytes and newly developing ECM. Mechanical loading of hydrated materials such as cartilage tissue has also been shown to influence ultrasonic propagation velocity measurements [Nieminen et al., 2007]. Tissueequivalent phantoms may eventually aid in standardizing the accuracy of developing cellbiomaterial construct measurements [Singh et al., 2008]. Articular cartilage is a highly hydrated tissue due to the negatively charged PG that binds fluid within its matrix. The 
mechanical performance of cartilage is dominated by these solid/fluid interactions. When the tissue degenerates through injury or disease, the PG and collagen network is disturbed, altering the load transfer to the subchondral bone. This cascade of degeneration ultimately compromises the tissue and joint mechanical properties, as recently assessed with ultrasound [Brown et al., 2007].

Ultrasonic wave transmission offers a highly resolved technique for characterizing these subtle changes in the tissue properties. However, distinguishing the ultrasonic propagation through its water content $(\sim 1,482 \mathrm{~m} / \mathrm{s})$ from the composite solid components (ECM and cells) will be very challenging. Ongoing efforts will apply forward and reverse acoustoelastic analysis to decipher bulk $\left(\mathrm{K}=\rho_{\mathrm{f}} \mathrm{v}_{\mathrm{ii}}{ }^{2}\right)$ and aggregate $\left(\mathrm{Ha}=\rho_{\mathrm{s}} \mathrm{v}_{\mathrm{ii}}{ }^{2}\right)$ moduli, which can be measured from separated fluid (f) and solid (s) ultrasound signals, respectively [Shull, 2002; Kobayashi \& Vanderby, 2007]. Recent efforts have correlated matrix content and mechanics in developing engineered cartilage constructs with positive success by applying reflective ultrasound [Rice et al., 2009]. In that work, the speed of sound (SoS) and slope of attenuation (SoA) were compared between developing cellbiomaterial constructs and nondegrading hydrogel controls from 50 and $100 \mathrm{MHz}$ ultrasound data. SoA was shown to be a better indicator of the density of accumulated matrix molecules than SoS, while SoS correlated better with mechanical modulus than SoA.

These promising data have encouraged the incorporation of ultrasound sensors as described within two recent reports characterizing a novel bioreactor design for cell and tissue engineering [Mason et al., 2011; Popp et al., 2012]. This non-destructive approach 
reduces the bench-top assessment modality to a practical tool for online, real-time evaluation of the developing analogous living system created within the bioreactor environment. As neotissue forms within the cell-seeded agarose constructs, it will be important to detect any critical changes to the mechanical properties in a nondestructive manner in order to optimize TE development. Overall, ultrasonic wave propagation offers a potential means to gather constituent content and mechanical metrics for characterizing the biokinetics of native and engineered cartilage.

\section{Section 4.09 Conclusion}

In this work, we explored the application of ultrasonic propagation velocity as a metric for comparing native cartilage explants and a hydrogel biomaterial as design specifications for ongoing cartilage tissue engineering. This approach has identified both the benefits of interfacing ultrasonic sensors with a novel bioreactor as well as the limitations of assaying hydrated materials, where the resulting wave propagation is dominated by the water content. A more refined acoustoelastic analysis will facilitate distinguishing the cell and matrix biokinetics as modeled previously. 


\section{ACKNOWLEDGMENTS}

The technical contributions from Hank Y. Chiu and Thadeous C. Bamford were greatly appreciated. Additional mentoring support provided by Dr. Randy D. Zelick (PSU), Dr. Cadance Lowell (CSU), and Dr. Sharath Krishna (CSU). Financial support was provided by a National Institutes of Health, National Center on Minority Health and Health Disparities, Exploratory Program award (Grant No. MD003350), the Collins Medical Trust, the Oregon Engineering \& Technology Industry Council, Saturday Academy Apprentices in Science \& Engineering, and the PSU Maseeh College of Engineering and Computer Science Undergraduate Research and Mentor Program.

\section{REFERENCES}

Agemura DH, O'Brien WD Jr, Olerud JE, Chun LE, Eyre DE. Ultrasonic propagation properties of articular cartilage at $100 \mathrm{MHz}$. J Acoust Soc Am. 87(4):178691, 1990.

Buckwalter JA, Mankin HJ. Articular cartilage, part I: Tissue design and chondrocyte-matrix interactions. J Bone Joint Surg Am. 79(4):600-11, 1997.

Brown CP, Hughes SW, Crawford RW, Oloyede A. Ultrasound assessment of articular cartilage: analysis of the frequency profile of reflected signals from naturally and artificially degraded samples. Connect Tissue Res. 48(6):277-85, 2007.

D'Arrigo G, Paparelli A. Sound propagation in water-ethanol mixtures at low temperatures. I. Ultrasonic velocity. J Chem Phys. 88(1):010405-11, 1988. 
Ginat DT, Hung G, Gardner TR, Konofagou EE. High-resolution ultrasound elastography of articular cartilage in vitro. Conf Proc IEEE Eng Med Biol Soc. S6644-7, 2006.

Hattori K, Takakura Y, Ohgushi H, Habata T, Uematsu K, Yamauchi J, Yamashita K, Fukuchi T, Sato M, Ikeuchi K. Quantitative ultrasound can assess the regeneration process of tissue-engineered cartilage using a complex between adherent bone marrow cells and a three-dimensional scaffold. Arthritis Res Ther. 7:R552-559, 2005.

Jurvelin JS, Buschmann MD, Hunziker EB. Optical and mechanical determination of Poisson ratio of adult bovine humeral articular cartilage. J Biomech. 3(3):235-241, 1997.

Kobayashi H, Vanderby R. Acoustoelastic analysis of reflected waves in nearly incompressible, hyper-elastic materials: forward and inverse problems. J Acoust Soc Am. 121(2):879-87, 2007.

Kohles SS, Bowers JR, Vailas AC, Vanderby R Jr. Ultrasonic wave velocity measurement in small polymeric and cortical bone specimens. J Biomech Eng. 119(3):232-6, 1997.

Kohles SS, Roberts JB. Linear poroelastic cancellous bone anisotropy: trabecular solid elastic and fluid transport properties. J Biomech Eng. 124(5):521-6, 2002.

Kohles SS, Wilson CG, Bonassar LJ. A mechanical composite spheres analysis of engineered cartilage dynamics. J Biomech Eng. 129(4):473-80, 2007. 
Korhonen RK, Julkunen P, Wilson W, Herzog W. Importance of collagen orientation and depth-dependent fixed charge densities of cartilage on mechanical behavior of chondrocytes. J Biomech Eng. 130(2):021003, 2008.

Mason SS, Kohles SS, Zelick RD, Winn SR, Saha AK. Three-Dimensional Culture of Cells and Matrix Biomolecules for Engineered Tissue Development and Biokinetics Model Validation. J Nanotechnol Eng Med. 2(2):25001-25007, 2011.

Mata A. Micro and nanotechnologies for bioengineering regenerative medicine scaffolds. International Journal of Biomedical Engineering and Technology. 5(2/3):266$291,2011$.

Morsi YS, Shi P, Li Z. Advancement of lung tissue engineering: an overview. International Journal of Biomedical Engineering and Technology. 5(2/3):195-210, 2011.

Nicodemus GD, Bryant SJ. Cell encapsulation in biodegradable hydrogels for tissue engineering applications. Tissue Eng Part B Rev. 14(2):149-65, 2008.

Nieminen HJ, Julkunen P, Töyräs J, Jurvelin JS. Ultrasound speed in articular cartilage under mechanical compression. Ultrasound Med Biol. 33(11):1755-66, 2007.

Popp JR, Roberts JJ, Gallagher DV, Anseth KS, Bryant SJ, Quinn TP. An instrumented bioreactor for mechanical stimulation and real-time, nondestructive evaluation of engineered cartilage tissue. J Med Device Design. in press, 2012.

Rice MA, Waters KR, Anseth KS. Ultrasound monitoring of cartilaginous matrix evolution in degradable PEG hydrogels. Acta Biomater. 5(1):152-61, 2009. 
Saha AK, Kohles SS. A Cell-Matrix Model of Anabolic and Catabolic Dynamics During Cartilage Biomolecule Regulation. International Journal of Computers in Healthcare, 2(1): 2012.

Shieh AC, Athanasiou KA. Biomechanics of single zonal chondrocytes. J Biomech. 39(9):1595-602, 2006.

Shull PJ (ed). Nondestructive Evaluation: Theory, techniques and applications. Marcel Dekker Inc., New York, 2002.

Singh M, Singh HR, Kumar A, Singh VR, Pant K, Sethi P. Development of tissueequivalent phantoms for biomedical ultrasonic applications. International Journal of Biomedical Engineering and Technology. 1(3): 273-286, 2008.

Waldman SD, Spiteri CG, Grynpas MD, Pilliar RM, Kandel RA. Long-term intermittent compressive stimulation improves the compression and mechanical properties of tissue-engineered cartilage. Tissue Eng. 10(9-10):1323-1331, 2004.

Walker JM, Myers AM, Schluchter MD, Goldberg VM, Caplan AI, Berilla JA, Mansour JM, Welter JF. Nondestructive evaluation of hydrogel mechanical properties using ultrasound. Ann Biomed Eng. 39(10):2521-2530, 201. 


\title{
Chapter V. EXTRAHEPATIC 25-HYDROXYLATION OF VITAMIN D 3 IN AN ENGINEERED OSTEOBLAST PRECURSOR CELL LINE EXPLORING THE INFLUENCE ON CELLULAR PROLIFERATION AND MATRIX MATURATION DURING BONE DEVELOPMENT
}

\author{
Shelley S. Mason ${ }^{1}$ \\ Sean S. Kohles ${ }^{1, *}$ \\ Shelley R. Winn ${ }^{2}$ \\ Randy D. Zelick ${ }^{1}$ \\ Regenerative Bioengineering Laboratory, \\ ${ }^{1}$ Department of Biology, \\ and \\ ${ }^{2}$ Department of Molecular and Medical Genetics, \\ Oregon Health \& Science University, Portland, Oregon, USA 97239.
}

Portland State University, P.O. Box 751, Portland, Oregon, USA 97207-0751; 


\section{Section 5.01 Preface}

This chapter contains material from a manuscript that was submitted to: International Scholarly Research Network (ISRN) Biomedical Engineering as a Research Paper (MS \# 956362) in March 2013. The final version was published In May 2013. The work presented here was the $1^{\text {st }}$ part of a two-series experiment on the influence of extraendocrine vitaD $\mathrm{D}_{3}$ metabolism on the in vitro temporal bone development sequence.

\section{Section 5.02 Authors Contribution}

The work presented here was carried out in collaboration between all authors. SSM, SSK, SRW, and RDZ defined the research theme. SSM designed the biological methods and experiments, while SSK designed the mathematical modeling. SSM carried out the laboratory experiments, analyzed the data, interpreted the results and wrote the paper. SSK co-worked on associated data collection and their interpretation. SRW codesigned the biological experiments. All authors have contributed to, seen and approved the manuscript.

\section{Section 5.03 Hypothesis}

The overall goal of these experiments was to demonstrate the extrahepatic metabolism of parental vitaD $\mathrm{D}_{3}$ precursor to the active vitamin $\mathrm{D}$ metabolite $1,25 \mathrm{OH} 2 \mathrm{D} 3$ by osteoblast precursor cells in a dose-dependent manner. The global hypothesis was that the conversion of vitaD 3 to $1,25 \mathrm{OH}_{2} \mathrm{D}_{3}$ would lead to an increase in alkaline phosphatase (ALP) activity associated with osteoblast ECM maturation and an increase ECM mineralization indicated by calcium deposition detected by alizarin red stain (ARS). 


\section{Section 5.04 Abstract}

Osteoblastic precursors experience distinct stages during differentiation and bone development, which include proliferation, extracellular matrix (ECM) maturation, and ECM mineralization. It is well known that vitamin D plays a large role in the regulation of bone mineralization and homeostasis via the endocrine system. The activation of vitamin D requires two sequential hydroxylation steps, first in the kidney and then in the liver, in order to carry out its role in calcium homeostasis. Recent research has demonstrated that human-derived mesenchymal stem cells (MSCs) and osteoblasts can metabolize the immediate vitamin $\mathrm{D}$ precursor 25-dihydroxyvitamin $\mathrm{D}_{3}\left(25 \mathrm{OHD}_{3}\right)$ to the

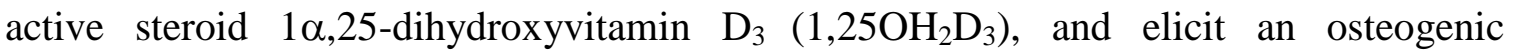
response. However, reports of extrahepatic metabolism of vitamin $\mathrm{D}_{3}\left(\operatorname{vitaD_{3}}\right)$, the parental vitamin D precursor, have been limited. In this study, we investigated whether osteoblast precursors have the capacity to convert vitaD $\mathrm{D}_{3}$ to $1,25 \mathrm{OH}_{2} \mathrm{D}_{3}$ and examined the potential of vitaD 3 to induce $1,25 \mathrm{OH}_{2} \mathrm{D}_{3}$ associated biological activities in osteoblast precursors. It was demonstrated that the engineered osteoblast precursor derived from human marrow (OPC1) is capable of metabolizing vitamin $\mathrm{D}_{3}$ to $1,25 \mathrm{OH}_{2} \mathrm{D}_{3}$ in a dosedependent manner. It was also demonstrated that administration of vitaD $\mathrm{D}_{3}$ leads to the increase in alkaline phosphatase (ALP) activity associated with osteoblast ECM maturation and calcium deposits, and a decrease in cellular proliferation in both osteoblast precursor cell lines OPC1 and MC3T3-E1. These findings provide a two- 
dimensional culture foundation for future three-dimensional engineered tissue studies using the OPC1 cell line.

\section{Section 5.05 Introduction}

An osteoblastic precursor cell line (OPC1), derived from human fetal bone tissue, was originally established to provide a consistent and reproducible culture system for evaluating bone development, cell/biomaterial interactions, and screening putative bone differentiating factors (Winn et al., 1999). In addition, OPC1 can be used to study the growth and differentiation of osteoprogenitors and offers the possibility of examining events associated with stem cell differentiation to osteoblasts. Proliferation and differentiation of osteoblasts is regulated by their respective microenvironment, which encompasses cells, growth factors and cytokines, and their extracellular matrix (ECM) [Atanga et al., 2011]. Osteoblasts are a main target for calcitropic hormones including vitamin D [Biswas \& Zanello, 2009].

Several studies have demonstrated changes in bone devlopment in response to the steroid hormone vitamin D, especially with regard to the inhibition of growth during the proliferation stage and the stimulation of osteogenic differentiation during the maturation and mineralization stages, albeit the outcomes appear to be variable and dependent upon the stage of cellular maturation or differentiation at the time of hormone responsivness [Pockwinse et al., 1995; Lian \& Stein, 1995]. Because OPC1 is a stable osteoblast precursor that has displayed consistent reproducible cultures, it is an ideal culture system to study the effects of vitamin D on bone development, and elucidate the extraendocrine metabolism of vitamin D in osteoblasts. 
Vitamin D, also known as calciferol, refers to a collective group of fat-soluble pluripotent, seco-steroid metabolites that together carry out the known vitamin D-related functions. The classic understanding of vitamin $\mathrm{D}$ is the essential role it plays in the regulation and maintenance of calcium and phosphorous homeostasis and bone metabolism. Elucidating the steps required for the metabolism of vitamin D precursors, vitamin $\mathrm{D}_{3}$ (cholecalciferol) and 25-hydroxyvitamin $\mathrm{D}_{3}\left(25 \mathrm{OHD}_{3}\right.$; calcidiol), to the active hormone $1 \alpha, 25$-dihydroxyvitamin $\mathrm{D}_{3}\left(1,25 \mathrm{OH}_{2} \mathrm{D}_{3}\right.$; calcitriol $)$ led to the discovery of regulatory cytochrome P-450 (CYP-related hydroxylases) involved in the activation and inactivation of vitamin $\mathrm{D}$, and the nuclear vitamin $\mathrm{D}$ receptor (VDR) and its interactions with transcriptional machinery inside vitamin D target cells [Jones, Strugnel, \& DeLuca, 1998]. $1,25 \mathrm{OH}_{2} \mathrm{D}_{3}$ directly influences osteoblast binding to the VDR, which consequently elicits nuclear and extra-nuclear cellular responses related to the production and maintenance of the skeleton [Biswas \& Zanello, 2009]. Once it was demonstrated that VDR and vitamin D regulatory CYPs were present in multiple tissues and cells not involved in the classic endocrine actions of vitamin $\mathrm{D}$, it was acknowledged that its functions extended far beyond mineral homeostasis and bone metabolism. It is now recognized that vitamin $\mathrm{D}$ is associated with the regulation of many cellular process including proliferation, differentiation, and apoptosis in multiple tissues in a paracrine/autocrine manner [Brannon, 2012; Hobaus et al., 2013; Jones et al., 1998].

Vitamin $\mathrm{D}$, in the form of vitamin $\mathrm{D}_{3}$, is endogenously made from cholesterol in the skin when it is exposed to ultra-violet light (UVB). Alternatively vitamin D can be acquired by diet in either the vita $\mathrm{D}_{3}$ (derived from animals) or vitamin $\mathrm{D}_{2}$ (derived from 
plants) form. There are many metabolites or isomers of vitamin D. The active metabolite $1,25 \mathrm{OH}_{2} \mathrm{D}_{3}$ and the immediate metabolic precursor to the active metabolite, $25 \mathrm{OHD}_{3}$, are among the most studied. Vitamin $\mathrm{D}_{3}$, the metabolic precursor to $25 \mathrm{OHD}_{3}$, itself is biologically inert, or inactive, in that it does not directly increase the active transport of calcium or mediate any of the other vitamin D-related activities in physiological concentrations unless it its metabolized to a more polar compound [Kumar, 1990].

In the classic endocrine metabolic pathway of vitamin $\mathrm{D}$, both endogenous and dietary vitamin $D_{3}$ undergoes sequential steps of activation by being hydroxylated in the liver to $25 \mathrm{OHD}_{3}$ by CYP-related 25-hydroxylase (CYP27A1) and then to $1,25 \mathrm{OH}_{2} \mathrm{D}_{3}$ by 25-hydroxyvitaminD 3 -1 $\alpha$-hydroxylase (CYP27B1) in the kidneys (Ahmed \& Shoker 2010; Norman, 1998; Jones et al. 1998). While early data suggested that the liver is the only significant site of 25-hydroxylation in vivo, there have been occasional reports of extrahepatic 25-hydroxylation of vitamin $\mathrm{D}_{3}$ (Jones et al., 1998; Hollick, 2010). Recently extrarenal metabolism of $25 \mathrm{OHD}_{3}$ to $1,25 \mathrm{OH}_{2} \mathrm{D}_{3}$ has been demonstrated definitively (Zhou et al., 2012; Hobaus et al., 2013). In vitro, many non-renal cells, including mesenchymal stem cells (MSCs), bone, cartilage, keratinocytes, placenta, prostrate, macrophages, lymphocytes, dendritic cells, and several cancer cell lines can convert $25 \mathrm{OHD}_{3}$ to $1,25 \mathrm{OH}_{2} \mathrm{D}_{3}$ (Zhou et al., 2012). Several of these cell types have been shown to express both CYP27 hydroxylase enzymes required for the activation of vitamin $\mathrm{D}_{3}$, which may explain the occasional reports of extrahepatic 25-hydroxylation of vitamin $\mathrm{D}_{3}$ [Lehman, 2008; Hollick, 2010; Jones et al.,1998]. 
The molecular effects of vitamin $\mathrm{D}$ are mediated through the intra-nuclear receptor VDR, which acts as a ligand-activated transcription factor for target genes when bound to $1,25 \mathrm{OH}_{2} \mathrm{D}_{3}$ [Seiffert et al., 2004]. $1,25 \mathrm{OH}_{2} \mathrm{D}_{3}$ has a high affinity for VDR and upon binding forms a heterodimer with the retinoid $\mathrm{X}$ receptor, which allows it to bind to the response/receptor element (VDRE) in the promoter regions of target genes [Flanagan et al., 2006; Brannon, 2012; Geng et al., 2011]. The genes include those associated with calcium homeostasis, immune response and maintenance of immune cells, cellular growth, differentiation, cell cycle arrest, apoptosis, and the enzymes required for their own metabolism [Chen et al., 2011; Flanagan et al., 2006; Boyan et al., 2009; Geng et al., 2011]. $1,25 \mathrm{OH}_{2} \mathrm{D}_{3}$ influences many aspects of bone cell biology, and has been implicated in the regulation of both osteoblastic and osteoclastic activity affecting both resorptive and synthetic phases of bone remodeling [Atkins, et al., 2007]. In addition, $1,25 \mathrm{OH}_{2} \mathrm{D}_{3}$ has been demonstrated to regulate osteoblast and chondrocyte gene transcription, proliferation, differentiation, and mineralization of ECM [Boyan et al., 2009; Atkins et al., 2007]. More than 30 tissues are known to have nuclear receptors for $1,25 \mathrm{OH}_{2} \mathrm{D}_{3}$, and it is known to regulate the function of more than 200 genes [Flanagan et al., 2006; Hollick, 2010; Norman, 1998; Naeem, 2010]. Because of its role in proliferation and differentiation, it has been hypothesized that the local production of $1,25 \mathrm{OH}_{2} \mathrm{D}_{3}$ in extrarenal tissues serves to regulate growth and differentiation in an autocrine/paracrine fashion [Atkins et al., 2007; Lehmann \& Meurer, 2003].

Despite the increase in research over the last few decades, further investigation on vitamin D metabolism and regulation needs to be carried out in order to elucidate extra- 
endocrine metabolism and local production of $1,25 \mathrm{OH}_{2} \mathrm{D}_{3}$. While there has been an increase in the reports of extrarenal $1,25 \mathrm{OH}_{2} \mathrm{D}_{3}$ synthesis and occasional reports of extrahepatic 25 -hydroxylation of vitamin $\mathrm{D}_{3}$, to our knowledge, there is no detailed analysis of extrahepatic vitamin $\mathrm{D}_{3}$ metabolism in osteoblast precursors. Furthermore, paracrine/autocrine regulation and gene expression that results in local changes in proliferation and differentiation need to be further investigated to understand the potential application of vitamin D for regenerative medicine. In this study, we investigated whether osteoblast precursors have the capacity to convert the parental vitamin D precursor, vitamin $\mathrm{D}_{3}$, to $1,25 \mathrm{OH}_{2} \mathrm{D}_{3}$ and examined the potential of vitamin $\mathrm{D}_{3}$ to induce $1,25 \mathrm{OH}_{2} \mathrm{D}_{3}$ associated biological activities in osteoblast precursors.

\section{Section 5.06 Materials and Methods}

\section{(i) OPC-1 and MC3T3-E1 Cell Cultures}

Vitamin $\mathrm{D}_{3}$ (cholecalciferol) and $1,25 \mathrm{OH}_{2} \mathrm{D}_{3}$ (calcitriol) were purchased and maintained in $10 \mathrm{mM}$ and $10 \mu \mathrm{M}$ stock solutions in ethanol, respectively (SigmaAldrich, St. Louis, MO). All other reagents and chemicals were purchased from the same vendor unless otherwise indicated. Original OPC1 and MC3T3-E1 cell lines were cultured on-site (Department of Molecular \& Medical Genetics, Oregon Health \& Science University, Portland, OR). Cells were cultured at populations of $2.5 \times 10^{5}$ in $75 \mathrm{~cm}^{2}$ tissue culture flasks in alpha modified essential medium ( $\alpha$-MEM) with 5\% fetal bovine serum (FBS). Once confluent, OPCs 
were plated in 12-well plates after trypsin-ethylenediaminetetraacetic acid (EDTA) enzymatic removal and counted with $0.4 \%$ trypan blue (1:1) on a hemacytometer. Cultures were then prepared in duplicate at a seeding density of $2.5 \times 10^{4}$ cells/well in the initial bone medium (designated as BM-) with $200 \mathrm{mM}$ L-Glutamine and antibiotics for at least 4 hours before creating experimental groups based on additive culture medium. Six types of medium-based groups were prepared. BM- provided a negative control (Group 1) and the additional groups included: BM- supplemented with $1 \mu \mathrm{M}$ vitamin $\mathrm{D}_{3}$ (Group 2); BMsupplemented with $10 \mathrm{nM} 1,25 \mathrm{OH}_{2} \mathrm{D}_{3}$ (Group 3); BM- supplemented with osteogenic factors $(\mathrm{BM}+)$ comprised of $10 \mathrm{mM} \beta$-glycerophosphate, $10 \mathrm{nM}$ dexamethasone, and $50 \mu \mathrm{g} / \mathrm{ml}$ of ascorbic acid phosphate (Wako Chemical, Osaka, Japan) represented the positive control (Group 4); BM+ supplemented with $1 \mu \mathrm{M}$ vitaD 3 (Group 5); and $\mathrm{BM}+$ supplemented with $10 \mathrm{nM} 1,25 \mathrm{OH}_{2} \mathrm{D}_{3}$ (Group 6). Fresh medium was added every 1 to 3 days.

\section{(ii) Cell Proliferation}

OPC1 and MC3T3-E1 cell lines were evaluated for growth kinetics while maintained in the presence of vitamin $\mathrm{D}$ metabolites, vitaD $\mathrm{D}_{3}$ and $1,25 \mathrm{OH}_{2} \mathrm{D}_{3}$, with $(\mathrm{BM}+)$ or without (BM-) osteogenic factors, at the indicated experimental group concentrations. Each sample set was cultured for at least two weeks in duplicate or quadruplicate. Every 2 to 5 days, following the addition of experimental media and at the end of each incubation period, cell proliferation was measured using 
crystal violet solution (CVS, Sigma-Aldrich). Cultures were rinsed with Dulbecco's phosphate buffered saline (DPBS) and fixed for 15 minutes in $95 \%$ ethanol. The fixed cells were rinsed several times with distilled water, and stained for 10 minutes with CVS. The CVS was then extracted from the cells after a $4 \mathrm{~h}$ incubation in $1 \%$ Triton $\mathrm{X}-100$ at room temperature. The samples were then stored at $-80^{\circ} \mathrm{C}$ until the end of each experimental period. Triton extracts were measured at $570 \mathrm{~nm}$ on a microplate reader (Cary 50, Varian Australia Pty. Ltd). Absorbance values were converted into cell numbers extrapolated from standard growth curves.

\section{(iii) Alkaline Phosphatase}

As described above, OPC-1 and MC3T3-E1 were treated with both vitaD $\mathrm{D}_{3}$ and $1,25 \mathrm{OH}_{2} \mathrm{D}_{3}$ in the $\mathrm{BM}$ - and $\mathrm{BM}+$ experimental groups. Alkaline phosphatase (ALP) activity was measured every 3 to 4 days. At the end of the incubation, the cell layers were washed three times with DPBS, scraped off of the plates with 500 $\mu \mathrm{DPBS}$ and stored at $-80^{\circ} \mathrm{C}$ until the end of each experimental period (2 to 3 weeks). Each sample was subjected to three freeze-thaw cycles in order to lyse the cells. ALP activity in the cell lysates was measured using $\rho$-nitrophenyl phosphate liquid substrate system at $37^{\circ} \mathrm{C}$ for 30 minutes. Protein content was measured using a micro-volume spectrophometer system (Epoch, Biotek, Winooski, VT). 


\section{(iv) Matrix Mineralization}

A histochemical analysis of mineralization was evaluated utilizing an Alizarin Red S (ARS) assay. ARS staining is used to evaluate calcium-rich deposits by cells in culture, and is considered a functional in vitro endpoint reflecting advanced cell differentiation (Hoemann et al. 2009). In brief, after 10 to 15 days in culture, cells were fixed in $95 \%$ ethanol for 15 minutes, then rinsed thoroughly with distilled water and stained with $40 \mathrm{mM}$ of $\mathrm{ARS}(\mathrm{pH}=4.1)$ at room temperature for $20 \mathrm{~min}$ with gentle shaking. The cell layers were efficiently rinsed with distilled water and observed both grossly and microscopically. For semiquantification, ARS was extracted from the cells after incubating for one hour in at room temperature in $10 \%$ volume to volume (v/v) acetic acid with gentle shaking, and then the residual dye was further extracted by scraping the cells and heating at $85^{\circ} \mathrm{C}$ on a heating block with a layer of mineral oil to prevent evaporation. The samples were neutralized with $10 \%(\mathrm{v} / \mathrm{v})$ ammonium hydroxide and the extracts were read at a resolution of $405 \mathrm{~nm}$ on the microplate-reader. The samples were compared to a serially diluted ARS standard. The resulting data were normalized using cell numbers extrapolated from the CVS proliferation data.

\section{(v) Vitamin $D_{3}$ Metabolism}

Vitamin D metabolism by OPC1 was performed in a dose-dependent manner over a 24-hour period. The conversion of $1,25 \mathrm{OH}_{2} \mathrm{D}_{3}$ from vitamin $\mathrm{D}$ was quantitatively measured using an enzyme-linked immuno sorbent assay (ELISA) 
kit (Human1,25-dihydroxyvitamin $\mathrm{D}_{3}$ DVD/DHVD3, NB-E10878, Novatein Biosciences, Cambridge, MA). OPC-1 was plated in 6-well plates at a seeding density of $10^{5}$ cells/well. Upon confluency, experimental media was added in duplicates when creating experimental groups slightly modified from those described in Section 2.1: base medium (BM-) provided a negative control (Group

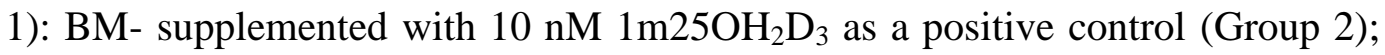
BM- supplemented with $10 \mathrm{nM}$ vitaD ${ }_{3}$ (Group 3); BM- supplemented with $1 \mu \mathrm{M}$ vitaD $\mathrm{D}_{3}$ (Group 4); and $\mathrm{BM}$ - supplemented with $10 \mu \mathrm{M}$ vitamin $\mathrm{D}_{3}$ (Group 5). The assay was carried out via manufacturer's protocol.

\section{(vi) Statistical Analysis and Mathematical Modeling}

Statistical analyses were carried out using commercial software (Prism, Irvine, CA; JMP Pro v10, SAS Concepts, Inc., Cary, NC; Excel, Microsoft, Redmond, WA). Data were expressed as means \pm standard error of the mean (SEM) of samples characterized in three two-week sample sets plated in duplicate or quadruplicate, and assayed in duplicate ( $\mathrm{n}=12$ or $\mathrm{n}=24$, respectively). One-way and two-way analysis of variance (ANOVA) and linear regression statistically assessed the culture treatments through time and between experimental groups, with asterisks of $* p<0.05, * * p<0.01$ and $* * * p<0.001$ indicating varying levels of statistical significance. Bonferonni Post-test (direct comparisons with controls) and Dunnett's Test (pairwise comparisons) were applied where appropriate. Through the ELISA assay protocol for examining the dose-response of the 
metabolized form of vitamin $\mathrm{D}$, the input dosage levels (x-values) were controlled and distributed at logarithmic concentration levels (in units of ng/ml). A log-base10 model was applied to the resulting response data ( $\mathrm{y}$-values in $\mathrm{pmol} / \mathrm{mg}$ protein) in the form:

$\mathrm{y}=\mathrm{m} \log 10 \mathrm{x}$

Here, the coefficient $(\mathrm{m})$ was identified as a fitting parameter optimizing the model's representation of the collected data. The model was applied to the metabolized vitamin D concentration data. Least squares estimates were constructed for the log-coefficient via a quasi-Newton convergence method with commercially available software (Solver, Frontline Systems, Inc., Incline Village, NV; Excel, Microsoft, Redmond, WA). The model fit was again determined by minimizing the root mean square error (RMSE) between the actual and response concentrations. The correlation coefficient $\left(\mathrm{R}^{2}\right)$ further assayed the strength of the modeled relationship.

\section{(vii) Microscopic Imaging}

Microscopic images were taken using an advanced transmitted light inverted microscope (EVOS-XL) and accompanying software (EVOS3), both commercially available (Advanced Microscopy Group, Bothell, WA). Images were processed using an open source, image-processing package (FIJI, ImageJ 
v1.47d, National Institutes of Health, Bethesda, MD). To maintain consistency, each image was processed in the same manner including maintaining consistent light intensities during optical density measurements. The operations included the background subtraction command, mean filter, and local contrast (CLAHE commands: blocksize 100 , bin 256 , and maximum slope 2.50 , respectively). 


\section{Section 5.07 Results}

\section{(i) ALP Activity and Early Matrix Mineralization}

As described, in order to determine the optimal dose of vitaD $\mathrm{D}_{3}$, OPC1 and MC3T3-E1 cells were cultured at a seeding density of $5.0 \times 10^{4}$ in quadruplicates with 1 or $10 \mu \mathrm{M}$ vitaD $_{3}$ in standard bone medium (BM-), or in a BM- vehicle control containing the equivalent amount of ethanol for 10 days in 12-well plates. After 10 days, two wells from each group were prepared for ALP assay, and two wells were stained with ARS to assess ECM calcium deposition. [the previous sentences are Methods, and should be moved to that section] OPC1 treated with vitamin $\mathrm{D}_{3}$ at concentrations of 1 or $10 \mu \mathrm{M}$ had a statistically significant $(p<$ 0.001) increase in ALP activity compared to that of the control (Figure 5-1). There was no statistically significant difference $(p>0.05)$ between experimental groups containing either $1 \mu \mathrm{M}$ or $10 \mu \mathrm{M}$ vitamin $\mathrm{D}_{3}$. There was also no statistically significant difference $(p=0.2388)$ in ALP activity between MC3T3E1 treated with either $1 \mu \mathrm{M}$ or $10 \mu \mathrm{M}$ vitamin $\mathrm{D}_{3}$ compared to that of the control, however in the wells treated with $10 \mu \mathrm{M}$ vitamin $\mathrm{D}_{3}$ we observed a variable affect on ALP activity and an adverse affect on cell viability (not shown), which was observed microscopically throughout the experiment (Figures 2 and 3). There was not a significant increase in calcium deposition in ECM in either cell lines compared to the ethanol vehicle control $(p>0.05)$. 


\section{Influence of Vitamin D3 Concentration of Alkaline Phosphatase Activity (ALP)}

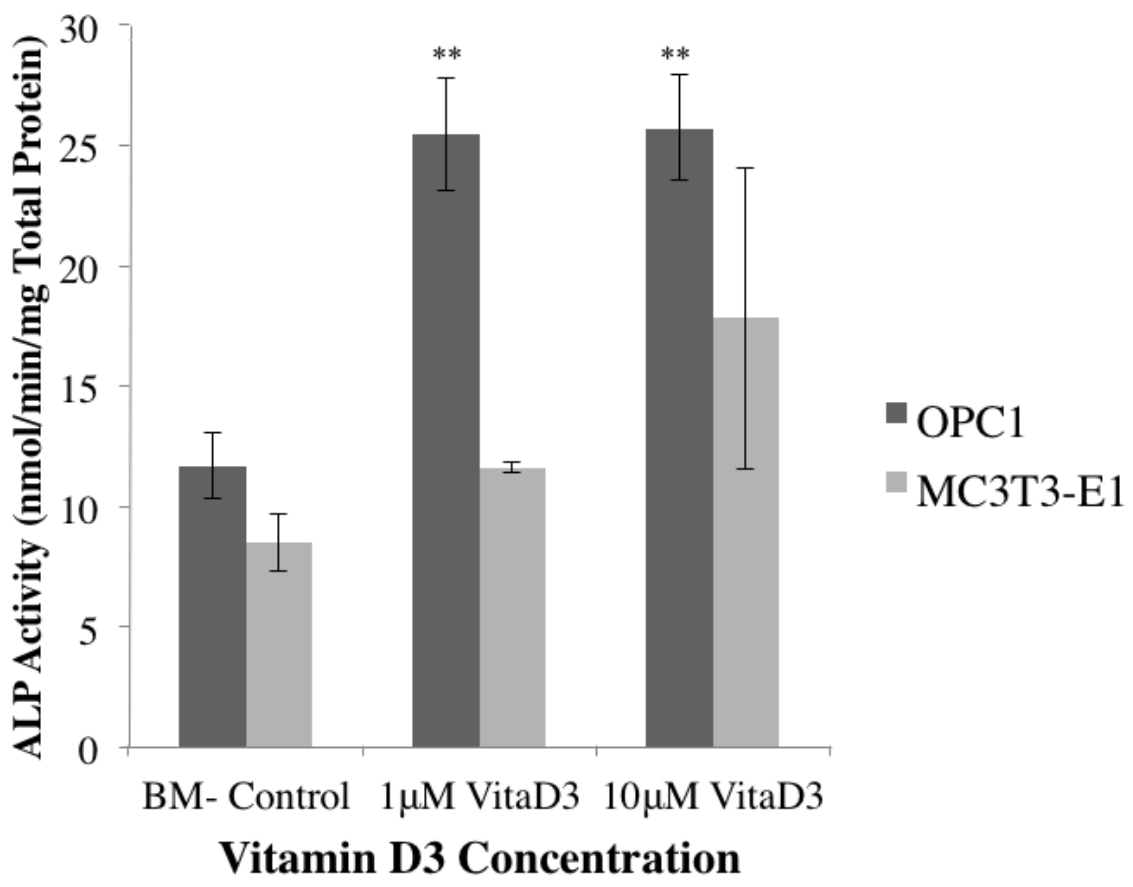

Figure 5-1. Alkaline phosphatase activity (ALP) of osteoblast precursor OPC1 and MC3T3-E1 after 10 days in culture after being treated with or without vitaD ${ }_{3}(\mathrm{BM}-$ Control). After 10 days there was not a significant effect $(p=0.2166)$ on ALP activity between treatment with either $1 \mu \mathrm{M}$ or $10 \mu \mathrm{M}$ vitaD $\mathrm{D}_{3}$, however there was an overall statically significant increase $(p=0.0026)$ in ALP activity between vitaD $\mathrm{D}_{3}$ treated cultures and controls. 


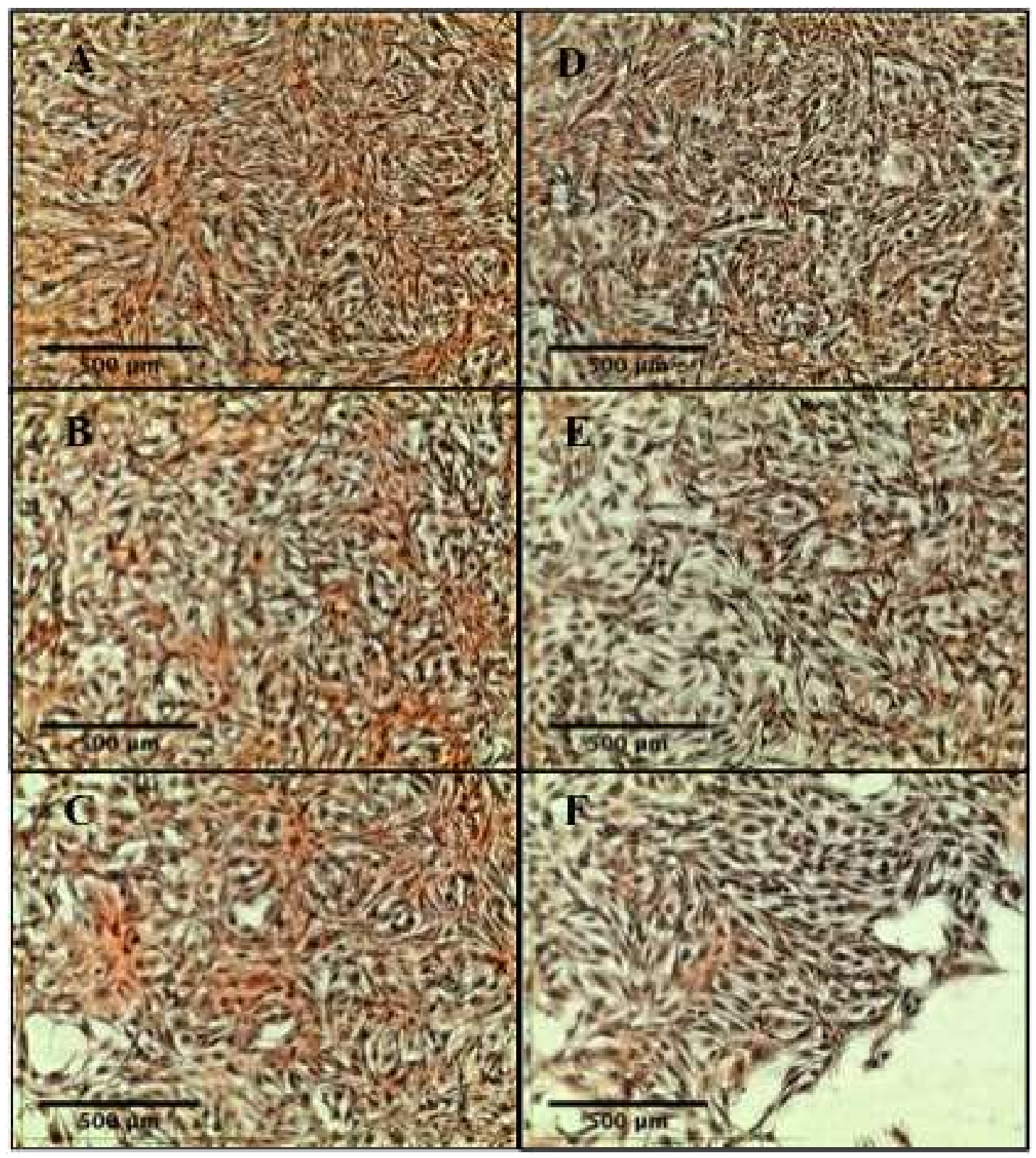

Figure 5-2. Osteoblast precursor cell lines OPC1 (A-C) and MC3T3-E1 (D-F) stained with ARS after 10 days in culture. OPC1 without treatment of vitamin $\mathrm{D}_{3}$ (ethanol control) (A) did not absorb a statistically significant amount of ARS per cell population (see Figure 3), than with treatment of either $1 \mu \mathrm{M}$ vitamin $\mathrm{D}_{3}(\mathrm{~B})$ or $10 \mu \mathrm{M}$ vitamin $\mathrm{D}_{3}(\mathrm{C})$. Similar results were seen with MC3T3-E1 without vitamin $\mathrm{D}_{3}$ (ethanol control) (D), $1 \mu \mathrm{M}$ vitamin $\mathrm{D}_{3}(\mathrm{E})$, and $10-\mu \mathrm{M}$ vitamin $\mathrm{D}_{3}(\mathrm{~F})$. 


\section{Influence of Vitamin D3 Concentration on ECM Mineralization}

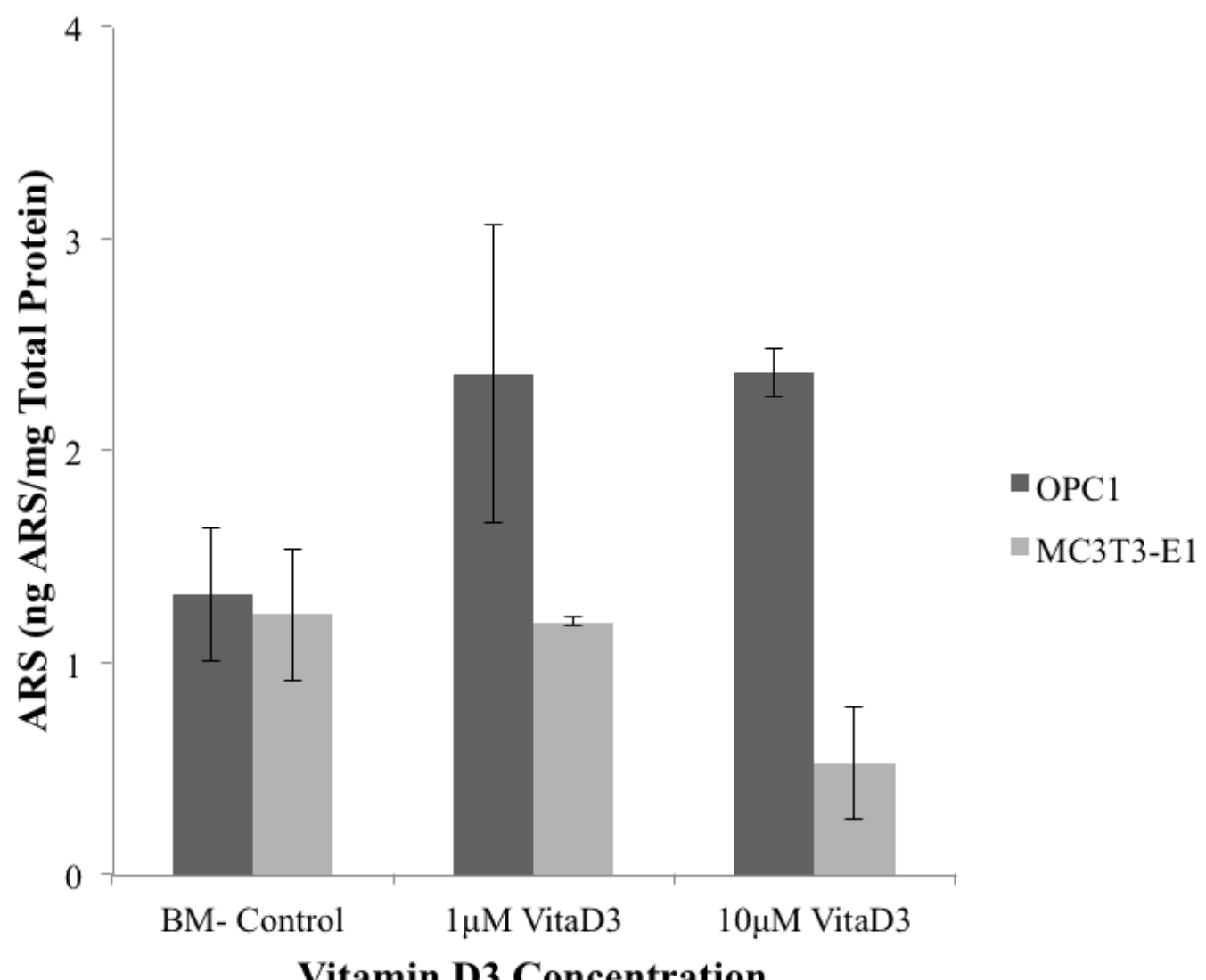

Figure 5-3. Semi-quantification of matrix mineralization was conducted by taking the optical density (resolution, $450 \mathrm{~nm}$ ) of the ARS extracted from each treatment group (shown in Figure 2). Vitamin $\mathrm{D}_{3}$ at both $1 \mu \mathrm{M}$ and $10 \mu \mathrm{M}$ did not have a statistically significant effect on the ECM mineralization of OPC1 $(p=0.2881)$ or MC3T3-E1 $(p=$ 0.1101 ) after 10 days, compared to the control group. 


\section{(ii) Influence of Vitamin $D_{3}$ and $1,25 \mathrm{OH}_{2} D_{3}$ on Osteoprecursors}

(a) Antiproliferative Effects

As described, OPC1 and MC3T3-E1 were cultured for two weeks with either $10-\mu \mathrm{M}$ vitaD $\mathrm{D}_{3}$ or $10 \mathrm{nM} 1,25 \mathrm{OH}_{2} \mathrm{D}_{3}$ with $(\mathrm{BM}+)$ or without osteogenic factors (BM-), and then compared to BM- and $\mathrm{BM}+$ ethanol vehicle controls. Proliferation kinetics was quantitatively compared after conducting a CVS assay as a function of time. The CVS proliferation assay indicated a statistically significant inhibition of cell proliferation in OPC1 treated with $10 \mu \mathrm{M}$ vitaD ${ }_{3}$ in the same manner as cells treated with $10 \mathrm{nM} 1,25 \mathrm{OH}_{2} \mathrm{D}_{3}$, compared to that of the $\mathrm{BM}-$ and $\mathrm{BM}+$ ethanol controls (shown as absolute cell populations and percentages in Figures 5-4 and 5-5, respectively). Groups containing BM+ overall, had lower proliferation rates than with BM- groups, however groups treated with $\mathrm{BM}+$ containing either vitaD $\mathrm{D}_{3}$ or $1,25 \mathrm{OH}_{2} \mathrm{D}_{3}$ were significantly lower then the BM- groups. Growth kinetics of MC3T3-E1 cultured with BM+ and $10 \mu \mathrm{M}$ vitaD $\mathrm{D}_{3}$ was indistinguishable from cells cultured in $\mathrm{BM}+$ containing $10 \mathrm{nM}$ $1,25 \mathrm{OH}_{2} \mathrm{D}_{3}$ (shown as absolute cell populations and percentages in Figures 6 and 7, respectively). 


\section{Influence of Vitamin $\mathrm{D}_{3}$ and $1,25 \mathrm{OH}_{2} \mathrm{D}_{3}$ on OPC1 Proliferation}

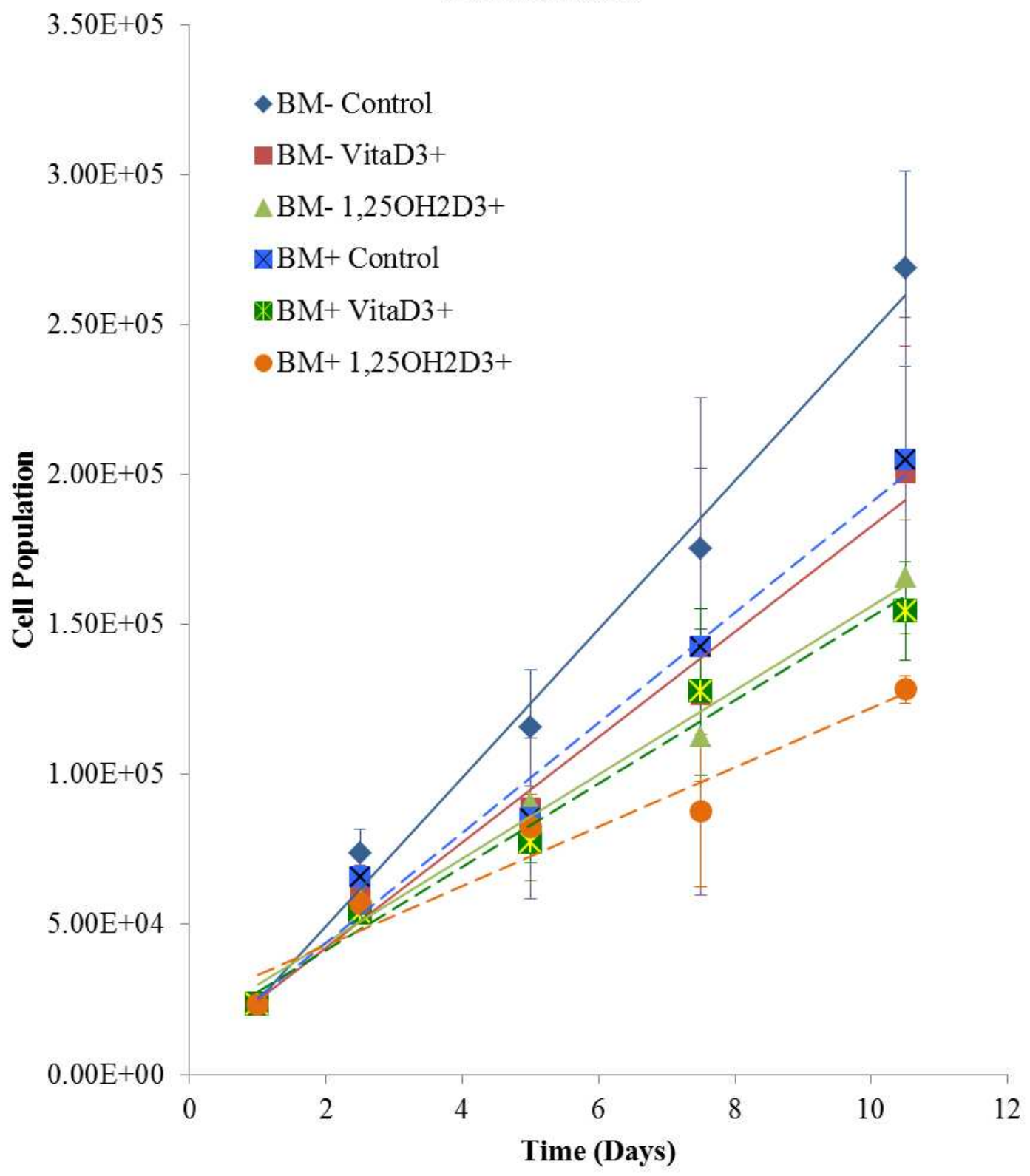

Figure 5-4. Absolute proliferation of OPC1 cells maintained in six types of tissue culture medium over three two-week periods $(\mathrm{n}=24)$. At day 5 , the OPC1 cell counts in the wells containing vitamin $\mathrm{D}$ metabolites \pm osteogenic factors $(\mathrm{BM}+)$ were statistically lower then than the negative control (BM-). OPC1 treated with $\mathrm{BM}+$ and $1,25 \mathrm{OH}_{2} \mathrm{D}_{3}$ experienced the largest statistically $(\mathrm{p}<0.001)$ anti-proliferative effect. The effect of vitamin $\mathrm{D}_{3}$ was similar to $1.25 \mathrm{OH}_{2} \mathrm{D}_{2}$ in both groups of medium. 


\section{Influence of Vitamin $\mathrm{D}_{3}$ and $1,25 \mathrm{OH}_{2} \mathrm{D}_{3}$ on OPC1 Proliferation}

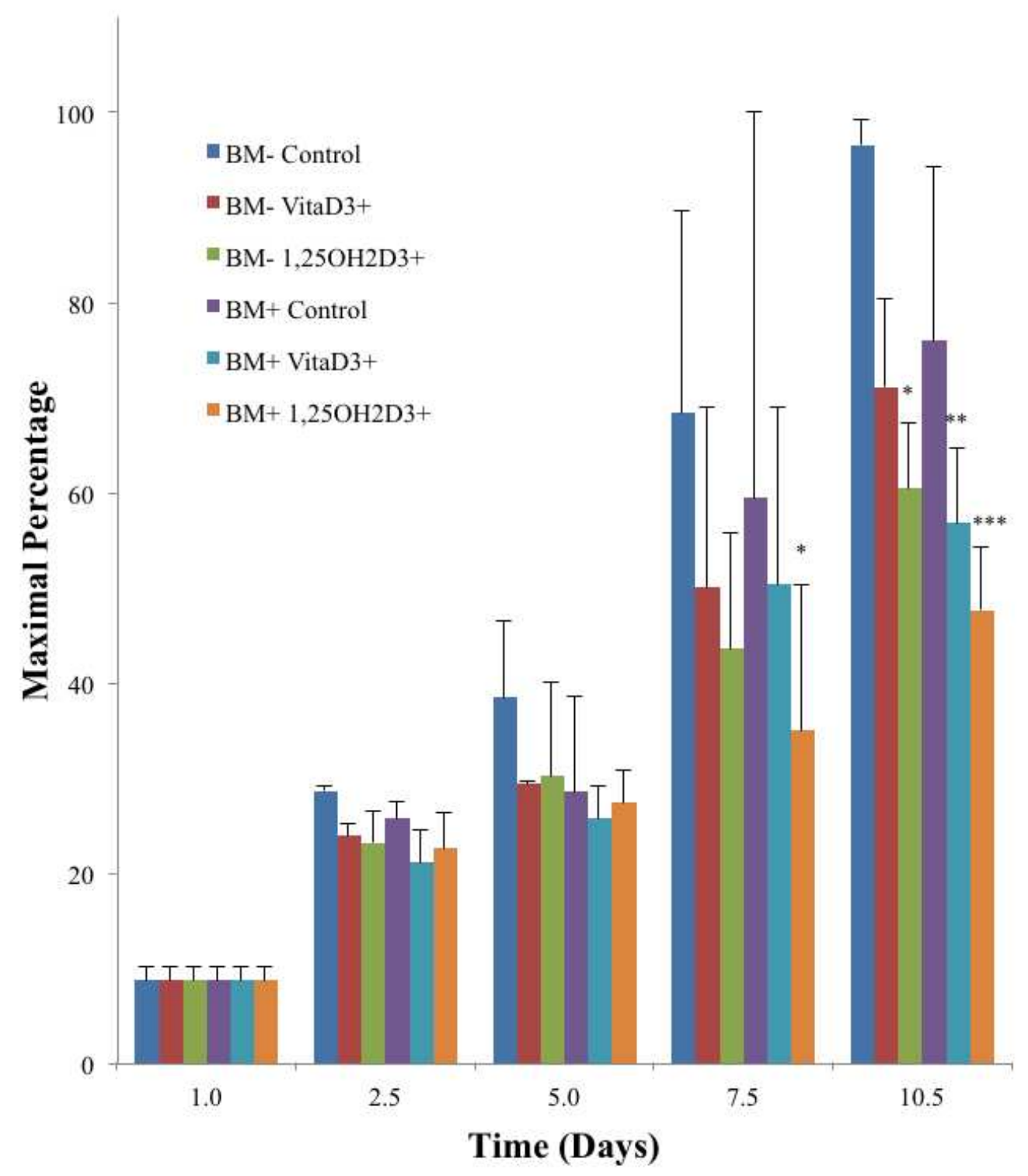

Figure 5-5. Percent proliferation of OPC1 cells maintained in six types of tissue culture medium over three two-week periods $(n=24)$. By 7 to 10 days, the OPC1 cell counts in the wells containing vitamin $\mathrm{D}$ metabolites \pm osteogenic factors $(\mathrm{BM}+)$ were statistically lower then than the negative control (BM-). By day $10, \mathrm{OPC} 1$ treated with $\mathrm{BM}+$ and active $1,25 \mathrm{OH}_{2} \mathrm{D}_{3}$ remained around $50 \%$ of the BM- cellular confluency. In both BM- and BM+ groups, vitamin $\mathrm{D}_{3}$ treated cells proliferated in a manner very similar to those treated with $1,25 \mathrm{OH}_{2} \mathrm{D}_{3}$. 


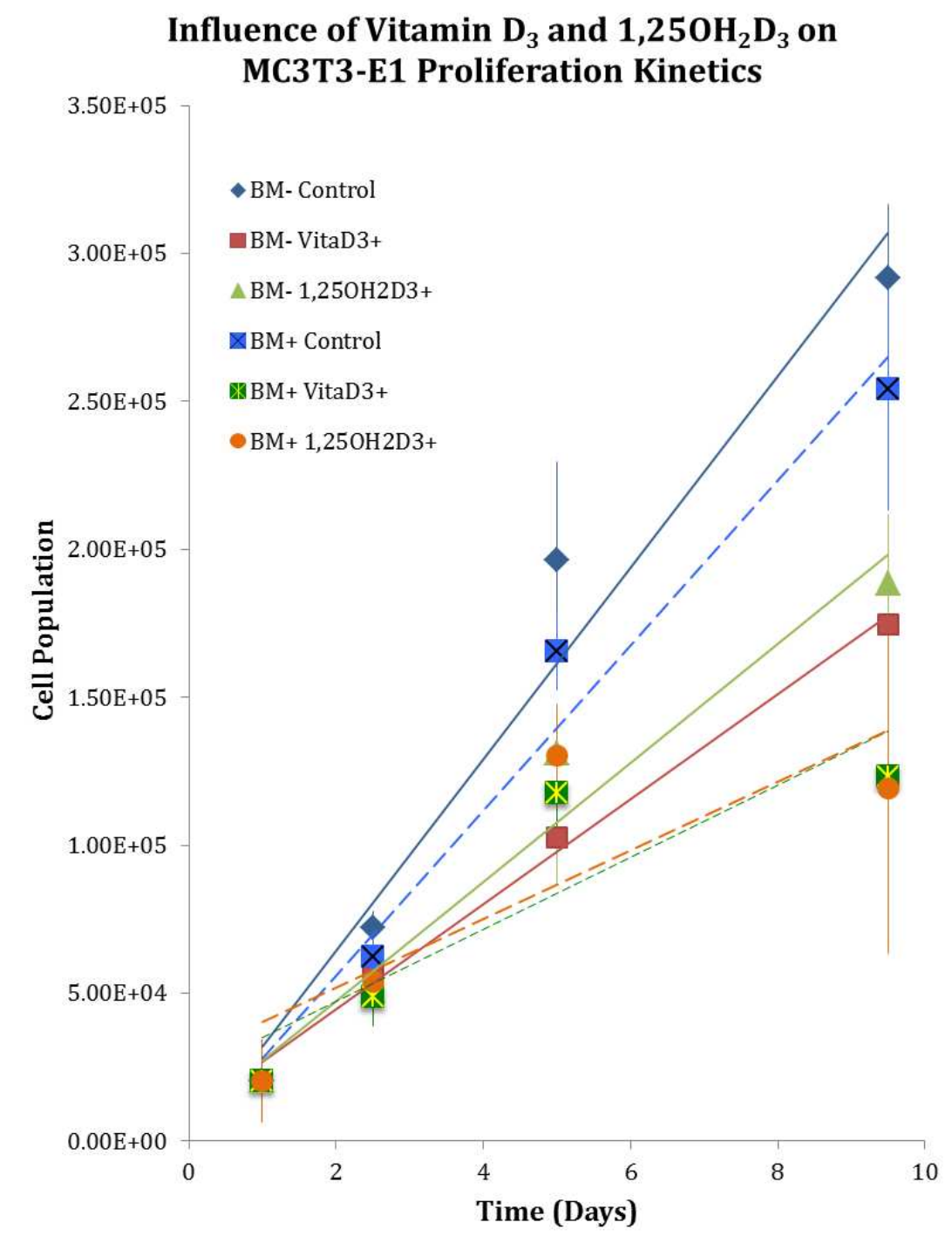

Figure 5-6. Absolute proliferation of MC3T3-E1 cells maintained in six types of tissue culture medium in duplicates over three two-week periods, and assayed in duplicates $(\mathrm{n}=$ 12). Two types of medium was used, one with osteogenic factors $(\mathrm{BM}+)$, and one without (BM-). At day 5, the MC3T3-E1 cell counts in the wells containing vitamin D metabolites \pm osteogenic factor were statistically lower then than the negative control (BM-). MC3T3E1 cells treated with $\mathrm{BM}+$ and vitamin $\mathrm{D}_{3}$ were indistinguishable from $1,25 \mathrm{OH}_{2} \mathrm{D}_{3}$, in that both experienced the largest statistically $(p<0.001)$ anti-proliferative effect. 


\section{Influence of Vitamin D3 and 1,250H2D3 on MC3T3-E1 Proliferation Kinetics}

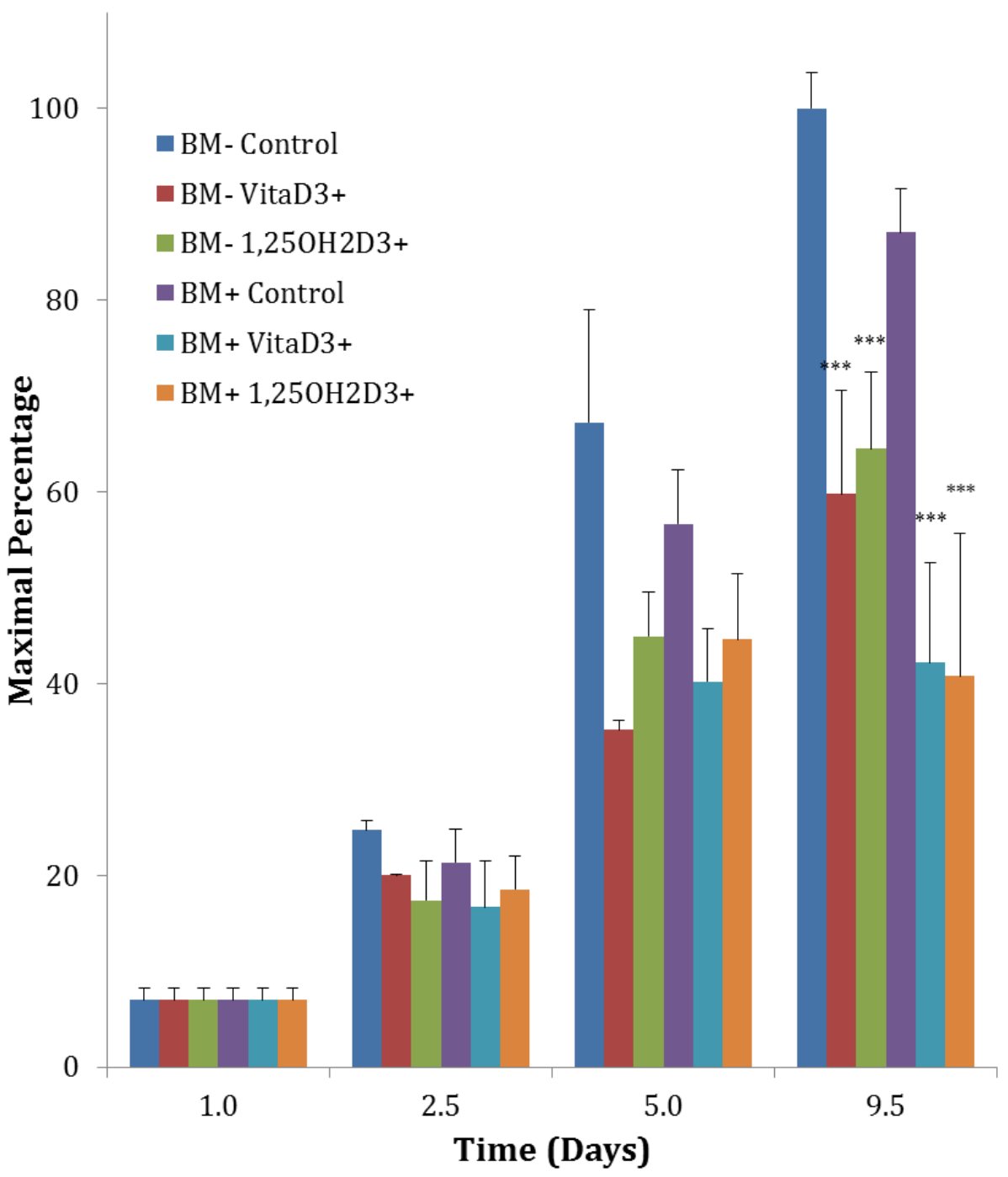

Figure 5-7. Percent proliferation of MC3T3-E1 cells maintained in six types of tissue culture medium. At day 10, the OPC1 cell counts in the wells containing vitamin D metabolites \pm osteogenic factors $(\mathrm{BM}+)$ were very statistically lower $(* * *)$ then than the negative control (BM-) and remained at around 50\% of the BM- cellular confluency. By day 10, MC3T3-E1 cells treated with $\mathrm{BM}+$ and vitamin $\mathrm{D}_{3}$ were indistinguishable from $1,25 \mathrm{OH}_{2} \mathrm{D}_{3}$, as in the absolute proliferation, both experienced the most significant ( $p<$ 0.001 ) anti-proliferative effect. 


\section{(b) ECM Maturation}

Increased ALP activity was directly associated with osteoblast function and matrix maturation during the active stages of bone development (Figure 8). Treatment of OPC-1 cells with standard bone medium (BM-) and both vitaD $\mathrm{D}_{3}$ and $1,25 \mathrm{OH}_{2} \mathrm{D}_{3}$ stimulated a 2 to 3 fold increase in ALP activity after two weeks relative to the parallel control culture, while treatment with osteogenic medium $(\mathrm{BM}+)$ containing $1,25 \mathrm{OH}_{2} \mathrm{D}_{3}$ stimulated a 5 fold increase in ALP activity in comparison to BM- and a $20 \%$ increase in comparison with the $\mathrm{BM}+$ control (Figure 9). However, treatment of MC3T3-E1 cells with BM- containing either vitaD 3 or $1,25 \mathrm{OH}_{2} \mathrm{D}_{3}$ showed a slight increase in ALP Activity, while BM+ containing either vitamin D metabolite was increased by $20 \%$ when compared to the parallel control, and a 70 to $80 \%$ increase when compared to the BM- control (Figure 5-10). 


\section{Osteoprecursor ALP Activity After Two- Weeks of Treatment of Vitamin D}

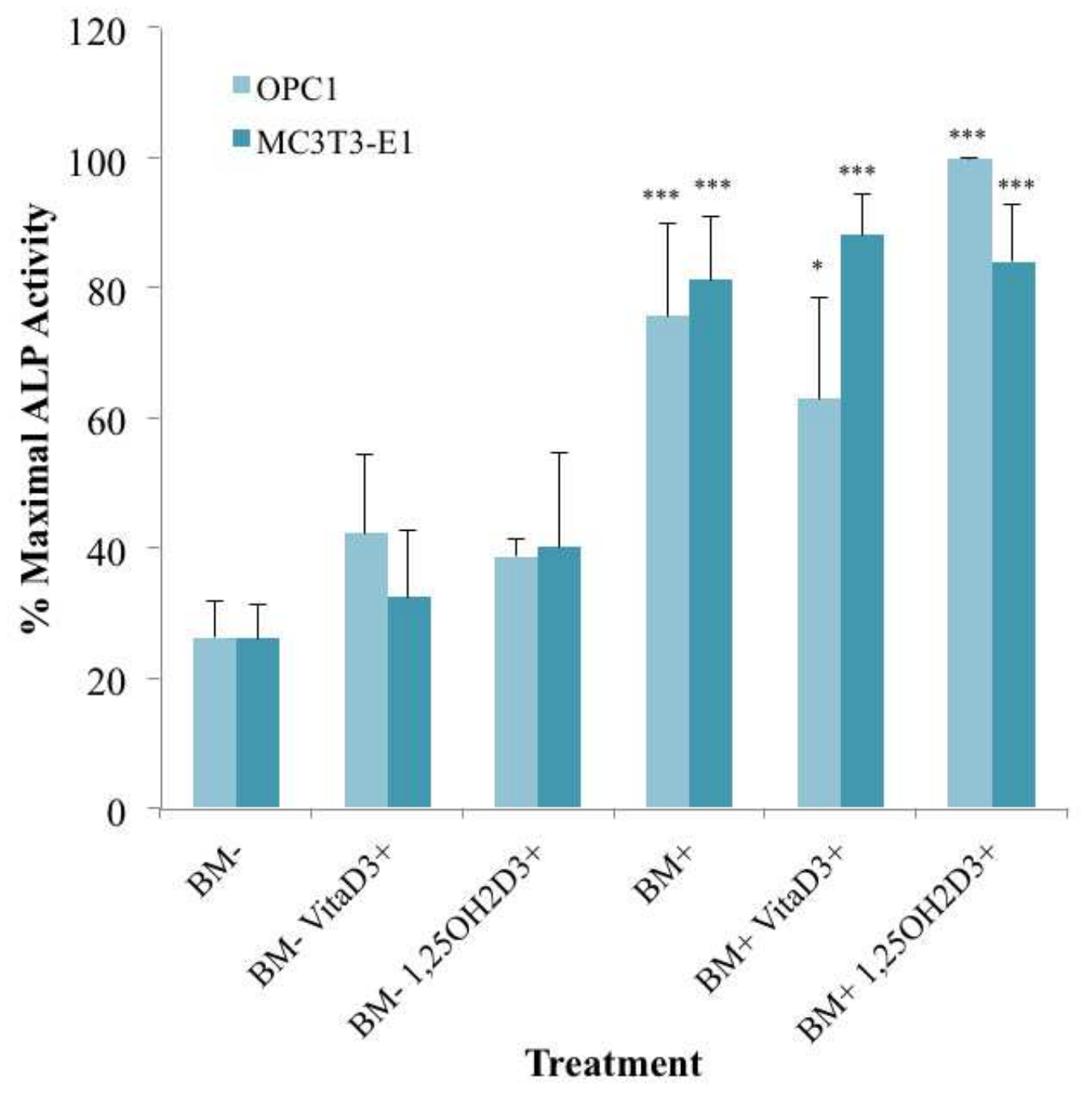

Figure 5-8. ALP activity of OPC1 and MC3T3-E1 cells maintained in six types of tissue culture medium aggregated over three two-week periods $(n=12)$. After two-weeks, the OPC1 ALP activity of $1,25 \mathrm{OH}_{2} \mathrm{D}_{3}$ and osteogenic factors (BM+) treated cells were statistically greater when compared to the negative control (BM-). ALP activity of OPC1 treated with vitamin $\mathrm{D}_{3}$ and $\mathrm{BM}+$ was significantly higher then $\mathrm{BM}-$, but not higher then the $\mathrm{BM}+$ control containing ethanol vehicle. All cellular groups containing $\mathrm{BM}+$ had a significantly higher ALP activity compared to the control within the MC3T3-E1 cell line. MC3T3-E1 response to vitamin $\mathrm{D}_{3}$ was indistinguishable from the response to $1,25 \mathrm{OH}_{2} \mathrm{D}_{3}$ 


\section{Influence of Vitamin D3 and 1,25OH2D3 on OPC1 ALP Activity}

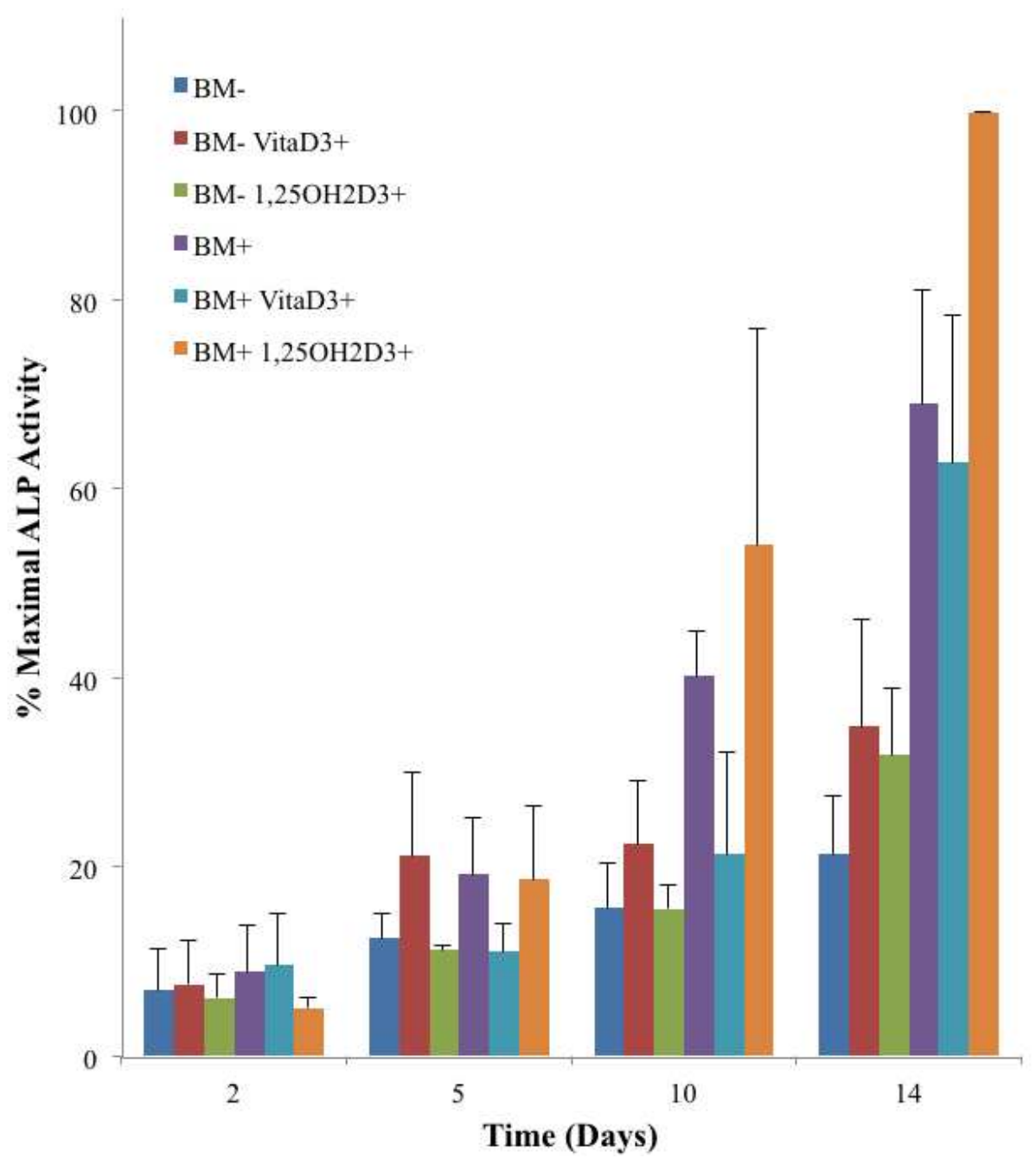

Figure 5-9. ALP activity of OPC1 cells maintained in six types of tissue culture medium described over three two-week periods $(n=12)$. After two-weeks, the OPC1 ALP activity of $1,25 \mathrm{OH}_{2} \mathrm{D}_{3}$ and osteogenic factors (BM+) treated cells were statistically greater than the negative control (BM-). ALP activity of OPC1 treated with vitamin $\mathrm{D}_{3}$ and $\mathrm{BM}+$ was significantly higher than $\mathrm{BM}-$, but not higher than the $\mathrm{BM}+$ control containing ethanol vehicle. 


\section{Influence of Vitamin D3 and 1,250H2D3 on MC3T3-E1 ALP Activity}

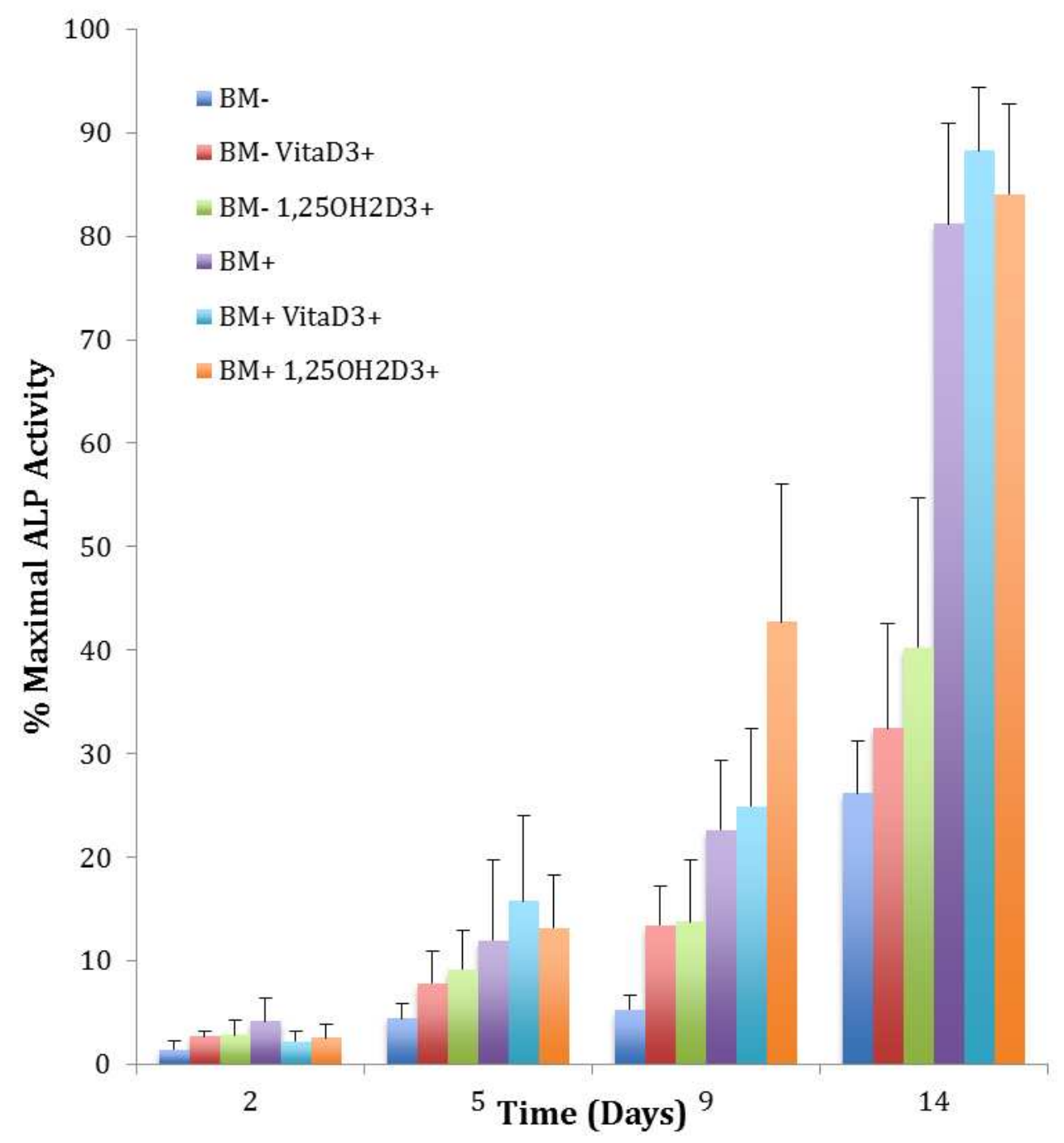

Figure 5-10. ALP activity of MC3T3-E1 cells maintained in six types of tissue culture medium and characterized over three two-week periods $(n=12)$. After two-weeks, the MC3T3-E1 ALP activity of $1,25 \mathrm{OH}_{2} \mathrm{D}_{3}$ and osteogenic factors (BM+) treated cells were again statistically greater than the negative control (BM-). All groups containing BM+ had a statistically greater ALP activity compared to the control in the MC3T3-E1 cell line. The MC3T3-E1 response to vitamin $\mathrm{D}_{3}$ treatment was indistinguishable from the response to $1,25 \mathrm{OH}_{2} \mathrm{D}_{3}$ treatment. 


\section{(c) ECM Mineralization}

The ability to mineralize the ECM during bone development provides the functional niche of osteoblasts in vitro and in vivo (Halvorsen et al., 2001). OPC1 groups cultured in $\mathrm{BM}+$ containing vitaD $3(n=8)$ or $1,25 \mathrm{OH}_{2} \mathrm{D}_{3}(n=8)$ had a statistically larger amount of ECM calcium compared to the BM- $(\mathrm{p}<0.001)$ and $\mathrm{BM}+(\mathrm{p}=0.027)$ ethanol vehicle controls based on ARS measurements (Figure 11). The optical density of the OPC1 cell culture (measured in normalized ARS), increased by $100 \%$ relative to the negative control (BM-) and by about $10 \%$ compared to the $\mathrm{BM}+$ parallel control (Figure 13). OPC1 cells treated with $\mathrm{BM}+$

and vitaD $3\left(39.68 \mathrm{ng} / \mathrm{mg} / 10^{6}\right.$ cells $\left.\pm 0.75, n=8\right)$ were indistinguishable from cells cultured with $\mathrm{BM}+$ and $1,25 \mathrm{OH}_{2} \mathrm{D}_{3}(39.69$ mean $\pm 1.00, n=8)(p<0.05) . \mathrm{MC} 3 \mathrm{~T} 3-$ E1 groups cultured in $\mathrm{BM}+$ containing vitaD $\mathrm{D}_{3}(n=8)$ or $1,25 \mathrm{OH}_{2} \mathrm{D}_{3}(n=8)$ had a statistical greater amount of ECM calcium compared with treatment groups with only BM- $(\mathrm{p}<0.001)$. Meanwhile, cultures with $\mathrm{BM}+$ and $1,25 \mathrm{OH}_{2} \mathrm{D}_{3}$ had a statistically greater amount of ECM calcium compared with the $\mathrm{BM}+$ parallel control ( $p=0.0055)$ (Figures 12 and 13). 


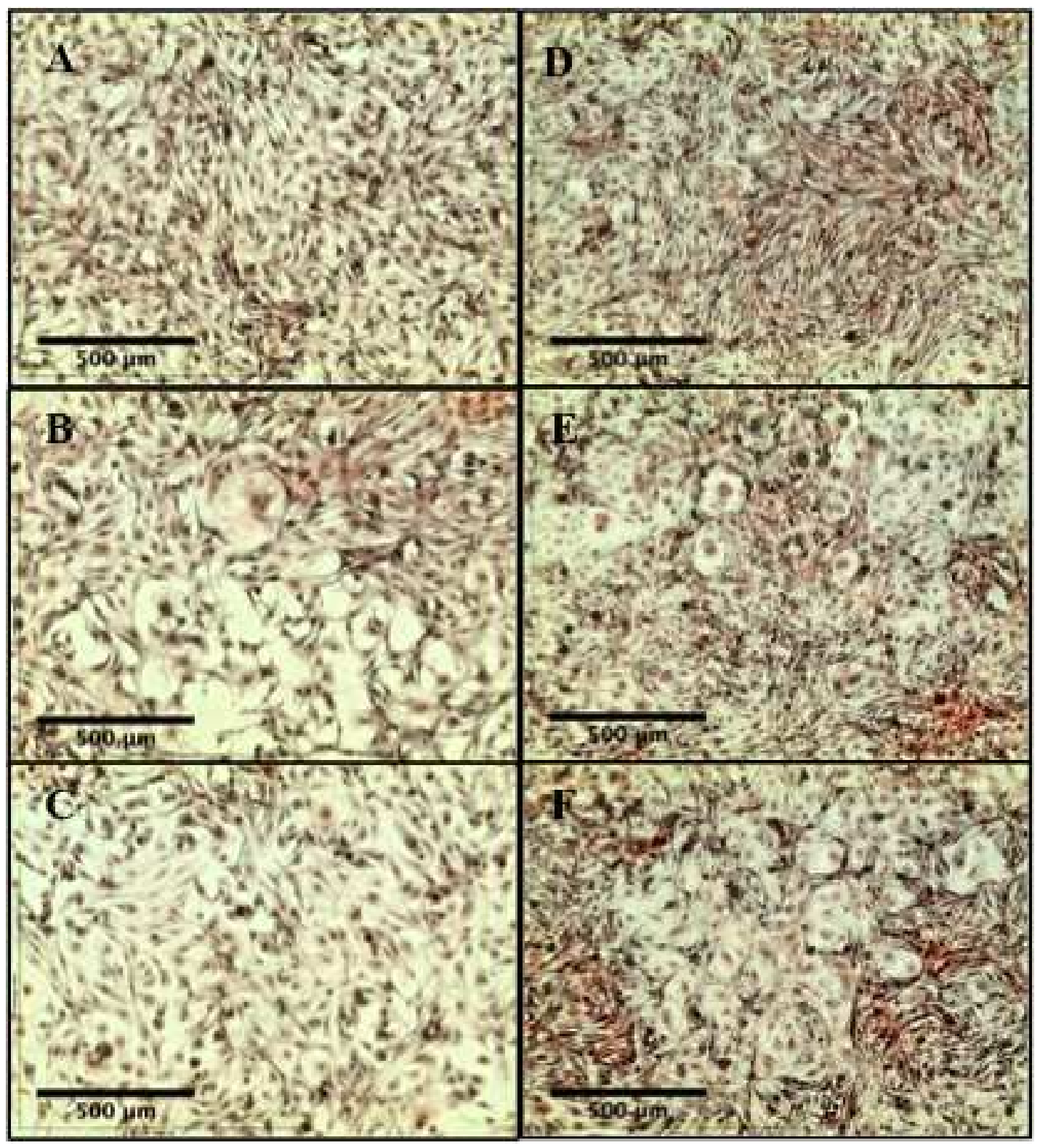

Figure 5-11. Osteoblast precursor cell lines OPC1 stained with ARS after two weeks in experimental conditions. Images of OPC1 cells without either osteogenic factors (BM-) or vitamin $\mathrm{D}$ (ethanol control) (A), BM- with $1 \mu \mathrm{M}$ vitamin $\mathrm{D}_{3}(\mathrm{~B})$, and $\mathrm{BM}$ - with $10 \mu \mathrm{M}$ vitamin $\mathrm{D}_{3}(\mathrm{C})$, consistently did not absorb a statistically perceptible amount of ARS compared to groups containing osteogenic factors $(\mathrm{BM}+)(\mathrm{D}-\mathrm{F})$. However, cells cultured with $\mathrm{BM}+$ and $1 \mu \mathrm{M}$ vitamin $\mathrm{D}_{3}(\mathrm{E})$, and $\mathrm{BM}+$ with $10 \mu \mathrm{M}$ vitamin $\mathrm{D}_{3}(\mathrm{~F})$ had a statistically significant $(p<0.05)$ amount of calcium associated with ECM mineralization compared to the $\mathrm{BM}+$ control (D). 


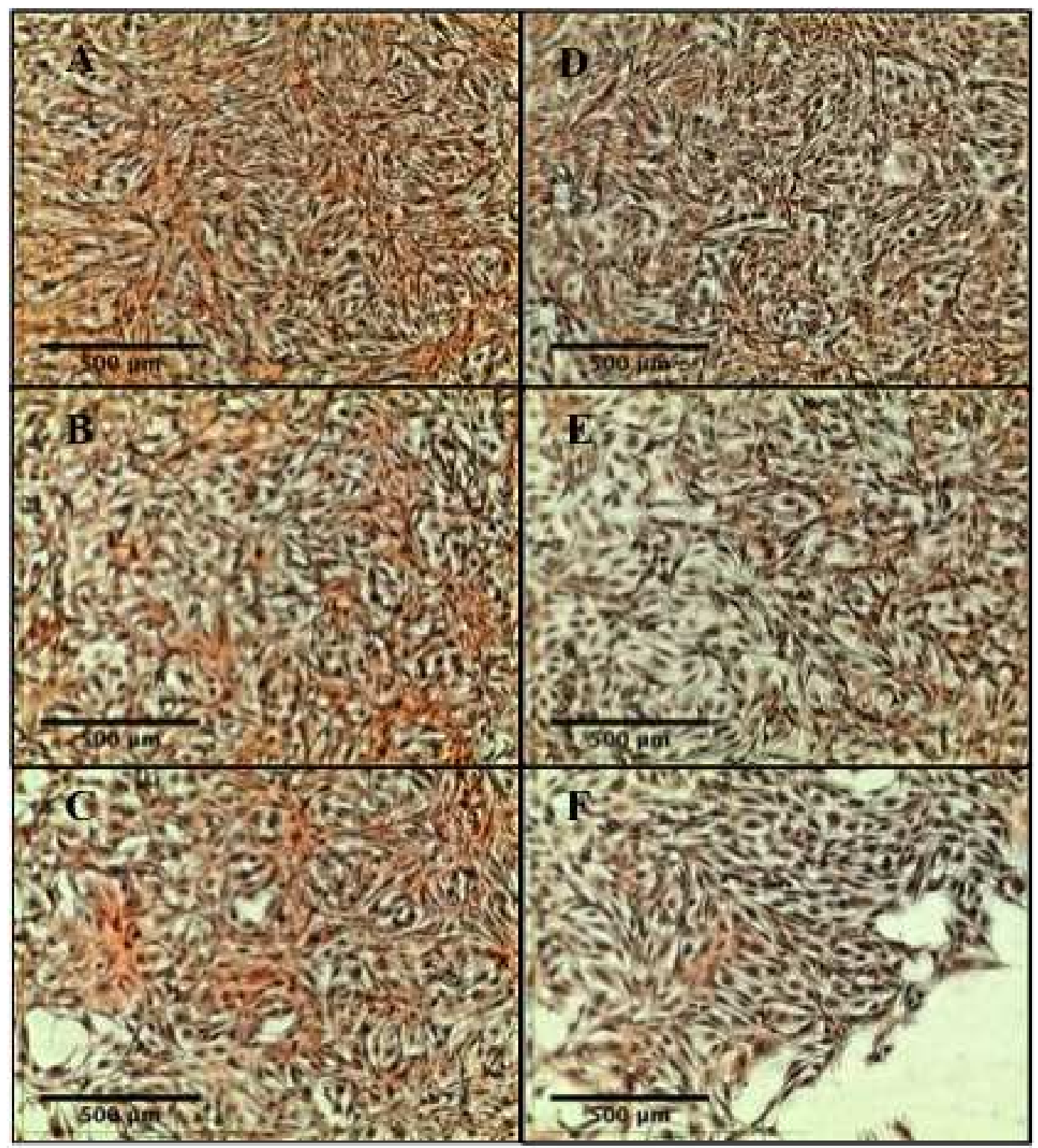

Figure 5-12. Osteoblast precursor cell line MC3T3-E1 stained with ARS after two weeks within the experimental treatment groups. MC3T3-E1 cells without either osteogenic factors (BM-) or vitamin $\mathrm{D}$ (ethanol control) (A), BM- with $1 \mu \mathrm{M}$ vitamin $\mathrm{D}_{3}(\mathrm{~B})$, and $\mathrm{BM}$ - with $10 \mathrm{nM} 1,25 \mathrm{OH}_{2} \mathrm{D}_{3}$ (C), consistently did not absorb a significant amount of ARS compared to groups containing osteogenic factors $(\mathrm{BM}+)(\mathrm{D}-\mathrm{F})$. Cells cultured with vitamin $\mathrm{D}_{3}$ and $\mathrm{BM}+(\mathrm{E})$ were statistically significant compared to the negative control (A), but were not comparable with the parallel control (D). However, cells cultured with $\mathrm{BM}+$ and $10 \mathrm{nM} 1,25 \mathrm{OH}_{2} \mathrm{D}_{3}(\mathrm{~F})$ had a statistically significant $(p=0.0055)$ amount of calcium associated with ECM mineralization compared to the $\mathrm{BM}+$ control (D). 


\section{Osteoprecursor Calcium Deposition After 2 Weeks of Vitamin D}

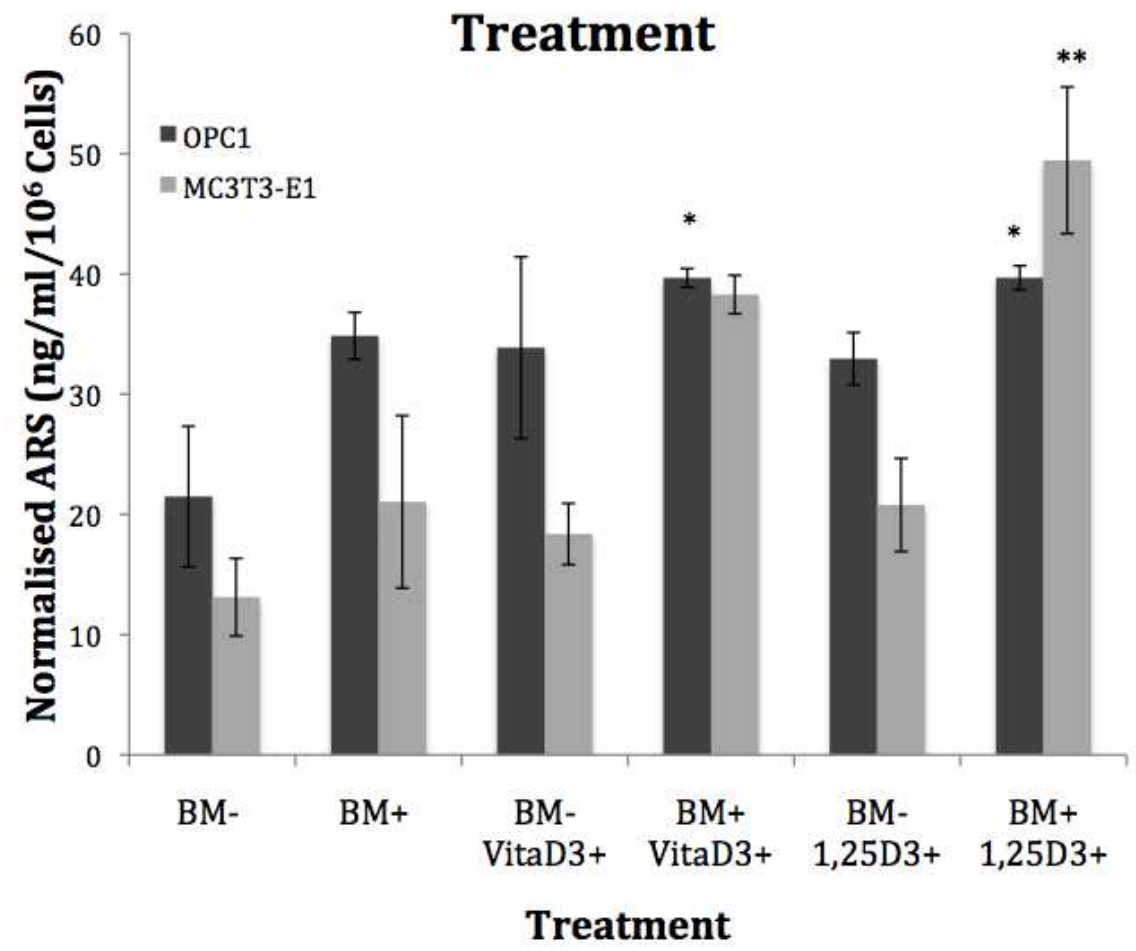

Figure 5-13. Semi-quantification of matrix mineralization of cultured experimental groups qualitatively shown in Figures 11 and 12). OPC1 treated with vitamin $\mathrm{D}_{3}$ or $1,25 \mathrm{OH}_{2} \mathrm{D}_{3}$ in $\mathrm{BM}+$ had a statistically significant $(p<0.05)$ amount of calcium deposition in comparison to both BM- and BM+ controls. MC3T3-E1 cells cultured with $1,25 \mathrm{OH}_{2} \mathrm{D}_{3}$ in $\mathrm{BM}+$ had a statistically significant $(p=0.0055)$ amount of calcium deposition in comparison with both $\mathrm{BM}$ - and $\mathrm{BM}+$ controls. 


\section{(iii) Endogenous 1,25OH $\mathrm{H}_{2} \mathrm{D}_{3}$ Synthesis by $\mathrm{OPC1}$.}

OPC 1 cultures were tested for their ability to synthesize $1,25 \mathrm{OH}_{2} \mathrm{D}_{3}$ from the parental precursor vitaD $\mathrm{D}_{3}$. For this dose-response assay, cells were cultured at high density in order to maximize the concentration of secreted $1,25 \mathrm{OH}_{2} \mathrm{D}_{3}$. Low serum conditions were also used and compared with a serum control to account for any potential influence of vitamin D metabolites present in the serum. OPC1 cultured in the presence of vita $\mathrm{D}_{3}$ produced a detectable level of $1,25 \mathrm{OH}_{2} \mathrm{D}_{3}$ that elevated with increasing concentration. The synthesis of $1,25 \mathrm{OH}_{2} \mathrm{D}_{3}$ in $\mathrm{OPC} 1$ correlated logarithmically to the dosage of vita $\mathrm{D}_{3}$ when applying the log-model of equation $1\left(R^{2}=0.9898, p=0.0051, \mathrm{~m}=7.23 \mathrm{ng} / \mathrm{ml}\right)$ (Figure $\left.5-14\right)$. 


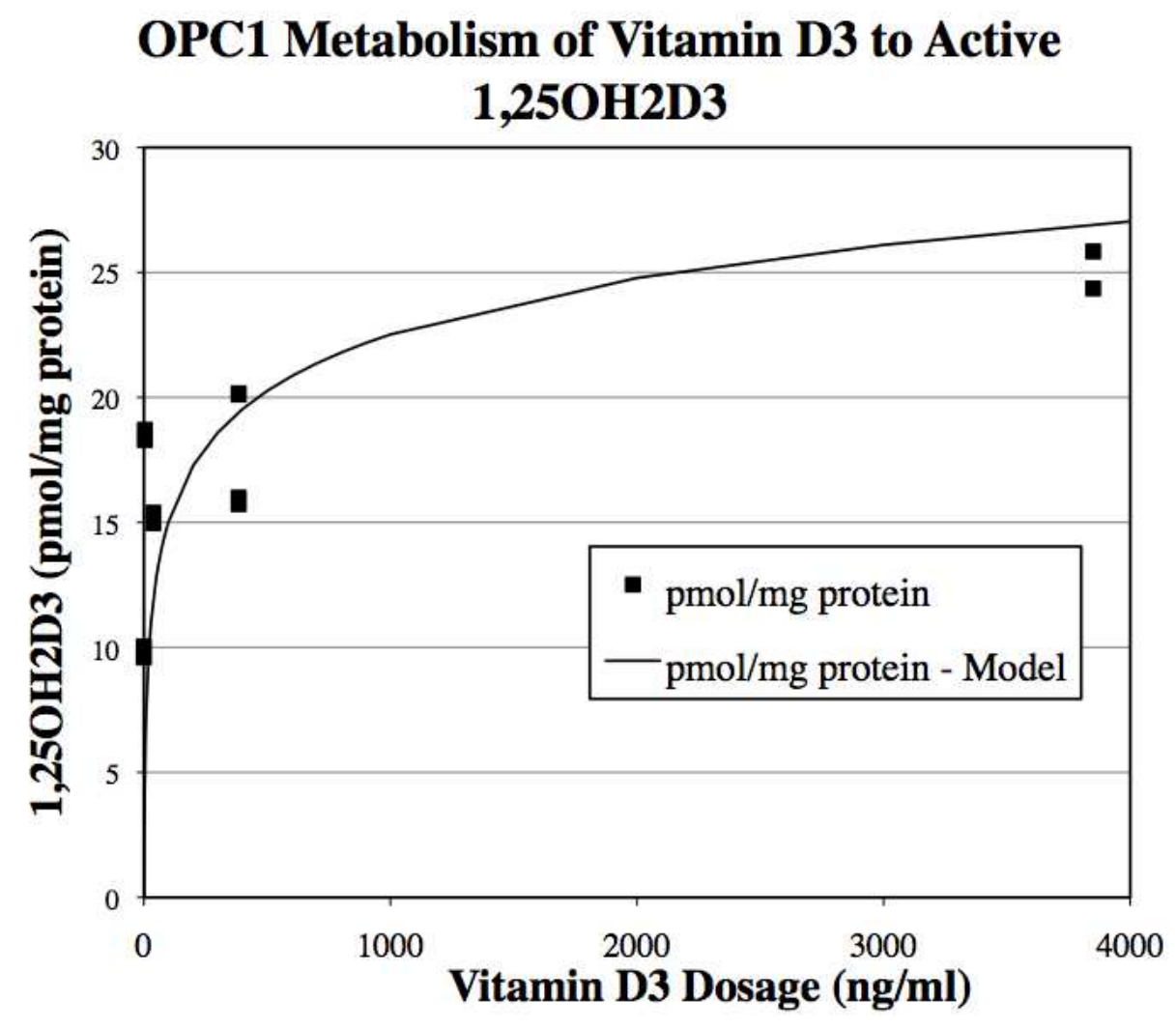

Figure 5-14. Endogenous production of $1,25 \mathrm{OH}_{2} \mathrm{D}_{3}$ by $\mathrm{OPC} 1$ in response to incubation with vitamin $\mathrm{D}_{3}$. A $1,25 \mathrm{OH}_{2} \mathrm{D}_{3} /$ VDR ELISA was performed to analyze the metabolism of precursor vitamin $\mathrm{D}_{3}$ to the hormonally active form. The dose of vitamin $\mathrm{D}_{3}$ was controlled and administered at logarithmic concentration levels. A log base-10 model was applied to the resulting response data. 


\section{Section 5.08 Discussion}

We investigated whether osteoblast precursors have the capacity to convert vitaD $\mathrm{D}_{3}$ to $1,25 \mathrm{OH}_{2} \mathrm{D}_{3}$ and examined the potential of vitaD $\mathrm{D}_{3}$ to induce $1,25 \mathrm{OH}_{2} \mathrm{D}_{3}$ associated biological activities in osteoblast precursors. The active form of vitamin $\mathrm{D}, 1,25 \mathrm{OH}_{2} \mathrm{D}_{3}$, is generated from the parental precursor of vitamin $\mathrm{D}_{3}$ which requires two sequential hydroxylation steps catalyzed by mitochondrial cytochrome P450 enzymes, CYP27A1 and CYP27B1, respectively (Hewison et al., 2004). We found that OPC1 is capable of synthesizing $1,25 \mathrm{OH}_{2} \mathrm{D}_{3}$ by administering vitaD $\mathrm{D}_{3}$ in a dose-dependent manner, and that the influences of vita $\mathrm{D}_{3}$ on antiproliferation and osteoblast differentiation was very similar to $1,25 \mathrm{OH}_{2} \mathrm{D}_{3}$. It was also found that vitaD $\mathrm{D}_{3}$ induced ALP activity and calcium deposition associated with ECM maturation and mineralization during early bone development in a manner that was indistinguishable from groups treated with $1,25 \mathrm{OH}_{2} \mathrm{D}_{3}$. These findings have important implications for bone and vitamin $\mathrm{D}$ research because it provides further evidence that local production of active $1,25 \mathrm{OH}_{2} \mathrm{D}_{3}$ can occur in osteoprecursors and the local metabolism of vita $\mathrm{D}_{3}$ can influence bone development.

Several osteoblast culture systems have demonstrated that cells undergo a temporal developmental sequence that starts with a proliferation phase and results in fully mature osteocyte-like cells embedded in mineralized ECM (Pockwinse et al., 1995; Owen et al., 1991). There are three stages of in vitro bone development that have been characterized by morphology and gene expression. These are (1) a proliferation and ECM biosynthesis stage, (2) an ECM development and maturation stage noted by an increase in 
ALP activity, and (3) a final stage of ECM mineralization in which hydroxyapetite is organized and deposited (Pockwinse et al., 1995; Owen et al., 1991; Lian \& Stein, 1995). In the first stage, following initial cell-seeding, the cells actively proliferate for the first 10 to 12 days of culture and several genes associated with ECM formation, including type I collagen and osteopontin, are actively expressed then gradually decline as proliferation rate decreases and ECM maturation begins. We report that both $\mathrm{vitaD}_{3}$ and $1,25 \mathrm{OH}_{2} \mathrm{D}_{3}$ had similar effects on two osteoprecursor cell lines, which influenced the proliferation stage of bone development by significantly hampering the growth rate.

Immediately following the decrease in proliferation, ALP activity is greatly increased. This post-proliferative period occurs between days 12 and 18, and it is during this time that the ECM matures and becomes competent for mineralization (Pockwinse et al., 1995; Lian \& Stein, 1995). Here, ALP activity of untreated osteoprecursors steadily increased, while the groups containing osteogenic factors $(\mathrm{BM}+)$ and either vitaD 3 or $1,25 \mathrm{OH}_{2} \mathrm{D}_{3}$ increased more then 10 fold over a two week period of time. While the measurement of increased ALP expression is used as an osteogenic marker as an indication of osteoblast phenotype, its function still remains unclear. It has been postulated to increase concentration of inorganic phosphate, a concept known as the "booster hypothesis" (Golub \& Boesze-Battaglia, 2007). During the third stage of bone development, ALP expression decreases and other genes associated with bone mineralization are expressed at maximal level (Owen et al., 1991; Lian \& Stein, 1995; Golub \& Boesze-Battaglia, 2007). These bone cell synthesized proteins include osteopontin (OP) and osteocalcin (OC) and are known to interact with the mineralized 
ECM in vivo (Lian \& Stein, 1995). OP is expressed in both the proliferation and mineralization periods, and down-regulated post-proliferatively during matrix maturation; however, during proliferation, OP expression reaches only about $25 \%$ of its maximal level which peaks between days 16 and 20 during mineralization. In contrast, the calcium binding protein $\mathrm{OC}$, which binds to hydroxyapetite, is expressed only post-proliferatively with the onset of nodule formation, and is expressed maximally with ECM mineralization in vivo and in vitro (Lian \& Stein, 1995). We saw minimal calcium mineralization after two weeks in untreated cell cultures as well as calcium mineralization of the ECM in cultures that were treated with osteogenic factors $(\mathrm{BM}+)$ and $\operatorname{vitaD_{3}}$ or $1,25 \mathrm{OH}_{2} \mathrm{D}_{3}$. However, further studies need to be carried out for a longer duration to see maximal levels of ECM mineralization that is associated with bone development.

The osteoprecursor cultures observed in the present work were non-confluent cultures with actively dividing cells. Because vitamin D has an anti-proliferative effect, it is important to look at its influence on osteoblast precursors after proliferation begins to decrease in order to get a better understanding of how vitamin D effects a confluent cell population. Both OPC1 and MC3T3-E1 cultures treated with vitaD $\mathrm{D}_{3}$ or $1,25 \mathrm{OH}_{2} \mathrm{D}_{3}$ did not reach confluency during the 15 day culture period, while the control groups reached confluency at around 10 to 12 days after an initial seeding density of about 6,500 cells $/ \mathrm{cm}^{2}$. Confluent osteogenic cultures, including MC3T3-E1 cells and human bone marrow derived stromal cells (BMSCs), follow a two-stage developmental process including a 1 to 2 week initiation phase during which cells slowly proliferate, express ALP activity and other bone specific genes, and produce and assemble a collagen matrix, 
and a second maturation phase occurring in weeks 2 to 3 in which ECM mineralization is observed (Hoemann et al., 2009). Mineralization has been demonstrated in BMSC cultures that achieve a minimal ALP activity $(\sim 0.25 \mathrm{nmol} / \mathrm{min} / \mu \mathrm{g}$ protein or 1.2 $\mathrm{nmol} / \mathrm{min} / 10,000$ cells) at some point during the 2 to 3 week culture period, albeit some BMSC cultures can produce high-levels of ALP in vitro without ever mineralizing (Hoemann et al., 2009). Treatments applied here tended to speed up maturation at the expense of proliferation, hence confluencey would be achieved more slowly (or not at all, in this case) relative to control cultures. The effects of vitamin D on ALP activity and mineralization of ECM on confluent OPC1 cultures is currently under way.

One limitation here is that because supra-physiological doses $\left(\geq 10^{-7} \mathrm{M}\right)$ of vitaD 3 $(10 \mu \mathrm{M})$ and $1,25 \mathrm{OH}_{2} \mathrm{D}_{3}(10 \mathrm{nM})$ were used to achieve a maximal response, it is unclear how relevant our findings are to the action of lower vitaD $\mathrm{D}_{3}$ levels within the physiologic range. In vivo, doses of vitaD 3 as low as $10 \mu \mathrm{g}$ (400 IU) have been shown to stimulate bone mineral augmentation in adolescents (Viljakainen, et al., 2006), and the administration of physiological doses of $1,25 \mathrm{OH}_{2} \mathrm{D}_{3}$ has been shown to cure vitamin Ddependency rickets I (Vanhooke, et al., 2006). Our findings indicated, for an in vitro system, supra-physiological doses had a positive effect on bone maturation and mineralization and a negative response in cellular proliferation.

Another limitation is that an insufficient amount of RNA was obtained from the groups containing vitaD 3 and $1,25 \mathrm{OH}_{2} \mathrm{D}_{3}$ to permit simultaneous analysis by qRT-PCR of multiple primers. This was due to the fact that both vitaD $\mathrm{D}_{3}$ and $1,25 \mathrm{OH}_{2} \mathrm{D}_{3}$ inhibited proliferation, which lead to a much smaller population size in comparison to the controls. 
Advancements in the design of biomedical engineering technologies, especially that supporting regenerative medicine through cell and tissue engineering, include the use of precursor cell lines which can consistently be manipulated to develop neotissue. The OPC1 cell line investigated here maintained consistent proliferation, ECM synthesis, and boney maturation, albeit during an abbreviated two-dimensional study. Future investigations will recreate the culture scenarios in a three-dimensional, cell-biomaterial construct with concomitant mechanical stimulation through the application of a novel bioreactor (Mason et al., 2011). This approach will establish a surrogate living tissue model for pharmacokinetic assessment of the dose-response relationship building off of the foundation described here.

\section{ACKNOWLEDGMENTS}

The authors appreciate the generous support given by fellow laboratory members in the Department of Molecular and Medical Genetics, Oregon Health \& Science University. Partial funding was provided by the National Institutes of Health (Grant No. P20 MD003350) and the Collins Medical Trust. 


\section{REFERENCES}

Ahmed, M. S., \& Shoker, A. (2010). Vitamin D metabolites; protective versus toxic properties: molecular and cellular perspectives. . Nephrology Reviews , 2 (1).

Ando, K., Lmai, S., Isoya, E., Kubo, M., Mimura, T., Shioje, S., et al. (2009). Effect of dynamic compressive loading and its combination with a growth factor on chondrocytic phenotype of 3-dimmensional scaffold-embedded chondrocytes. Acta Orthopaedica, 80 (60), 724-733.

Appleman, T. P., Mizrahi, J., Elisseeff, J. H., \& Seliktar, D. (2009). The differential effect of scaffold composition and architecture on chondrocyte response to mechanical stimulation. Biomaterials, 30, 518-525.

Atala, A., \& Lanza, R. P. (2002). Methods of Tissue Engineering. Philadelphia, PA: Elisevier.

Atanga, E., Dolder, S., Dauwalder, T., Wetterwald, A., \& Hofstetter, W. (2011). TNFa inhibits the development of osteoclasts through osteoblast-derived GM-CSF. Bone , 49, 1090-1100.

Atkins, G. J., Andersin, P. H., Findlay, D. M., Welldon, K. J., Vincent, C., Zannettino, A. C., et al. (2007). Metabolism of vitamin D3 in human osteoblasts: evidence of autocrine and paracrine activities of 1a,25-dihydroxyvitamin D3. Bone , 40, $1517-1528$.

Bahney, C. S., Hsu, C. W., Yoo, J. U., West, J. L., \& Johnstone, B. (2011). A bioresponsive hydrogel tuned to chondrogenesis of human mesenchymal stem cells. FASEB $J$. 
Barbero, A., \& Martina, I. (2007). Tissue Engineering (2nd ed.). (H. Hauser, \& M. Fussenegger, Eds.) Totowa, NJ: Humana.

Barlic, A., \& Kregar-Velikonja, N. (2008). Re-differentiation of human articular chondrocytes is not enhance by a rotary bioreactor system. Folia Biol , 54, 177-179.

Berg, J. P. (1999). Vitamin D-binding protein prevents vitamin D deficiency and present itamin D for its renal a ctivation. Eur J of Endicrinology, 141, 321-322.

Biswas, P., \& Zanello, L. P. (2009). 1,25(OH)2D vitamin D3 induction of ATP secretion in osteoblasts. J Bone Miner Res , 24, 1450-1460.

Bouillon, R., Carmeliet, G., Verlinden, L., van Etten, E., Verstuyf, A., Luderer, H. F., et al. (2008). Vitamin D and human health: lessons from vitamin D receptor null mice. Endocrine Reviews , 29 (6), 726-776.

Boyan, B. D., Hurst-Kennedy, J., Denison, T. A., \& Schwartz, Z. (2009). Cellular responses to 24R,25-dihydroxyvitamin D3 in bone and cartilage. Immun, Endoc \& Metab Agents in Med Chem , 9, 137-142.

Brannon , P. M. (2012). Key questions in vitamin D research. Scand J Clin Lab Invest , 73 (Suppl 243), 154-162.

Brockbank, K. G. (2000). Tissue engineering constructs and comercialization. Austin, TX: Landes Biosciene.

Cartnmell, S. H., Porter, B. D., Garcia, A. J., \& Guldberg, R. E. (2003). Effects of medium perfusion rate on cell-seeded three-dimensional bone constructs in vitro. Tissue Eng , 9 (6), 1197-1203. 
Chen, G., Kim, S. H., King, A. N., Zhao , L., Simpson , R. U., Christensen, P. J., et al. (2011). CYP24A1 is an independent prognostic marker of survival in patients with lung carcinoma. Clin Cancer Res , 17, 817.

Cheung, Y. K., Azeloglu, Shiovitz, D. A., Costa, K. D., Seliktar, D., \& Sia, S. K. (2009). Microscale control of stiffness in a cell-adhesive substrate using microfluidicsbased lithography. Angew Chem Int Ed, 48, 7188-7192.

Choi, J. B., Youn, I., Cao, L., Leddy, H. A., Cilchrist, C. L., Setton, L. A., et al. (2007). Zonal changes in the three-dimensional morphology of the chondron under compression: the relationship among cellular, pericellular, and extracellular deformation in articular cartilage. J Biomech , 40, 2596-2603.

Chung, P. G., \& Burdick, J. A. (2008). Engineering cartilage tissue. Adv Drug Delivery Rec , 60 (2), 243-262.

Cooper, G. M. (2000). Signaling Molecules and Their Receptors. In G. M. Cooper, The Cell: A Molecular Approach (2nd ed.). Sunderlan, MA: Sinauer Associates.

Flanagan, J. N., Young, M. V., Persons, K. S., Wang, L., Mathieu, J. S., Whilatch, L. W., et al. (2006). Vitamin D metabolism in human prostate cells: impications for prostate cancer chemoprevention by vitamin D. Anticancer Research, 26, 2567-72.

Freed, L. E., Guilark, F., Guo, E., Gray, M. L., Tranquilo, R., Holmes, J. W., et al. (2006). Advanced tools for tissue engineering: scaffolds, bioreactors, and signaling. Tissue Engineering , 12 (12), 3285-3305. 
Geng, S., Zhou, S., \& Glowacki, J. (2011). Effects of 25-hydroxyvitamin D3 on proliferation and osteoblast differentiation of human marrow stromal cells require CYP27B1/1a-hydroxylase. J of Bone and Miner Res , 26 (5), 1145-1153.

Golub, E. E., \& Boesze-Battaglia, K. (2007). The role of alkaline phosphatase in mineralization. Curr Opin Orthop , 444-448.

Halvorsen , Y. C., Franklin, D., Bond, A. L., Hitt, D. C., Auchter, C., Boskey , A. L., et al. (2001). Extracellular matrix mineralization and soteoblast gene expression by human adipose tissue-derived stromal cells. Tissue Engineering , 7 (6), 729-741.

Hardingham, T., Tew, S., \& Murdoch. (2002). Tissue engineering: chondrocytes and cartilage. Arthritis Res , 4, S63-68.

Hattori, K., Takakura, Y., Ohgushi, H., Habata, T., Uematsu, K., Yamauchi, J., et al. (2005). Quantitative ultrasound can assess the regeneration proess of tissue-engineered cartilage using a complex between adherent bone marrow cells and a three-dimensional scaffold. Arthritis Resarch and Therapy, 7 (3), R552-R559.

Hein, A., \& O'Brien, W. J. (1993). Current time-domain methods for assessing tissue motion by analysis from reflected ultrasound echos-a review. IEEE Transcactions on Ultrasonics, Ferroelectris and Frequency Control , 40 (2), 84-102.

Hewison, M., Zehnder, D., Chskraverty, R., \& Adams, J. S. (2004). Vitamin D and barrier function: a nove role for extra-renal 1a-hydroxylase. Molecular and Cellular Endocrinology, 215, 31-38. 
Hobaus, J., Thiem, U., Hummel, D. M., \& Kallay, E. (2013). Role of calcium, vitamin $\mathrm{D}$, and the extrarenal vitamin D hydroxylases in carcinogenesis. Anti-Cancer Agent in Medicinal Chemistry, 13 (1), 20-35.

Hoemann, C. D., El-Gabalawy, H., \& McKee, M. D. (2009). In vitro osteogenesis assays: influence of the primary cell source on alkaline phosphatase activity and mineralization. Pathologie Biologie , 57, 318-323.

Hollick, M. F. (2010). Vitamin D. Boston, MA: Springer.

Hosmer, D. W., \& Lameshow, S. (2000). Applied Logistic Regression. New York, NY: Wiley.

Jones, G., Strugnel, S. A., \& DeLuca, H. F. (1998). Current Understanding of the molecualr actions of vitamin D. Physiological Reviews , 78 (4), 1193-1211.

Kohles, S. S., Bowers, J. R., Vailas, A. C., \& Vanderbery, R. (1997). Ultrasonic wave velocity measurement in small polymeric and cortical bone speciments. J Biomech Eng , 119 (3), 232-236.

Kohles, S. S., Bradshaw, S., Mason, S. S., \& Looft, F. J. (2011). A multivariate logistical model for identifying the compressive sensitivity of single rat tactiles receptors as nanobiosensors. J Nanotechnol Eng Med, 2 (1).

Kohles, S. S., Kohles, D. A., Karp, A. P., Erlich, V. M., \& Polissar, N. L. (2004). Time-dependent surgical outcomes following cauda equina syndrom diagnosis: comments on a meta-analysis. Spine , 29 (11), 1281-1287. 
Kohles, S. S., Wilson, C. G., \& Bonassar, L. J. (2007). A mechanical composite sphers analysis of engineered cartilage dynamics. ASME J Biomech Eng , 129 (4), 473480.

Kumar, R. (1990). Vitamin D metabolism and mechanisms of calcium transport. $J$ Am Soc Nephrol , 1 (1), 30-42.

Lanza, R., Langer, R., \& Vacanti, J. (2007). Principles of Tissue Engineering. San Diego, CA: Elisever.

Lehman, B. (2008). Role of vitamin D3 pathway in healthy and diseased skin facts, contradictions and hypotheses. Experimental Dermatology, 18, 97-108.

Lehmann, B., \& Meurer, M. (2003). Extrarenal sites of calcitriol synthesis: the particular role of the skin. . Recent Results Cancer Res , 164, 237-245.

Lian, J. B., \& Stein, G. S. (1995). Develpment of the osteoblast phenotype: molecular mechanisms mediating osteoblast growth and differentiation. The Iowas Orthopaedic J, 15, 118-140.

Liu, P., Oyahobi, B. O., Russell, R. G., \& Scutt, A. (1999). Regulation of osteogenic differentiation of human bone marrow stromal cells: interaction between transforming growth factor-B and 1,25(OH)2 vitamin D3 in vitro. Calcif Tissue Int , 65, 173-180.

Mason, S. S., Kohles, S. S., \& Zelick, R. D. (2011). Three-dimensional culture of cells and matrix biomolecules for engineered tissue development and biokinetic model validation. J Nanotechnol Eng Med, 2 (2), 025001-7. 
Naeem, Z. (2010). Vitamin D defficiency - an ingnored epidenmic. Int J Health Sci , 4 (1), V-VI.

Owen, T. A., Aronow, M. S., Barone, L. M., Bettencourt, B., Stein, G. S., \& Lian, J. B. (1991). Pleiotropic effects of vitamin D on osteoblast gene expression are related to the proliferative and differentiated state of the bone cell phenotype: dependency upon basal levels of gene expression, duration of exposure, and bone matrix competency in norma. Endocrinology, 1496-1504.

Park, K., Min, B. H., Han, D. K., \& Hasty, K. (2007). Quantitive anaylsis of temporal and spatial variation of chondrocyte nehavior in engineered cartilage during long-term culture. Annals Biomed Eng , 35 (3), 419-428.

Pazanno, D., Mercier, K. A., Moran, J. M., Fong, S. S., DiBiaso, D. D., Rulf, J. X., et al. (2000). Comparison of chondrogenesis in static and perfused bioreactor culture. Biotechnol Prog , 16, 893-896.

Pockwinse, S. M., Stein, J. L., Lian, J. B., \& Stein, G. S. (1995). Developmental stage-specific cellular responses to vitamin $\mathrm{D}$ and glucocorticoids during differentiation of the osteoblast phenotype: interrelationship of morphology and gene expression by in situ hybridization. Experimental Cell Research , 216, 244-260.

Ramage, G., Nuki, D., \& Salter, M. (2009). Signaling cascades in mechanotransduction: cell-matrix interaction and mechanical loading. Scand J Med sci Sports , 19, 4757-4769. 
Saha, A. K., \& Kohles, S. S. (2011). A cell-matrix model of anabolic and catabolic dynamics during cartilage biomolecule regulation. International Journal of Computers in Healthcare.

Saha, A. K., \& Kohles, S. S. (2010). A distinct catabolic to anabolic threshold due to single-cell nanomechanical stimulation in a cartilage biokinetics model. J Nanotechnol Eng Med, 1 (3), 031005.

Saha, A. K., \& Kohles, S. S. (2010). Periodic nanomechanical stimulation in a biokinetics model identifying anabolic and catabolic pathways associated withh cartilage matrix homeostasis. J Nanotechnol Eng Med, 1 (4), 041001.

Schuurman, W., Gawlitta, D., Lein, T. J., Hoope, W. T., Riijen, M. H., Dhert, W. J., et al. (2009). Zonal chondrocyte subpopulations reacquire zone-specific characteristics durin in vitro redifferentiation. AJSM , 20 (10), 1-8.

Seiffert, M., Rech, M., Meineke, V., Tilgen, W., \& Rechrath, J. (2004). Differential biological effects of 1,25-dihydroyxy Vitamin D3 on melanoma cell lines in vitro. J of Steroid Biochem \& Molec Bio , 89-90, 375-379.

Tellisi, N., \& Nureddin, A. (2007). Comparison of meshes, gels and ceramic for cartilage tissue engineering in vitro. Eur J Plast Surg .

Tibbitt, M. W., \& Anseth, K. S. (2009). Hydrogels as extracellular matrix mimics for 3D cell culture. Biotechnol Bioeng , 103, 656-669.

Tortelli, F., \& Cancedda, R. (2009). Three-dimensional cultures of osteogenic and chondrogenic cells: a tittue engineering approach to mimic bone and cartilage in vitro. Eur Cell Mater , 17, 1-4. 
Vanhooke, J. L., Prahl, J. M., Kimmel-Jehan, C., Mendelsohn, M., Danielson, E. W., Healy, K. D., et al. (2006). CYP27B1 null mice with LacX reporter gene display no 25-hydroxyvitamin D3-1a-hydroxylase promote activity in the skin. PNAS , 103 (1), 7580.

Viljakainen , H. T., Natri, A. M., Karkainen , M., Huttunen , M. M., Palssa, A., Jakobsen, J., et al. (2006). A positive dose-response effect of vitamin D supplementation on site-specific bone mineral augmentation in adolescent girls: a double-blinded randomized placebo-conrolled 1-year intervention. J Bone Miner Res , 21 (6), 836-44.

Villanueva, I., Weigal, C. A., \& Bryant, S. J. (2009). Cell-matrix interactions and dynamic mechanical loading influence chondrocyte gene expression and bioactivity in PEG-RGD hydrogels. Acta Biomaterialia , 5 (8), 2832-2846.

Vinatier, C., Mrugala, D., Jorgensen, C., Guicheux, J., \& Noel, D. (2009). Cartilage engineering: a crucial combination of cells, biomaterials, and biofactors. Trens Biotecnol , 19, 307-314.

Walker, J. M., Myers, A. M., Scluchter, M. D., Goldberg, V. M., Caplan, A. I., Berilla, J. A., et al. (2011). Nondestructive evaluation of hydrogel mechanical properties using ultrasound. Annals of Biomedical Engineering , 39 (10), 2521-2530.

Wilson, C. G., Bonassar, L. J., \& Kohles, S. S. (2002). Modeling the dynamic composition of engineered cartilage. Arch Biochem Biophys , 408 (2), 246-254.

Winn, S. R., Randolph, G., Uludag, H., Wong, S. C., Hair, G. A., \& Hollinger, J. O. (1999). Establishing an Immortalized Human Osteoprecursor Cell Line: OPC1. J of Bone and Miner Res , 14 (10), 1721-1733. 
Yilmaz, B. C., Yilmaz, G., Yilmaz, N. S., Balli, E., \& Tasdelen, B. (2010). Optimal transport time and conditions for cartilage tissue samples and expanded chondrocyte suspensions. Orthopaedics, 33 (1), 25.

Zhou, S., Glowacki, J., Kim, S. W., Hahne, J., Geng, S., Mueller, S. M., et al. (2012). Clinical characterizatics influence in vito action of 1,25-dihydroxyvitamin $\mathrm{D}(3)$ in human marrow stromal cells. .J Bone Miner Res, Ahead of Print.

Zuwei, M. A., Kotaki, M., Inani, R., \& Ramakrishna, A. (2005). A potential of nanofiber matrix as tissue-engineering scaffolds. . Tissue Eng , 11 ((1-2)), 101-10. 


\title{
Chapter VI. INVESTIGATION THE REGULATION OF MRNA EXPRESSION INVOLVED IN EXTRA-ENDOCRINE VITAMIN D METABOLISM DURING OPC1 BONE MATURATION AND MINERALIZATION
}

\author{
Shelley S. Mason ${ }^{1}$ \\ Sean S. Kohles ${ }^{1}$ \\ Shelley R. Winn ${ }^{2}$ \\ Randy D. Zelick ${ }^{1}$ \\ ${ }^{1}$ Department of Biology, Portland State University, Portland, Oregon; ${ }^{2}$ Department \\ of Molecular and Medical Genetics, Oregon Health Science University, Portland, \\ Oregon.
}




\section{Section 6.01 Preface}

This chapter contains material from a manuscript that will be submitted for publication at a later date. The work presented here is the $2^{\text {nd }}$ part of a two-series experiment on the influence of extra-endocrine vita $\mathrm{D}_{3}$ metabolism on in vitro temporal bone development sequence.

\section{Section 6.02 Authors Contribution}

The work presented here was carried out in collaboration between all authors. SSM, SSK, SRW, and RDZ defined the research theme. SSM designed the methods and experiments, carried out the laboratory experiments, analyzed the data, interpreted the results and wrote the paper. SSK edited the manuscript. SRW co-designed the biological experiments. All authors have contributed to, seen and approved the manuscript.

\section{Section 6.03 Hypothesis}

The overall goal of this experiment was to demonstrate the extrahepatic metabolism of parental vita $\mathrm{D}_{3}$ precursor to the active vitamin $\mathrm{D}$ metabolite $1,25 \mathrm{OH}_{2} \mathrm{D}_{3}$ by the osteoblast precursor cell line OPC1, and demonstrate the subsequent influence on bone maturation and mineralization. The global hypothesis was that the conversion of vitamin $\mathrm{D}_{3}$ to $1,25 \mathrm{OH}_{2} \mathrm{D}_{3}$ would lead to an increase in alkaline phosphatase (ALP) activity associated with osteoblast ECM maturation and an increase ECM mineralization indicated by calcium deposition detected alizarin red stain (ARS). It was also hypothesized that the presence of $\mathrm{vitaD}_{3}$ would enhance the temporal bone developmental sequence of OPC1. 


\section{Section 6.04 Abstract}

Multipotential precursor cell lines derived from human bone marrow, capable of differentiating into cartilage or bone, may provide a useful tissue development model for studying the regulation and metabolism of putative growth and differentiation factors necessary for tissue regeneration. In mammals, the process of bone development depends on the proliferation and differentiation of osteoblast lineage cells, and the subsequent synthesis and mineralization of bone extracellular matrix (ECM). Vitamin D metabolites play a pivotal role in bone and mineral homeostasis, and are positive factors on bone development. Recently, it was demonstrated that human-derived engineered osteoblast precursor cell line, OPC1, derived from human bone marrow, can metabolize the parental precursor vitamin $\mathrm{D}_{3}\left(\operatorname{vitaD}_{3}\right)$ to the active steroid $1 \alpha, 25$-dihydroxyvitamin $\mathrm{D}_{3}$ $\left(1,25 \mathrm{OH}_{2} \mathrm{D}_{3}\right)$, and elicit an osteogenic response that results in the decrease in proliferation and increase of ECM synthesis during early bone development. In this study, we investigated whether vitaD $\mathrm{D}_{3}$ influences bone ECM mineralization in the same manner as $1,25 \mathrm{OH}_{2} \mathrm{D}_{3}$. In addition, we explored the influence of vitamin $\mathrm{D}$ metabolites, in combination with other commonly used osteogenic factors, ascorbic acid, $\beta$ glycerophosphate, dexamethasone (dex) and bone morphogenetic protein-2 (BMP-2) on the osteoinduction of $\mathrm{OPC} 1$ during early bone development. It was demonstrated that OPC1 expresses the mRNA for the enzymatic equipment necessary to convert vitaD $\mathrm{D}_{3}$ to $1,25 \mathrm{OH}_{2} \mathrm{D}_{3}$, as well as the mRNA associated with the catabolic enzyme known to regulate the concentration of active $1,25 \mathrm{OH}_{2} \mathrm{D}_{3}$. It was also demonstrated that mRNA 
expression for the vitamin $\mathrm{D}$ receptor (VDR) was influenced by both $\operatorname{vitaD}_{3}$ and $1,25 \mathrm{OH}_{2} \mathrm{D}_{3}$. Differential results using vitamin $\mathrm{D}$ metabolites in combination with ascorbic acid, $\beta$-glycerophosphate, and either dex and/or BMP-2 were observed in ALP activity and calcium deposition, and mRNA expression of procollagen (proColI), osteocalcin (OC), and osteopontin (OP). Overall it was demonstrated that vitamin D in combination with osteogenic factors influence the temporal bone development sequence in a positive manner. 


\section{Section 6.05 Introduction}

Most of the load-bearing demand placed on the human body is transduced by skeletal tissue, and the skeleton's capacity to articulate in various opposing directions is essential for mobility and locomotion [Buttery, et al., 2001]. Consequently, cartilage and bone defects due to trauma, disease, and developmental abnormalities results in severe disabling pain and immobility for millions of people worldwide [Mason, et al., 2011]. Multipotential precursor cell lines derived from human bone marrow, capable of differentiating into cartilage or bone, may provide a useful tissue development model for studying the regulation and metabolism of putative growth and differentiation factors necessary for tissue regeneration.

There are several factors that need to be taken into consideration for in vitro model systems, such as cell source and acquisition, phenotypic stability, reproducibility, and the incorporation of appropriate signaling molecules. One of the challenges using mesenchymal stromal cells (MSCs)/progenitor cells isolated from bone marrow aspirates is isolation sufficiency and expansion, because of the relatively low frequency at which they occur in the marrow stroma (reported to be in the range of $1 / 10,000$ cells to 1/100,000 cells) [Hicok, et al., 1998; Buttery, et al., 2001; Huang et al., 2012]. In addition, MSCs have a finite capacity for self-renewal, and the potential to proliferate and differentiate diminishes with age [Buttery, et al., 2001]. In addition, MSC isolates tend to be heterogeneous, containing progenitor cells with varying levels of potency. 
Osteoblastic precursor cell line (OPC1) is a conditionally immortalized cell line derived from human bone, and has been demonstrated to maintain phenotypic stability and a consistent pattern of differentiation for more than 70 passages, therefore it provides an ideal model for the study of osteoblast differentiation and bone development as an alternative to MSCs [Winn, et al., 1999]. OPC1 has been used in previous studies and has shown to provide a consistent and reproducible culture system for evaluating bone development [Mason, et al. 2013]. Recently, we were able to demonstrate the extraendocrine metabolism of vita $\mathrm{D}_{3}$ to $1,25 \mathrm{OH}_{2} \mathrm{D}_{3}$ by $\mathrm{OPC} 1$, which resulted in decreased proliferation and increased ALP activity and calcium deposition associated with ECM bone maturation and mineralization.

In the early 1900's vitamin D was the fourth identified essential vitamin, thus named vitamin “D” by convention. It wasn't until 50 years later that it was realized that vitamin D is metabolized and acts as a steroid hormone in an endocrine manner, a paradigm that has dominated the classic thought of vitamin D function until the end of the $20^{\text {th }}$ century [Morris \& Anderson, 2010]. Recently, it has been demonstrated that number of organ systems are influenced by vitamin D in an autocrine manner, that is $1,25 \mathrm{OH}_{2} \mathrm{D}_{3}$ is being synthesized within those cells, and/or within adjacent cells (paracrine action). While the vitamin $\mathrm{D}$ endocrine system plays a principal role in the maintenance of calcium and phosphate homeostasis, extra-endocrine metabolism has been postulated to have cellular functions that include the regulation of proliferation, differentiation, and apoptosis in many target tissues [Brannon, 2012; Hobaus, et al., 2013; Jones, et al., 1998; Atkins, et al. 2007], including bone and cartilage. 
$\mathrm{VitaD}_{3}$ is biologically inactive in physiological concentrations until it is sequentially hydroxylated and the polarity is increased. $\mathrm{VitaD}_{3}$ is activated by twosequential hydroxylations, first by the cytochrome P450 oxidase (CYP) 25-hydroxylase, CYP27A1 (mitochondrial) and CYP2R1 (microsomal), resulting in the metabolite 25hydroxyvitamin $\mathrm{D}_{3}\left(25 \mathrm{OHD}_{3}\right)$, and then to the active metabolite, $1,25 \mathrm{OH}_{2} \mathrm{D}_{3}$, by 25 hydroxyvitaminD $\mathrm{D}_{3}$-1 $\alpha$-hydroxylase (CYP27B1) [Ahmed \& Shoker 2010; Norman 1998; Jones, et al. 1998; Trump, et al., 2010].

$1,25 \mathrm{OH}_{2} \mathrm{D}_{3}$ is the most active form of vitamin $\mathrm{D}$ because of its high affinity for the intranuclear vitamin D receptor (VDR), in which it mediates its biological effects upon binding. VDR belongs to the nuclear hormone receptor family and serves as a liganddependent transcription factor (TF) that controls the expression of vitamin D associated target genes which include those associated with calcium homeostasis, cellular proliferation and differentiation, cell division and cycle arrest, and apoptosis [Yamamoto, et al., 2013; Seiffert, et al., 2004; Flanagan, et al., 2006; Hollick, 2010; Naeem, 2010]. Upon $1,25 \mathrm{OH}_{2} \mathrm{D}_{3}$ binding, VDR forms a heterodimer with the retinoid $\mathrm{X}$ receptor, which allows it to bind to vitamin D receptor elements (VDRE) in the promoter regions of target genes [Flanagan, et al., 2006; Brannon , 2012; Geng, et al., 2011; Trump, et al., 2010]. Coupled with other TFs, this complex induces transcription of vitamin D responsive genes including those associated with the CYP-related enzymes required for vitamin D metabolism [Chen, et al., 2011; Flanagan, et al., 2006; Boyan, et al., 2009; Geng, et al., 2011; Trump, et al., 2010]. 
The action of vitamin $\mathrm{D}$ is limited by the catabolic enzyme 24-hydroxylase (CYP24A1), which results in a compound that is more soluble and has a substantially lower affinity for VDR [Trump, et al., 2010; Ahmed \& Shoker, 2010; Ambrecht, et al.,1998]. CYP24A1 has been shown to hydroxylate both $25 \mathrm{OHD}_{3}$ and $1,25 \mathrm{OH}_{2} \mathrm{D}_{3}$ to form $24,25 \mathrm{OH}_{2} \mathrm{D}_{3}$ and $1,24,25 \mathrm{OH}_{3} \mathrm{D}_{3}$, respectively [Flanagan, et al., 2006]. The main function of CYP24A1 is to regulate the circulating concentration of $1,25 \mathrm{OH}_{2} \mathrm{D}_{3}$ by inactivating it. The catabolic pathway of CYP24A1, collectively known as the C-24 oxidation pathway, starts with the 24-hydroxylation of $25 \mathrm{OH}_{2} \mathrm{D}_{3}$ or $1,25 \mathrm{OH}_{2} \mathrm{D}_{3}$ followed by sequential steps of hydroxylation that lead to the progressive loss of biological activity until vitamin $\mathrm{D}$ is converted to the water-soluble biliary excretory form, calcitroic acid [Ahmed \& Shoker, 2010; Jones et al., 1998; Pairse et al., 2006]. 1,25OH $\mathrm{O}_{2} \mathrm{D}_{3}$ induces and mediates CYP24A1 via an autocatalytic loop through VDRE located in the promoter region of the CYP24A1 gene [Chen et al., 2011]. Generally, basal expression of CYP24A1 is extremely low but the gene is highly induced by $1,25 \mathrm{OH}_{2} \mathrm{D}_{3}$ [Geng, et al., 2011; Atkins, et al., 2007]. Thus, the synthesis and degradation of $1,25 \mathrm{OH}_{2} \mathrm{D}_{3}$ is highly regulated, and the concentration is controlled at the cellular level.

Vitamin D affects many aspects of bone cell biology, and has been implicated in the regulation of both osteoblastic and osteoclastic activity effecting both resorptive and synthetic phases of bone remodeling [Atkins, et al., 2007]. In addition, $1,25 \mathrm{OH}_{2} \mathrm{D}_{3}$ has been demonstrated to regulate osteoblast and chondrocyte gene transcription, proliferation, differentiation, and ECM maturation [Boyan, et al., 2009; Atkins, et al., 2007]. VDR is nearly ubiquitously expressed, almost all cells respond to $1,25 \mathrm{OH}_{2} \mathrm{D}_{3}$ 
[Bouillon, et al., 2008], and it is known to regulate the function of more than 200 genes [Flanagan et al., 2006; Hollick, 2010; Norman, 1998; Naeem, 2010].

In this study, OPC1 was used to study the differentiation of osteoprogenitors towards the osteoblast lineage and the events associated with bone development in the presence of vitamin $\mathrm{D}$ metabolites, vitaD $\mathrm{D}_{3}$ and $1,25 \mathrm{OH}_{2} \mathrm{D}_{3}$, in combination with osteogenic factors ascorbic acid, $\beta$-glycerophosphate, dexamethasone and bone morphogenetic protein-2 (BMP-2). Because in vitro temporal bone development encompasses three stages, proliferation, bone ECM maturation, and mineralization, and vitamin D has been shown to significantly hamper OPC1 proliferation [Mason et al. 2013], confluent cultures were used in order to investigate the influence on bone ECM maturation and mineralization. 


\section{Section 6.06 Materials and Methods}

\section{(i) Materials}

Vitamin $\mathrm{D}_{3}$ (cholecalciferol) and (calcitriol) $1,25 \mathrm{OH}_{2} \mathrm{D}_{3}$ were purchased from Sigma-Aldrich (St. Louis, MO), and maintained in $10 \mathrm{mM}$ and $10 \mu \mathrm{M}$ stock solutions in ethanol respectively. All other reagents and chemicals were purchased from Sigma-Aldrich (St. Louis, MO) unless otherwise indicated. Tissue plastic-ware was obtained from USA scientific (Ocala, FL). OPC1 and rhBMP-2 were a generous gift from Dr. S. R. Winn (Department of Molecular and Medical Genetics Laboratory, Oregon Health Science University, Portland, OR).

\section{(ii) Methods}

(a) OPC1 Cell Cultures

Cells were cultured at $2.5 \times 10^{5}$ in $75-\mathrm{cm}^{2}$ tissue culture flasks in alpha modified essential medium ( $\alpha-\mathrm{MEM}$ ) with $5 \%$ fetal bovine serum (FBS). Once confluent, OPCs were plated in 12-well plates after trypsin-EDTA enzymatic removal and counted with $0.4 \%$ trypan blue (1:1) on a hemacytometer. Cultures were prepared in duplicate at a seeding density of $3.0 \times 10^{4}$ cells/well in a standard bone medium (BM-) of $\alpha$-MEM supplemented with 5\% FBS, 200mM LGlutamine, and antibiotics until 85-90\% confluent prior to adding experimental medium. Nine types of medium were utilized in quadruplicates. BM- with $95 \%$ 
ethanol $(\mathrm{EtOH})$ in amount that equated the $\mathrm{EtOH}$ vehicle for vitamin D metabolite delivery provided a negative control (group 1) and the additional groups included: BM- supplemented with $1 \mu \mathrm{M}$ vitaD 3 (group 2); BM- supplemented with $10 \mathrm{nM}$ $1,25 \mathrm{OH}_{2} \mathrm{D}_{3}$ (group 3); $\mathrm{BM}$ - supplemented with osteogenic factors $(\mathrm{BM}+$ ) comprised of $50 \mu \mathrm{g} / \mathrm{ml}$ ascorbic acid, $10 \mathrm{mM} \beta$-glycerophosphate, $10 \mathrm{nM}$ dexamethasone (dex), and $50 \mu \mathrm{g} / \mathrm{ml}$ of ascorbic acid phosphate (Wako Chemical, Osaka, Japan) provided as a positive control (group 4); BM+ supplemented with

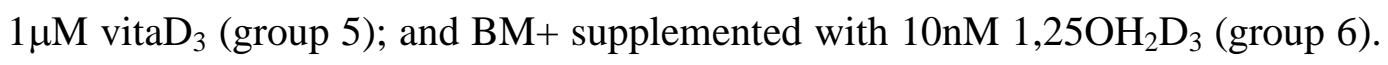
$\mathrm{BM}+$ supplemented with rhBMP-2 (BMP+) (group 7), $\mathrm{BMP}+$ with $1 \mu \mathrm{M}$ vitaD 3 (group 8); and BMP+ supplemented with $10 \mathrm{nM} 1,25 \mathrm{OH}_{2} \mathrm{D}_{3}$ (group 9). Fresh medium was added every 1-2 days.

\section{(b) ALP activity associated with bone matrix maturation}

OPC-1 was treated with both vitaD $\mathrm{D}_{3}$ and $1,25 \mathrm{OH}_{2} \mathrm{D}_{3}$ in $\mathrm{BM}-, \mathrm{BM}+$, and $\mathrm{BMP}+$, in duplicate at the indicated concentrations. ALP activity was measured every 7 days. At the end of the incubation, the cell layers were washed with cold DPBS, and $500 \mu 10.1 \%$ triton-X in DPBS and stored at $-80^{\circ} \mathrm{C}$ until the end of each experimental period. ALP activity in the cell lysates was measured using $\rho$ nitrophenyl phosphate liquid substrate system at $37^{\circ} \mathrm{C}$ for 30 minutes. Protein content was measured using a micro-volume spectrophometer system (Epoch; 
Biotek, Winooski, VT). For statistical analysis of ALP over time, a two-way ANOVA and Bonferonni posttest control comparison was performed.

\section{(c) Calcium deposition during bone matrix mineralization}

A hystochemical analysis of mineralization was evaluated utilizing an Alizarin Red S (ARS. ARS staining is used to evaluate calcium-rich deposits by cells in culture, and is considered a functional in vitro endpoint reflecting advanced cell differentiation [Hoemann et al. 2009]. In brief, every 7 days cells were fixed in $10 \%$ neutral buffered formalin for $15 \mathrm{~min}$. followed by fixation in $100 \%$ cold methanol. Each well was rinsed thoroughly with cold DPBS, and stained with $40 \mathrm{mM}$ of $\mathrm{ARS}, \mathrm{pH} 4.1$, at room temperature (RT) for $20 \mathrm{~min}$ with gentle shaking. The cell layers were efficiently rinsed and observed both grossly and microscopically. For semiquantification, ARS was extracted from the cells after incubating for one hour in at RT in $10 \%(\mathrm{v} / \mathrm{v})$ acetic acid with gentle shaking, and then the residual dye was further extracted by scraping the cells and heating at $85^{\circ} \mathrm{C}$ on a heating block with a layer of mineral oil to prevent evaporation. The samples were neutralized with $10 \%(\mathrm{v} / \mathrm{v})$ ammonium hydroxide and the extracts were read at $405 \mathrm{~nm}$ on a microplate-reader (Cary 50; Varian Australia Pty. Ltd). The samples were compared to serially diluted ARS standard. The resulting data was normalized with total protein content measured using a micro-volume spectrophometer system (Epoch; Biotek, Winooski, VT). For 
statistical analysis of ARS over time, a two-way ANOVA and Bonferonni posttest control comparison was performed.

\section{(d) Quantitative RT-PCR}

Established RT-PCR qualitative analysis techniques were used to characterize the presence of CYP24A1 [Zhou, et al., 2012], CYP27A1 [Seiffert, et al., 2004], CYP27B1 and VDR (see Table 6-1) [Seiffert, et al., 2004; Zhou, et al., 2012], osteopontin (OP), procollagen I (proColI), and osteocalcin (OC) (see Table 6-2) [Winn, et al., 1999]. The oligionucleotide RT-PCR primer sequences (see Table 6-3) were purchased from Intergrated DNA Technologies (Coralville, Iowa,

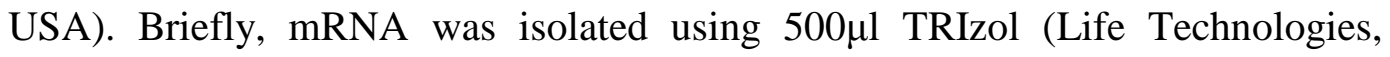
Grand Island, NY, USA) per well of 12-well plates. Samples were collected every 7 days and stored at $-80^{\circ} \mathrm{C}$. The mRNA was purified from TRIzol according to the manufacturer's specifications and the concentration was determined by spectrophotometric absorbance (Epoch; Biotek, Winooski, VT) of light at 260nm and $280 \mathrm{~nm}\left(\mathrm{~A}_{260} / \mathrm{A}_{280}\right)$ in $\mu \mathrm{g} / \mathrm{ml}$. The cDNA was synthesized from $2 \mu \mathrm{g}$ of mRNA using a high capacity cDNA reverse transcriptase kit from Applied Biosystems (Life-Technologies, Grand Island, NY, USA) according to manufacturer's instructions. Aliquots of the total cDNA were amplified in each PCR using fast SYBR ${ }^{\circledR}$ green master mix from Applied Biosystems (Life-Technologies, Grand Island, NY, USA) with the primers listed in Table 1 and performed in a RotorGene Q RT-PCR thermocycler (Qiagen, Germantown, Maryland, USA), for 45 
cycles $\left(30\right.$ s denaturation at $95^{\circ} \mathrm{C}, 45 \mathrm{~s}$ annealing at $58^{\circ} \mathrm{C}$, and 60 s extension at $\left.72^{\circ} \mathrm{C}\right)$. Quantification and analysis was carried out using Rotor-Gene Q Operating Software and Microsoft Excel (Microsoft Corp. Seattle, WA, USA).

Table 6-1. Vitamin D biomarkers associated with vitamin D metabolism.

\begin{tabular}{ll}
\hline $\begin{array}{l}\text { Vitamin D Associated } \\
\text { Biomarker }\end{array}$ & Function \\
\hline CYP24A1 & $\begin{array}{l}\text { The gene that encodes the mitochondrial protein that initiates } \\
\text { the degradation of vitamin } \mathrm{D} \text { metabolites } 25 \mathrm{OHD}_{3} \text { and } \\
1,25 \mathrm{OH}_{2} \mathrm{D}_{3} \text { to calcitroic acid [Schlingmann et al. 2011]. }\end{array}$ \\
\hline CYP27A1 & $\begin{array}{l}\text { The gene that encodes the mitochondrial protein involved in } \\
\text { the metabolism of vitamin } \mathrm{D}_{3} \text { to } 25 \mathrm{OHD}_{3} \text { [Sawada et al. 2000]. }\end{array}$ \\
CYP27B1 & $\begin{array}{l}\text { The gene that encodes the mitochondrial protein responsible } \\
\text { for the hydroxylation of the vitamin } \mathrm{D} \text { metabolite } 25 \mathrm{OHD}\end{array}$ to \\
& $\begin{array}{l}1,25 \mathrm{OH} \mathrm{D}_{3} \text { [Jones, 2013]. } \\
\text { The gene that encodes the nuclear hormone receptor for } \\
\text { vitamin } \mathrm{D} . \text { Downstream targets of this nuclear hormone } \\
\text { receptor are known to be involved with mineral metabolism, } \\
\text { proliferation, differentiation, apoptosis, and immune response } \\
\text { [Freedman, 1999]. }\end{array}$ \\
\hline
\end{tabular}


Table 6-2. Osteoblast biomarkers associated with bone development.

\section{Osteoblast Marker $\quad$ Function}

Alkaline Phosphatase (ALP)
A hydrolase involved in bone ECM maturation and mineralization, postulated to increase inorganic phosphate concentration. ALP is thought to be regulated by $1,25 \mathrm{OH}_{2} \mathrm{D}_{3}$ [Boyan et al. 1989].

Osteocalcin (OC), bone gammacarboxyglutamate protein (BGLAP)

A noncollagenous protein found in bone that binds $\mathrm{Ca}^{2+}$ and hydroxyapatite, is vitamin D-responsive, related to bone mineralization, and involved in the recruitment and differentiation of osteoclasts. OC synthesis has been shown to be stimulated by $1,25 \mathrm{OH}_{2} \mathrm{D}_{3}$ [Beresford et al. 1984].

Osteopontin (OP), secreted phosphoprotein 1 (SPP1) A noncollagenous extracellular glycophosphoprotein found in bone that binds to hydroxyapatite, and plays a role in osteoblast adhesion, migration, cell survival, and bone remodeling [Standal, Borset, \& Sundan, 2004].

Procollagen Type I (proColI)
Synthesized prior to collagen type I, the principal structural protein of bone ECM. 
Table 6-3. Oligionucleotide primers use in quantitative real-time RT-PCR.

\begin{tabular}{|c|c|c|}
\hline Primer Set & Forward & Reverse \\
\hline CYP24A1 & 5' - GCA GCC TAG TGC AGA TTT - 3' & 5' - ATT CAC CCA GAA CTG TTG - 3', \\
\hline CYP27A1 & 5' - GGC AAG TAC CCA GTA CGG - 3' & $5^{\prime}-$ AGC AAA TAG CTT CCA AGG - 3' \\
\hline CYP27B1 & 5' - TGT TTG CAT TTG CTC AGA - 3' & 5' - CCG GGA GAG CTC ATA CAG - 3' \\
\hline VDR & 5' - CCA GTT CGT GTG AAT GAT GG - 3, & 5' - GTC GTC GGT GAA GGA - 3', \\
\hline $\mathrm{OC}$ & 5' - CTG GCC ACT GCA TTC TGC - 3' & 5' - AAC GGT GGT GCC ATA GAT GCG- 3' \\
\hline OP/SPP1 & $5^{\prime}$ - AAA TAC CCA GAT GTG GC - $3^{\prime}$ & $5^{\prime}-$ AAC CAC ACT ACC TCG GC -3 ' \\
\hline ProColI & 5' - TGA CGA GAC CAA GAA CTG - 3, & 5' - CCA AAG TCA CCA AAC CTA CC - $3^{\prime}$ \\
\hline
\end{tabular}

(e) Statistical Analysis

Statistical analysis was carried out using Prism (Irvine, CA, USA) and Microsoft Excel Software. Data were expressed as means \pm SEM of samples characterized in three two-week sample sets plated in duplicate or quadruplicate, and assayed in duplicate ( $n=12$ or $n=24$ respectively). A two-tailed ANCOVA with a Bonferonni posttest control comparison and non-linear regression (polynomial quadratic function) was used for statistical analysis of treatment over time, with $* p<0.05, * * p<0.01$ and $* * * p<0.001$ as significantly and very significantly different, respectively. 


\section{(f) Microscopic Imaging}

Microscopic images were taken using an advanced transmitted light inverted EVOS-XL microscope and accompanying software (EVOS3) from Advanced Microscopy Group (AMG, Bothell, WA, USA). Images were processed using FIJI, an Open Source image-processing package based on ImageJ. To maintain consistency, each image was processed in the same manner. The operations included the background subtraction command, mean filter and Enhance Local Contrast (CLAHE; blocksize 100, bin 256, max. slope 2.50), respectively. 


\section{Section 6.07 Results}

\section{(i) Influence of vitamin D metabolites and osteogenic factors on OPC1 bone}

matrix maturation.

Increased ALP activity is associated with osteoblast function and the matrix maturation stage of bone development. ALP activity was found to be significantly $(\mathrm{P}<0.01)$ higher in groups cultured in standard bone medium $(\mathrm{BM}-)$ containing vitaD3 by week two of culture, and significantly higher $(\mathrm{P}<0.001)$ in groups containing either vitaD 3 or $1,25 \mathrm{OH}_{2} \mathrm{D}_{3}$ by week three compared to the BM- ethanol vehicle control (see Figure 6-1A). For groups in osteogenic medium $(\mathrm{BM}+)$ both vitamin $\mathrm{D}$ metabolites displayed significantly $(\mathrm{P}<0.001)$ higher ALP activity compared to the $\mathrm{BM}+\mathrm{EtOH}$ control in both the second and third week (see Figure 6-1B). All groups cultured in $\mathrm{BM}+$ were significantly $(\mathrm{P}<0.001)$ higher the groups cultured in BM- during the three week culture period, and reached maximal ALP, while groups in BM- did not reach maximal ALP activity. Groups cultured in $\mathrm{BM}+$ containing rhBMP (BMP+) showed a significant increase $(\mathrm{P}<0.001)$ only in the second week compared to the $\mathrm{BMP}+\mathrm{EtOH}$ control, and by week three all groups displayed low levels of ALP activity (see Figure 6-1C). While groups cultured in $\mathrm{BM}+$ continued to increase in ALP activity throughout the three-week culture period, $\mathrm{BM}+$ reached a peak in between week 1 and 3, and began to decline in between week 2 and 3 . 


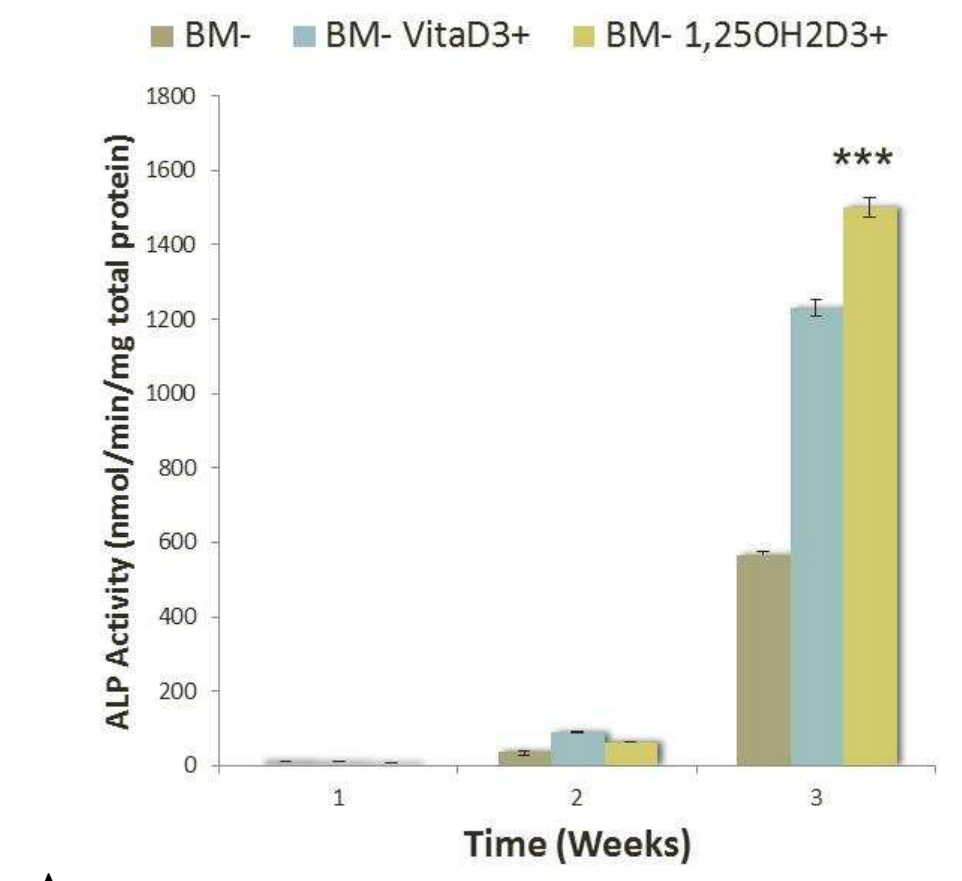

A

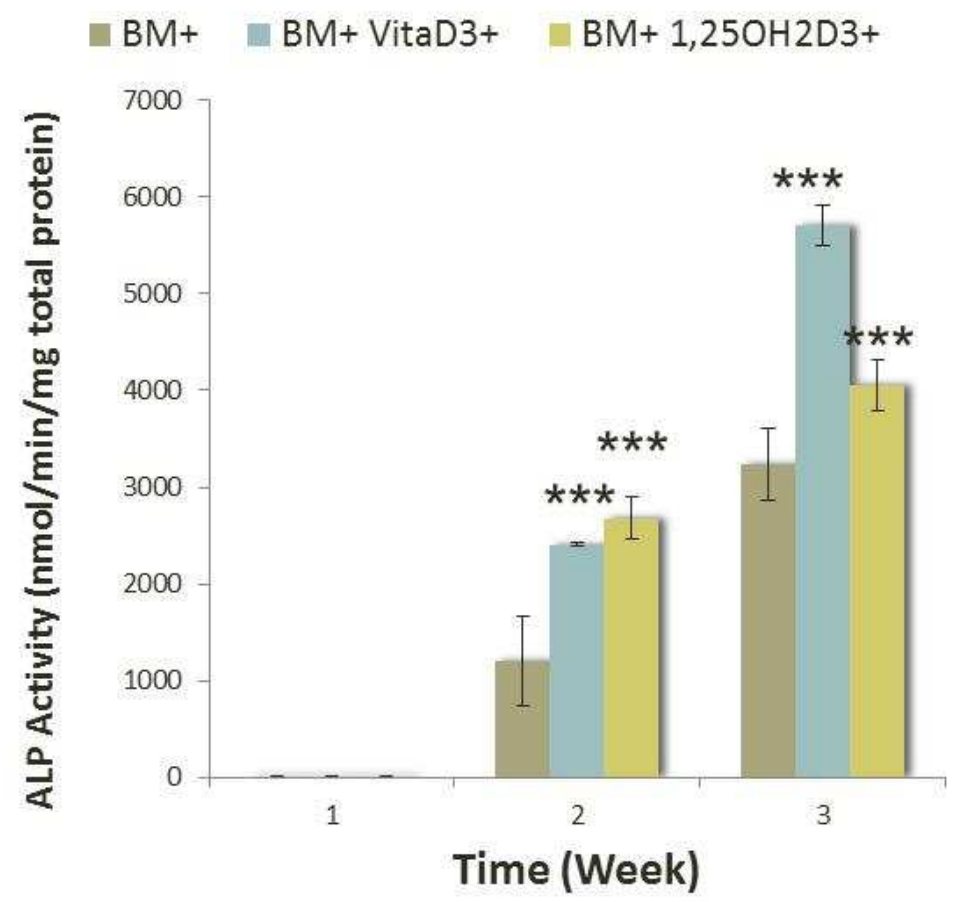

B 


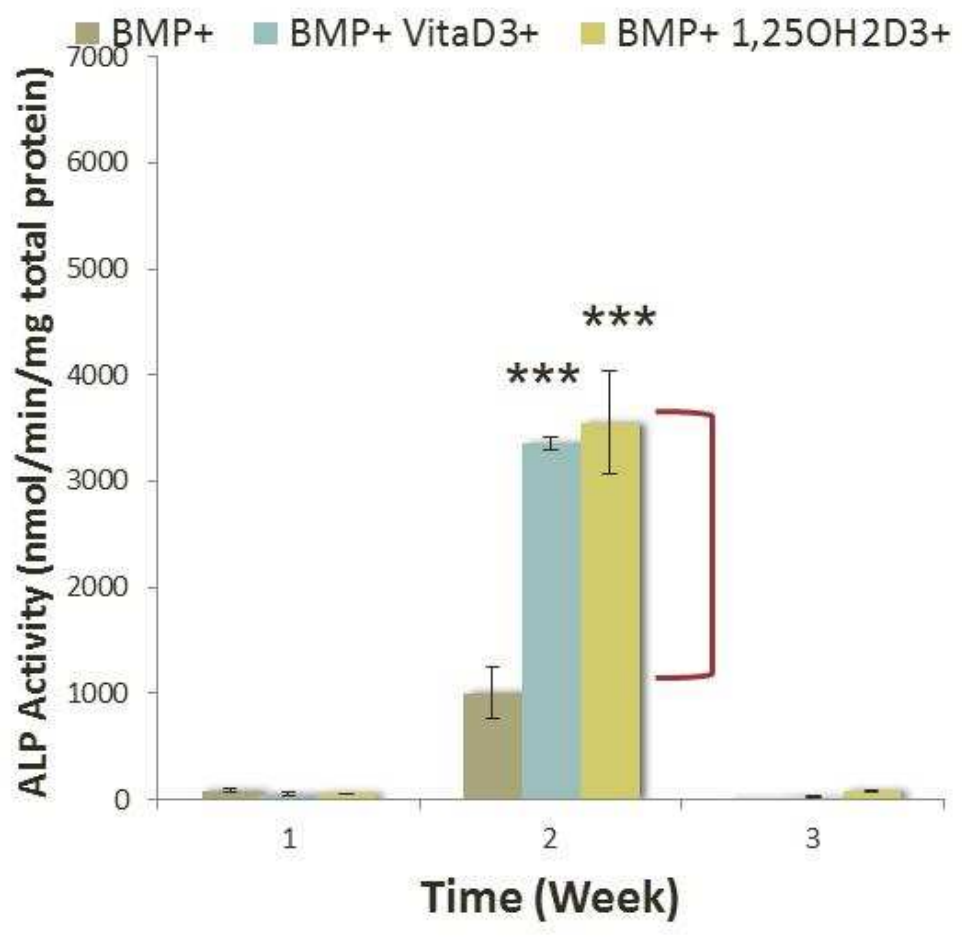

C

Figure 6-1. Temporal alkaline phosphatase activity of OPC1 treated with (A) ethanol vehicle control in standard bone medium (BM-), BM- containing $10 \mu \mathrm{M}$ vitamin $\mathrm{D}_{3}$, and $\mathrm{BM}$ - with $1,25 \mathrm{OH}_{2} \mathrm{D}_{3}$; (B) ethanol control in osteogenic medium $(\mathrm{BM}+)$ containing ascorbic acid, $\beta$-glycerophosphate, and dexamethasone, $\mathrm{BM}+$ containing $10 \mu \mathrm{M}$ vitamin $\mathrm{D}_{3}$, and $\mathrm{BM}+$ with $1,25 \mathrm{OH}_{2} \mathrm{D}_{3}$; (C) ethanol control in $\mathrm{BM}+$ containing rhBMP (BMP+), BMP+ containing $10 \mu \mathrm{M}$ vitamin $\mathrm{D}_{3}$, and $\mathrm{BM}$ - with $1,25 \mathrm{OH}_{2} \mathrm{D}_{3}$. Cellular isolates were collected on day 7, 14, and 21 during the differentiation time course. Treatment with both vitamin $\mathrm{D}$ metabolites significantly $(\mathrm{P}<0.01)$ influenced OPC1 ALP activity in all medium groups. 
(ii) Influence of vitamin D metabolites and osteogenic factors on OPC1 bone matrix mineralization.

The primary function of osteoblasts is to produce and maintain mineralized bone ECM. For samples cultured in BM- with or without vitamin D metabolites, vitaD $\mathrm{D}_{3}$ and $1,25 \mathrm{OH}_{2} \mathrm{D}_{3}$, calcium deposition was significantly $(\mathrm{P}<0.001)$ greater in cultures containing either vitamin D metabolites compared with the BM- ethanol control (see Figure 6-2). OPC1 cultured in BM+ with or without vitamin D metabolites showed a significantly $(\mathrm{P}<0.001)$ higher amount of calcium deposition throughout the three week culture period compared to that of cultures in BM-, and cultures containing either vitaD $\mathrm{D}_{3}$ or $1,25 \mathrm{OH}_{2} \mathrm{D}_{3}$ were significantly $(\mathrm{P}<0.001)$ higher than the $\mathrm{BM}+\mathrm{EtOH}$ control by the third week of culture time (see Figure 6-3). Cultures containing rhBMP (BMP+) showed a significant $(\mathrm{P}<0.001)$ amount of calcium deposition compared to that of the groups cultured in BM- throughout the three-week culture period. The presence of vitaD3 in $\mathrm{BMP}+$ medium showed a significant $(\mathrm{P}<0.01)$ amount of calcium deposition compared to that of the $\mathrm{BMP}+\mathrm{EtOH}$ control, and slightly significant $(\mathrm{P}<0.05)$ in the presence of $1,25 \mathrm{OH}_{2} \mathrm{D}_{3}$ (see Figure 6-4). 


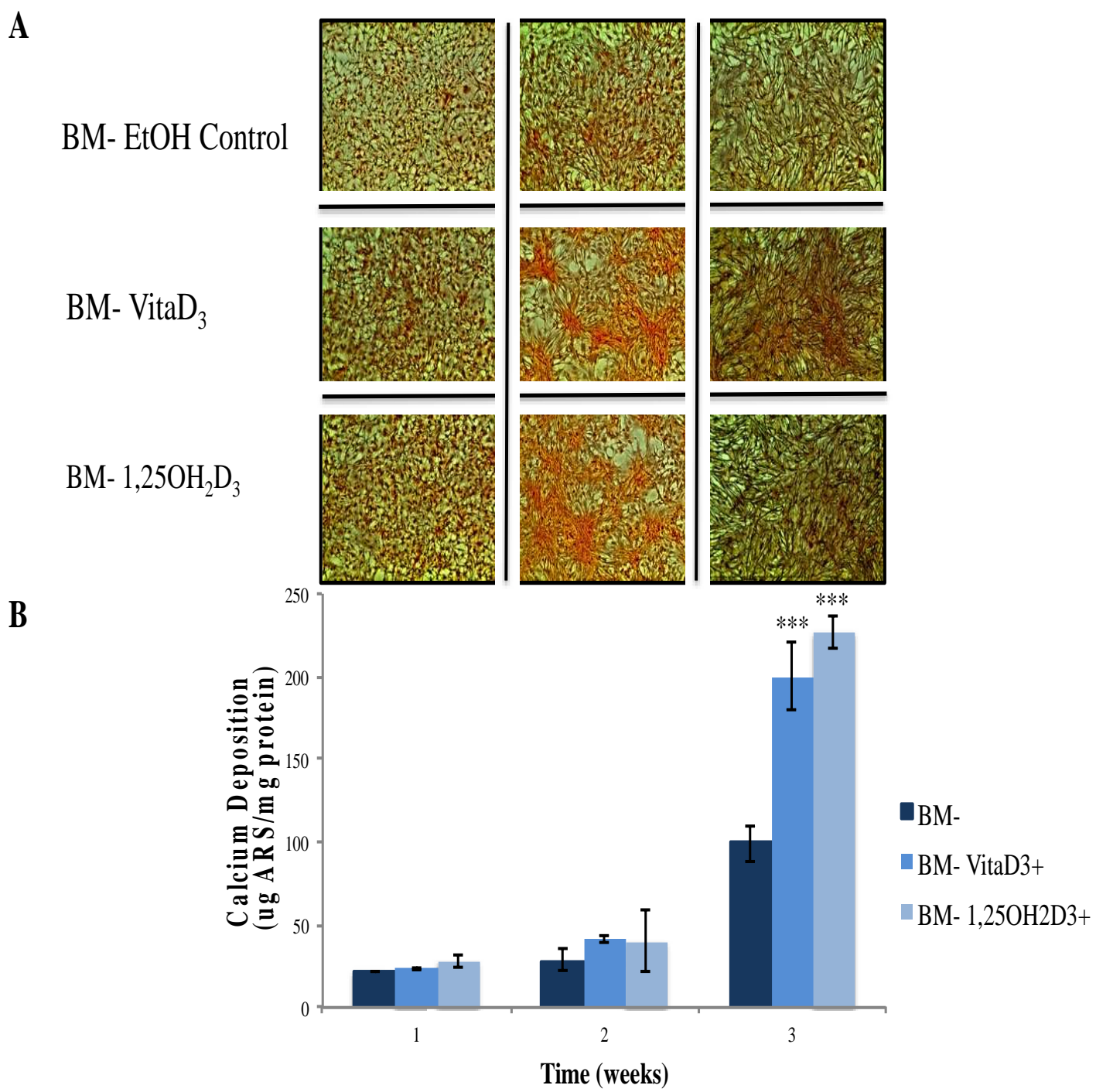

Figure 6-2. Calcium deposition stained with alizarin red stain (ARS) (A) of OPC1 cultured in $\mathrm{BM}$ - and vitamin $\mathrm{D}$ metabolites vita $\mathrm{D}_{3}$ and $1,25 \mathrm{OH}_{2} \mathrm{D}_{3}$. After microscopic analysis, ARS was extracted from each culture well, and read on a microplate reader (B). By week three of culture time, there was a significant $(\mathrm{P}<0.001)$ amount of calcium deposition detected by ARS in cells treated with either vita $\mathrm{D}_{3}$ or $1,25 \mathrm{OH}_{2} \mathrm{D}_{3}$ compared to that of the ethanol control. 


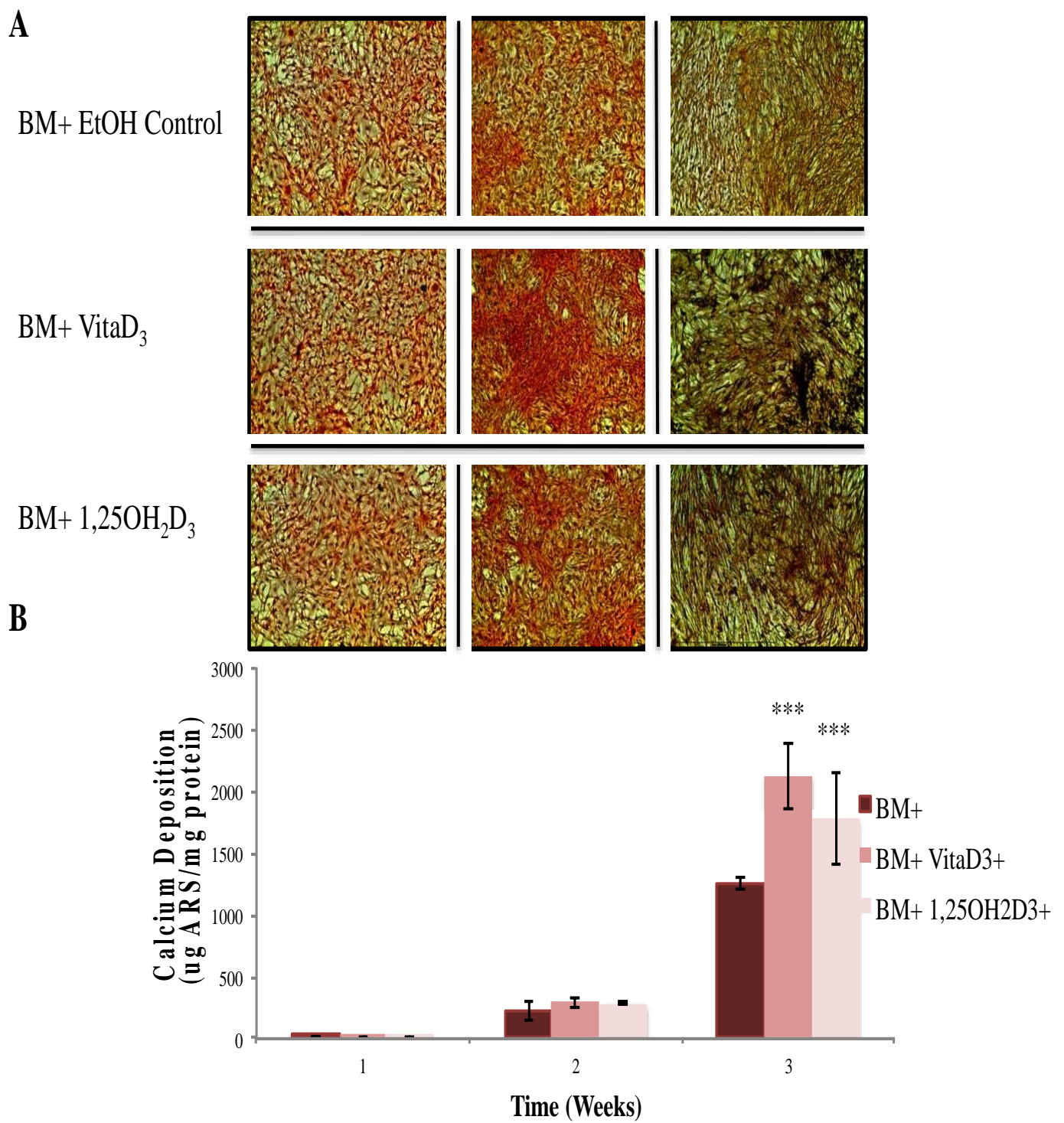

Figure 6-3. Calcium deposition stained with ARS (A) of OPC1 cultured in $\mathrm{BM}+$ and $\mathrm{vita}_{3}$ or $1,25 \mathrm{OH}_{2} \mathrm{D}_{3}$. After microscopic analysis, ARS was extracted from each culture well, and read on a microplate reader $(\mathrm{B})$. By week three of culture time, there was a significant $(\mathrm{P}<0.001)$ amount of calcium deposition detected by ARS in cells treated with either vita $\mathrm{D}_{3}$ or $1,25 \mathrm{OH}_{2} \mathrm{D}_{3}$ compared to that of the ethanol control. There was a significant $(\mathrm{P}<0.001)$ amount of calcium deposition compared to all BM-groups (see Figure 6-2). 
BMP+ EtOH Control
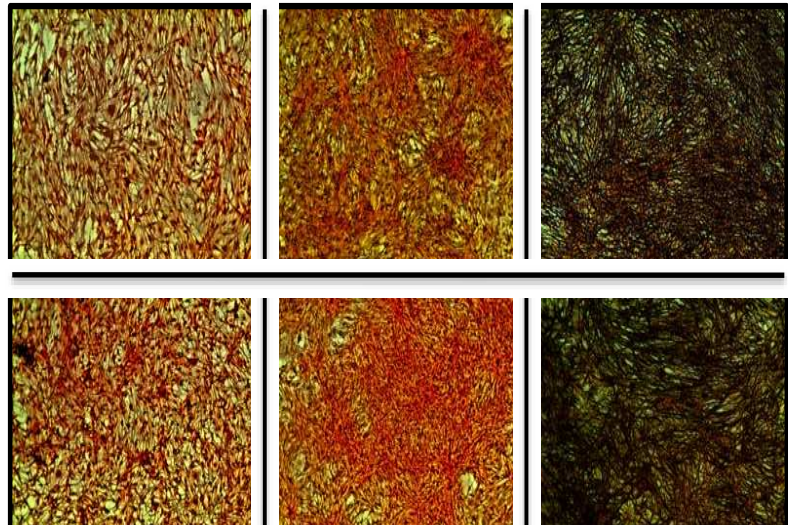

$\mathrm{BMP}+\mathrm{VitaD}_{3}$

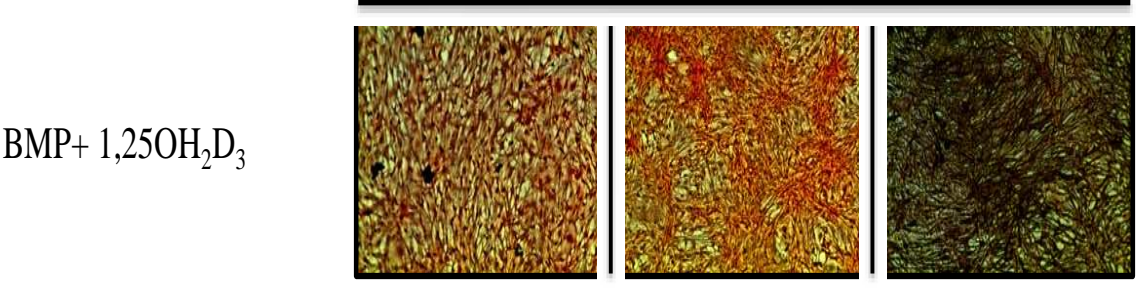

B

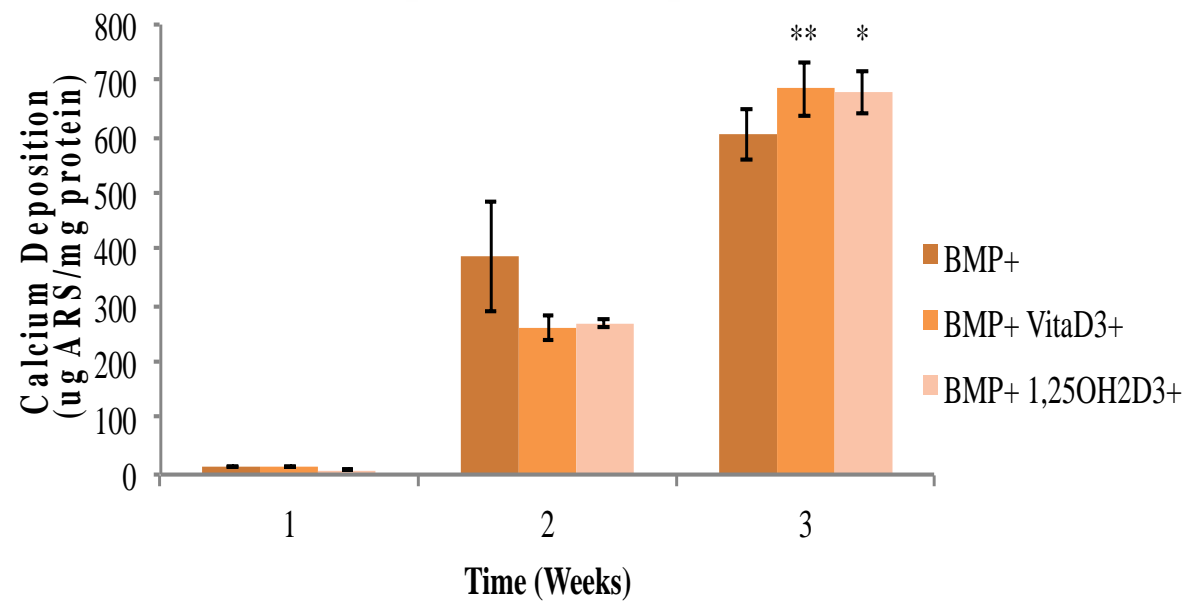

Figure 6-4. Calcium deposition stained with ARS (A) of OPC1 cultured in BM+ containing

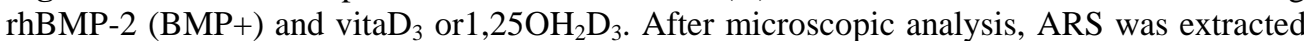
from each culture well, and read on a microplate reader $(\mathrm{B})$. In the second week of culture time, the BMP+ EtOH control had a significant amount of calcium deposition in comparison with the treatment groups. By week three of culture, there was a significant $(\mathrm{P}<0.01)$ amount of calcium deposition detected by ARS in cells treated with either vitaD $\mathrm{D}_{3}$ or $1,25 \mathrm{OH}_{2} \mathrm{D}_{3}$ compared to that of the ethanol control. There was a significant $(\mathrm{P}<0.001)$ amount of calcium deposition compared to all BM- groups (see Figure 6-2). 


\section{(iii) Expression of Vitamin D Associated mRNA in OPC1.}

CYP27A1 and CYP27B1 are hydroxylases demonstrated to be involved in the metabolism of vitaD3 to $25 \mathrm{OHD}_{3}$, and convert $25 \mathrm{OHD}_{3}$ to $1,25 \mathrm{OH}_{2} \mathrm{D}_{3}$ respectively. OPC1 expressed both CYP27A1 (Figure 6-5A) and CYP27B1 (Figure 6-5B) in response to the presents of $\mathrm{vitaD}_{3}$, relative to the $\mathrm{BM}-\mathrm{EtOH}$ control. Significant $(\mathrm{P}<0.001)$ increases occurred within the first 72 hours of treatment (treatment added on day 4 of culture), but decreased dramatically by the second week in the continuous presents of vita $\mathrm{D}_{3}$ (see Figure 6-5A and 6-5B). In the groups containing osteogenic factors $(\mathrm{BM}+$ and $\mathrm{BMP}+)$ the expression of CYP27A1 was higher than in the $\mathrm{BM}$ - group treated with vitaD $\mathrm{D}_{3}$, however in groups treated with $\mathrm{BMP}+, \mathrm{CYP} 27 \mathrm{~B} 1$ expression was lower than in the BM- and $\mathrm{BM}+$ groups treated with vitaD $\mathrm{D}_{3}$ OPC1 expressed CYP24A1 and VDR mRNA in response to vitaD $\mathrm{D}_{3}$ and $1,25 \mathrm{OH}_{2} \mathrm{D}_{3}$ (see Figure 6-5C and 6-5D). In the first week all groups treated with vitamin $\mathrm{D}$ metabolites had a significant $(\mathrm{P}<0.001)$ increase in CYP24A1 and VDR expression relative to the BM- control, however BMcultures treated with vitamin D expressed a much higher amount of CYP24A1 mRNA relative to BM- control, compared to the cultures containing osteogenic factors. After continuous presents of vitamin D, in the second week of culture time, CYP24A1 expression decreased for the BM- groups, but increased in groups containing $\mathrm{BM}+$ and $\mathrm{BMP}+$. All groups treated with vitaD $\mathrm{D}_{3}$ and $1,25 \mathrm{OH}_{2} \mathrm{D}_{3}$ had significant $(\mathrm{P}<0.001)$ VDR mRNA expression relative to the BM- control during the first week of culture time which decreased by the second week. 
$\mathbf{A}$

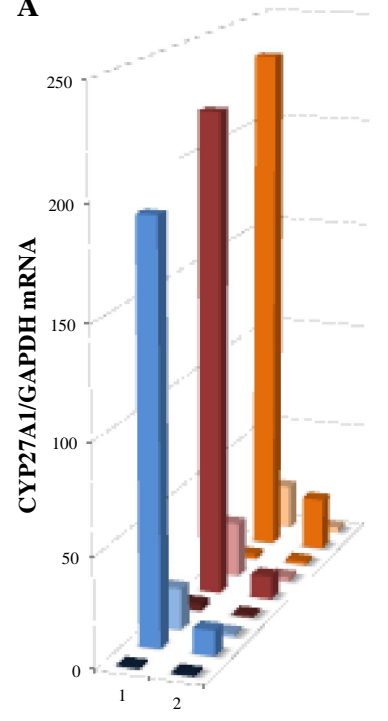

Time (Weeks)
B

- BM-

- $\mathrm{BM}-\mathrm{VitaD} 3+$

- BM- 1,25OH2D3+

- $\mathrm{BM}+$

- $\mathrm{BM}+\mathrm{VitaD} 3+$

$=\mathrm{BM}+1,25 \mathrm{OH} 2 \mathrm{D} 3+$

$=$ BMP+

= BMP+ VitaD3+

= $\mathrm{BMP}+1,25 \mathrm{OH} 2 \mathrm{D} 3+$
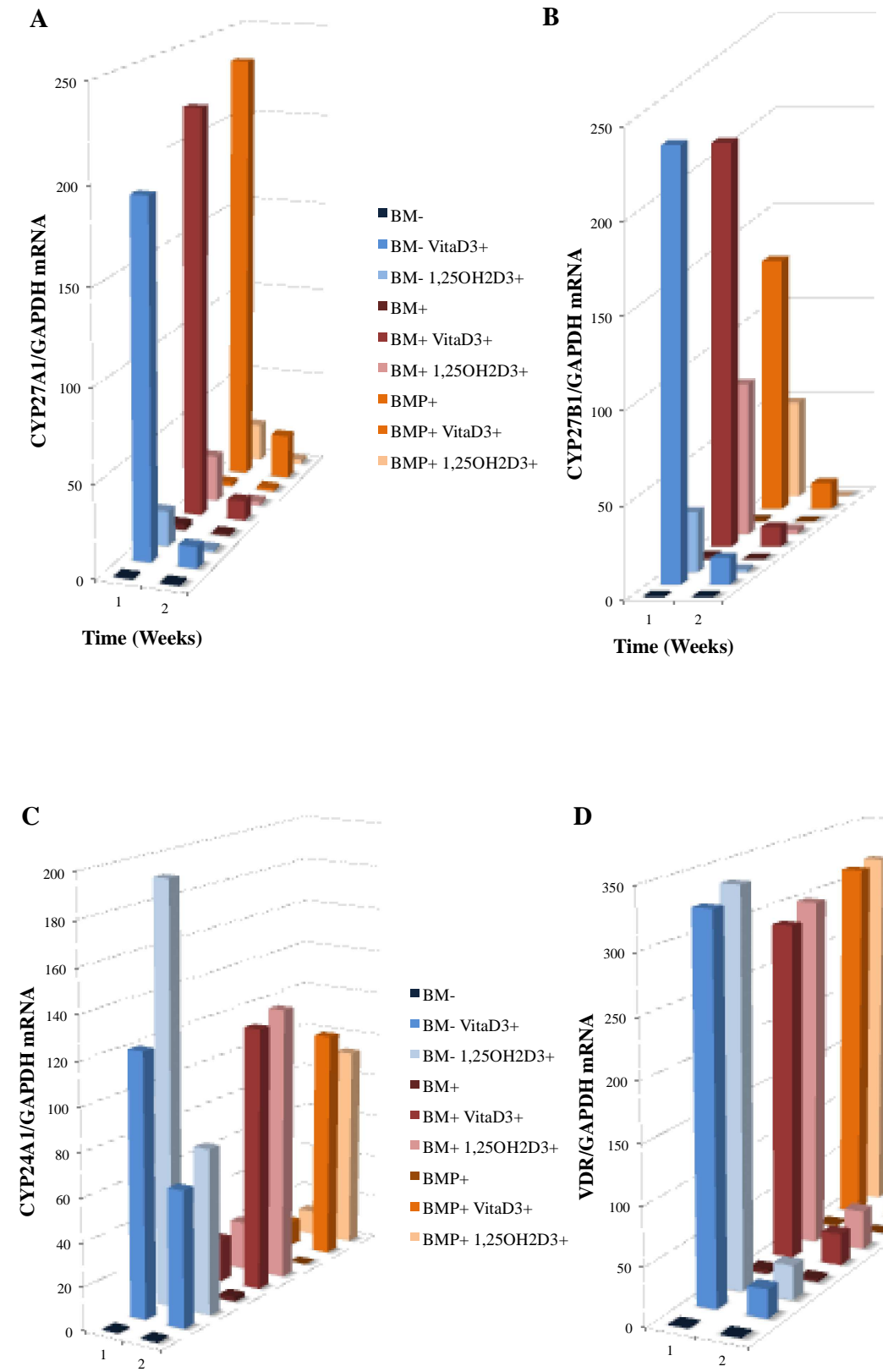

Time (Week)

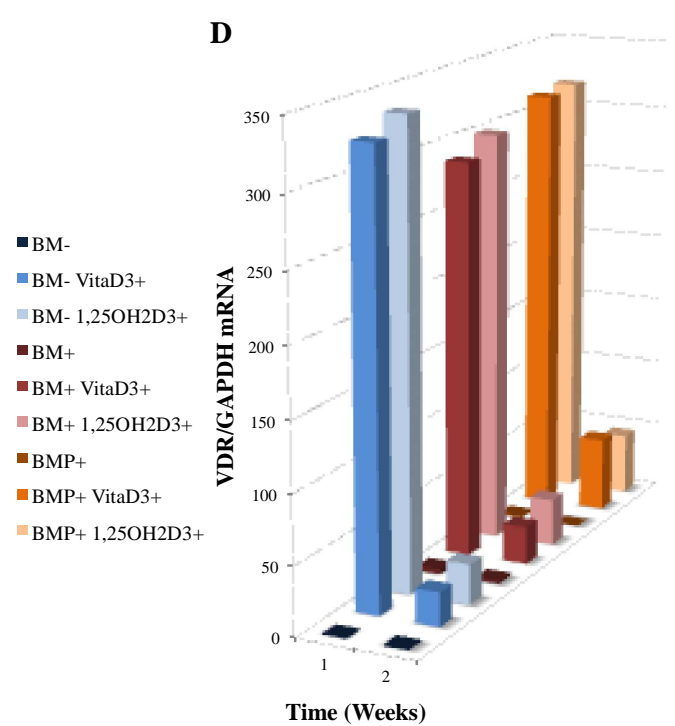

Time (Weeks)

Figure 6-5. Induced mRNA expression of (A) CYP27A1, (B) CYP27B1, (C) CYP24A1, and (D) VDR in OPC1 by vitaD3 and 1,25OH2D3 in standard bone medium (BM-) and medium containing osteogenic factors (BM+ and $\mathrm{BMP}+$ ). Total RNA was isolated and examined by quantitative RT-PCR. Data was normalized to GAPDH. 


\section{(iv) Expression of Osteogenic mRNA in OPC1}

Procollagen type I (proColI) precedes the production of ColI, a major component of bone ECM, has been shown to be enhanced during early osteoblast differentiation, while $\mathrm{OC}$ and $\mathrm{OP}$ are identified with later stages of osteoblast differentiation and bone development. Real-time PCR analysis showed a significant $(\mathrm{P}<0.001)$ increase in proColI mRNA expression during the first week of OPC1 culture in all groups relative to the BM- control, and a higher increase with treatment groups containing either vitaD $\mathrm{D}_{3}$ or $1,25 \mathrm{OH}_{2} \mathrm{D}_{3}$ (see Figure 6-6A). There was no significant expression of proColI mRNA in the second week in any of the culture groups. In contrast to the expression of proColI, OP mRNA expression was not seen in the first week of culture time in any of the groups and increased in both second and third week of culture relative to the BM- control (see Figure 6-6B). The $\mathrm{BMP}+$ control without vitamin D displayed the highest OP mRNA expression relative to the BM- control. Similar to OP mRNA expression, expression of $\mathrm{OC}$ mRNA was highest in the $\mathrm{BMP}+$ control group, but was increased in all groups relative to the BM- control (see Figure 6-6C). However, in contrast to OP mRNA expression, OC expression was increased in the first week, and continued to increase during the three-week culture period. 


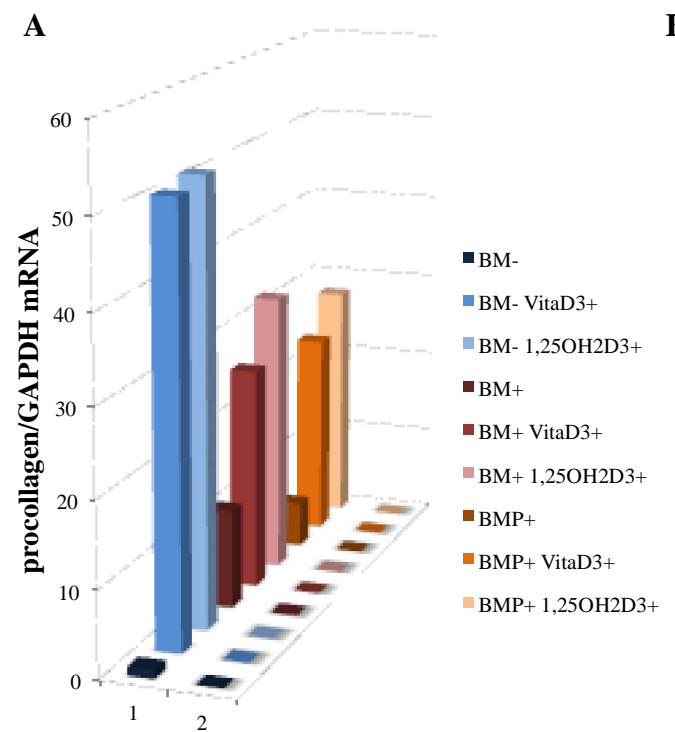

Time (Weeks)

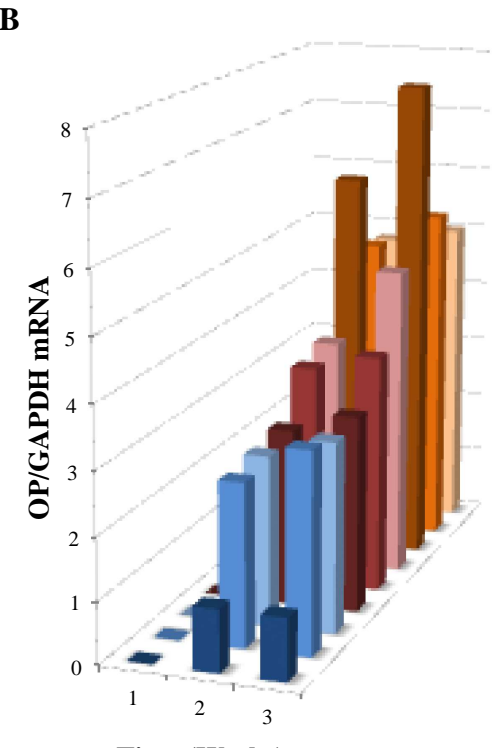

Time (Weeks)

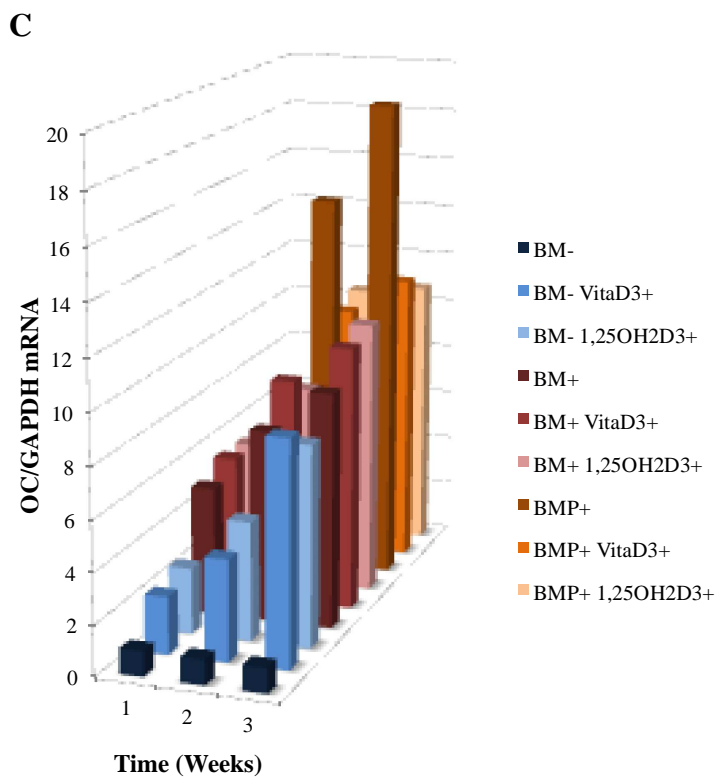

Figure 6-6. Induced mRNA expression of (A) proColI, (B) OC, and (C) OP mRNA in OPC1 cultures containing vitaD $\mathrm{D}_{3}$ or $1,25 \mathrm{OH}_{2} \mathrm{D}_{3}$ and/or osteogenic factor $(\mathrm{BM}+$ or $\mathrm{BMP}+)$. Total RNA was isolated and examined by quantitative RT-PCR. Data was normalized to GAPDH. 


\section{Section 6.08 Discussion}

In this study, an engineered osteoblast precursor cell line, OPC1, was used to examine the effect of vitamin $\mathrm{D}$ metabolites, vitaD 3 and $1,25 \mathrm{OH}_{2} \mathrm{D}_{3}$, on the maturation and mineralization of culture expanded cells during bone development. In comparison to the untreated cells, vitamin D metabolites in combination with ascorbic acid, $\beta$ glycerophosphate, dex and/or BMP-2, produced more calcium deposition and showed a greater increase in ALP over time. Cultures containing osteogenic factors varied in ALP activity depending on the present of rhBMP-2. In addition to ALP activity and calcium deposition, mRNA expression of proColI, OC, and OP were analyzed over the threeweek culture period, as well as the mRNA expression of genes associated with vitamin D action and metabolism.

Osteoblasts are bone-forming cells derived from multipotential progenitor cells within the bone marrow stroma that also are capable of committing to other mesenchymal lineages, including fibroblasts, myoblasts, chondrocytes, adipocytes, and osteoblasts [Hicok, et al., 1998; Swolin-Eide, 2002]. Once precursors have committed to a specific lineage, tissue specific molecules are expressed. Phenotypical characteristics of an osteoblast include the synthesis and mRNA expression of $\operatorname{prCol} I$ preceded by $\mathrm{Col} I$, OC, OP, VDR, increased ALP activity, and the ability to mineralize ECM. When osteoblast precursors commit to the osteoblastic lineage, the osteoblasts express bone matrix protein genes at different expression levels depending on the maturation level of the cells [Komori, 2010]. For example, immature mesenchymal cells and preosteoblasts weakly express ColI and ColII, while immature osteoblasts express OP, and bone sialoprotein 
(BSP), and mature osteoblasts strongly express OC [Komori, 2010]. Mature osteoblasts become osteocytes when they are embedded into the bone matrix and express dentin matrix protein 1 (DMP-1).

In vitro human osteoblasts respond to exogenous $1,25 \mathrm{OH}_{2} \mathrm{D}_{3}$ by decreasing their rate of proliferation while increasing their expression of mRNA of osteogenic biomarkers such as OC and OP. While it has been known that circulating vitamin D is derived from the kidneys, recently a number of studies have demonstrated the extra-renal synthesis of $1,25 \mathrm{OH}_{2} \mathrm{D}_{3}$ from $25 \mathrm{OHD}_{3}$ in skin, liver, lymph nodes, activated monocytes/macrophages, dendritic cells, and osteoblasts [Atkins, et al., 2007]. In contrast to extra-renal metabolism of $25 \mathrm{OHD}_{3}$ to $1,25 \mathrm{OH}_{2} \mathrm{D}_{3}$, there have been occasional reports of extrahepatic metabolism of $\operatorname{vitaD}_{3}$, but no detailed analysis until now. Recently, we demonstrated that OPC1 could metabolize vita $\mathrm{D}_{3}$ to $1,25 \mathrm{OH}_{2} \mathrm{D}_{3}$ in a dose-dependent manner, and in this experiment, we were able to demonstrate the upregulation of mRNA expression of vitamin D associated hydroxylases CYP27A1, CYP27B1, and CYP24A1, as well as VDR in response to vitaD $\mathrm{D}_{3}$. It was also demonstrated that vita $\mathrm{D}_{3}$ influenced the expression of osteogenic mRNA proColI, OC, and $\mathrm{OP}$ in the same manner as $1,25 \mathrm{OH}_{2} \mathrm{D}_{3}$.

In addition to the effects of vitamin D on OPC1, vitamin D in combination with common osteogenic factors, ascorbic acid, $\beta$-glycerophosphate, dex, and BMP-2 was investigated. It was demonstrated that in combination with these osteogenic factors, matrix maturation and mineralization was significantly increased. However, there were differential results in bone maturation associated with ALP activity seen in cultures treated with BMP+ (see Figure 6-1C). ALP expression is associated with bone cell 
phenotype, and in heavily mineralized cultures, cellular levels of ALP decline [Lian \& Stein, 1992]. OPC1 cultured with BMP+ with or without vitamin D metabolites demonstrated an increase in mineralization, and consequently with the mRNA expression of $\mathrm{OC}$ and $\mathrm{OP}$, proteins that are known to increase with the accumulation of mineralization, compared to $\mathrm{BM}-$ and $\mathrm{BM}+$ groups with or without vitamin $\mathrm{D}$ metabolites. These results indicate that rhBMP-2 had a major influence on OPC1 bone mineralization, that may exceed the influence of vitamin D. A major limitation to this results, was that $\mathrm{BMP}+$ cultures were so heavily mineralized that by day 17 of culture time, the monolayer began to detach from the culture vessel.

It has been demonstrated that using dex, BMP-2, and $1,25 \mathrm{OH}_{2} \mathrm{D}_{3}$ enhance a more differentiated osteoblast phenotype [Jorgensen, et al., 2004], however in this study, OP and OC mRNA expression in groups treated with vita $\mathrm{D}_{3}$ or $1,25 \mathrm{OH}_{2} \mathrm{D}_{3}$ and $\mathrm{BMP}+$ was slightly lower then the BMP+ control, but higher then the osteogenic medium containing vitamin D metabolites and no BMP $(\mathrm{BM}+)$ (see Figure 6-6B and 6-6C). This may be because we used a higher dose of $1,25 \mathrm{OH}_{2} \mathrm{D}_{3}$, which would also explain the very significant increase in catabolic enzyme mRNA expression of CYP24A1 seen in the second week of culture (see Figure 6-5). In addition, it could be postulated that as a regulator of ECM mineralization, vitamin D dampened the effects of BMP. Many in vitro vitamin D studies investigating the anti-proliferative and pro-differentiative effects of vitamin $\mathrm{D}$ are short-term and use a supra-physiological dose, howver, for long-term cultures using vitamin D as an osteognenic factor, it may be beneficial to use a dose that is more closely resmbles the phsyiological dose. 
It has been long recognized that long-term or excessive use of glucocorticoid (GC) excess, whether from endogenous hypersecretion or iatrogenically, manifests adverse skeletal effects such as osteoporosis [Walsh, et al., 2001]. In human subjects receiving long-term GC treatment, bone loss is associated with the decrease in overall bone formation rate and in the mean thickness of the walls on newly synthesized trabecular bone, a pattern consistent with the decrease in number and/or activity of osteoblasts rather than the increase in number and/or activity of osteoblasts [Walsh, et al., 2001]. Paradoxically, several studies have demonstrated that treating cells derived from human bone with GCs promotes osteogenic differentiation, and has been proposed as a standard supplement for the ex vivo expansion of cells with osteogenic potential for use in tissue reconstruction and repair [Walsh, et al, 2001]. Dexamethasone (dex) is a GC that is commonly used as an inducer of bone marrow stromal cell differentiation, which reliably stimulates the development of many, but not all, phenotypic features of human osteoblasts [Jorgensen, et al., 2004]. However, GCs have deleterious effects in vivo, resulting in inhibition of osteoblast function. Bone morphogenetic protein-2 (BMP-2) is another inducer of osteoblast differentiation, and is essential for postnatal bone formation. BMP-2 has been used to induce osteoblast differentiation in vitro in many human and animal models, and is believed to provide a more physiologic stimulus than dex, however it appears to enhance a more mature osteoblast characteristic [Jorgensen, et al., 2004], as was seen here. 


\section{ACKNOWLEDGEMENT}

The authors appreciate the generous support given by fellow laboratory members in the Department of Molecular and Medical Genetics, Oregon Health \& Science University. Partial funding was provided by the National Institutes of Health (Grant No. P20 MD003350) and the Collins Medical Trust.

\section{REFERENCES}

Ahmed, M. S., \& Shoker, A. (2010). Vitamin D metabolites; protective versus toxic properties: molecular and cellular perspectives. Nephrology Reviews , 2 (1):e5.

Ambrecht, H. J., Hodam, T. L., Boltz, M. A., Patridge, N. C., Brown, A. J., \& Kumar, V. B. (1998). Induction of the vitamin D 24-hydroxylase (CYP24) by 1,25dihydroxyvitamin D3 is regulated by parathyroid hormone in UMR106 osteoblastic cells. $139(8), 3375-81$.

Atanga, E., Dolder, S., Dauwalder, T., Wetterwald, A., \& Hofstetter, W. (2011). TNFa inhibits the development of osteoclasts through osteoblast-derived GM-CSF. Bone , 49, 1090-1100.

Atkins, G. J., Anderson, P. H., Findlay, D. M., Welldon, K. J., Vincent, C., Zannettino, A. C., et al. (2007). Metabolism of vitamin D3 in human osteoblasts: evidence for autocrine and paracrine activities of 1a, 25-dihydroxyvitamin D3. Bone , 40, 1517-1528.

Biswas, P., \& Zanello, L. P. (2009). 1,25(OH)2 vitamin D3 induction of ATP secretion in osteoblasts. $J$ of Bone and Miner Res , 34 (8), 1450-1460. 
Bouillon, R., Carmeliet, G., Verlinden, L., van Etten, E., Verstuyf, A., Luderer, H. F., et al. (2008). Vitamin D and human health: lessons from vitamin D receptor null mice. Endocrine Reviews , 29 (6), 726-776.

Boyan, B. D., Chen, J., \& Schwartz, Z. (2012). Mechanims of Pdia3-dependent 1,25-dihydroxy vitamin D3 signaling in muscloskeletal cells. Steroids , 77 (10), 892-896.

Boyan, B. D., Hurst-Kennedy, J., Denison, T. A., \& Schwartz, Z. (2009). Cellular responses to 24R,25-dihydroxyvitamin D3 in bone and cartilage. Immun, Endoc \& Metab Agents in Med Chem, 9, 137-142.

Brannon , P. M. (2012). Key questions in vitamin D research. Scand J Clin Lab Invest , 73 (Suppl 243), 154-162.

Buttery, L. D., Bournes, S., Xynos, J. D., Wood, H., Hughes, F. J., Hughes, S. P., et al. (2001). Differentiation of osteoblasts and in vitro bone formation from murine embryonic stem cells. Tissue Eng , 7 (1), 89-99.

Chen, G., Kim, S. H., King, A. N., Zhao , L., Simpson , R. U., Christensen, P. J., et al. (2011). CYP24A1 is an independent prognostic marker of survival in patients with lung carcinoma. Clin Cancer Res , 17, 817.

Flanagan, J. N., Young, M. V., Persons, K. S., Wang, L., Mathieu, J. S., Whilatch, L. W., et al. (2006). Vitamin D metabolism in human prostate cells: impications for prostate cancer chemoprevention by vitamin D. Anticancer Research, 26, 2567-72.

Geng, S., Zhou, S., \& Glowacki, J. (2011). Effects of 25-hydroxyvitamin D3 on proliferation and osteoblast differentiation of human marrow stromal cells require CYP27B1/1a-hydroxylase. J of Bone and Miner Res , 26 (5), 1145-1153. 
Hicok, K. C., Thomase, T., Gori, F., Rickard, D. J., Speksberg, T. C., \& Riggs, B. L. (1998). Development and characterization of chonditionally immortalized osteoblast precursor cells from human stroma. JBMR, 13 (2), 205-217.

Hobaus, J., Thiem, U., Hummel, D. M., \& Kallay, E. (2013). Role of calcium, vitamin D, and the extrarenal vitamin D hydroxylases in carcinogenesis. Anti-Cancer Agent in Medicinal Chemistry, 13 (1), 20-35.

Hoemann, C. D., El-Gabalawy, H., \& McKee, M. D. (2009). In vitro osteogenesis assays: influence of the primary cell source on alkaline phosphatase activity and mineralization. Pathologie Biologie , 57, 318-323.

Hollick, M. F. (2010). Vitamin D: extraskeletal health. Endocrin and Metab Clin, $39(2)$.

Huang, Y. L., Qiu, R. F., Mai, W. Y., Kuang, J., Cai, X. Y., Dong, Y. G., et al. (2012). Effects of insulin-like growth factor-1 on the properties of mesenchymal stem cells in vitro. J Zhehiang Univ Sci B , 13 (1), 20-8.

Jones, G., Strugnell, \& DeLuca, H. F. (1998). Curent understandings of the molecular action of vitamin D. Physiological Reviews , 78 (4), 1193-1231.

Jorgensen, N. R., Henriksen, Z., Sorensen, O. H., \& Civitelli, R. (2004).

Dexamethasone, BMP-2, and 1,25-dihydroxyvitamin D enhance a more differentiated osteoblast phenotype: validation of an invitro model for human bone marrow-derived primary osteoblasts. Steroids , 69, 219-226.

Komori, T. (2010). Regulation of bone development and extracellular matrix protein gene by RUNX2. Cell and Tissue Research, 330 (1), 189-195. 
Lian, J. B., \& Stein, G. S. (1992). Concepts of osteoblast growth and differentiation: bass for modulation of bone cell development and tissue formation. Critical Reviews in Oral Biology and Medicine , 3 (2), 269-305.

Mason, S. S., Koles , S. S., Zelick, R. D., Winn, S. R., \& Saha, A. K. (2011). Three-dimensional culture of cells and matrix biomolecules for engineered tissue development and biokinetics model validation. J Nanotechnol Eng Med, 2 (2), 025001-7. Naeem, Z. (2010). Vitamin D defficiency - an ingnored epidenmic. Int J Health Sci , 4 (1), V-VI.

Mason, S.S., Kohles, S. S., Zelick, R. D, Winn, S. R. (2013). Extrahepatic 25hydroxylation of vitamin D3 in an engineered osteoblast precursor cell line exploring the influence on cellular proliferation and matrix maturation during bone development. ISRN Biomedical Engineering. [Ahead of Print].

Norman, A. W. (1998). Sunlight, season, skin pigmentation, vitamin D, and 25hydroxyvitamin D: integral components of the vitamin D endocrine system. Am J clin Nutr , 67, 1108-10.

Otero, M., Favero, M., Dragomir, C., Hachem, K. E., Hashimoto, K., Plumb, D. A., et al. (2012). Human chondrocyte cultures as models of cartilage-specific gene regulation. In Human cell culture protocols (Vol. 806, pp. 301-336). Humana Press. Pairse, R. A., Egorin, M. J., Kanterewicz, B., Taimi, M., Petkovich, M., Lew, A. M., et al. (2006). CYP24, the enzyme that catabolizes the antiproliferative agent vitamin $\mathrm{D}$, is increased in lung cancer. In J Cancer , 119, 1819-1828. 
Pevsner-Fischer, M., Levin, S., \& Zipori, D. (2011). The origins of mesenchymal stromal cell heterogeneity. Stem Cell Rev and Rep , 7, 560-568.

Seiffert, M., Rech, M., Meineke, V., Tilgen, W., \& Rechrath, J. (2004).

Differential biological effects of 1,25-dihydroyxy Vitamin D3 on melanoma cell lines in vitro. J of Steroid Biochem \& Molec Bio , 89-90, 375-379.

Swolin-Eide, D. (2002). Studies of human osteoblast-like cells;-effects of growth hormone and steroids. JIFCC, 13 (4).

Trump, D. L., Deeb, K., \& Johnson, C. S. (2010). Vitamin D: Considerations in the continued development as an agent for cancer prevention and therapy. Cancer $J, 16$ (1), 1-9.

Walsh, S., Jordan, G., Jefferiss, C., Stewart, K., \& Beresford, J. (2001). High concentrations of dexamethasone supress the proliferation but not the differentiation or further maturation of human osteoblast precursors in vitro: relevance to glucocorticoidinduced osteoprosis. Rheumatology, 40, 74-83.

Winn, R. S., Randolph, G., Uludag, H., Wong, S. C., Hair, G. A., \& Hollinger , J. O. (1999). Establishing an Immortalized Human Osteoprecursor Cell Line: OPC1. Journal of Bone and Mineral Research, 14 (10), 1721-1733.

Yamamoto, Y., Yoshizawa, T., Fukuda, T., Shirode-Fukuda, Y., Nakamichi, Y., Watanabe, T., et al. (2013). Vitamin D receptor in osteoblasts is a negative regulator of bone mass control. Calcium-Regulating Hormones , 154 (3), 1008-1020. 
Zhou, S., Glowacki, J., Kim, S. W., Hahne, J., Geng, S., Mueller, S. M., et al. (2012). Clinical characterizatics influence in vito action of 1,25-dihydroxyvitamin $\mathrm{D}(3)$ in human marrow stromal cells. . J Bone Miner Res, Ahead of Print. 


\section{WORKS CITED}

Adorini, L., Penna, G., Amuchastegui, S., Cossetti, C., Aquilano, F., Mariana, R., et al. (2007). Inhibition of prostate growth and inflammation by the vitain D receptor agonist BXL-628 (elocalcitol). J of Steroid Biochem \& Molec Bio, 193, 689-690.

Ahmed, M. S., \& Shoker, A. (2010). Vitamin D metabolites; protective versus toxic properties: molecular and cellular perspectives. . Nephrology Reviews, 2(1).

Ambrecht , H. J., Hodam, T. L., Boltz, M. A., Patridge, N. C., Brown , A. J., \& Kumar, V. B. (1998). Induction of the vitamin D 24-hydroxylase (CYP24) by 1,25dihydroxyvitamin D3 is regulated by parathyroid hormone in UMR106 osteoblastic cells. $139(8), 3375-81$.

Ando, K., Lmai, S., Isoya, E., Kubo, M., Mimura, T., Shioje, S., et al. (2009). Effect of dynamic compressive loading and its combination with a growth factor on chondrocytic phenotype of 3-dimmensional scaffold-embedded chondrocytes. Acta Orthopaedica, 80(60), 724-733.

Annweiler, C., Schott, A. M., Berrut, G., Chauvre, V., Le Gal, D., Inzitari , M., et al. (2010). Vitamin D and ageing: neurological issues. Neuropsychobiology, 62(3), $139-50$.

Appleman, T. P., Mizrahi, J., Elisseeff, J. H., \& Seliktar, D. (2009). The differential effect of scaffold composition and architecture on chondrocyte response to mechanical stimulation. Biomaterials, 30, 518-525.

Atala, A., \& Lanza, R. P. (2002). Methods of Tissue Engineering. Philadelphia, PA: Elisevier. 
Atanga, E., Dolder, S., Dauwalder, T., Wetterwald, A., \& Hofstetter, W. (2011). TNFa inhibits the development of osteoclasts through osteoblast-derived GM-CSF. Bone, 49, 1090-1100.

Atkins, G. J., Anderson, P. H., Findlay, D. M., Welldon, K. J., Vincent, C., Zannettino, A. C., et al. (2007). Metabolism of vitamin D3 in human osteoblasts: evidence for autocrine and paracrine activities of 1a, 25-dihydroxyvitamin D3. Bone, 40, $1517-$ 1528 .

Bahney, C. S., Hsu, C. W., Yoo, J. U., West, J. L., \& Johnstone, B. (2011). A bioresponsive hydrogel tuned to chondrogenesis of human mesenchymal stem cells. FASEB J.

Barbero, A., \& Martina, I. (2007). Tissue Engineering (2nd ed.). (H. Hauser, \& M. Fussenegger, Eds.) Totowa, NJ: Humana.

Barlic, A., \& Kregar-Velikonja, N. (2008). Re-differentiation of human articular chondrocytes is not enhance by a rotary bioreactor system. Folia Biol, 54, 177179.

Barlic, A., \& Martina, I. (2008). Re-differentiation of human and articular chondrocytes is not enhanced by a rotary bioreactor system. Folia Biol, 54, 177-179.

Beal, M. (2001). Aging, energy, and oxidative stress in neurodegenerative disease. Annals of Neurology, 38(3), 357-366.

Berg, J. P. (1999). Vitamin D-binding protein prevents vitamin D deficiency and present itamin D for its renal a ctivation. Eur J of Endicrinology, 141, 321-322. 
Biswas, P., \& Zanello, L. P. (2009). 1,25(OH)2D vitamin D3 induction of ATP secretion in osteoblasts. J Bone Miner Res, 24, 1450-1460.

Bosshardt, D. D., Zalzal, S., Mckee, M. D., \& Nanci, A. (1998). Developmental appearence and distribution of bone sialoprotein and osteopontin in human and rat cementum. Anat Rec, 250(1), 13-33.

Bouillon, R., Carmeliet, G., Verlinden, L., van Etten, E., Verstuyf, A., Luderer, H. F., et al. (2008). Vitamin D and human health: lessons from vitamin D receptor null mice. Endocrine Reviews, 29(6), 726-776.

Boulion, R., Van Assche, F., Van Baelen, H., Heyns, W., \& De Moor, P. (1981). Influence of vitamin D-binding protein on the serum concentration of 1,25dihydroxyvitamin D3. J Clin Inves, 67, 589-596.

Boyan, B. D., Chen, J., \& Schwartz, Z. (2012). Mechanims of Pdia3-dependent 1,25dihydroxy vitamin D3 signaling in muscloskeletal cells. Steroids, 77(10), 892896.

Boyan, B. D., Hurst-Kennedy, J., Denison, T. A., \& Schwartz, Z. (2009). Cellular responses to 24R,25-dihydroxyvitamin D3 in bone and cartilage. Immun, Endoc \& Metab Agents in Med Chem, 9, 137-142.

Brannon , P. M. (2012). Key questions in vitamin D research. Scand J Clin Lab Invest, 73(Suppl 243), 154-162.

Brockbank, K. G. (2000). Tissue engineering constructs and comercialization. Austin, TX: Landes Biosciene. 
Bruder, S. P., Fink, D. J., \& Caplan, A. I. (1994). Mesenchymal stem cells in bone development, bone repair, and skeletal regeneration therapy. Journal of Cellular Biochemistry, 56(3), 283-294.

Burdick, J. A., \& Vunjak-Novakovic, G. (2009). Engineered microenvironments for controlled stem cell differentiation. Tissue Eng Part A, 15(2), 205-219.

Buttery, L. D., Bournes, S., Xynos, J. D., Wood, H., Hughes, F. J., Hughes, S. P., et al. (2001). Differentiation of osteoblasts and in vitro bone formation from murine embryonic stem cells. Tissue Eng, 7(1), 89-99.

Cartnmell, S. H., Porter, B. D., Garcia, A. J., \& Guldberg, R. E. (2003). Effects of medium perfusion rate on cell-seeded three-dimensional bone constructs in vitro. Tissue Eng, 9(6), 1197-1203.

Chan, B. P., \& Leong, K. W. (2008). Scaffolding in tissue engineering: general approaches and tissue-specific considerations. Eur Spine J, 17(Suppl 4), 467-479.

Chao, P. G., Grayson, W., \& Vunjak-Novakovic, G. (2007). Engineering cartilage and bone using human mesenchymal stem cells. J Orthop Sci, 12(4), 398-404.

Chen, G., Kim, S. H., King, A. N., Zhao , L., Simpson , R. U., Christensen, P. J., et al. (2011). CYP24A1 is an independent prognostic marker of survival in patients with lung carcinoma. Clin Cancer Res, 17, 817.

Cheung, Y. K., Shiovitz, D. A., Costa, K. D., Seliktar, D., \& Sia, S. K. (2009). Microscale control of stiffness in a cell-adhesive substrate using microfluidicsbased lithography. Angew Chem Int Ed, 48, 7188-7192. 
Choi, J. B., Youn, I., Cao, L., Leddy, H. A., Cilchrist, C. L., Setton, L. A., et al. (2007). Zonal changes in the three-dimensional morphology of the chondron under compression: the relationship among cellular, pericellular, and extracellular deformation in articular cartilage. J Biomech, 40, 2596-2603.

Chui, H., Janichich, C., \& Kohles, S. S. (2009). An instrumented bioreactor with biomechanical and biochemical assessment for tissue engineering. Sigma Xi Columbia Willamette Res Symp. Portland.

Chung, P. G., \& Burdick, J. A. (2008). Engineering cartilage tissue. Adv Drug Delivery Rec, 60(2), 243-262.

Clark, B. (2008). Normal bone anatomy and physiology. American Society of Nephrology, S131-139.

Cooper, G. M. (2000). Signaling Molecules and Their Receptors. In G. M. Cooper, The Cell: A Molecular Approach (2nd ed.). Sunderlan, MA: Sinauer Associates.

De Kok, I. J., Hicok, K. C., Padilla, R. J., Young, R. G., \& Cooper, L. F. (2006). Effect of vitamin D pretreatment of human mesenchymal stem cells on extopic bone formation. Research, 32(3), 103-109.

Eijken, M., Koedame, M., van Driel, M., Burrman, C. J., Pols, H. A., \& van Leuuwen, J. T. (2006). The essential role of glucocorticoids for proper human osteoblast differentiation and matrix mineralization. Molecular and Cellular Endocrinology.

El-Bialy, T. H. (2010). Low intemsity pulsed ultrasound: a laboratory and clinical promotor in tissue engineering. In E. D, Tissue Engineering (pp. 307-322). Rijeka, Croatia: InTech. 
Flanagan, J. N., Young, M. V., Persons, K. S., Wang, L., Mathieu, J. S., Whilatch, L. W., et al. (2006). Vitamin D metabolism in human prostate cells: impications for prostate cancer chemoprevention by vitamin D. Anticancer Research, 26, 256772.

Fodor, W. : (2003). Tissue engineering and cell based therapies, from the bench to the clinic: the potential to replace, repair and regenerate. Reproductive Biology and Endocrinology, 1, 102-108.

Francioli, S. E., Candrian, C., Martin, K., Heberer, M., Martin, I., \& Barbero, A. (2010). Effect of three-dimensional expansion and cell seeding density on the cartilageforming capacity of human articular chondrocytes in type II collagen sponges. $J$ Biomed Mater Res A, 95(3), 924-31.

Freed, L. E., Guilark, F., Guo, E., Gray, M. L., Tranquilo, R., Holmes, J. W., et al. (2006). Advanced tools for tissue engineering: scaffolds, bioreactors, and signaling. Tissue Engineering, 12(12), 3285-3305.

Geng, S., Zhou, S., \& Glowacki, J. (2011). Effects of 25-hydroxyvitamin D3 on proliferation and osteoblast differentiation of human marrow stromal cells require CYP27B1/1a-hydroxylase. J of Bone and Miner Res, 26(5), 1145-1153.

Godschalk, M., Levy , J. R., \& Downs, R. W. (1992). Glucocorticouds decrease vitamin D receptor number and gene expression in human osteosarcoma cells. $J$ Bone Miner Res, 21-27.

Golub, E. E., \& Boesze-Battaglia, K. (2007). The role of alkaline phosphatase in mineralization. Curr Opin Orthop, 444-448. 
Grant, W. B. (2002). An estimate of premature cancer mortality i the U.S. due to inadequate doses of solar ultraviolet-B radiation. Cancer, 94(6).

Haj, A. J., Wood, M. A., Thomas, P., \& Yang, Y. (2005). Controlling cell biomechanics in orthopaedic tissue engineering repai. Pathologie Biologie, 53, 581-589.

Hardingham, T., Tew, S., \& Murdoch. (2002). Tissue engineering: chondrocytes and cartilage. Arthritis Res, 4, S63-68.

Hardingham, T., Tew, S., \& Murdoch, A. (2002). Tissue engineering: chondrocytes and cartilage. Arthritis Res, 4(Suppl 3), S63-S68.

Harris, J. R., Graham, J., \& Rickwood, D. (2006). Cell Biology Protocols. New Jersey, NY: John Wiley \& Sons Ltd.

Hattori, K., Takakura, Y., Ohgushi, H., Habata, T., Uematsu, K., Yamauchi, J., et al. (2005). Quantitative ultrasound can assess the regeneration proess of tissueengineered cartilage using a complex between adherent bone marrow cells and a three-dimensional scaffold. Arthritis Resarch and Therapy, 7(3), R552-R559.

Heaney. (2008). Vitamin D in health and disease. Clin J Soc Nephrol, 3, 1535-1541.

Heaney. (2008). Vitamin D in health and disease. Clin J Am Soc Nephrol, 3, 1535-1541.

Hein, A., \& O'Brien, W. J. (1993). Current time-domain methods for assessing tissue motion by analysis from reflected ultrasound echos-a review. IEEE Transcactions on Ultrasonics, Ferroelectris and Frequency Control, 40(2), 84-102.

Hens, J. R., Wilson, K. M., Dann, P., Chen, X., Horowitz, M. C., \& Wysolmerski, J. J. (2005). TOPGAL mice show that the canonical Wnt signaling pathway is active 
during bone development and grwoth and is activated by mecahnical loading in vitro. JBMR, 20(7), 1103-1113.

Hewison, M., Zehnder, D., Chskraverty, R., \& Adams, J. S. (2004). Vitamin D and barrier function: a nove role for extra-renal 1a-hydroxylase. Molecular and Cellular Endocrinology, 215, 31-38.

Hicok, K. C., Thomase, T., Gori, F., Rickard, D. J., Speksberg, T. C., \& Riggs, B. L. (1998). Development and characterization of chonditionally immortalized osteoblast precursor cells from human stroma. JBMR, 13(2), 205-217.

Hicok, K. C., Thomase, T., Gori, F., Rickard, D. J., Spelsberg, T. C., \& Riggs, B. L. (1998). Development and characterization of conditionally immortalized osteoblast precursor cells line from human marrow stroma. $J$ of Bone and Miner Res, 13(2), 205-217.

Hill, T. P., Spater, D., Taketo, M. M., Birchmeler, W., \& Hartmann, C. (2005). Canonical Wnt/B-catenin signaling prevents osteoblast from differentiation into chondrocytes. Developmental Cell, 8(5), 727-738.

Hobaus, J., Thiem, U., Hummel, D. M., \& Kallay, E. (2013). Role of calcium, vitamin D, and the extrarenal vitamin D hydroxylases in carcinogenesis. Anti-Cancer Agent in Medicinal Chemistry, 13(1), 20-35.

Hoemann, C. D., El-Gabalawy, H., \& McKee, M. D. (2009). In vitro osteogenesis assays: influence of the primary cell source on alkaline phosphatase activity and mineralization. Pathologie Biologie, 57, 318-323.

Hollick, M. F. (2010). Vitamin D: extraskeletal health. Endocrin and Metab Clin, 39(2). 
Hollick, M. F., Biancuzzo, R. M., Chen, T. C., Klein, E., Young, A., Bibuild, D., et al. (2008). Vitamin D2 is as effective as vitamin D3 in mainting circulating concentrations of 25-hydroxyvitamin D. J Clin Endocrinol Metab, 93, 677-681.

Hosmer, D. W., \& Lameshow, S. (2000). Applied Logistic Regression. New York, NY: Wiley.

Huang, Y. L., Qiu, R. F., Mai, W. Y., Kuang, J., Cai, X. Y., Dong, Y. G., et al. (2012). Effects of insulin-like growth factor-1 on the properties of mesenchymal stem cells in vitro. J Zhehiang Univ Sci B, 13(1), 20-8.

Jones, G., Strugnell, \& DeLuca, H. F. (1998). Curent understandings of the molecular action of vitamin D. Physiological Reviews, 78(4), 1193-1231.

Jorgensen, N. R., Henriksen, Z., Sorensen, O. H., \& Civitelli, R. (2004). Dexamethasone, BMP-2, and 1,25-dihydroxyvitamin D enhance a more differentiated osteoblast phenotype: validation of an invitro model for human bone marrow-derived primary osteoblasts. Steroids, 69, 219-226.

Klotz, B., Mentrup, B., Regensburger , M., Zeck, S., Schneidereit , J., Schupp, N., et al. (2012). 1,25-dihydroxyvitamin D3 treatment delays cellular aging in human mesenchymal stem cells while maintaining their multipotent capcity. PLoS One, 7(1), e29959.

Kock, L., van Donkelaar, C. C., \& Ito, K. (2012). Tissue engineering of functional articular cartilage: the current status. Cell Tissue Res, 373(3), 613-627. 
Kohles, S. S., Bowers, J. R., Vailas, A. C., \& Vanderbery, R. (1997). Ultrasonic wave velocity measurement in small polymeric and cortical bone speciments. $J$ Biomech Eng, 119(3), 232-236.

Kohles, S. S., Bradshaw, S., Mason, S. S., \& Looft, F. J. (2011). A multivariate logistical model for identifying the compressive sensitivity of single rat tactiles receptors as nanobiosensors. J Nanotechnol Eng Med, 2(1).

Kohles, S. S., Kohles, D. A., Karp, A. P., Erlich, V. M., \& Polissar, N. L. (2004). Timedependent surgical outcomes following cauda equina syndrom diagnosis: comments on a meta-analysis. Spine, 29(11), 1281-1287.

Kohles, S. S., Mason, S. S., Adams, A. P., Berg, R. J., Blank, J., Gibson, F., et al. (2012). Ultrasonic wave propagation assessment of native cartilage explants and hydrogel scaffolds for tissue engineering. Int J Biomedical Engineering and Technology, 10(3), 296-307.

Kohles, S. S., Wilson, C. G., \& Bonassar, L. J. (2007). A mechanical composite sphers analysis of engineered cartilage dynamics. ASME J Biomech Eng, 129(4), 473480.

Komori, T. (2010). Regulation of bone development and extracellular matrix protein gene by RUNX2. Cell and Tissue Research, 330(1), 189-195.

Kondo, H., Ohyama, T., Ohya, K., \& Kasugai, S. (1997). Temporal changes of mRNA expression of matrix proteins and parathyroid hromone and parathyroid hormonerelated protein (PTH/PTHrP) receptro in bone development. $J$ of Bone and Mineral Res, 12(12), 2089-2097. 
Kumar, R. (1990). Vitamin D metabolism and mechanisms of calcium transport. J Am Soc Nephrol, 1(1), 30-42.

Lanza, R., Langer, R., \& Vacanti, J. (2007). Principles of Tissue Engineering. San Diego, CA: Elisever.

Lehman, B. (2008). Role of vitamin D3 pathway in healthy and diseased skin - facts, contradictions and hypotheses. Experimental Dermatology, 18, 97-108.

Lian, J. B., \& Stein, G. S. (1992). Concepts of osteoblast growth and differentiation: bass for modulation of bone cell development and tissue formation. Critical Reviews in Oral Biology and Medicine, 3(2), 269-305.

Lian, J. B., \& Stein, G. S. (1995). Develpment of the osteoblast phenotype: molecular mechanisms mediating osteoblast growth and differentiation. The Iowas Orthopaedic J, 15, 118-140.

Liu, P., Oyahobi, B. O., Russell, R. G., \& Scutt, A. (1999). Regulation of osteogenic differentiation of human bone marrow stromal cells: interaction between transforming growth factor-B and 1,25(OH)2 vitamin D3 in vitro. Calcif Tissue Int, 65, 173-180.

Luellen BA, M. D. (2003). Neuronal and Astroglial Responses to the Serotonin and Norepinephrine Neurotoxin: 1-Methyl-4-(2'-aminpophenyl)-1,2,3,6tetrahydropyridine. The Journal of Pharmacology and Experimental Therapeutics, 307(3), 923-931. 
MacLaughlin , J. A., Anderson, R. R., \& Hollick, M. F. (1982). Spectral character of sunlight modulates photosynthesis of previtamin D3 and its photoisomers in the human skin. Science, 216(4549), 1001-3.

Mao P, M. C. (2012). CART Peptide is a Potential Endogenous Antioxidant and Preferentially Localized in Mitochondria. PLoS one, 7(1), e29343.

Marolt, D., Knezevic, M., \& Vunjak-Novakovic, G. (2010). Bone tissue engineering with human stem cells. Stem Cell Research \& Therapy, 1(10).

Marolt, D., Knezevic, M., \& Vunjak-Novakovic, G. (2010). Bone tissue engineering with human stem cells . Stem Cell Research \& Therapy, 1(10).

Mason, S. S., Koles , S. S., Zelick , R. D., Winn, S. R., \& Saha, A. K. (2011). Threedimensional culture of cells and matrix biomolecules for engineered tissue development and biokinetics model validation. J Nanotechnol Eng Med, 2(2), 025001-7. .

Mendel, C. M. (1992). The free hormone hypothesis. J Androl, 13, 107-116.

Meredith GE, T. S. (2009). Impaired glutamate homeostasis and programmed cell death in chronic MPTP mouse model of Parkinson's disease. Exp Neurol, 219(1), 334340.

Merry, K., Dodds, R., Littlewood, A., \& Gowen, M. (1993). Expression o osteopontin mRNA by osteoblasts and osteoblasts in modelling adult human bone. $J$ of Cell Science, 104, 1013-1020.

Morris , H. A., \& Anderson , P. H. (2010). Autocrine and paracrine actions of vitamin D. Clin Biochem, 31, 129-138. 
Naeem, Z. (2010). Vitamin D defficiency - an ingnored epidenmic. Int J Health Sci, 4(1), V-VI.

Nickell H, P. F. (2005). Age-related changes in the dynamics of potassium-evoked Lglutamate release in the striatum of Fischer 344 rats. Journal of Neural Transmission, 112, 87-96.

Norman, A. W. (1998). Sunlight, season, skin pigmentation, vitamin D, and 25hydroxyvitamin D: integral components of the vitamin D endocrine system. Am J clin Nutr, 67, 1108-10.

Nutt. (2004). The dopamine transporter: importance in Parkinson's disease. 55(6), 76673.

Nykjaer, A., Fyfe , J. C., Lecheste, J. R., Jacobesen , C., Nielson , M. S., Verroust , P. J., et al. (2001). Cubilin dysfunction causes abnormal metabolism of the steroid hormone 25OH vitamin D(3). Proc Natl Acad Sci, 98(24), 13985.

O'Brien, F. J. (2011). Biomaterials and scaffolds for tissue engineering. Materials Today, 14(3).

O'Brien, F. J. (2011). Biomaterials and scaffolds for tissue engineering. Materials Today, 14(3).

Olivares-Navarrete, R., Sutha, K., Hyzy, S. L., Hutton, D. L., Schwartz, Z., McDevitt, T., et al. (2012). Osteogenic differentiation of stem cells alters vitamin D receptor expression. Stem Cells Dev, 21(10), 1726-35.

Otero, M., Favero, M., Dragomir, C., Hachem, K. E., Hashimoto, K., Plumb, D. A., et al. (2012). Human chondrocyte cultures as models of cartilage-specific gene 
regulation. In Human cell culture protocols (Vol. 806, pp. 301-336). Humana Press.

Pairse, R. A., Egorin, M. J., Kanterewicz, B., Taimi, M., Petkovich, M., Lew, A. M., et al. (2006). CYP24, the enzyme that catabolizes the antiproliferative agent vitamin $\mathrm{D}$, is increased in lung cancer. In J Cancer, 119, 1819-1828.

Park, K., Min, B. H., Han, D. K., \& Hasty, K. (2007). Quantitive anaylsis of temporal and spatial variation of chondrocyte nehavior in engineered cartilage during long-term culture. Annals Biomed Eng, 35(3), 419-428.

Pazanno, D., Mercier, K. A., Moran, J. M., Fong, S. S., DiBiaso, D. D., Rulf, J. X., et al. (2000). Comparison of chondrogenesis in static and perfused bioreactor culture. Biotechnol Prog, 16, 893-896.

Pevsner-Fischer, M., Levin, S., \& Zipori, D. (2011). The origins of mesenchymal stromal cell heterogeneity. Stem Cell Rev and Rep, 7, 560-568.

Piek, E., Sleumer, L. S., van Someren, E. P., Heuver, L., Haan, d., Grijs, I. D., et al. (2010). Osteo-transcriptomic of human mesenchymal cells: acelerated gene expression and osteoblast differentiation indeced by vitamin D reveals cMYC as an. Bone.

Pockwinse, S. M., Stein, J. L., Lian , J. B., \& Stein, G. S. (1995). Developmental stagespecific cellular responses to vitamin D and glucocorticoids during differentiation of the osteoblast phenotype: interrelationship of morphology and gene expression by in situ hybridization. Experimental Cell Research, 216, 244-260. 
Pollack, S. R., Meany, D. F., Levine, E. M., Litt, M., \& Johnston, E. D. (2000). Numerical model and experimental validation of microcarrier motion in a rotating bioreactor. Tissue Engineering, 6(5), 519-530.

Quarles, L. D., Yohay, D. A., Lever, L. W., Caton, R., \& Wenstrup, R. J. (1992). Distinct proliferative and differentiated stages of murine MC3T3-E1 cells in culture: an in vitro model of osteoblast development. J of Bone MIner Res, 7(6), 683-692.

Quinn, T. P., Flannery, C. M., Lauria, D. S., Gallagher, D. V., \& Anseth, K. S. (2009). An instrumented bioreactor for cartilage tissue engineering. Ann Mtg Expo Soc Biomat. San Antonio.

Raeber, G. P., Lutolf, M. P., \& Hubbell, J. A. (2005). Moleculary engineered PEG hydrogels: a novel model system for proteolytically mediated cell migration. Biophys J, 89(2), 1374-1388.

Ramage, G., Nuki, D., \& Salter, M. (2009). Signaling cascades in mechanotransduction: cell-matrix interaction and mechanical loading. Scand J Med sci Sports, 19, 47574769.

Revelli, A., Massobrio, M., \& Tesarik, J. (1998). Nongenomic effects of 1a-25dihydroxyvitamin D3. TEM, 9(10), 419-427.

Saha, A. K., \& Kohles, S. S. (2010). A distinct catabolic to anabolic threshold due to single-cell nanomechanical stimulation in a cartilage biokinetics model. $J$ Nanotechnol Eng Med, 1(3), 031005. 
Saha, A. K., \& Kohles, S. S. (2010). Periodic nanomechanical stimulation in a biokinetics model identifying anabolic and catabolic pathways associated withh cartilage matrix homeostasis. J Nanotechnol Eng Med, 1(4), 041001.

Saha, A. K., \& Kohles, S. S. (2011). A cell-matrix model of anabolic and catabolic dynamics during cartilage biomolecule regulation. International Journal of Computers in Healthcare.

Schuurman, W., Gawlitta, D., Lein, T. J., Hoope, W. T., Riijen, M. H., Dhert, W. J., et al. (2009). Zonal chondrocyte subpopulations reacquire zone-specific characteristics durin in vitro redifferentiation. AJSM, 20(10), 1-8.

Seiffert, M., Rech, M., Meineke, V., Tilgen, W., \& Rechrath, J. (2004). Differential biological effects of 1,25-dihydroyxy Vitamin D3 on melanoma cell lines in vitro. J of Steroid Biochem \& Molec Bio, 89-90, 375-379.

Sekiya, I., Larson, B. L., Smith, J. R., Pochampally, R., Cui, J. G., \& Prockop, D. J. (2002). Expansion of human adult stem cells from bone marrow stroma: conditions that maximize the yields of early progenitors and evaluate their quality. Stem Cells, 20(6), 530-541.

Shea, L. D., Wang, D., Franceschi, R. T., \& Mooney, D. J. (2000). Engineered bone development from a pre-osteoblast cell line on three-dimensional scaffolds. Tissue Engineering, 6(6), 605-618.

Shi, Y. C., Worton, L., Esteban, L., Baldock, P., Fong, C., Eisman, J. A., et al. (2007). Effects of continuous activation of vitamin D and Wnt response pathways on osteobastic proliferation and differentiation. Bone, 41, 87-96. 
Siegal GJ, A. B. (1999). MPTP-Induced Parkinsonian Syndrom. In A. B. Siegal GJ, Basic Neurochemistry: Molecular, Cellular and Medical Aspects . Phildelphia: Lippincott-Raven.

Steward, A. J., Liu, Y., \& Wagner, D. R. (2011). Engineering cell attachments to scaffolds in cartilage tissue engineering. Biomaterials for Regenerative Medicine, 63(4), 74-82.

Suda, T., Takahashi , F., \& Takahashi , N. (2012). Bone effect of vitamin D discrepancies between in vivo and in vitro studies. Arch Biochem Biophys, 523(1), 22-29.

Swolin-Eide, D. (2002). Studies of human osteoblast-like cells;-effects of growth hormone and steroids. JIFCC, 13(4).

Tata DA, Y. B. (2007). Interactions between methamphetamine and environmental stress: role of oxidative stree, glutamate and mitochondrial dysfunction. Addiction, 102(suupl.1).

Tellisi, N., \& Nureddin, A. (2007). Comparison of meshes, gels and ceramic for cartilage tissue engineering in vitro. Eur J Plast Surg.

Tew, S. R., Murdoch, A. D., Rauchenberg, R. P., \& Hardingham, T. E. (2008). Cellular methods in cartilage research: primary human chondrocytes in culture and chondrogenesis in human bone marrow stem cells. Methods, 45(1), 2-9.

Thompson, L., Wang, S., Tawfik, O., Templeton, K., Tanacabeli, J., Pinson , D., et al. (2012). Effects of 25-hydroxyvitamin D3 and 1,25-dihydroxyvitamin D3 on 
differentiation and apoptosis of human osteosarcoma cell lines. J Orthop Res, 30(5), 831-844.

Tibbitt, M. W., \& Anseth, K. S. (2009). Hydrogels as extracellular matrix mimics for 3D cell culture. Biotechnol Bioeng, 103, 656-669.

Tortelli, F., \& Cancedda, R. (2009). Three-dimensional cultures of osteogenic and chondrogenic cells: a tittue engineering approach to mimic bone and cartilage in vitro. Eur Cell Mater, 17, 1-4.

Trump, D. L., Deeb, K., \& Johnson, C. S. (2010). Vitamin D: Considerations in the continued development as an agent for cancer prevention and therapy. Cancer J, 16(1), 1-9.

Van Den Eeden SK, T. C. (2003). Incidence of Parkinson's Disease: Variation by Age, Gender, and Race/Ethnicity. American Journal of Epidemilogy, 157(11), 10151022.

van Driel, M., Koedam, M., Burrman, C. J., Hewison, M., Chiba, H., Uitterlinden, A. G., et al. (2006). Evidence for auto/paracine actions of vitamin D in bone : 1ahydroxylase expression and activity in human bone cells. FASEB, 20, E18112419.

Vanhooke, J. L., Prahl, J. M., Kimmel-Jehan, C., Mendelsohn, M., Danielson, E. W., Healy, K. D., et al. (2006). CYP27B1 null mice with LacX reporter gene display no 25-hydroxyvitamin D3-1a-hydroxylase promote activity in the skin. PNAS, 103(1), 75-80. 
Viljakainen , H. T., Natri, A. M., Karkainen , M., Huttunen , M. M., Palssa, A., Jakobsen, J., et al. (2006). A positive dose-response effect of vitamin D supplementation on site-specific bone mineral augmentation in adolescent girls: a double-blinded randomized placebo-conrolled 1-year intervention. J Bone Miner Res, 21(6), 83644.

Villanueva, I., Weigal, C. A., \& Bryant, S. J. (2009). Cell-matrix interactions and dynamic mechanical loading influence chondrocyte gene expression and bioactivity in PEG-RGD hydrogels. Acta Biomaterialia, 5(8), 2832-2846.

Villanueva, I., Weigal, C. A., \& Bryant, S. J. (2009). Cell-matrix interactions and dynamic mechanical loading influence chondrocyte gene expression and bioactivity in PEG-RGD hydrogels. Acta Biomater.

Vinatier, C., Mrugala, D., Jorgensen, C., Guicheux, J., \& Noel, D. (2009). Cartilage engineering: a crucial combination of cells, biomaterials, and biofactors. Trens Biotecnol, 19, 307-314.

Walker, J. M., Myers, A. M., Scluchter, M. D., Goldberg, V. M., Caplan, A. I., Berilla, J. A., et al. (2011). Nondestructive evaluation of hydrogel mechanical properties using ultrasound. Annals of Biomedical Engineering, 39(10), 2521-2530.

Walsh, S., Jordan, G., Jefferiss, C., Stewart, K., \& Beresford, J. (2001). High concentrations of dexamethasone supress the proliferation but not the differentiation or further maturation of human osteoblast precursors in vitro: relevance to glucocorticoid-induced osteoprosis. Rheumatology, 40, 74-83. 
Wilson, C. G., Bonassar, L. J., \& Kohles, S. S. (2002). Modeling the dynamic composition of engineered cartilage. Arch Biochem Biophys, 408(2), 246-254.

Winn, R. S., Randolph, G., Uludag, H., Wong, S. C., Hair, G. A., \& Hollinger, J. O. (1999). Establishing an Immortalized Human Osteoprecursor Cell Line: OPC1. Journal of Bone and Mineral Research, 14(10), 1721-1733.

Wood, A. M., Bassford, C., Webster, D., Newby , P., Rajesh, P., Stockley, R. A., et al. (2010). Vitamin D-binding protein contributes to COPD by activation of alveloar macrophages. Thorax, 66(3).

Worstman, J., Matsuoka , L. Y., Chen, T. C., Zhiren , L., \& Hollick, M. F. (2000). Decreased bioavailability of vitamin D in obsesity. Am J Clin Nutr, 72, 690-693.

Yamamoto, Y., Yoshizawa, T., Fukuda, T., Shirode-Fukuda, Y., Nakamichi, Y., Watanabe, T., et al. (2013). Vitamin D receptor in osteoblasts is a negative regulator of bone mass control. Calcium-Regulating Hormones, 154(3), 10081020.

Yang, H., Zhang, Z., Zhou, Z., Jiang, X., \& Shen, A. (2011). Snail-1 regulates VDR signaling and inhibits 1,25OH-D3 action in osteosarcoma. Eur H Pharmacol, 67(2-3), 341-346.

Yilmaz, B. C., Yilmaz, G., Yilmaz, N. S., Balli, E., \& Tasdelen, B. (2010). Optimal transport time and conditions for cartilage tissue samples and expanded chondrocyte suspensions. Orthopaedics, 33(1), 25. 
Zhou, S., Glowacki, J., Kim, S. W., Hahne, J., Geng, S., Mueller, S. M., et al. (2012).

Clinical characterizatics influence in vito action of 1,25-dihydroxyvitamin $\mathrm{D}(3)$ in human marrow stromal cells. . J Bone Miner Res, Ahead of Print.

Zuwei, M. A., Kotaki, M., Inani, R., \& Ramakrishna, A. (2005). A potential of nanofiber matrix as tissue-engineering scaffolds. . Tissue Eng, 11((1-2)), 101-109. 


\section{APPENDICES}

\section{A. Modeling of OPC-1 and MC3T3-E1 Cell Proliferation}

\section{(i) Growth Model Application.}

An exponential cell growth model was applied to characterize the normalized proliferation as a percentage of the initial cell population through culture time, $\mathrm{C}(\mathrm{t})$, such that:

$$
\mathrm{C}(\mathrm{t})=\mathrm{C}_{\mathrm{i}} \mathrm{e}^{\mathrm{t} / \tau}
$$

Where the experimental input includes the initial cell population $\left(C_{i}=100 \%\right)$ and culture time, $\mathrm{t}$, in days. The result of the fitting procedure produces a characteristic growth rate constant similar to a time constant, $\square$. This fitting metric provides a quantitative value by which to compare cell population growth curves, where lower values represent a shorter culture time leading to a maximum cell count [Wilson et al., 2002; Kohles et al., 2007].

The model was applied to the aggregate cell population data for the OPC-1 and MC3T3-E1 cells as well as to the individual test group data for each cell type. This approach constructed least squares estimates of the growth time 
constants via a quasi-Newton convergence method with commercially available software (Solver, Frontline Systems, Inc., Incline Village, NV, and Excel, Microsoft, Redmond, WA). The model fit was determined by minimizing the root mean square error (RMSE in similar units) between the actual and modeled cell population percentages for each dataset. The correlation coefficient $\left(\mathrm{R}^{2}\right)$ assayed the strength of the modeled relationship.

The aggregate plots contain all repeated measures data as well as the model curves. The test group curves are presented in rank order of their respective time constants. Statistical influences of the test group culture combinations were further explored with repeated measures analysis of co-variance (MANCOVA).

Table A-1: Proliferation modeling metrics summary

\begin{tabular}{|l|l|l|l|l|l|l|}
\hline \multirow{2}{*}{ Test Group } & \multicolumn{2}{|c|}{$\square$ (days) } & \multicolumn{2}{c|}{ RMSE (\%) } & \multicolumn{2}{c|}{ R } \\
\cline { 2 - 7 } & OPC-1 & $\begin{array}{l}\text { MC3T3- } \\
\text { E1 }\end{array}$ & OPC-1 & $\begin{array}{l}\text { MC3T3- } \\
\text { E1 }\end{array}$ & OPC-1 & $\begin{array}{l}\text { MC3T3- } \\
\text { E1 }\end{array}$ \\
\hline Aggregate & 4.49 & 3.87 & 209 & 453 & 0.77 & 0.67 \\
\hline BM-Control & 3.86 & 3.39 & 199 & 597 & 0.91 & 0.74 \\
\hline BM+Control & 3.96 & 3.56 & 242 & 479 & 0.85 & 0.76 \\
\hline BM-VitaD & 4.61 & 3.72 & 128 & 297 & 0.89 & 0.86 \\
\hline BM+VitaD & 5.19 & 5.28 & 161 & 262 & 0.73 & 0.49 \\
\hline BM-1 $\square, 25 \mathrm{OH}_{2} \mathrm{D}$ & 4.80 & 3.54 & 119 & 210 & 0.89 & 0.94 \\
\hline $\mathrm{BM}+1 \square, 25 \mathrm{OH}_{2} \mathrm{D}$ & 5.50 & 5.94 & 103 & 249 & 0.85 & 0.32 \\
\hline
\end{tabular}




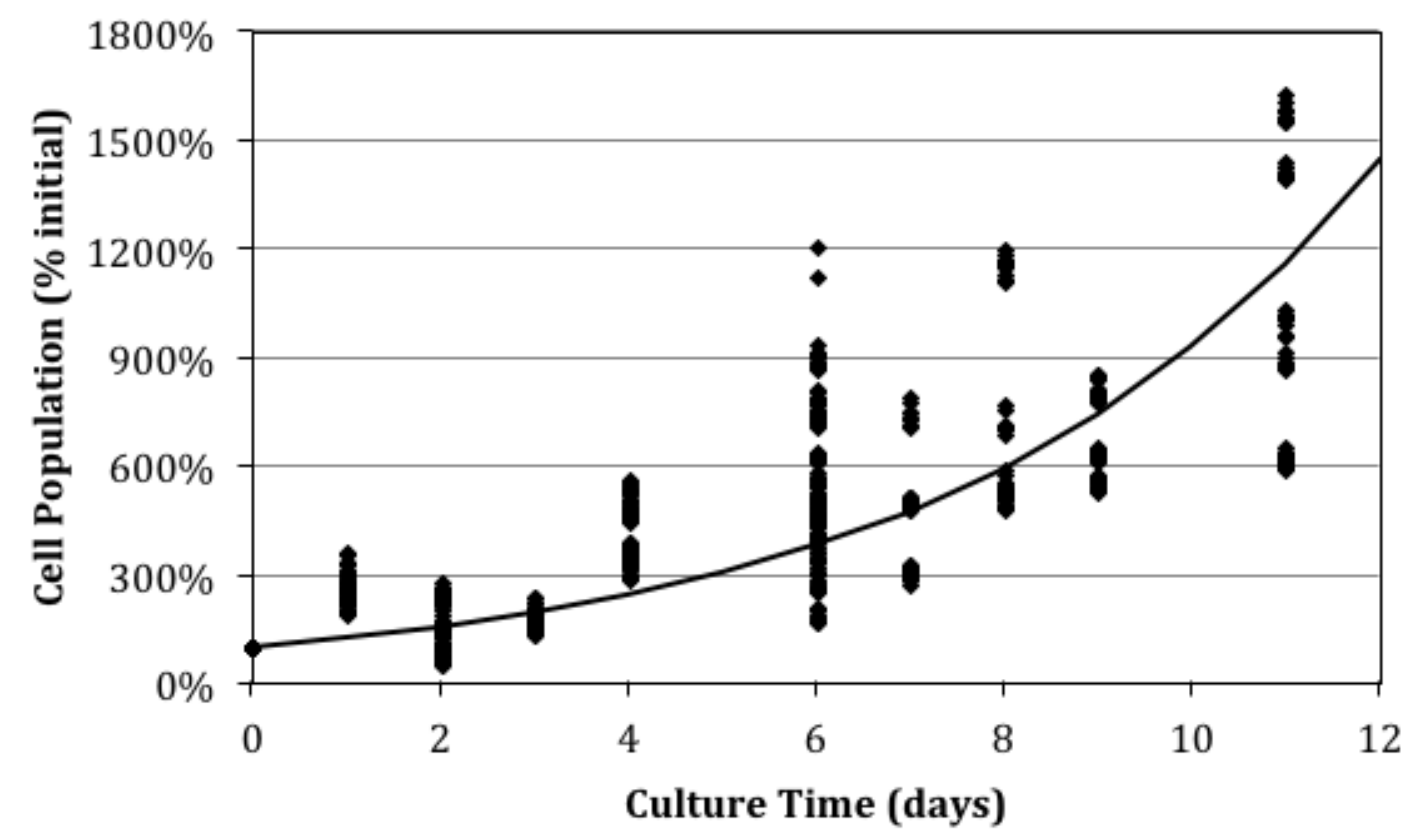

Figure A-1. OPC-1 Aggregate Data, cell population over time.

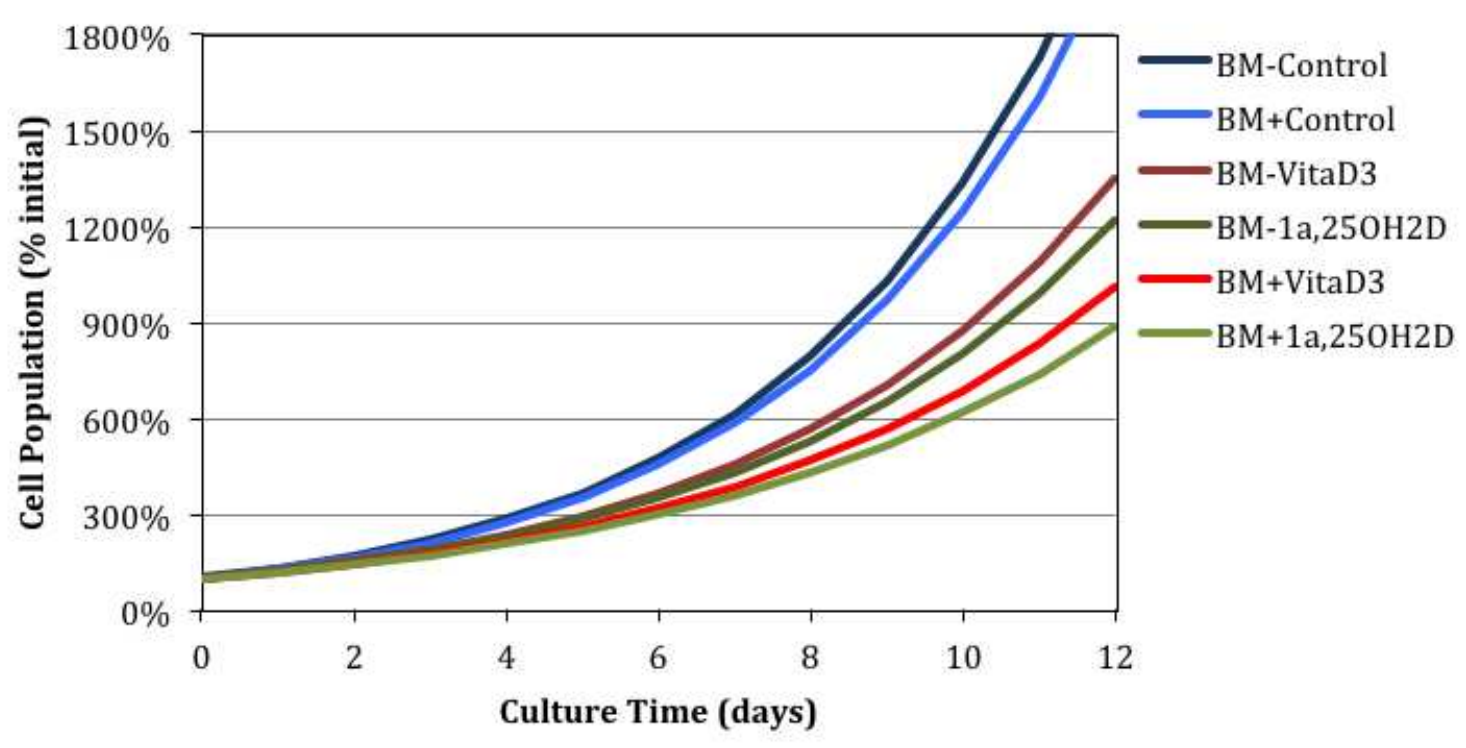

Figure A-2: OPC-1 Isolated Test Group Data, cell population over time. 


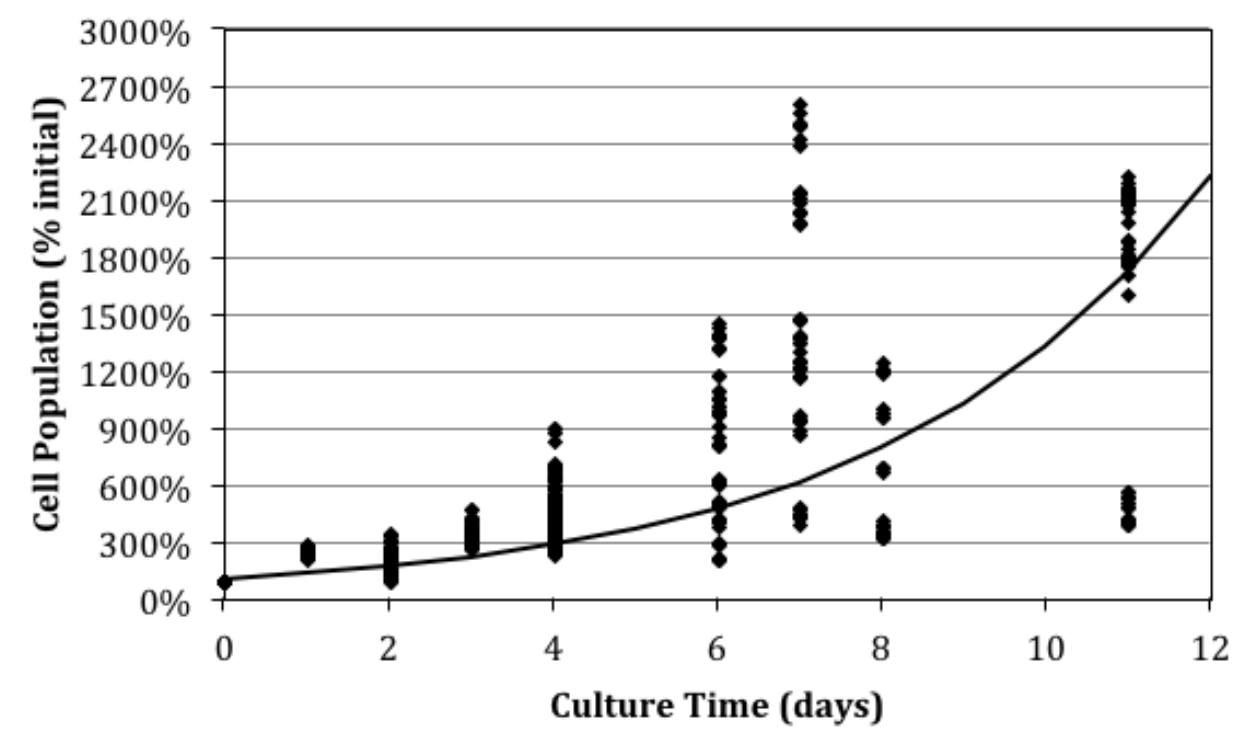

Figure A-3. MC3T3-E1 Aggregate Data, cell population over time.

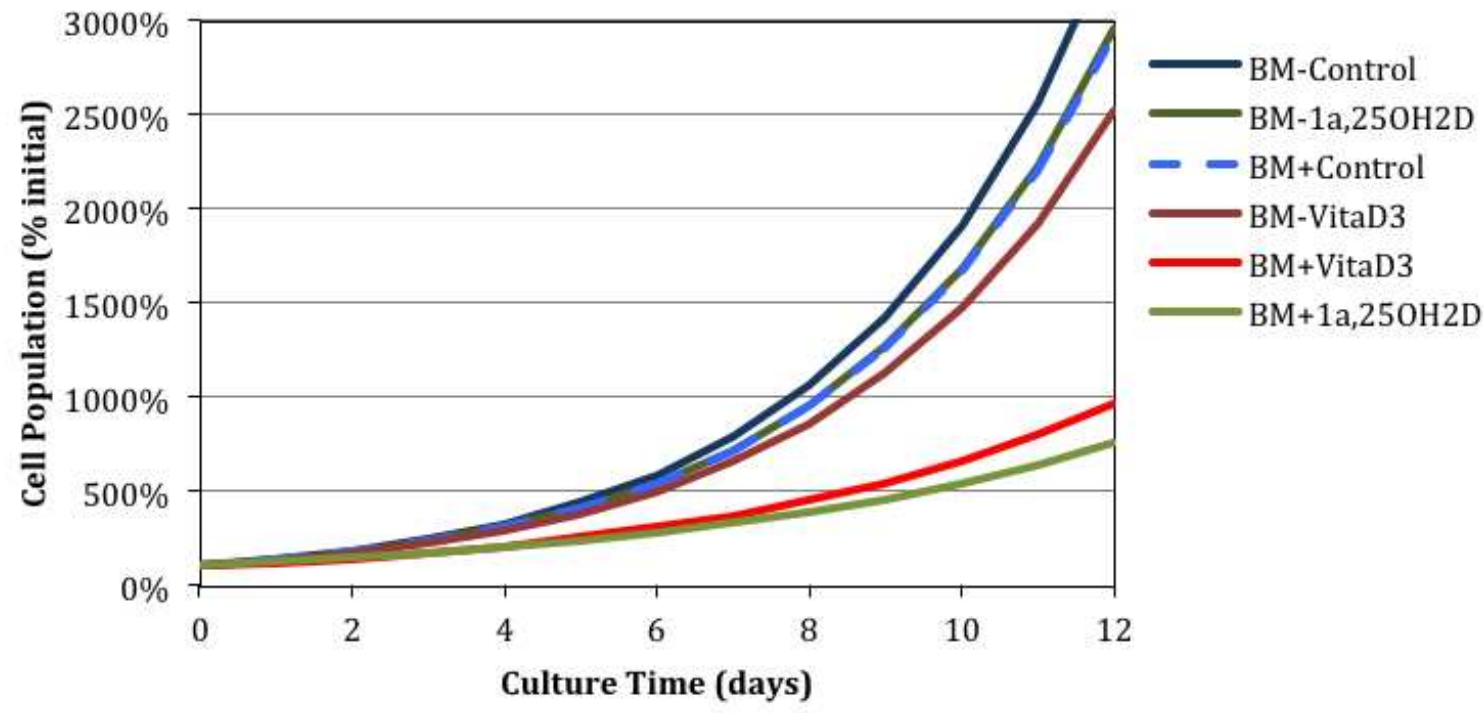

Figure A-4 MC3T3-E1 Isolated Test Group Data, cell population over time. 


\section{B. Supplemental Material and Methods: Cartilage Engineering (Chapters 3 and 4)}

\section{(ii) Materials and Reagents}

Chondrocyte/Cartilage Culture Medium.

Dulbecco's modified essential medium/Ham's F-12 (DMEM/F12) $10 \%$

10\% Fetal Bovine Serum (FBS)

$200 \mathrm{mM}$ L-Glutamine

$1 \%$ antibiotic/antimycotic solution (AB/AM).

Liberase Blendzyme III (Roche Diagnostics, Madison, WI)

Reconstitute $5 \mathrm{mg}$ vial in $2 \mathrm{ml}$ PBS $(2.5 \mathrm{mg} / \mathrm{ml})$

Place vial on ice to rehydrate the enzyme

Gently agitate the vial at $2-8^{\circ} \mathrm{C}$ until enzyme is dissolved

Store unused stock solution in single used aliquots at $-1520^{\circ} \mathrm{C}$.

Collagenase (Sigma-Aldrich)

Cell or tissue dispersal $0.5-2.5 \mathrm{mg} / \mathrm{ml}$

Cartilage dispersal is $1-2 \mathrm{mg} / \mathrm{ml}$

solubilized in calcium-free DPBS 


\section{(iii) Methods}

\section{(a) Harvesting Cartilage Tissue}

Tissue is excised from articular cartilage of bovine metacarophalangeal joints within 8 hours of slaughter. After dissection, chondrocytes are isolated from tissue fragments by mechanically disaggregation and enzymatic digestion. Freshly isolated chondrocytes cultured are expanded in 2D monolayers and /or seeded within a 3D biomatieal scaffold according to conventional cell culture techniques.

\section{Procedure:}

1. Obtain several calf hooves that include the first joint (metacarpophalangeal joint or fetlock) above the hoof.

2. Wash and scrub each hoof with water and antibacterial soap to remove all traces of dirt from the skin and the hoof.

3. Once all dirt is removed and water runs clear, generously spray the specimen with $70 \%$ ethanol.

4. Using a no. 23 disposable scalpel, make a lengthwise incision and dissect away the skin, taking care not to pierce the joint capsule. Wash the skinned limb with water, than generously spray with $70 \%$ ethanol. 
5. Place the skinned limb upright, anterior side forward, inside the hood, and on top of an absorbent protective sheet (see Figure A5A). Flex the limb back at the joint.

6. Make a horizontal incision through the anterior side of the joint capsule, taking care not to cut into cartilage (see Figure A-5B), and continue the incision around the side until the joint is exposed on three sides. Carefully sever the internal ligament and open the joint fully (see Figure A-5C), and wash away the clear viscous synovial fluid with sterile PBS. If blood is visible in the joint capsule when it is opened, the joint should be discarded, as it may be necrotic or contaminated with microorganisms.

7. Using a sterile no. 15 disposable scalpel, obtain shavings from the metacarpophalangeal chondylar surface (see Figure A-5D). Follow the curve of the joint as closely as possible so as to obtain long, uniformly shaped shavings, ideally in one or two long pieces per joint surface. Long pieces are especially desirable when cartilage is to be sectioned into chips. If uniformity of cartilage shavings is not critical (i.e., if chips are to be enzymatically digested to release chondrocytes for culture), it can also be excised from other surfaces within the joint to increase the overall yield of chondrocytes. Excessive oozing blood from the shavings indicates that the 
incision was deep and included bone, which (unlike cartilage) is vascularized.

8. As the cartilage is scrapped off the joint, transfer the shavings to a petri-dish containing $0.1 \%$ collagenase and $2.5 \% \mathrm{AB} / \mathrm{AM}$ in cold PBS to prevent sticking and contamination. Shavings from each hoof should be placed in a separate dish to minimize the possibility of cross-contamination.

9. Wash the shavings three times with $2.5 \% \mathrm{AB}-\mathrm{AM}$ in cold PBS and immerse washed tissue in growth media containing $1-2.5 \%$ AB/AM.

10. Add $30 \mathrm{ml}$ of sterile growth medium to each sample

11. [OPTIONAL] To allow timely detection of microbial contamination, it has been suggested to incubate chips for 24-48 hrs before digestion. Microbial contamination typically presents as cloudy medium (bacteria) or visible mold. 

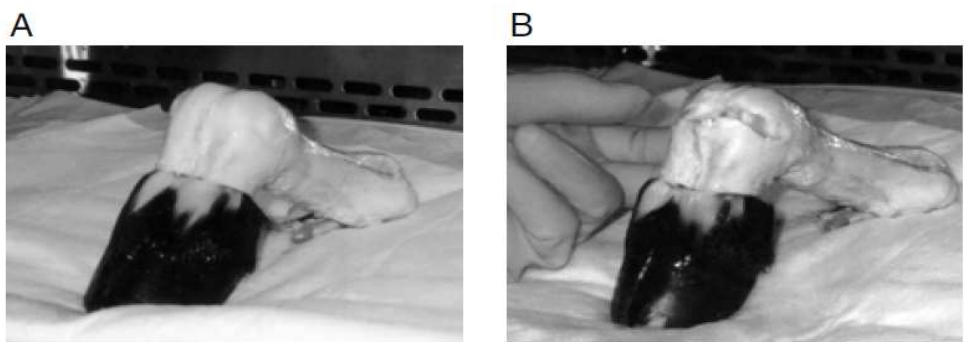

C

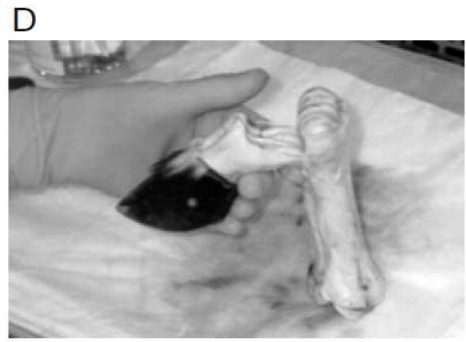

Figure A-5. Dissection of cartilage from the bovine metacarpophalangeal joint. (A) The skins is removed, exposing the outer joint capsule. (B) An incision through the anterior surface of the join capsule is made which spares the cartilage within. (C) After the joint has been opened and exposed, a scalpel is used to excise articular cartilage by shaving along the curved surface of the exposed joint. (D) The same joint with some of the cartilage removed, revealing the underlying bone [Liebman and 
(b) Mechanical Disaggregation of Tissue.

Mincing or chopping tissue in liquid medium releases cells from the supporting matrix. Most disaggregation procedures begin with a mechanical step to reduce the tissue to small fragments, providing a larger surface area for exposure to the digesting enzymes and facilitating penetration of enzymes into the tissue [Harris et al.; 2006]. Soft tissues can be minced finely with scissors and harder tissues chopped with scalpels. Further release of cells from minced tissue is achieved by vigorous pipetting of the smaller fragments in the suspending fluid, creating shear forces strong enough to separate cells from the fragments.

\section{Procedure:}

1. Place the freshly harvest cartilage tissue into the glass petri dish and moisten its surface with a small volume of $5 \% \mathrm{AB} / \mathrm{AM}$ in calciumfree Hank's buffered salt solution (HBSS).

2. Using sterile dissecting scissors or scalpels mince the tissue into small fragments. (Note 1: It is easier to cut or mince the tissue if the volume is kept small because the fragments then stay on the surface of the dish and cannot float away from the dissecting instruments. Note 2: Mince soft tissue with scissors and chop harder tissue with two opposed scalpel blades.) 
3. Tilt the dish to an angle of $\sim 30^{\circ}$ from the horizontal and allow the medium and released cells to wash down into the angle of the dish. Use a sterile pastette to aspirate the cell suspension and transfer it to a sterile culture tube.

4. Add a small volume of HBSS to the dish with a pastette and wash it over the fragments and surface to release and recover more cells.

5. Repeat the last three steps two more times, aiming to reduce the tissue fragments $\sim 1-2 \mathrm{~mm}$ across. Pool the released cells from each stem. Keep the fragments for further digestion.

6. Centrifuge the cell suspension at $1000 \mathrm{rpm}$ for $5 \mathrm{~min}$. (Note: If the cell suspension is of low viability it may be enhanced by keeping the recovered cell at $4{ }^{\circ} \mathrm{C}$. Released cells may be of low viability because damaged cells separate more easily from the surrounding matrix and the physical forces involved damage cells. However, some tissues are disaggregated effectively with mechanical methods.)

7. Decant the supernatant from the cell pellet and resuspend the cells in $10 \mathrm{ml}$ of storage medium. Store in refrigerator at $4{ }^{\circ} \mathrm{C}$. (Note: the volume of medium added should be increased to $20 \mathrm{ml}$ if the cell pellet is $>5 \mathrm{ml}$.) 


\section{(c) Enzymatic Digestion of Cartilage Tissue}

Isolation of chondrocytes is a two-step procedure: digestion of cartilage tissue and isolation of cells from the tissue digest. Freshly harvested cartilage tissue is rinsed several times and transferred to a digestion vessel after weighing. For tissue weighing $<300 \mathrm{mg} \mathrm{w}$ use a $50-\mathrm{ml}$ tube as the digestion vessel and for a larger amount of tissue use a 225-ml spinner flask [Atala and Lonza, 2002].

Trypsin Digestion. Trypsin damages cells if exposure is prolonged and care must be taken to minimize this when devising tissue-specific protocols. Trypsinization can be carried out at $37^{\circ} \mathrm{C}$ (warm trypsinization) or at $4{ }^{\circ} \mathrm{C}$ (cold trypsinization). DNA released from damaged cells becomes viscous and its presence impairs the recovery of free cells. DNAse is therefore included at low concentrations to digest DNA and reduce viscosity. Serum contains trypsin inhibitors and these must be washed away from the tissue before digestion is started. Conversely, the action of trypsin is neutralized by the addition of serum.

\section{$\underline{0.25 \% \text { Trypsin }}$}

$1 \mathrm{ml}$ of $2.5 \%$ stock solution

9ml cation-free DPBS or HBSS 


\section{$\underline{0.4 \% \text { DNAse Type I }}$}

$0.4 \mathrm{~g}$ per $\mathrm{ml}$ cation-free DPBS or HBSS

Filter-sterilize through a sterile $0.22 \mu \mathrm{m}$ filter membrane Store as $1 \mathrm{ml}$ aliquots in sterile containers at $-20{ }^{\circ} \mathrm{C}$.

$\underline{0.25 \% \text { Trypsin/0.004\% DNAse }}$

Thaw out $1 \mathrm{ml}$ aliquot of DNAse

Add to $100 \mathrm{ml} 0.25 \%$ trypsin

\section{Procedure:}

1. Rinse the minced fragments from mechanical disaggregation in $3 \mathrm{X}$ $10 \mathrm{ml}$ washes of HBSS to remove trypsin inhibitors in the serum and discard the washings.

2. Transfer the minced tissue mince from the petri dish to the conical flask containing a sterile magnetic stirrer bar. Add 10 volumes of $0.25 \%$ trypsin $/ 0.004 \%$ DNAse (pre-warmed to $37^{\circ} \mathrm{C}$ ) to 1 volume of tissue.

3. Re-cap the flask with the aluminum foil lid and place on the stirrer. Set the stir speed to keep the fragments in suspension; there should be a small vortex with no frothing.

4. Carry out trypsinization for 20-30 minutes. 
5. Remove the flask from the stirrer and allow the larger undigested fragments to settle. Remove the foil cap and carefully decant the enzyme solution containing released cells into a universal container. This can be done by using a sterile filter $(70 \mu \mathrm{m})$ large enough to contain the left over fragments (should appear more gelatinous then solid) or by using a long-form pastette or $10 \mathrm{ml}$ pipette. For the latter, tilt the flask and allow the fragments to settle in the angle of the flask and aspirate the cell suspension from the fragments.

6. Add an equal volume of serum-containing medium to neutralize the effects of trypsin.

7. Centrifuge the cell suspension at $1000 \mathrm{rpm}$ for $5 \mathrm{~min}$ and resuspend the cells in medium. Label T1 and store at $4^{\circ} \mathrm{C}$.

8. Add fresh pre-warmed $0.25 \%$ trypsin/ $0.004 \%$ DNAse to the flask and repeat the last two steps two times (T2 and T3). (Note: trypsinization is complete when only fluffy white connective tissue remain.)

9. Pool freshly isolated cells and calculate cell number and viability using $0.4 \%$ trypan blue and hemacytometer. 
Collagenase Digestion. Literature suggests a large range of collagenase concentrations (0.1-0.5\%) depending on the collagenase used. The digestion time can range from 4 to 24 hours depending on brand. Collagenase and dispase (neutral protease) are less harmful to cells then trypsin and digestion with these enzymes can be carried out in the presence of serum. Contaminating fibroblasts are more likely in collagenase digest because it is more effective against the connective tissue matrix in which fibroblasts are found; this may be less irrelevant if cells are not to be cultured because there is no opportunity for fibroblast overgrowth. Collagenase Type I and IV are mainly used for tissue disaggregation, though crude collagenase is sometimes recommended because it contains small amounts of non-specific proteases, which contribute to matrix break-down [Harris et al. 2006].

Collagenase (Crude, Type I or IV)

Dissolve in HBSS (10X Stock Solution)

Filter sterilize

Dispense into $1 \mathrm{ml}$ aliquots

Store at $-20^{\circ} \mathrm{C}$. high. 


\section{Procedure:}

1. Transfer fragments from mechanical disaggregation and/or trypsinization into a culture flask using either a sterile spatula or teaspoon. Use a size of flask appropriate to the volume of tissue (aim to add $\sim 10$ volumes of enzyme per 1 volume of tissue fragments).

2. Incubate the flask horizontally in a $37^{\circ} \mathrm{C}$ incubator overnight. Note: Different media have different buffering capacities and the metabolic activity and the incubation period need to be taken into consideration when deciding about the medium to use. Phenol red is used as a $\mathrm{pH}$ indicator and the buffering system is based on bicarbonate concentration. Hanks $=0.35$ g/l: Earle's =2.2 g/l; Dulbecco's $=3.75$ g/l. HBSS is suitable when metabolic activity and $\mathrm{CO}_{2}$ production is low and a low buffering capacity is sufficient. Earle's is used when tissue/cells are metabolically active and a higher buffering capacity is needed; most culture media are based on Earle's salts.

3. The following day use a wide-bore pastette to aspirate the fragments several times and release loosened cells. Check the flask under an inverted phase-contrast microscope for cell release; continue digestion if cell yield is low and/or cells can still be seen within the tissue fragments. Note: If the medium becomes viscous, add DNAse at $0.004 \%$. 
4. Decant the cells from the tissue using a sterile pastette or use a sterile filter to separate the cells and media from the tissue.

5. Centrifuge the cells, discard the supernatant, and resuspend the cell pellet in culture medium.

6. Rinse and repeat at least 3 times to ensure no residual collagenase is present. It is best to rinse the cells with DPBS the first couple of times, and add $1 \mathrm{ml}$ of PBS the last time, resuspend in $1 \mathrm{ml}$ PBS and take 100 $\mu \mathrm{l}$ for cell count and viability. 
(d) 3D Culture Seeded in Biomaterial Scaffold

Scaffolds play a critical role in the reorganization of neotisues. The majority of mammalian cell types are anchorage-dependent, and will die if an adhesive substrate is not provided. The scaffold must provide a suitable substrate for cell attachment, cell proliferation, differentiated function, and cell migration [Khang et al. 2007].

Polyethylene Glycol (PEG) Biomaterial Scaffold. Degradable synthetic PEG-based hydrogels can be used as an inert structural platform due to its hydrophilicity and resistance to protein absorption [Raeber, Lutolf, \& Hubbell, 2005].

$\underline{\text { PEG-Diacrylate (PEGDA) }}$

$1.0 \mathrm{~g}$ PEGDA

$10 \mathrm{ml} 1 \% \mathrm{AB} / \mathrm{AM}$ in DPBS

\section{Procedure:}

1. Allow PEGDA and PBS to come to room temperature.

2. Under Aseptic conditions prepare PEGDA hydrogel solution by mixing in $1 \mathrm{ml}$ sterile PBS with penicillin $(100 \mathrm{u} / \mathrm{ml})$ and streptomycin $(100 \mathrm{mg} / \mathrm{ml})$ to $0.1 \mathrm{~g}$ PEGDA for a $10 \%(\mathrm{w} / \mathrm{v})$ solution. 
3. Invert the solution several times to dissolve. The solution will be clear and slightly viscous.

4. The photo-initiator, 1-hydroxycyclohexyl phenyl ketone (Sigma Aldrich), is added and mixed thoroughly to make a final concentration of $0.05 \%(\mathrm{w} / \mathrm{w})$. It is best to make this a separate solution and add to the PEGDA/PBS from step 1.

5. Immediately before photo-encapsulation, cells are re-suspended in polymer solution. $100 \mathrm{ml}$ of cells-PEGDA solution containing $\sim 10^{6}$ cells are transferred to mold and exposed to $365 \mathrm{~nm}$ light (long wave) for 5-15 $\mathrm{min}$ to form hydrogel. Make sure the UV light is in close proximity to the hydrogel solution.

6. Hydrogels are removed from their molds and incubated up to 21 days in chondrogenic medium containing 5\% FBS.

7. Unused PEGDA solution can be stored at $-20^{\circ} \mathrm{C}$ for up to one month. Protect from light. 
(e) Cartilage Staining with Safranin-O, Fast Green and Toluidine Blue.

Toluidine blue, Safranin-O and Fast Green can be used to easily detect aggrecan and type II collagen in cartilage. Toluidine blue and Safranin-O are cationic stains (basic dyes) that stain acidic proteoglycan present in cartilage tissues. Toluidine blue, also called metachromatic dye, shows subtle color changes depending on the tertiary structure of the sample. Cytoplasm stains light blue, nuclear region dark blue, and mast cell purple. Safranin-O, which binds to glycosaminoglycan and shows an orange color, is often used to stain articular cartilage. Fast green, the contrast stain of Safranin-O, is a sulfate-group containing acidic substrate, which binds strongly to the amino group on protein and thereby strongly stains the noncollagen sites.

$\underline{0.1 \%}$ Toluidine Blue O (Sigma-Aldrich)

0.1g Toluidine Blue/100 $\mathrm{ml}$ distilled water

$\underline{0.1 \% \text { Safranin (Sigma-Aldrich) }}$

0.1g Safranin/100ml distilled water

$\underline{0.1 \% \text { Fast Green (Sigma-Aldrich) }}$

0.1g Fast Green/100ml distilled water 


\section{Procedure (cells):}

1. Remove culture medium for culture

2. Add $500 \mu \mathrm{l}$ of fixation solution per $\mathrm{ml}$ of culture $\left(\sim 1 \times 10^{6}\right.$ cells $\left./ \mathrm{ml}\right)$ and let stand at room temperature for 10 minutes to fix the cells.

3. Remove the fixation solution from each sample after diluting it with $2-4$ $\mathrm{ml}$ of sterile PBS. Wash each sample twice with $2-4 \mathrm{ml}$ of sterile PBS and remove the final wash.

4. Add 500- $\mu$ l of $1 \%$ Acetic acid to each sample, allow to react for $10-15$ seconds and then remove the $1 \%$ Acetic acid.

5. Add 500- $\mu 1$ of stain solution (Toluidine, Safranin, or Green) and let stand at room temperature for 5 minutes to stain the cells.

6. Wash 3 times with sterile PBS. Adjust the color level by altering the number of washes.

7. Microscopic observation may be done in the presence of PBS. 


\section{Procedure (tissue sections):}

1. Prepare sections or paraffin sections. Paraffin sections require deparafinization:

Paraffin sections
$\begin{array}{ll}\text { Xylene I } & 5 \mathrm{~min} \\ \text { Xylene II } & 5 \mathrm{~min} \\ \text { Xylene III } & 5 \mathrm{~min} \\ 100 \% \text { Ethanol } & 5 \mathrm{~min} \\ 100 \% \text { Ethanol } & 5 \mathrm{~min} \\ 90 \% \text { Ethanol } & 5 \mathrm{~min} \\ 80 \% \text { Ethanol } & 5 \mathrm{~min} \\ \text { Wash under } & 2 \mathrm{~min} \\ \text { running water }\end{array}$ Rydration
After last wash, soak in distilled water.

2. Add $100-200 \mu 1$ of fixation solution to each tissue section for $1-4$ hours minimum. Remove the fixation solution.

3. Add $200 \mu 1$ of $1 \%$ acetic acid to each tissue section, allow to react for 10 15 seconds then remove acetic acid.

4. Add a $200 \mu \mathrm{l}$ aliquot of stain solution $(0.1 \%$ of Safranin, Toluidine, or Fast Green) to each tissue section and let stand at room temperature for 5 minutes to stain the tissue. Remove stain solution.

5. Add absolute ethanol for destaining. Destain until the color reaches the appropriate level.

6. Perform dehydration, clearing and mounting. Adjust the volume of fixation solution and stain depending on the size of the tissue section. 


\section{Supplemental Materials and Methods: Bone Development and VitaD Metabolism (Chapters 5 and 6)}

(iv) Materials and Reagents

$\underline{1 \mathrm{mM} \mathrm{VitaD}} \underline{3}_{3} \underline{\text { Stock Solution }}$

3.85mg vitaD 3 (MW 384.6) [C9756, Sigma-Aldrich]

$10 \mathrm{ml}$ Ethanol

store at $-20^{\circ} \mathrm{C}$ until use

$\underline{10 \mathrm{uM} 1,25 \mathrm{OH}_{2} \underline{\mathrm{D}}_{3}} \underline{\text { Stock Solution }}$

$10 \mu \mathrm{g}$ vile $1,25 \mathrm{OH}_{2} \mathrm{D}_{3}$ (MW 416.64) [D1530, Sigma-Aldrich]

$2.4 \mathrm{ml}$ ethanol

Store at $-20^{\circ} \mathrm{C}$ until use

$\underline{\text { rhBMP-2 (stock } 0.5 \mu \mathrm{g} / \mathrm{ml})}$

(50ng/ml) $5 \mu \mathrm{l} / 50 \mathrm{ml}$ media

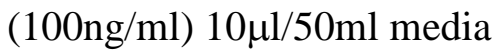

$\underline{\text { Standard Bone Medium (BM-) }}$

$500 \mathrm{ml} \alpha-\mathrm{MEM}$

25-ml FBS (5\%)

5-ml antibiotic/antimycotic (1\%) 
2.5ml L-Glut

$\underline{\text { 5X Osteogenic Medium (BM+) }}$

$250 \mathrm{ml} \mathrm{BM}(-)$

Dissolve $2.7 \mathrm{~g} \beta$-glycerophosphate

Dissolve $0.025 \mathrm{~g}$ ascorbate-2-phosphate

Add $50 \mu \mathrm{l} 1 \mathrm{mM}$ Dexamethasone (in ethanol)

Sterile Filter

$\underline{\text { Osteogenic medium }(\mathrm{BM}+)}$

$20 \mathrm{ml} \mathrm{5X} \mathrm{BM(+)}$

$80 \mathrm{ml} \mathrm{BM(-)}$

$\underline{\mathrm{BM}(+)+\text { rhBMP-2}}$

$20 \mu \mathrm{lhBMP}$

$100 \mathrm{ml} \mathrm{BM}(+)$

$\underline{\mathrm{BM}(-)+1 \mu \mathrm{M} \mathrm{VitaD}} \underline{3}_{3}$

$100 \mathrm{ml} \mathrm{BM(-)}$

$100 \mu \mathrm{l} 1 \mathrm{mM}$ vitaD $_{3}$ Stock Solution 


\section{$\underline{\mathrm{BM}(+)+1 \mu \mathrm{M} \mathrm{VitaD}} \underline{3}$}

$100 \mathrm{ml} \mathrm{BM}(+)$

100ul $1 \mathrm{mM}$ vitaD ${ }_{3}$ Stock Solution

$\underline{\mathrm{BM}(+)+\operatorname{rhBMP}-2+1 \mu \mathrm{M} \mathrm{VitaD}} \underline{3}_{3}$

$100 \mathrm{ml} \mathrm{BM}(+)+$ rHBMP-2

$100 \mu \mathrm{l} 1-\mathrm{mM}$ vitaD $_{3}$ Stock Solution

$\underline{\mathrm{BM}(-)+10 \mathrm{nM} 1,25 \mathrm{OH}} \underline{2}_{2} \underline{\mathrm{D}}_{3}$

$100 \mathrm{ml} \mathrm{BM(-)}$

$100 \mu \mathrm{l} 10-\mu \mathrm{M} 1,25 \mathrm{OH}_{2} \mathrm{D}_{3}$ Stock Solution

$\underline{\mathrm{BM}(+)+10 \mathrm{nM} 1,25 \mathrm{OH}_{2}} \underline{\mathrm{D}}_{3}$

$100 \mathrm{ml} \mathrm{BM(+)}$

$100 \mu \mathrm{l} 10-\mu \mathrm{M} 1,25 \mathrm{OH}_{2} \mathrm{D}_{3}$ Stock Solution

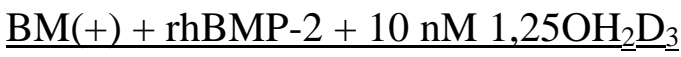

100ml BM(+) + BMP

$100 \mu \mathrm{l} 10-\mu \mathrm{M} 1,25 \mathrm{OH}_{2} \mathrm{D}_{3}$ Stock Solution 


\section{(v) Methods}

(a) Cell Culture.

Culture OPC-1 into 12 well plates at an initial seeding density of 25,000 cells per well, or 6 well plates at a seeding density of 100,000 cell per well. Maintain in standard bone medium (BM-) consisting of $\alpha$-MEM, $5 \%$ fetal bovine serum (FBS), 200mM L-Glutamine, and antibiotics/antimycotics for at least 4 hours (preferably overnight) following trypsinization $(0.025 \%$ trypsin-EDTA). Remove standard growth medium and replace with $1 \mathrm{~mL}$ of appropriate medium; e.g., duplicates or quadruplicates of:

a. $\mathrm{BM}(-)$ with $100 \square 195 \%$ ethanol (Control)

b. $\mathrm{BM}(+)$ with $100 \square 195 \%$ ethanol (Control)

c. $\mathrm{BM}(+)+$ rhBMP-2 with $100 \mathrm{ul} 95 \%$ ethanol (control)

d. $\mathrm{BM}(-)$ with $1 \mu \mathrm{M} 25 \mathrm{OHD}$

e. $\mathrm{BM}(+)$ with $1 \mu \mathrm{M} 25 \mathrm{OHD}$

f. $\mathrm{BM}(+)+$ rhBMP-2 with $1 \mu \mathrm{M} 25 \mathrm{OHD}$

g. $\mathrm{BM}(-)$ with $10 \mathrm{nM} 1 \alpha, 25 \mathrm{OHD}$

h. $\mathrm{BM}(+)$ with $10 \mathrm{nM} 1 \alpha, 25 \mathrm{OHD}$

i. $\mathrm{BM}(+)+$ rhBMP-2 with $10 \mathrm{nM} 1 \alpha, 25 \mathrm{OHD}$ 


\section{(b) Vitamin D.}

VitaD3 is soluble in ethanol at $50 \mathrm{mg} / \mathrm{ml}$. Stock solutions are prepared at $1 \mathrm{mM}(3.85 \mathrm{mg} / 10 \mathrm{ml} 95 \% \mathrm{EtOH})$ and kept at $-20^{\circ} \mathrm{C}$. Add $100 \mu \mathrm{l}$ stock solution to $100 \mathrm{~mL}$ of medium to obtain $1 \mu \mathrm{M}$ vitaD3 for the experimental group. Add $100 \mu \mathrm{l}$ of ethanol to the control medium (BM- and BM+ without vitamin D). 1,25OH2D3 is diluted into medium from $10 \mu \mathrm{M}$ stock solutions prepared in ethanol $(4.2 \mu \mathrm{g} / \mathrm{ml})$. For 1 vile of $1,25 \mathrm{OH} 2 \mathrm{D} 3$ containing $10 \mu \mathrm{g}$ add $2.38 \mathrm{ml}$ of ethanol and store at $-20^{\circ} \mathrm{C}$ until use. Add $100 \mu \mathrm{l}$ to $100 \mathrm{ml}$ of medium for experimental group.

(c) Feeding/Sample Collection Schedule.

Maintain cultures with the feeding schedule outlined below. Medium is replaced every 1-2 days with freshly diluted $10 \mathrm{nM}$ dexamethasone, $5 \mathrm{mM}$ $\beta$-glycerophosphate, and $50-\mu \mathrm{g} / \mathrm{mL}$ ascorbate-2-phosphate. From Day 2 onwards, cells (that require vitamin D) are cultured in the continuous presence of $1 \mu \mathrm{M} 25 \mathrm{OHD}$, and/or $10 \mathrm{nM}$ 1,25OH2D3. Because of the sensitivity to light, vitamin D has to be freshly diluted whenever the media is replaced.

D1: Cell lines are plated in 12 well cell culture plates at an initial seeding density of 25,000 cells per well in BM(-).

$\mathrm{D} 2$ : $\mathrm{BM}(-)$ from $\mathrm{D} 1$ is removed and $1 \mathrm{~mL}$ of appropriate medium is added to each well. 
D3, D7, D(end): Every 3 to 4 days supernatant and cells are collected/prepared for crystal violet $(\mathrm{CV})$ proliferation assay, alkaline phosphatase (ALP) assay, qRT-PCR, and on the last day of the sample set alizarin red S (ARS) assay. Supernatant is stored at $-20^{\circ} \mathrm{C}$ and cells are scraped from the bottom of the wells and stored in PBS containing $0.1 \%$ triton $\mathrm{X}-100$ at $-80^{\circ} \mathrm{C}$. Prior to use, cell lysates are freeze/thawed (3X) or sonicated. Cells from the other well are lysed with TRIzol and prepared for PCR and stored at $-80^{\circ} \mathrm{C}$ until qRT-PCR is conducted. For $\mathrm{CV}$ and ARS, wells are fixed and stained prior to sample collection. 
(d) Alkaline Phosphatase (ALP) Assay (Based on Lowry Method)

ALP is a membrane bound enzyme that is often used as a marker for osteogenic assay. This is a colorimetric assay in which the colorless paranitrophenol phosphate ( $\rho \mathrm{NPP}$ ) turns yellow as it is cleaved to paranitrophenol + phosphate. The cell number is normalized by measuring protein.

\section{$\underline{\text { 2-Amino-2 Methyl-1-Propanol (AMP) }}$}

For working solution, $1.5 \mathrm{M}$ balanced to $\mathrm{pH} 10.25$ with $\mathrm{HCl}$, Prepare $50 \mathrm{ml}$; store in 4C frig (good for 1 month). $7.18 \mathrm{ml} / 50 \mathrm{ml}$ and $3.59 \mathrm{ml} / 25 \mathrm{ml}$.

$\rho$-Nitrophenyl Phosphate ( $\rho$ NPP)

For working solution, $20 \mathrm{mM}$, prepare $50 \mathrm{ml}$, store in $4 \mathrm{C}$ and protect from light. Good for 1 month. $263.10 \mathrm{mg} / 50 \mathrm{ml}, 131.55 \mathrm{mg} / 25 \mathrm{ml}$. [N7653, liquid pNPP system; Sigma-Aldrich] Ready to use. Already has magnesium chloride buffer system in it.

\section{$\underline{\operatorname{MgCl}}_{2}\left(100 \% \mathrm{MgCl}_{2}\right)$}

For working solution, $10 \mathrm{mM}$; prepare $25 \mathrm{ml}$; store in $4 \mathrm{C}$. Good for 7 days. $0.2 \mathrm{ml} 1 \mathrm{M} / 25 \mathrm{ml}$. 


\section{$\underline{1 \mathrm{M} \mathrm{NaOH}}$}

For working solution, prepare 50 or $25 \mathrm{ml}$ depending on number of samples; mix fresh each day; maintain at room temperature. $1 \mathrm{~g} / 25 \mathrm{ml}$.

Ultrapure water or $0.05 \%$ Triton $\mathrm{X}-100$

Use the one your sample is suspended in.

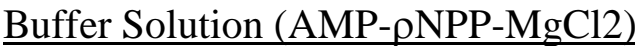

For working solution, prepare fresh solution from above. Prepare each day and maintain at room temperature. Combine AMP, pNPP, and $\mathrm{MgCl} 2$ in a 1:1:1 ratio.

$\rho-N i t r o p h e n y l$ Standard $(\rho N P)$

Combine 1 part stock with 9 parts ultrapure (1:10 dilution). Make 500ul aliquots and store in $4 \mathrm{C}$.

\section{Procedure}

1. Label microcentrifuge tubes appropriately.

2. Remove media from each well and transfer to sterile labeled microcentrifuge tubes. Freeze tubes. 
3. Carefully wash each well with $0.25 \mathrm{ml}$ EBSS (calcium and magnesium free). Remove and fill each well again with 0.25-ml EBSS.

4. Replace medium with $0.25 \mathrm{ml}$ of $0.025 \%$ trypsin $\left(37^{\circ} \mathrm{C}\right)$. Cap the tubes, mix well, vortex and freeze for at least $60 \mathrm{~min}$ in $-80^{\circ} \mathrm{C}$ or until assayed.

5. Tubes for ALP assay should contain at least $50 \mu \mathrm{l}$ of FBS containing medium to inactivate the trypsin. Once the cells come off the plastic of the well, pipette up and down to generate homogenous cell dispersion and place in tubes. Wash each well with $0.25 \mathrm{ml}$ of EBSS (calcium and magnesium free) and collect into the same tubes.

6. Pellet cells by centrifugation for $5 \mathrm{~min}$. Remove supernatant and discard. Resuspend the pellet in 300ul of the APase buffer.

7. Prepare reagents for APase assay according to the Lowry method. The APase buffer solution should be kept in $37^{\circ} \mathrm{C}$ water bath until use. Prepare $1 \mathrm{M} \mathrm{NaOH}$ (4 pellets $\mathrm{NaOH}$ with $10 \mathrm{ml}$ ultrapure). Mix tubes well, and load test wells in duplicate in 96-well plate with $100 \mu \mathrm{l}$ of sample starting with D1.

8. Load $100 \mu \mathrm{l} /$ test well with APase buffer solution (only to samples). Note the time carefully as the test is time dependent. Place multi-well plate in $37^{\circ} \mathrm{C}$ incubator. For reactive samples, check reaction color after $5 \mathrm{~min}$. To stop the enzyme reaction, add $100 \mu \mathrm{l}$ of the $1 \mathrm{~N} \mathrm{NaOH}$ to the test samples as needed. Be careful not to allow the test reaction to 235 
proceed too long (and become too yellow) as the plate reader will measure an absorbance at $405 \mathrm{~nm}$ up to 3.5, but not higher.

9. While the plate is in the incubator, make the standard solutions for the modified standards. To each standard add $500 \mu \mathrm{l}$ of ultrapure water. In descending order, add 250, 245, 240, 230, 220, and $210 \mu \mathrm{l}$ of the APase buffer to each tube. Finally add $0,5,10,20,30$, and $40 \mu l$ of the pNP stock solution to each tube, cap the tubes and mix each adequately. In triplicate, add $100 \mu \mathrm{l}$ of each solution to A1, B1, C1,...to A6, B6, C6 for an increasing concentration of $\rho$ NP. Immediately add $100 \mu$ of the $1 \mathrm{M} \mathrm{NaOH}$ to each standard well to stop the reaction. After $100 \mu \mathrm{l}$ of the $1 \mathrm{M} \mathrm{NaOH}$ has been added to all of the test samples and the standards have been loaded, the plate can be read on the multiplate reader at 405 nm.

Table A-2. ALP standards.

\begin{tabular}{|l|l|l|l|l|l|l|}
\hline Tube & 1 & 2 & 3 & 4 & 5 & 6 \\
\hline H2O & $500 \mathrm{ul}$ & $500 \mathrm{ul}$ & $500 \mathrm{ul}$ & $500 \mathrm{ul}$ & $500 \mathrm{ul}$ & $500 \mathrm{ul}$ \\
\hline APase & $250 \mathrm{ul}$ & $245 \mathrm{ul}$ & $240 \mathrm{ul}$ & $230 \mathrm{ul}$ & $220 \mathrm{ul}$ & $210 \mathrm{ul}$ \\
\hline pNP & 0 & $5 \mathrm{ul}$ & $10 \mathrm{ul}$ & $20 \mathrm{ul}$ & $30 \mathrm{ul}$ & $40 \mathrm{ul}$ \\
\hline
\end{tabular}


(e) Alizarin Red S Assay (ARS).

ARS is used to evaluate ECM mineralization and calcium deposits from cells in culture. ARS can be extracted from a stained monolayer and assayed. This method is for the recovery and semiquantification of ARS in a stained monolayer based on acetic acid extraction and neutralization with ammonium hydroxide followed by colorimetric detection at $405 \mathrm{~nm}$.

Alizarin Red S [A5533, Sigma; MW 342.26g/mol]

$40 \mathrm{mM}$ prepare in $\mathrm{dH} 2 \mathrm{O}$

$1.369 \mathrm{~g}$ ARS in $100 \mathrm{ml} \mathrm{dH} 2 \mathrm{O}$

$\mathrm{pH}$ adjusted to 4.1 using $10 \%(\mathrm{v} / \mathrm{v}) \mathrm{NaOH}$

\section{Procedure:}

1. Remove medium and rinse cell layers with PBS.

2. Fix cells with ice cold $70 \%$ ethanol for 1 hour at $4^{\circ} \mathrm{C}$, or Fix cells in $10 \%$ neutral buffered formalin for 5-10 minutes.

3. Rinse with distilled water and air dry.

4. Add $1 \mathrm{ml}$ of $40 \mathrm{mM}$ ARS ( $\mathrm{pH} 4.1)$ per well and incubate at room temperature for 20 min with gentle shaking.

5. Aspirate the unincorporated dye from each well.

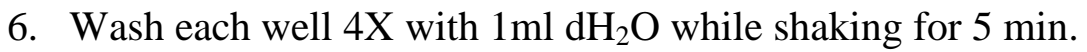


7. Remove excess water by leaving the plates at an angle for $2 \mathrm{~min}$. Aspirate again and then store plates at $-20^{\circ} \mathrm{C}$.

8. Stained monolayers are visualized by phase microscopy using an inverted microscope.

9. For quantification of staining: add $800 \mathrm{ul} 10 \%(\mathrm{v} / \mathrm{v})$ acetic acid to each well and incubate at room temperature for 30 min with shaking.

10. Scrape cell from plate and transfer (with $10 \%$ (v/v) acetic acid) to a $1.5 \mathrm{ml}$ microcentrifuge tube.

11. Vortex for $30 \mathrm{sec}$.

12. Overlay slurry with 500ul mineral oil.

13. Heat to $85^{\circ} \mathrm{C}$ for $10 \mathrm{~min}$, and transfer to ice for $5 \mathrm{~min}$. Tubes should not be opened until fully cooled.

14. Centrifuge at $20,000 \mathrm{~g}$ for $15 \mathrm{~min}$.

15. Remove 500ul of supernatant and add to new $1.5 \mathrm{ml}$ microcentrifuge tube.

16. Add $200 \mathrm{ul}$ of $10 \%$ (v/v) ammonium hydroxide to neutralize.

17. Aliquot $150 \mu \mathrm{l}$ in duplicate or triplicate into a 96 well plate (Opaque walled transparent bottom plates). Read at $405 \mathrm{~nm}$. 
Table A-3. Alizarin Red Standard Curve.

\begin{tabular}{|l|l|l|l|}
\hline Tube & $\begin{array}{l}\text { Standard (Concentration of } \\
\text { Alizarin Red S stain) }\end{array}$ & $\begin{array}{l}\text { Alizarin Red } \\
\text { Stain }\end{array}$ & $\begin{array}{l}\text { Solubilization } \\
\text { Solution }\end{array}$ \\
\hline A & $1 \mathrm{mg} / \mathrm{ml}$ & $50 \mathrm{ul} \mathrm{Stock}$ & $950 \mathrm{ul}$ \\
\hline $\mathrm{B}$ & $500 \mathrm{ug} / \mathrm{ml}$ & $500 \mathrm{ul}$ of A & $500 \mathrm{ul}$ \\
\hline $\mathrm{C}$ & $250 \mathrm{ug} / \mathrm{ml}$ & $400 \mathrm{ul}$ of B & $500 \mathrm{ul}$ \\
\hline $\mathrm{D}$ & $100 \mathrm{ug} / \mathrm{ml}$ & $500 \mathrm{ul}$ of C & $600 \mathrm{ul}$ \\
\hline $\mathrm{E}$ & $50 \mathrm{ug} / \mathrm{ml}$ & $500 \mathrm{ul}$ of D & $500 \mathrm{ul}$ \\
\hline $\mathrm{F}$ & $25 \mathrm{ug} / \mathrm{ml}$ & $500 \mathrm{ul}$ of E & $500 \mathrm{ul}$ \\
\hline $\mathrm{G}$ & $10 \mathrm{ug} / \mathrm{ml}$ & $400 \mathrm{ul}$ of F & $600 \mathrm{ul}$ \\
\hline $\mathrm{H}$ & $5 \mathrm{ug} / \mathrm{ml}$ & $500 \mathrm{ul}$ of G & $500 \mathrm{ul}$ \\
\hline $\mathrm{I}$ & $0 \mathrm{ug} / \mathrm{ml}$ & $0 \mathrm{ul}$ & $500 \mathrm{ul}$ \\
\hline
\end{tabular}




\section{(f) Crystal Violet Proliferation Assay.}

This is a simple assay useful for obtaining information about the relative density of cells adhering to multi-well cluster dishes. The dye in this assay, crystal violet, stains DNA. Upon solubilization, the amount of dye taken up by the monolayer can be quantitated in a spectrophotometer or plate reader.

\section{Procedure}

1. Remove culture medium from wells.

2. Wash plate gently with PBS warmed at least to room temperature: ( $0.2 \mathrm{ml} / 96$ well plate, $0.5 \mathrm{ml} / 48$ well plate, $1 \mathrm{ml} / 24$ well plate, $2 \mathrm{ml} / 12$ well plate, or $3 \mathrm{ml} / 6$ well plate)

3. Carefully remove PBS and fix in ethanol by adding $95 \%$ ethanol per well and incubate at RT for $10 \mathrm{~min}$. $(50 \mu \mathrm{l} / 96$ well plate, $100 \mu \mathrm{l} / 48$ well plate, $200 \mu \mathrm{l} / 24$ well plate, $500 \mu \mathrm{l} / 12$ well plate, $750 \mu \mathrm{l} / 6$ well plate)

4. Add crystal violet solution. Incubate $10 \mathrm{~min}$ at room temperature

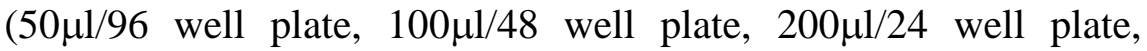
$500 \mu \mathrm{l} / 12$ well plate, $750 \mu 1 / 6$ well plate).

5. Wash wells extensively with $\mathrm{dH}_{2} \mathrm{O}$ to remove excess stain.

6. Add $1 \%$ SDS or $0.2 \%$ Triton $\mathrm{X}$ in $\mathrm{dH}_{2} \mathrm{O}$ and agitate. $(50 \mu \mathrm{l} / 96$ well plate, $100 \mu 1 / 48$ well plate, $200 \mu 1 / 24$ well plate, $500 \mu 1 / 12$ well plate, $750 \mu \mathrm{l} / 6$ well plate).

7. Read absorbance of each well at 570nm. 


\section{(g) Quantitative Reverse Transcriptase RT-PCR}

\section{RNA extraction with TRIzol}

1. Rinse cell monolayer with ice cold PBS once.

2. (homogenization) Lyse cells directly in a culture dish by adding 1 $\mathrm{ml}$ of TRIZOL reagent per $3.5 \mathrm{~cm}$ diameter dish and scrapping with cell scrapper. The amount of TRIZOL reagent added is based on the area of the culture dish $\left(1 \mathrm{ml}\right.$ per $\left.10 \mathrm{~cm}^{2}\right)$ and not on the number of cells present. An insufficient amount of TRIZOL reagent may result in DNA contamination of the isolated RNA.

3. Pass the cell lysate several times through a pipette and vortex thoroughly.

4. Incubate the homogenized sample for 5 minutes at RT to permit the complete dissociation of nucleoprotein complexes.

5. Centrifuge to remove cell debris and transfer the supernatant to new tube. It is recommended to freeze in Trizol at least 1 hour at $-80^{\circ} \mathrm{C}$ after incubating at RT. This is a potential stopping point. Samples can be kept at $-80^{\circ} \mathrm{C}$ indefinitely because RNA is stable in Trizol and TrIzol inactivates after 5 minutes. Thaw samples on ice.

6. (Phase Separation) Add $0.2 \mathrm{ml}$ of chloroform per $1 \mathrm{ml}$ of TRIZOL reagent. Cap sample tubes securely.

7. Vortex samples vigorously for 15 seconds and incubate at RT for 2 to 3 minutes. 
8. Centrifuge the samples at no more than $12,000 \mathrm{x}$ g for 15 minutes at $2-8^{\circ} \mathrm{C}$.

9. Work on ice from this point on. Following centrifugation, the mixture separates into lower red, phenol chloroform phase, an interphase, and a colorless aqueous phase. RNA remains exclusively in the aqueous phase carefully without disturbing the interphase into a fresh tube. Leave behind a small amount of clear phase; do NOT pick up any pink phenol-chloroform phase; use pipette tips with a large hole to prevent this from happening. Measure the volume of the aqueous phase. (The volume of the aqueous phase is about $60 \%$ of the volume of TRIZOL reagent used for homogenization). Incubate $1+\mathrm{hr}$ at $-80^{\circ} \mathrm{C}$. This is another potential indefinite stopping point.

10. (RNA Precipitation) Precipitate the RNA from aqueous phase by mixing with isopropyl alcohol (IPA). Use $0.5 \mathrm{ml}$ of IPA per $1 \mathrm{ml}$ of TRIZOL reagent used for the initial homogenization.

11. Incubate samples at 15 to $30^{\circ} \mathrm{C}$ for 10 minutes and centrifuge for no more than $12,000 \mathrm{x} \mathrm{g}$ for 10 minutes at 2 to $4^{\circ} \mathrm{C}$. The RNA precipitate, often invisible before centrifugation, forms a gel-like pellet on the side and bottom of the tube. 
12. (RNA Wash) Remove the supernatant completely. Wash the RNA pellet once with $75 \%$ ethanol. Adding at least $1 \mathrm{ml}$ of $75 \%$ ethanol per $1 \mathrm{ml}$ of TRIZOL Reagent used for the initial homogenization.

13. Mix the samples by vortexing and centrifuge at no more than 7,500 $\mathrm{x}$ g for 5 minutes 2 to $8^{\circ} \mathrm{C}$. Repeat above washing procedure once. Remove all leftover ethanol.

14. Air-dry or vacuum dry or vacuum dry RNA pellet for 5-10 minutes. So not dry the RNA pellet by centrifuge under vacuum. It is important not to let the RNA pellet dry completely as this will greatly decrease its solubility.

15. Partially dissolved RNA samples have an A260/A280 ration <1.6. Dissolve RNA in DEPC-treated water by passing solution a few times through a pipette tip.

16. The pellet should be resuspended in $12.5-15 \mu l$ of Nuclease-free water/DEPC-treated water. Incubate at RT for 2-3 min then place on ice.

17. (RNA Quantification) Spectrophotometric analysis: dilute $1 \mu \mathrm{l}$ of RNA with $39 \mu$ of DEPC-treated water (1:40 dilution). Using 10 $\mu$ l microcuvette, take OD at $260 \mathrm{~nm}$ and $280 \mathrm{n}$, to determine a sample concentration and purity. The A260/A280 ratio should be above 1.6. Apply the convention that $1 \mathrm{OD}$ at 260 equals $40 \mu \mathrm{g} / \mathrm{ml}$ RNA. 
Nanodrop quantification: quantify total RNA using a Nanodrop.

Store total RNA indefinitely at $-80^{\circ} \mathrm{C}$. 